\title{
Screening science:
}

\section{contexts, texts and science}

\section{in fifties science fiction film}

\author{
Errol Vieth \\ BA(UQ), DipEd(Flin), GradDipMulticultEd(BCAE), MEd(Deak)
}

School of Film, Media and Cultural Studies

Faculty of Arts

Griffith University

This thesis is submitted in fulfilment of the requirements of the degree of Doctor of Philosophy

date of submission: $25^{\text {th }}$ February 1999 


\section{Synopsis}

Science fiction films may be viewed as existing as threads within a web, and at the same time constituting the web. The metaphor is apt: texts and contexts and their relationship have a difficult accommodation with each other, an interdependent and dynamic relationship. The text is a thread in the web, as are elements of context, yet the threads are in a symbiotic and constantly changing relationship with each other, as the web is constantly in a state of renewal and change. At the same time, the text itself is a web, as are the various contexts. The threads are both ephemeral and fleeting, while incredibly strong.

This thesis is about the polysemy of science fiction film: its subject is the films of the fifties that belong to the genre of science fiction. But the area of study began as an investigation of the science in science fiction films; the way in which films construct that science, the end result of that construction and the totality of the discourse of science in relation to other discourses of power and influence. The investigation of those issues involves a multi-layered investigation into science fiction, in a similar way to Tulloch and Alvarado's approach to the Dr Who television series. 1

Approaching science fiction films from a perspective of genre, as in chapter one, uncovers a set of arguments about the science in science fiction, as well as establishing the global nature of some science fiction. These concerns lead into the discussion in chapter two of the social and historical context of the fifties, specifically in the US. Science plays a major role in these contexts, in the sense of the importance of science in creating these contexts (from this perspective) as well as the effects of the application of this science. But the historical and cultural contexts tend to suggest that science fiction films are in large part both a response to the social and historical context, and also create that context. This would not be quite accurate: the

1 Tulloch, John \& Manuel Alvarado 1983 Doctor Who: the unfolding text London: Macmillan 
production of many science fiction films mobilise other arguments, arguments relating to the industry of Hollywood, and the specific industrial context that gave rise to some very financially successful science fiction films, as well as some films where the budget was good for a few days filming. Science and technology are sometimes important elements in this industrial context as well.

Part II traces the nature of science in these films, using the contexts in Part I to anchor the science and its implications and effects. Foregrounded is the debate in which science is both key player and, in many cases, antagonist. The debate is traced and the various representations of science and its nature are tracked and highlighted. Science can cause change, by virtue of its nature of uncovering superstition, but the worth or desirability of that change is open to question. The control of science is a related issue.

The thesis examines science at a period that saw the efflorescence of science fiction films. The examination of those films tells us a great deal about the concerns of the time, as well as the science that figures so powerfully in the webs of culture of the fifties. 


\section{Contents}

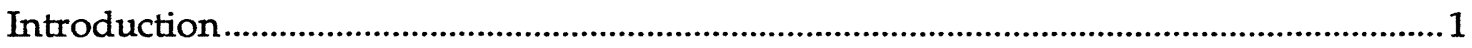

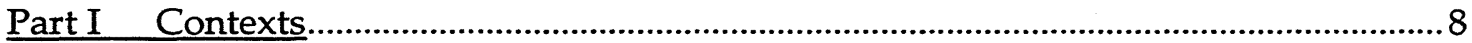

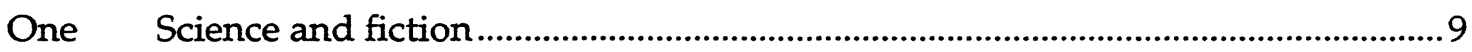

The genre according to the critics .................................................................................. 15

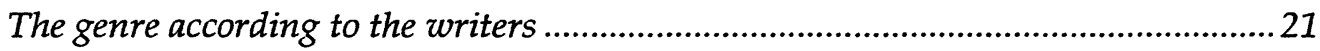

The boundaries of the science fiction film: horror and fantasy ..................................22

The genre web and genre threads................................................................................. 34

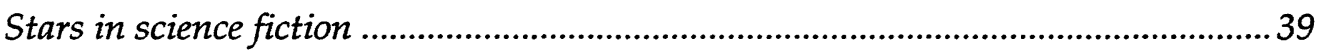

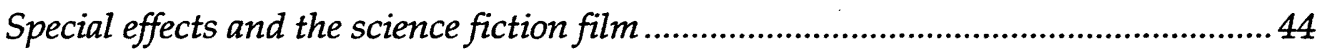

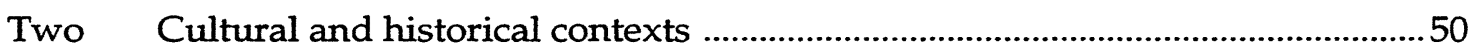

Grand narratives and the emergence of science fiction..............................................51

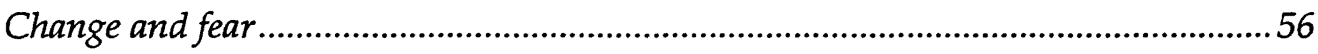

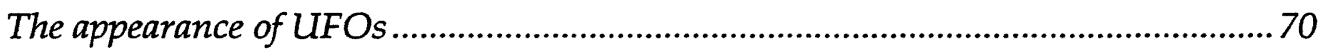

Hollywood and the Pentagon .................................................................................... 72

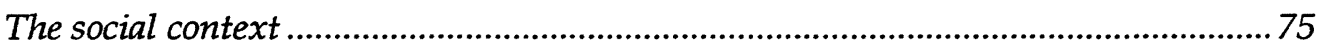

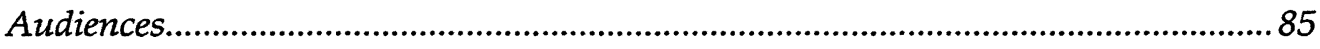

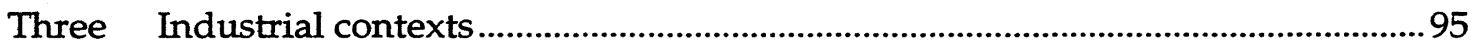

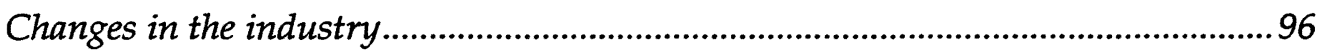

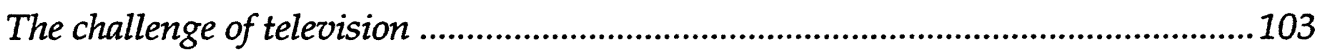

The growth of drive-ins .............................................................................................111

Science fiction films by corporation........................................................................ 115

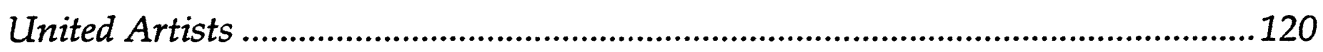

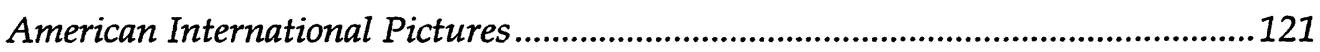

Special effects artists: George Pal and Ray Harryhausen......................................124 
Part II Science and scientists. 131

Four The (liberating) nature and (rhetorical) function of science ............................132

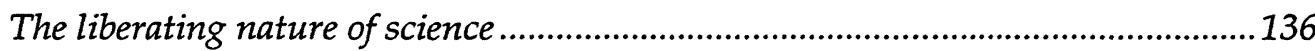

The rhetorical function of science ...........................................................................156

Five Medical and psychological science .....................................................................176

Invasion of the Body Snatchers...............................................................................180

Invaders from Mars...................................................................................................186

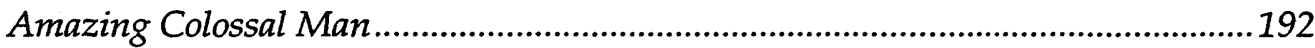

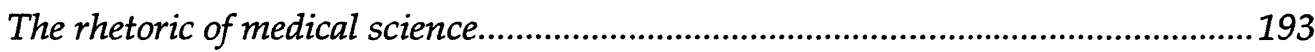

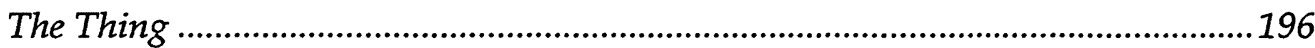

Conclusion

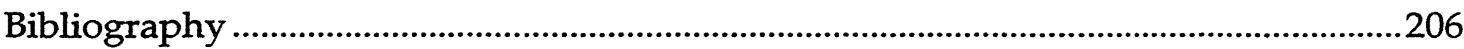

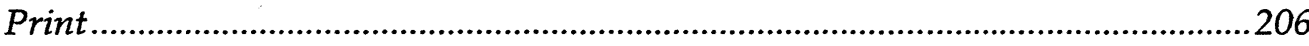

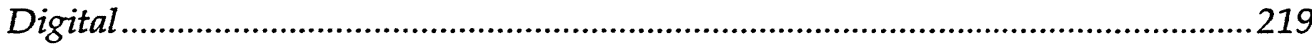

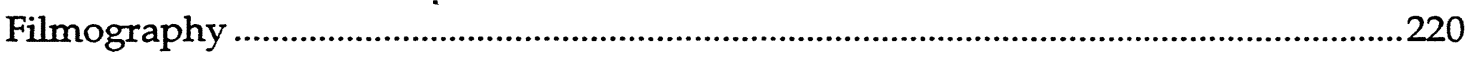

Illustrations

Figure 1: The Beast from 20,000 Fathoms questioned the old paradigms of science in

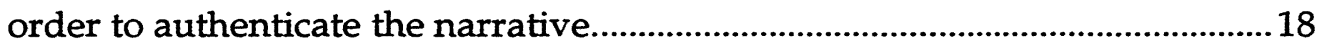

Figure 2: Ed Wood's entry into 'The worst film ever made' category.............................27

Figure 3: Robby is the malevolent alien, with grinning visage and evil intent..............43

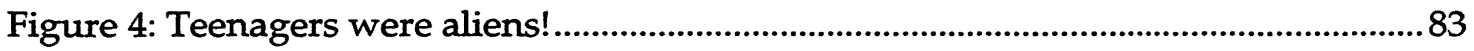

Figure 5: Project Moonbase postulated one woman as mission commander and another as President of the US.

Figure 6: While the film argued an equality of women, the poster was no different to

others.

Figure 7: The threat is from the woman, while the man is the victim

Figure 8: War of the Worlds exploited fear of the meaning of UFOs.

Figure 9: The community must prevail over untrammelled science 197 


\section{Tables}

Table 1: Number of science fiction films each year (author's criteria) ............................69

Table 2: Number of science fiction films each year (Willis) ...............................................70

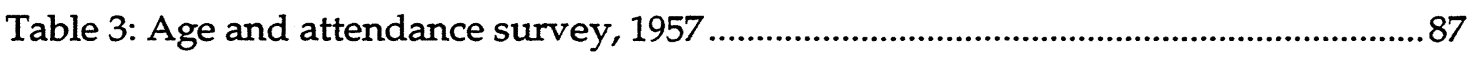

Table 4: Science fiction on television....................................................................................

Table 5: The growth of drive-ins...................................................................................111

Table 6: Drive-ins in southern states of the USA ...........................................................112

Table 7: The corporations and their science fiction films ...................................... 115-119 


\section{Acknowledgments}

Most importantly, thanks to Lea for accompanying me during the writing of this thesis. The writing has had many effects on our life together, some of which we do not realise fully. Thank you. Thanks too to Chloé, Jonas and Harry, who did a lot of growing up during this work, and whom I love and respect.

I wish to thank Griffith University for the provision of a scholarship that paid HECS fees for the duration of this research and writing. Without such assistance this work would not have been possible.

As my principal supervisor, Associate Professor Colin Crisp has worked with me and this thesis through a long and difficult gestation. His careful reading of the text and his care in making extensive comments has made me aware of my limitations but also has helped me to overcome those limitations. I will remain grateful for many years for that care and attention. Thank you.

As my co-supervisor, Dr Albert Moran has guided the general structure and writing process of this thesis. Long discussions with him have seen the thesis take shape and he has always been more than happy to assist me with the general difficulties and emotional processes of writing. His prodigious memory, his warmth and kindness will guide me through my dealings with any students I may have. Thank you.

To my colleagues at Central Queensland University: Associate Professor Tony Schirato for reading much of the thesis and making extensive comments; Dr Denis Cryle for his assistance in making it possible for me to have some time to work on this thesis, and who always supported this work in many committees; and for those others who, I suspect, wondered if I was actually doing anything at all, many thanks.

To the members of the Research Committees of the now restructured Faculty of Arts, and the current Faculty of Informatics and Communication, thank you for the financial assistance to visit supervisors.

Finally, many thanks to PPRS, whose knowledge of life has been invaluable. 
Statement of authorship

This work has not previously been submitted for a degree or diploma in any university. To the best of my knowledge and belief, the thesis contains no material previously published or written by another person except where due reference is made in the thesis itself.

\section{Errol Vieth}

25 February 1999 


\section{Introduction}

Independence Day (1996) was acclaimed as a blockbuster because of wide appeal that manifested in successful box office returns. Certain elements evince it as a nineties film: The urban geography of Los Angeles and New York, the media

hardware and software in various offices, cellular phones, for example, crystallise the film's setting in time. The artefacts on the moon suggest the present as does, in a different way, the enormous dimensions of the alien spacecraft, which have grown larger since the fifties. However, Independence Day can be seen as nothing more than recycled material from the nineteen fifties. The rhetoric of the narrative is not uncommon: the pitching of the ecological scientist against another, mad scientist, and initially against, but later in cohort with, the military complex, is an alignment and an area of concern that is from the fifties. Such an alignment is not uniform; indeed, the permutations of alignment of social institutions with each other and with human beings are represented in the films of the fifties.

The film opens with a gigantic shadow passing over the artefacts astronauts have left on the moon, foreshadowing the darkness that is about to descend on the inhabitants of planet Earth. Sequential events depict the global victory of the alien invasion intensifying to inevitability, but then human and scientific endeavour and ingenuity prevail and the alien threat is neutralised. The global rejoicing begins on Independence Day. The film relies on conventions of plot, character, special effects and the invasion sub-genre that were developed, that coalesced and were further refined in fifties' films that became known to audiences, filmmakers and critics as science fiction films. These conventions were thereafter developed and modified in parallel with the changing cultural, historical and industrial context in which the films were produced, distributed and exhibited.

For the sake of overview it is useful to generalise, for the time being, and say that certain conventions are specific to science fiction films and it is in the fifties that the science fiction film genre of film became recognisable to an audience through these characteristics. This decade marks the efflorescence of 
science fiction film into a genre that encompasses sub-genres of diverse characteristics but united under the umbrella of science fiction. The specific science fiction conventions in Independence Day that originate in the fifties include special effects, particular representations including the character of the scientist, the character of the engineer, narrative situations such as the possibility of other life forms in the universe that may be evil, the global paradigm where the threat is countered by global action and mutual support coordinated through global electronic communication and sometimes presented to the public through that same electronic communication network, the impact of technology in the shaping of history and culture and the foregrounding of the importance of the human spirit in controlling that technology and mobilising it for a common good.

The special effects in Independence Day are astounding and won an Academy Award in 1997, but they are not more astounding in relative terms than the special effects of many 50s science fiction films. The versatility of digital technology was not available in the fifties but the function of special effects today is no different from what it was then; that is, to transmogrify the unreal into the real and to make believable for our senses-especially the most powerful sense, vision-that which our intellect might reject. Special effects works on the premise that seeing is believing and that the more realistic the image the greater the chance that disbelief in the images and the narrative will be willingly suspended.

The scientist in Independence Day at area 51 is one archetype of the scientist in science fiction films. He greets the President with a giggle. The President knowingly raises his eyebrows to his advisers before returning his attention to the scientist, who is a middle-aged, squat, fleshy being with fishbowl glasses, very long hair, a white lab coat over trousers that resemble a clown's: about calflength and wide-bottomed, with the name of Dr Okun. In fact, he is almost an alien himself. His mannerisms and characteristics suggest that he is demented. The analogy with an insane person is continued when the scientist apologises to the president for his general demeanour, dissembling with the statement that 'they don't let us out often'. He is a 'long-hair', a 'nerd'. No one really likes him because he is not a 'real', or normal, person in that he does not exhibit the common characteristics displayed by other humans, and is too close to his work to like or relate to human beings.

With minor variations he has incarnated in science-fiction films since the fifties, sometimes more powerful, sometimes less. His presence signifies that the 
film is most likely of the science fiction or related genres and that the scientist will act within a narrative formation that sets him in opposition to either a military figure or an engineer. And certainly that engineer is Jeff Goldblum in Independence Day although in a slightly different guise. The characteristics of an engineer include success, a concern with the practical, a disdain for politics and politicians, success in a field outside the traditional world of academia and research, and an approach to life that is firmly realistic according to his own reference system. He is skilled in his work and is a problem-solver. David is the name of this figure and while the research scientist plays a support role engineerscientist David is in a lead role. The engineer scientist applies scientific knowledge to some utilitarian function, and in that application displays not only an understanding of the secrets of nature but a control over it and a harnessing of its secrets. The two representations of the scientist occupy niches at opposite ends of the spectrum of representations of the scientist and their sciences.

That other life forms may not only exist but may be visiting this solar system was a revealed truth for many who believed in the reality of UFOs in the fifties. There has been no contact with space beings in any scientific sense during that time even though SETI (Search for Extra-Terrestrial Intelligence) has been carrying out experiments designed to contact possible life forms for some time. (Of course, conspiracy theorists would maintain that there has been contact with UFOs and the government is simply lying to the people, a thread important to the plot of Independence Day.) Flying saucers are still reported with a similar degree of credibility as they had been in the 50s. Initially it might seem that the notion of UFOs is not quite so believable as it was in the fifties yet the evidence is that unquantifiable numbers of people believe in the existence of aliens. 1 The recycled notions of L Ron Hubbard are extant in Scientology while elements of New Age beliefs include similar teachings, such as that some human beings have been sent down as guides for others who might recognise them before an ascension. The suicide of the Heavens Gate believers reveals the power of such teachings although not the extent. 2

Unlike the alien in ET (1982) but like those in other fifties films, the aliens in

1 Judith Grant 1998 'Trust no one: paranoia, conspiracy theories and alien invasions' Undercurrent n6, Spring argues for a qualified reality of UFOs. http://darkwing.uoregon.edu/ ucurrent/uc6/6-grant.html (accessed 24/12/98)

2 see the archived Heaven's gate site at http://www.wave.net/upg/gate/index.htm (accessed 20/12/1998) 
Independence Day are determined to destroy people. They have evil intent and will stop at nothing in their attempt to destroy the world's civilisations and its people for their own particular use. The threat is global and while in ID4 it is a threat, more important is the global implication. While fifties science fiction film narratives were constructed around both good and evil aliens-as are later films-the implication of the alien visitation is global in science fiction films. The global cooperation that ultimately defeats the threat in ID4 is harnessed and directed by global communications systems, in this case using a simple code that was developed for communication systems that were subject to powerful interference and hence needed to be simpler than voice; namely Morse Code. As in other 50s films like Earth Versus the Flying Saucers (1956) the answer to the problem lies in unity. Warring factions join forces (Israel, Arab countries, for example) to beat the threat.

This global frame sets these films apart from other genres and is one differentiating factor from horror films that came before and continued through the fifties. The implications of the narrative in science fiction is global-although the particular event might be quite local-and globalisation both suggests and reflects the paradigm shift from the national to the global, from the individual consciousness of nationhood to an individual consciousness of belonging primarily to planet Earth and an appreciation of its beauty. Indeed, Heinlein's astronauts in Destination Moon (1950) might be regarded as the first humans with such a consciousness given their awe at seeing the sphere of the earth from space.

But Independence Day recycles other elements of earlier films. While the bacteria in War of the Worlds (1953) eventually destroys the aliens without any effective intervention on the part of humans, the virus that fulfils the same purpose in Independence Day is a computer virus that destroys the information processing and control centres of the alien mother ship. While this is a recycling of the idea of 'bacteria power', the recycling has changed the nature of the bacteria in accordance with current knowledge, interest and technology. In this sense science fiction film is a genre associated with cultural and technological change, and to some extent traces those changes.

The longevity of the genre attests to the resilience of the narratives, interests, subjects, representations, technology and rhetoric across decades. Yet the genre, while it has some traces back to the illusion, fantasy and special effects of Georges Melies' A Trip to the Moon (1902), is both a product of the economics, 
the 'grand narratives' and the discourses of the fifties, as well as a guide to those webs of influence and meaning. The task of this thesis is to trace the threads that comprise the web of science fiction films. Such a task bestows on science fiction films, and fifties science fiction films in particular, a legitimacy as cultural products that has not always been evident, as the genre has sometimes been marginalised in 'serious' criticism as being an inferior or even a deviant genre in cultural theories that divided culture into 'high' and 'low'. This thesis validates the claim to legitimacy of the genre as a significant, important cultural product, if such validation is still necessary.

This thesis follows Parrinder's view that science fiction provides a three dimensional insight into particular social and cultural contexts. ${ }^{3}$ A science fiction film can be seen as:

- a document or text, where the threads of values and taken-for-granted truths are woven to form the social fabric of the time;

- a cultural product, that is, the result of an industrial and corporate process involving studios, banks, executives and audiences, functioning within and constructing a system of production, distribution and exhibition;

- a message, in that science fiction films have something to say on particular issues.

The thesis is in two parts: part one, comprising the first three chapters, examines the genre of science fiction and the contextual elements of history and culture, and the film industry; part two, of two chapters, examines the nature of science and the scientist. Both parts arise from initial questions about science and its representation in western culture, narrowing to an attempt to understand the cultural representation of science in science fiction films, especially in the fifties when the film medium assumes significance for the genre.

Chapter one examines the genre of science fiction; that web comprising threads that are insignificant on their own, but when woven with other threads, comprise a web of tangible presence and strength. At the same time the web is constantly being modified and rewoven with new threads woven with old. While the metaphor has limitations, an understanding of those limitations strengthens the metaphor. The chapter discusses the history of the term 'genre' and its

3 Patrick Parrinder 1980 Science fiction: its criticism and teaching London: Methuen, 29-36 
meanings, as well as the appellation 'science fiction', from points of views of critics as well as science fiction writers. The notion of cultural change is identified as a primary element of the genre. At one level, science fiction lies between horror and fantasy, and the discussion suggests the link between science fiction and historical events, with a sense of global power and cooperation (or otherwise) representing a significant new thread that delimits the genre. The absence of stars in the traditional sense and the presence of special effects are traced as significant threads.

The next chapter examines the political, historical and cultural context of the United States and changing and contested paradigms of state and nation. Change is both featured in the discussion, and is also a motive force for the events described in the chapter. For example, the splitting of the atom requires a global perspective because its consequences are global, and that is a significant change requiring substantial re-weaving of the web of culture and politics, a reweaving where the nature of culture and politics is contested. At the same time, social change in the US is seen to be rapid and widespread, suggesting a fifties web that is something other than the time of stability and certainty that popular myth might suggest. Indeed, the fear of change and the effects of change are significant elements of science fiction films. The audiences of science fiction are also discussed.

The third chapter focuses on the industrial aspects of science fiction film, and the part the necessity of making profits plays in the face of a changing web of production, distribution and exhibition, a changing audience mix in the suburbs who are turning to television as a form of entertainment, the new target market of teenagers, and the emergence of drive-ins. The changing technology of filmmaking that makes it possible to improve the ability to transmogrify-that is, to magically transform the unreal into the real-is described through a brief examination of the work of George Pal and Ray Harryhausen.

Chapter four unravels the notion that science has both a nature and a function in science fiction films, and that this nature and this function are essentially arguable; that is, the representation of science is under the microscope, while the argument as to the rights and responsibilities of science and its agents, the scientists, is canvassed. Thus the films provide one window into the contemporary ways of thinking about science, and the representations of the scientist. However, at no time are films assumed to be mirrors of an alleged 
monoculture known as society. If they reflect, it is through a 'glass darkly', through a distorting mirror, or perhaps more appropriately through a prism, where a light can be separated into a number of component colours, or frequencies. The chapter argues that some science fiction films were at the forefront of social change.

While chapter four focuses on the 'non-human' sciences (that is, those that are not related to the human organism), chapter five examines the medical and psychological sciences and their agents. While this group appears in many science fiction films, critiques of their representation are not common. Generally they seem to be combined with other scientists practising other sciences, yet this chapter suggests that the discourse in which they play a part should be further examined as essentially different from the discourses of other types of science and scientist. The notion of community as a web built from individual families is a feature of this perspective on science fiction films in the examples used here.

The worlds of science fiction are worlds of change, where change is at the centre of the web. Science fiction moves away from light entertainment and the escapism that, arguably, drives audiences to the sword and sandal epic, or the musical, or the western. Science fiction film is, strangely enough, grounded in reality, and is a discourse about, and contributing to, a changing reality. 
PART I

CONTEXTS 


\section{One}

\section{Science and fiction}

Like the Mormons who convert dead people retrospectively to Mormonism, we can categorize as sf any film that even slightly fits the definition of sf. And we can shove the chosen film, screaming and protesting, into the box because the definition of $\mathrm{sf}$ is pretty flexible. In this particular situation an sf film is any film I say is an sf film. Good, I'm glad that's settled. So now we can properly begin.1

One problem inherent in the title of this thesis is the classification of films as science fiction. 'Science fiction films' implies a genre, a group of films defined or classified by elements or structures an audience recognises as science fiction. This chapter focuses initially on genre as a classificatory system, and examines the link between scientific methodology and the structuralist conception of genre.

The signifier genre does not have the apparent simplicity of signifieds which tree has to one who is not a botanist, a conservationist, or a person in the timber industry. The problem is obvious: while the signifier tree denotes at first glance a simple signified of leaves, branches, trunk and roots, further reflection produces multiple signifieds, multiple meanings for a plurality of participants in any discourse of which 'tree' is constitutive.

That meaning depends on the social and historical context of both the participants and the text. The participants create, recreate and exist in discourses determined by a combination of their own history and interest, and the traditions and practices of that discourse. An active conservationist, for example, is that because of the interplay of her history with her present; in part in the constant reworking and renegotiating of positions inherent in the societal tension between the binary oppositions of conservation and 'progress', as she and others construct them.

On the other hand, the timber-getter operates in a different cultural context and the meaning of 'tree' within his context of existence is arguably a sign of a different operational paradigm; a paradigm in which 'tree' signifies a set of

1 John Brosnan 1991 The primal screen: a history of science fiction film Sydney: Macdonald, 1 
values inherent in the timber-industry discourses, in which 'tree' is a part.

A similar problem exists with the signifier 'genre', in that the discourse in which it appears and the participants in that discourse determine its meaning. For a teacher of English in a Queensland school 'genre' might signify a unit of work focussed on the production of business letters. For a Russian formalist, the word might involve similarities in textual form and structure that allow for classification: the genre of the folk tale, for example, is a genre because of the common functions and structures within the narrative, and the social functions of the narrative.

Concerns with generic structures were an element of training in classical Greek rhetoric. Rhetoric was a collection of genres defined by criteria of form and function that became legitimised in idealised models against which other instances of rhetoric could be judged. Notions of ideal types provided the foundation for evaluation. 2 Further development by Aristotle and consolidation by Rome's Cicero limited the number of types of speech and prescribed rules for speakers on the basis of the genre of the speech act. ${ }^{3}$ More recently, concepts of genre in literature, of models against which texts could be compared for the purposes of classification and for establishing texts as authentic to the genre, reemerged with the school of criticism assembled under the umbrella of 'structuralism'.4 Propp's Morphology of the folktale heralded the structuralist movement in literary criticism, which produced such texts as Todorov's The fantastic. 5 Structuralism identified the common characteristics, common elements, and similarities in plot and narrative in texts. 6 These commonalties are based on structural linguistics rather than classical notions of genre associated with rhetoric.

This reformulation and re-emergence of an interest in genre as classification followed the descriptive and classificatory methodologies in the 'new' biological sciences, founded by Darwin's Origin of species.7 The focus in the

2 The concept of 'idealised types' is described in Robert Scholes 1974 Structuralism in literature London: Yale University Press, 131,132

3 see Don Stacks, Mark Hickson \& Sidney Hill 1991 An introduction to communication theory Sydney: Holt, Rinehart \& Winston, 101-107

4 Scholes 1974

5 Tzvetan Todorov 1973 The fantastic (trans Richard Howard) Cleveland: Case Western Reserve University;

Vladimir Propp 1970 Morphology of the folk tale Austin: University of Texas

6 Todorov 1973, 4

7 Charles Darwin 1859 On the origin of species by means of natural selection or the preservation of favoured races in the struggle for life 1st ed [1st ed, London: J Murray, reprinted] Cambridge 
life sciences was on classification: the classification of the fauna and flora of the planet, the classification of humans into groups according to the physical features of their anatomy as the so-called science of eugenics determined. The classification that belonged to science was transferred to literature, and in addition, the methodology of science, the methodology which was claimed to alone result in value-free conclusions, was reified as being the only methodology suitable for an understanding of literature. In justifying the examination of only a few texts in order to make statements about a genre as a whole Todorov wrote:

But one of the first characteristics of scientific method is that it does not require us to observe every instance of a phenomenon in order to describe it; scientific method proceeds rather by deduction. We actually deal with a relatively limited number of cases, from them we deduce a general hypothesis, and we verify this hypothesis by other cases, correcting (or rejecting) it as need be. 8

This methodology marks the degree to which the scientific method pervaded literary criticism.

The influence of the scientific paradigm does not conclude with methodology; the scientific method is not the only borrowing from the scientific paradigm. Todorov redefined the concept of genre to include biological and zoological interests, 9 likening the scientist's interest in palaeontology to the structuralist's interest in genre:

We postulate that every literary text functions in the manner of a system; which implies that there exist necessary and not arbitrary relations between the constitutive parts of this text. Cuvier...had provoked the admiration of his contemporaries by reconstructing the image of an animal starting from a single vertebra. Knowing the structure of a literary work, one ought to be able, given the knowledge of a single feature, to reconstruct all the rest.10

The function of 'genre', then, was to provide the framework for the identification and classification of a text on the basis of one piece of evidence; the interest in genre was in part for the purposes of classification. In addition, genre criticism aimed to produce a series of structural models that could be shown to underpin all existing texts, and to generate all future texts of the genre.11

The history of genre theory has had a chequered career described by writers such as Malmgren and Kuhn.12 Malmgren continues the Todorovian

Mass: Harvard University Press, 1966

Todorov 1973, 4

Todorov 1973, 5

Todorov 1973, 75

Patrick Parrinder 1980 Science fiction: its criticism and teaching London: Methuen, xviii

12 Carl Malmgren 1991 'Against genre/theory: the state of science fiction criticism' Poetics today 12:1 (Spring) 
tradition of deriving a descriptive notion of genre using scientific methodology, namely modelling. In so doing he folds Medawar's 'intuition' into his description of the process of modelling: 13

...I believe that there is another sense to theory in literary studies, one in line with the nature of theory in scientific studies, that is, as having to do with the construction of theoretical models that can describe and account for a certain group of phenomena. I believe in genre theory in the "strong" sense; not as a set of family resemblances derived from extensive empirical research but, rather, as a hypothetical model based partly on intuition, partly on definition....

The scientific model is also descriptive rather than normative; it seeks to classify, identify, and describe the phenomena that prompted it and not to evaluate them. 14

The elements of the discourse are clear, but the metaphors are mixed: there are certain phenomena which exist 'out there' as palaeontological and anthropological artefacts which are available for classification into a 'family'. Using this classification and the construction of a model indicating the parts and their interrelationship, structuralists can classify other texts by applying this model.

But any theory that relies on scientific methodology must deal with problems of objectivity and subjectivity. The scientific method laid claims to objectivity - a claim still made by some scientists - but this claim has been tempered by theorising in science about the nature of the observer/observed relationship at the sub-atomic level: the Heisenberg Principle. While admitting that the object of the inquiry-namely cultural systems and language models-prevents 'value-free' theorising, Malmgren states that objectivity is a 'goal':

Since one is dealing with cultural systems and using language models, one's theory cannot, of course, be entirely value-free, so pure objectivity is an illusory goal to which one can only aspire. 15

Malmgren aspires to a goal he admits is impossible: his goal is impossible because the nature of 'objectivity' is impossible. In addition, unlike naturally occurring phenomena, texts are the product of human agency and hence imply history and a hermeneutic. Genre, as a product of human agency, both in its selfconstructed sense as well as in the artefacts to which it applies, does not function in absolutist terms; it does not function outside of an audience and a context.

Annette Kuhn (ed) 1990 Alien zone: cultural theory and contemporary science fiction cinema New York: Verso, 1-12

13 Peter Medawar 1986 The limits of science Oxford University Press

14 Malmgren 1991, 138

15 Malmgren 1991, 139 
Genre is not simply a set of conventions that exist in some timeless aesthetic but a set of conventions intimately associated with, and defined and modified by, a human agency.

In film this circulation of genre for definition through industry and audience is far more complex than a simple noting of the elements that might, arguably, constitute the genre. Firstly cinema is both an industry and a social institution where the Hollywood economic and filmic imperatives are mobilised and married to an audience set of imperatives that have been internalised through intertextual functioning. ${ }^{16}$ A genre is the site for a particular set of produced meanings and positions:

As systematised forms of the articulation of meaning and position, they [genres] are a fundamental part of the cinema's 'mental machinery'. Approached in this way, genres are not to be seen as forms of textual codifications, but as systems of orientations, expectations and conventions that circulate between industry, text and subject.17

The appearance of various types of people in a film does not mean that the film is a particular genre, an issue discussed later in this chapter. The difficulty with Neale's definition is that the Hollywood industry certainly does take a particular set of codifications in order to produce films of a particular genre according to an audience's perception-as the Hollywood industry comprehends that perception-and definition of that particular genre. The film is then marketed according to the contemporary marketing strategies for that particular genre to an audience who is made aware of the likely genre of the film through these marketing strategies and through other sources like film reviews and wordof-mouth.

Accordingly, any film may be classified as science fiction according to a certain set of characteristics which the film has, coupled with the interests of the classifier. The film's characteristics are identifiable through an investigation of these elements, the skeletal remains of iconography, plot/narrative, character and technical codes. But while the description of the genre initially appears a mechanical task, the classification of individual films-and even the discussion of the genre-is problematic: the tension between narrative and spectacle in the case of science fiction film is one such problematic. 18

16 Stephen Neale 1980 Genre British Film Institute

17 Neale 1980, 19

18 Brooks Landon 1992 The aesthetics of ambivalence: rethinking science fiction film in the age of electronic (re)production London: Greenwood Press 
To continue this discussion of the nature of genre in general it is worthwhile to examine its boundaries as determined and argued by critics, science fiction writers and various others constituting the human agency that is central in the act of definition. I'll return to a conception of genre before discussing further the textual elements of the genre, but first I'll trace the emergence of the term 'science fiction'. Science fiction as the name for an emergent and developing genre germinated when Hugo Gernsback coined the term 'scientifiction' to describe what became in the 1920s a flood of stories in a flood of 'pulp' magazines. Gernsback wrote about the 'flood' in 1927, boasting that in the second edition of Amazing stories quarterly all submissions were original as compared with the single original story in the first edition.19 Gernsback's vision was for a USA that was a 'hotbed' of scientifiction, with 'authors of the better kind' then taking to scientifiction like 'ducks to water'. But the term can be traced back to 1851, to William Wilson's A little earnest book upon a great old subject:

[Thomas] Campbell says that 'Fiction in poetry is not the reverse of truth, but her soft and enchanting resemblance'. Now this applies especially to Science-Fiction, in which the revealed truths of Science may be given interwoven with a pleasing story which may itself be poetical and true-thus circulating a knowledge of the Poetry of Science clothed in a garb of the Poetry of Life.20

However, the term did not enter into general use-as that use is measured by a presence in the pulp magazines of the 30s-until 1928. Then Gernsback's rival Astounding stories became Astounding science fiction.21 Gernsback's own Wonder stories featured on the title page headers such as 'Interplanetary stories', 'The robot technocrat', more commonly 'Adventures of future science', and on the August 1934 edition, 'The best in science fiction'.22 The term was applied exclusively to magazines and their stories, and only in the fifties was it applied to paperback novels. 23 In one sense there may well be no point in trying to trace science fiction to some earlier styles of writing. After all, as the science fiction writer and academic Samuel Delany suggests, the notion of 'literature' itself as

19 Hugo Gernsback (ed) 1928 'The rise of scientifiction' Amazing stories quarterly 1:2, Spring, reproduced in Anthony Frewin @1974, published 1988 One hundred years of science fiction illustration London: Bloomsbury, 56

20 in Sam Moskowitz 1976 "That early coinage of "science fiction"' Science-fiction studies iii:part 3, November, 313

21 Parrinder 1980, 2

22 David Kyle 1977 The illustrated book of science fiction ideas and dreams Sydney: Hamlyn

23 Parrinder 1980, 2 
we now study and read it is only 100 years old.24 The notion of a stable entity called science fiction being present for the past century and identifiable as such does not sit with the notion that literature itself was not a stable entity within this time frame.

Jules Verne locates his type of writing within a world of scientific knowledge, but firmly linked to the romantic tradition: 'Reality provides us with facts so romantic that imagination itself could add nothing to them'.25 Although Mary Shelley's Frankenstein is regarded as the forerunner of science fiction, Jules Verne's stories contributed the 'hard science' element that was to be a feature of most science fiction film in the fifties. The majority of stories in the nineteenth century were set on Earth, beginning with de Grainville's The last man in 1805, continuing with Frankenstein, and stories by Poe, Melville, and Jules Verne. In 1895 HG Wells published The time machine, and began what Brian Ash has called the second period of science fiction, where narratives expanded their spatial boundaries to the edge of the solar system. 26 After 1926, stories began delving into other galaxies. This moving frame of science fiction from the Earth to the solar system to other galaxies is one order of development that marks science fiction. Another order is to examine the archeology of the term 'science fiction' to trace other threads of the genre's history.

\section{The genre according to the critics}

The question 'What is science fiction?' commonly leads the discussion of science fiction whether as literature or film. 27 Writing that focuses on science fiction usually begins with a description of the genre, or at least some reasons science fiction cannot be easily defined; why any definition of science fiction will lack some element; why a definition will not include those films which, for some reason, should be included. In writing about other genres the problem does not arise so intrusively, and discussions about other genres do not begin with a debate about contentious definitions. Rose suggests that those writing about other genres 'are fairly confident of the boundaries of the genre in question' and (p)erhaps this is so because those genres seem to be defined by their subject

24 Samuel R Delany 1994 Silent interviews Hanover, NH: University Press of New England, 26

25 in David Kyle 1976 A pictorial history of science fiction London: Hamlyn, 168

26 Brian Ash 1977 The visual encyclopedia of science fiction London: Pan, 10

27 for example, Vivian Sobchack 1987 Screening space: the American science fiction film 2 edn, New York: Ungar, 17 
matter; detective stories are about crime, westerns are about cowboys, Indians, and life on the old frontier. In what sense is science fiction about science?28

Kingsley Amis acknowledges the difficulty of definition, not with the 'fiction' element but with the 'science' element:

With the 'fiction' part we are on reasonably secure ground; the 'science' part raises several kinds of difficulty, one of which is that science fiction is not necessarily fiction about science and scientists, nor is science necessarily important in it. Prolonged cogitation, however, would lead one to something like this: Science fiction is that class of prose narrative treating of a situation that could not arise in the world we know, but which is hypothesised on the basis of some innovation in science or technology, or pseudo-science or pseudo technology, whether human or extra-terrestrial in origin. 29

Amis is here concerned with prose but the definition encompasses many films traditionally categorised as science fiction. His suggestion that science fiction explores situations that could not exist in our everyday world requires qualification since it is the very fact that they could occur in the everyday, commonsensical world that makes some science fiction so powerful and that makes it worthwhile as genuine literature according to Arbur's classification.30

David Thompson also draws attention to the juxtaposition of the two conceivably contradictory terms-science and fiction-and suggests this contradiction imbues science fiction with its interest. He notes that science fiction is often described as the genre that exploits the application of science; that is, it exploits the technology that is one element of scientific knowledge. But beyond this common understanding of science is science-as-knowledge, as ontology. Hence the paradox of science fiction: 'the confrontation of established fact and make-believe'.31

According to Thomson, the genre has a philosophy and the philosophy defines the genre. Science fiction is not story-telling about knowledge;

knowledge is 'the terrain and the leading character':

Whereas most stories are moral fables, science fiction may be a metaphor on our relationship with intelligence....[A]s we examine the place of knowledge and intellect in science fiction, we are not looking at one small room in the house, we are assessing the structure as a whole and its place in the landscape....Science fiction's intimation of disaster comes from its worrying over whether knowledge is good or evil, forbidden fruit or true

28 Mark Rose 1981 Alien encounters: anatomy of science fiction Cambridge: Harvard University 2

29 Kingsley Amis 1976 'Starting points' in M Rose (ed) Science fiction: a collection of critical essays Englewood Cliffs, NJ: Prentice-Hall, 11

30 Rosemarie Arbur 1983 'Teleology of human nature for mentality' in Robert Myers (ed) The intersection of science fiction and philosophy London: Greenwood Press, 71-91.

31 David Thomson 1984 'The fear of intelligence in futuristic films' in Danny Peary (ed) Omni's screen flights/screen fantasies New York: Doubleday, 77 
nourishment. 32

Science fiction is the popular discourse about science and humanity, about human values juxtaposed against knowledge, about the nature of knowledge. It matters not whether films are classified as good or bad, as possible or impossible, as successful or not successful. The fact of commercial reality in the production of science fiction films is irrelevant to that particular aspect of the discourse.

From the historical perspective and accepting that science fiction film is discourse where the relationship between humanity and knowledge is contested, then science fiction is a recent phenomenon. As science has become knowledge-that is, as scientific knowledge has become the only knowledge to the exclusion or marginalisation of other forms of knowledge (such as mystical experience, for example) - then science fiction films are products of this 'growth' in science and its application to all aspects of living.

This does not suggest that the quest for knowledge, and its relationship with humanity, is new. The quest for understanding is not, but understanding as that is defined by science is new; as new as the science that is the stuff of science fiction films. Given that science is the measure by which we define knowledge and progress ('we are undergoing an explosion in knowledge'; 'there is more knowledge now than there ever was before' etc-all related to knowledge about the world in some way, and the world includes people), then scientific knowledge underpins progress and change. The change in the application of science as technology makes people comment on how different the world is to when I was a child'. Hence classifying science fiction as "what if", as consequence, is fitting, as there would seem to be few times in the history of the planet where 'what if' became an important discourse. 'What if' can only be asked within a paradigm of perceived change.

While other genres may have a more or less common formula containing elements that are present in all narratives of that genre to some extent, for science fiction this is not the case. There is a plurality of elements, combined in different proportions and emphasised to different degrees, which suggest that certain texts can be classified as science fiction but which are not, in all likelihood, all present in any one text. No definition of science fiction will please all; no taxonomy of the features of the genre-if indeed such a taxonomy could be devised-would

32 Thomson 1984, 77 
account for all science fiction films, nor will it settle arguments as to the 'nonscience fiction' elements of any film. Some surface features of fifties science fiction film are: an aspect of science; space ships; astronomy; invasion from outer space; nuclear explosions and effects (giants, mutants both animal and human); special effects. At another level: education about science and technology; persuading to the worth or otherwise of science and technology; arguing the case either for or against science and technology; something outside the known that affects many people, or has the potential to affect many people.

Science fiction is difficult to define because the paradigms of science that underpin it change. At the same time genres are classifications within historical and social contexts and describing of those contexts. Scientific paradigms exist within those historical and social contexts and constitute those contexts. Because these constructions of science are subject to change as the paradigms of science change, then cultural artefacts-or perhaps 'mentifacts' would be a more appropriate term ${ }^{33}$ - such as science fiction films, that reflect and constitute different paradigms of science will be quite different. The nature of science changes over time, the topics it concerns itself with change, the extent of the ability of science to answer questions changes, the nature of the

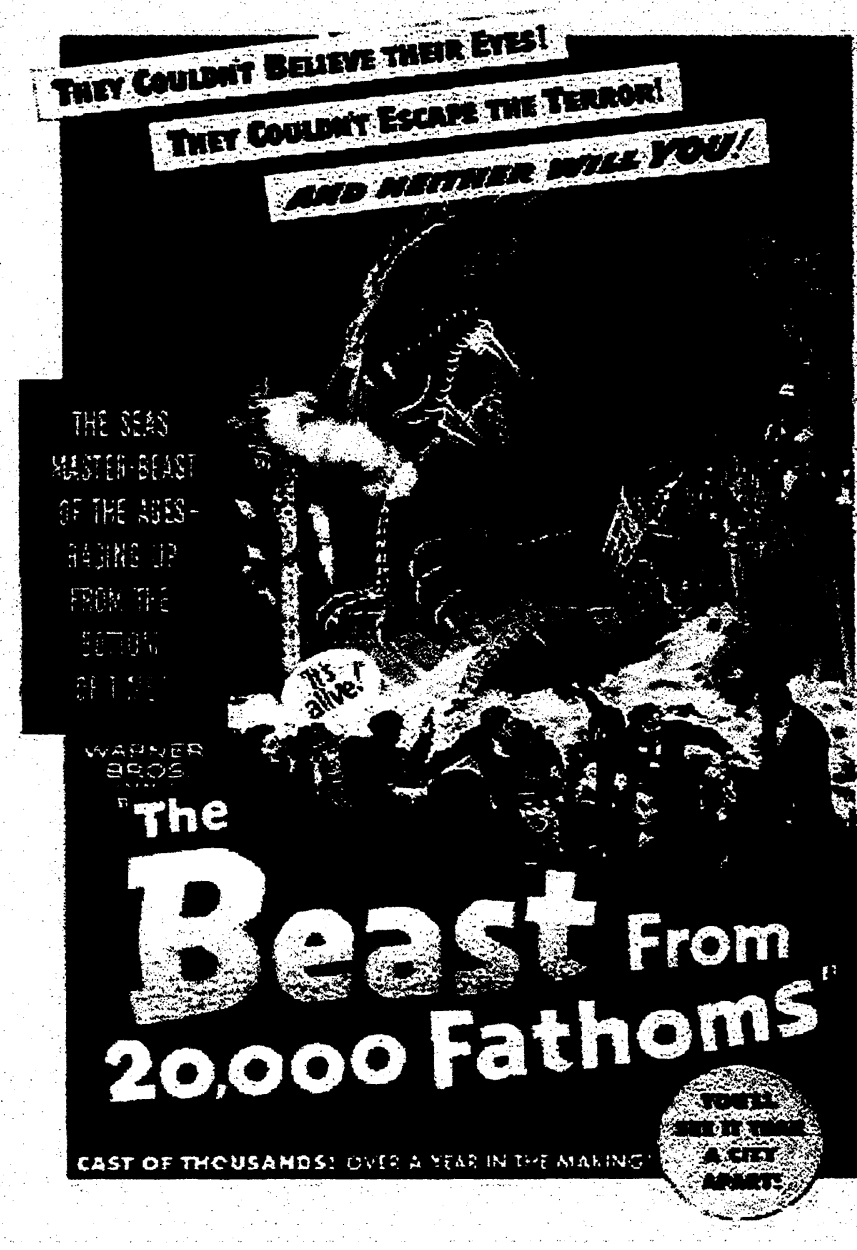

Figure 1: The Beast From 20,000 Fathoms questioned the old paradigms of the scientific method in order to authenticate the narrative.

33 John Hartley 1996 Popular reality: journalism, modernity, popular culture Sydney, Arnold, 2 
'examination' changes, the definition of science itself changes. In The Beast From 20,000 Fathoms (1953) for example, the methodology of science is the subject of debate leading to the surrender of the old paradigm to the new. The change resembles a microcosm of a Kuhnian paradigmatic revolution, as those two paradigms are argued respectively by the old palaeontologist steeped in the old traditions of science, and the young and vigorous nuclear physicist, whose argument for the speculative truths of science is underpinned by the possibilities suggested by the new science of nuclear physics. Other science fiction stories set science in binary opposition to nature-both 'science' and 'nature' are constructs -and the narratives weave this space between the constructed poles of the binary.

Given the fluid nature of the various constructions of science and their relationships with other paradigms-the various threads that comprise the web of science fiction-any artefact which depends on science for its definition is sure to be the subject of dissension when commentators attempt categorisation. Stanislaw Lem, creator of the novel on which Solyaris (1972) is based, links scientific notions of progress to the difficulty of defining science fiction films. 34 Progress in any field implies the abolition of previously valid definitions. Science fiction concerns itself with progress; therefore definitions of science fiction will also change when notions of science are reconstituted. Yet even Lem's nondefinition defines: science, in whatever guise, is an integral element of science fiction films.

Science fiction film is a genre that relies for its classification on the notion of change as its defining substantive, differentiating itself in the process from other genres such as the western or film noir. Westerns are less difficult to classify because the western is about the past and hence an historical 'truth' exists alongside the myths that are recycled about the west. That historical truth is subject to revisionist tendencies yet some fundamental generic markers do not change. Sixguns and society details the structures of the western and uses these, along with plot, iconography and narrative as signifiers of the genre. 35 The creation and representation of character, structure and iconographical archetypes

34 Philip Strick 1976 Science fiction movies London: Octopus, 4

35 Will Wright 1975 Six guns and society Berkeley: University of California Press 
marks the genre, easily recognisable by an audience:

A lone rider, sitting easily in the saddle of his dusty horse, travels across the plains toward a small, new town with muddy streets and lively saloons. He wears a tattered, wide-brimmed hat, a loose-hanging vest, a bandanna around his neck, and one gun rests naturally at his side in a smooth, wellworn holster. Behind him, the empty plains roll gently until they end abruptly in the rocks and forests that punctuate the sudden rise of towering mountain peaks. 36

Nevertheless the location alone does not define the genre; the evocation of social and moral meanings, which the audience understands as defining the western, contributes to the definition as well. The scene recreates the various but limited, meanings associated with westerns; indeed, it recreates what Kitses-drawing on Platonic or, perhaps more accurately, Aristotelian notions of 'idea' - calls 'the idea of the West'. 37

Similarly, the genre of film noir is readily identifiable through various combinations of characterisation, narrative and iconography. Yet these elements alone do not constitute the genre; Bruce Crowther argues that

More than content or appearance, it is that pessimistic mood which most identifies film noir - often one of foreboding; a peculiarly intense anxiety; obsession, usually sexual; and above all a tension created by fear of violence and the inevitability of death. 38

The classification of a literary or filmic text as science fiction is more problematic than the classification as western or film noir. Some writers do not even attempt such a classification, preferring to place science fiction within other more traditional genres; William Bayer does not create a specific category for science fiction films. He includes Dr Strangelove (1964) in the category of 'Comedies', and groups Metropolis (1926) and 2001 (1968) with Psycho (1960) and The Manchurian Candidate (1962) in the category 'Fantasy and horror' ${ }^{39}$ Star Wars (1977) wins his award as the best adventure film in a listing of traditional genres. Perhaps this is a reflection of the traditional lack of acceptance of science fiction in 'high culture' definitions of literature and film where the popular forms are of somewhat less value than the canonical texts. Rosemarie Arbur argues against such marginalisation by suggesting that science fiction follows Aristotle's precepts as to what constitutes literature. She invokes a canonical authority to argue against marginalisation of science fiction:

According to Aristotle's Poetics literature artfully and verbally represents

Wright 1975,4

Jim Kitses 1969 Horizons West Bloomington, Indiana: Indiana University Press, 8

Bruce Crowther 1988 Film noir: reflections in a dark mirror London: Columbus, 8.

William Bayer 1973 The great movies New York: Grosset \& Dunlap 
human action by imitating what is, what was, and what could be or should be. Science fiction belongs in the last of these categories. It presents us with a speculative, probable could and, insofar as all literature is thematic to some degree it provides approximations of the probable in order for us to learn or to form judgments about whether the could is should. If it is, the theme

becomes a kind of guide; if the could is should not, the theme becomes a clear admonition. 40

Yet her definition is incomplete because it limits science fiction to the realm of warnings about the future; an element of much science fiction such as The Day the Earth Stood Still (1951) but it excludes other obvious candidates like I Married a Monster From Outer Space (1958). That science fiction is in fact focussed on the present is a position this thesis supports.

Such ambivalence surrounding the genre occurs at the popular level as well. A survey of the local video store revealed that they too have problems classifying films as science fiction. ET was in the 'family' section with Cocoon (1985) while The Blob (1958) and The Fly (1958) were in the 'horror' category. On the other hand, Star Wars and its sequels were in the science fiction shelves although they have, arguably, fewer science fiction elements than any of ET, The Blob, The Fly or Cocoon.

Philip Strick overturns any notion that science fiction film has any intrinsic nature through maintaining that science fiction film has become its own definition.41 A film is science fiction because science fiction fans call it science fiction. Strick is aware of the irony of such a seemingly irrational position in what should be a rational process but it is the position adopted by Brosnan in the quote that begins this chapter and taken into account by Sobchack. To create an absolute and sharply defined genre can 'imprison the critic in an ontological construct which has little to do with cinematic reality'. .42

\section{The genre according to the writers}

Science fiction writers do not agree about definitions of science fiction any more than do critics, film production companies, local video lending libraries or science-fiction fans. The issue is not confined to a discussion of critics and readers, or audience and filmmakers, but includes science fiction writers as well. In a letter to agent Lurton Blassingame in 1949, Robert Heinlein complains about

40 Arbur 1983, 71-91

41 Strick 1976, 4

42 Vivian Sobchack 1987 Screening space: the American science fiction film 2nd ed New York: Ungar, 17 
his editor at Scribner's publishing house, Alice Dalgleish, whom he constantly refers to as 'Miss Dalgleish'. She had rejected his draft of Red planet, a juvenile novel for boys:

She has firmly fixed in her mind a conception of what a "science fiction" book should be, though she can't define it and the notion is nebulous-she has neither the technical training nor the acquaintance with the body of literature in the field to have a clearly defined criterion.....it [her definition of science fiction] reads something like this: Science has to do with machines and machinery and laboratories. Science fiction consists of stories about the wonderful machines of the future which will go striding around the universe, as in Jules Verne.... [On the other hand] speculative fiction (I prefer that term to science fiction) is also concerned with sociology, psychology, esoteric aspects of biology, impact of terrestrial culture on the other cultures we may encounter when we conquer space etc, without end. However, speculative fiction is not fantasy fiction, as it rules out the use of anything as material which violates established scientific fact, laws of nature, call it what you will, ie., it must be possible to the universe as we know it. Thus Wind in the Willows is fantasy, but the much more incredible extravaganzas of $\mathrm{Dr}$ Olaf Stapledon are speculative fiction-science fiction. 43

Certainly the 'wonderful machines' are an element of science fiction as is the status of science and, more particularly, engineering in the work of Jules Verne. Extrapolation on scientific facts and engineering possibilities underpin From the Earth to the Moon where Verne devotes significant pages to a discussion of the physical laws surrounding the idea of firing a projectile to the moon and the calculations required to ensure all constructed objects will operate satisfactorily. 44

But for Heinlein science fiction novels are much more than the 'light, escape literature' pulp publisher John Campbell Jr suggested they should be, although he is not consistent in his expectations of science fiction. He later says:

Science fiction is not, was not, and will not be an escape literature-the 'safe' fantasy...that certainly is becoming more and more popular. [My type of science fiction] never pretended it was kidding and has been the non-escape literature that seeks to meet the problems of tomorrow... 45

And Heinlein underlines this interrogation of the social problems of the

future. His concern with the future manifested in writing about the possible worlds that could be brought into existence through extrapolation on current scientific work and the social and cultural implications:

My real claim to being a student of the future...lies in noting things going on now and then in examining speculatively what those trends could mean - particularly with respect to atomics, space travel, geriatrics, genetics, propaganda techniques, and food supply. 46

43 Robert Heinlein (Virginia Heinlein ed) 1990 Grumbles from the grave New York: Ballantine, 49

44 Jules Verne undated From the Earth to the Moon Sydney: Scholastic

45 in David Kyle 1976 A pictorial history of science fiction London: Hamlyn, 168

46 Heinlein 1990 letter to Lurton Blassingame 7 November 1949, 148 
Heinlein is also concerned to extrapolate on social issues and to perceive of science fiction as in some way posing a challenge. But, as he notes, those speculations are the result of change brought about by science and its application as technology. An interesting case is that of the reformulation of the roles and expectations of women in postwar USA. In Delilah and the space riggers Heinlein constructs a space station where women are beginning to work in construction jobs traditionally performed by men and are equal to men in all respects, and the plot revolves about the social upheavals that might occur when such events take place. 47 Heinlein's story argues a case; the case was that women could do the task equally as well as men and would work on an equal footing with men. Yet women inhabit the world of business and science on an equal footing to men as early as 1941, with the introduction of the robot psychologist Dr Susan Calvin at the topmost level of the US Robots and Mechanical Men Corporation in Isaac Asimov's third robot story, Liar, in 1941.48 She appears in ten robot stories up to 1969. Some science fiction films construct similar stances for, and arguments about, women, like Them! (1954), It Came From Beneath the Sea (1955)-both discussed in some detail in chapter four-The Brain Machine (1956) and The Wasp Woman (1960).

While extrapolation on emergent social and scientific trends, such as the equality of women in the working field, is one thread of science fiction it is not the only thread in the web. Lester del Rey defines extrapolation as taking known trends to their ultimate development and while agreeing that extrapolation is important for some science fiction, del Rey argues that science fiction is more. It is 'an attempt to deal rationally with alternate possibilities in a manner which will be entertaining' ${ }^{49}$ In reality though, his and Heinlein's definitions do not seem to be very different.

Heinlein is critical of publishers Scribner's Sons focus on machines, spaceships and laboratories; similarly, science fiction writer Harlan Ellison is critical of Hollywood's conception of science fiction as, collectively, anything to

47 Robert Heinlein 1954 The green hills of Earth Sydney: Pan, 7-19. To date though, women have not become the radio technicians Heinlein suggested they would become.

48 Isaac Asimov 1941 'Liar' Astounding Science Fiction reprinted in Asimov 1983 The complete robot Sydney: Grafton Books. Perhaps one might argue that the appearance of a woman leading a company that made mechanical men could be seen to forecast the later feminist push to reconstitute the male, reaching a significant point with Sarah Connor judging the Terminator to be the most successful father to her son John in Terminator 2.

49 Lester del Rey 1980 The world of science fiction New York: Garland, 5 
do with monsters: 50

From Them, perhaps, but not from the hordes of giant fleas, katydids, mantises, sloths, spiders, and other flopping lurching, slithering grotesqueries an aberrated Hollywood has proffered as their conception of the ne plus ultra in science fiction films....

For Hollywood's conception of what to do with sf...has usually been on the level of The Tapioca Pudding that Had Intercourse with Cleveland.51

Ellison does not subscribe to the view that these science fiction films were

based on science in any way:

The imbecilic lack of research that characterised what most people thought of as "sf films" defies belief. Take the giant ant, for instance. It simply can't be. No which way.

In this he echoes Heinlein: science fiction must conform to the physical laws we think govern the universe. Nor has this aspect of science fiction films improved over time:

Not even the dawn of the Age of Star Wars (1977) has much enhanced the genre of science fiction films. A generation of film school graduates...come to puberty but not necessarily maturity, surfeited with television sf and a seeming ignorance of the written word, ga-ga over special effects and utterly unfamiliar with the concept of plagiarism, has perpetuated the worst aspects of cinematic sophorism [sic] by paying homage to the idiocies of the Fifties. 52

For Ellison, two films of the 60 s are seminal in science fiction filmography:

Stanley Kubrick's 2001: A Space Odyssey and Charly (1968). His inclusion of Charly as a science fiction film is, he admits, outside the normal classification: "But that ain't sci-fi,' I'm told." 53 The public expectation of science fiction is, according to Ellison, an expectation that excludes films like Charly (1968), Seconds (1966), Wild in the Streets (1968) and Yellow Submarine (1968):

The public image of what is, and what ain't, science fiction film....is the result of decades of paralogia, arrogant stupidity, conscious flummery, and amateurism that have comprised the universal curriculum of milieu that passes for filmic education for a gullible audience. If it goes bangity-bang in space; if it throbs and screams and breaks out of its shell with slimy malevolence; if it seeks to enslave your body, your mind, your gonads or your planet; if it looks cuddly and beeps a lot, it's "sci-fi." 54

For Ellison, the exploration of the impact the cultural 'device' of science has on people signifies a science fiction film. Later, he defines science fiction film as

'What if'; that is, as explorations of consequences, extrapolation:

But science fiction is a very special genre. It is the game of "what if". What if: we were forced to abandon the land and adapt physically to life in the seas?

50 Harlan Ellison 1984 'Lurching down memory lane with It, Them, The Thing, Godzilla, HAL 9000 ...that whole crowd' in Danny Peary (ed) Omni's screen flights/screen fantasies New York: Doubleday, 1-14

51 Ellison 1984, 2

52 Ellison 1984, 3

53 The novel won a Nebula award before the film was made, however.

54 Ellison 1984, 10 
What if: everyone was telepathic and could read everyone else's mind, how could you commit a murder and not be discovered when your thoughts gave you away? What if: the male contraceptive became as common as the pill women use? What if. 55

Lester del Rey arrives at the same conclusion, written in the same way, in his chapter entitled 'What science fiction is':

In the final analysis, science fiction is largely based upon the asking of a single question: What if...? What if men found a way to live together? What if men suddenly met an alien race?...56

But, according to Ellison, because science-fiction film has some relationship with science, it must have the internal logic of science, no matter how strange that paradigm as a whole may be:

And playing that game is the core of the story. But it must be internally consistent. It must have a much more rigorous logic than an ordinary, mimetic story, because you are asking the audience to suspend its disbelief, to go with you into a completely new, never-before-existed landscape. If what goes on in the story is irrational and diffuse, then it all comes up looking like spinach. 57

While Ellison is quick to dismiss Star Wars as 'spinach', his own science fiction stories are sometimes characterised by the 'errors' he sees in those science fiction films that comprise giant ants which break physical rules and which cannot exist according to physical laws. In Adrift just off the Islets of Langerhans Ellison asks us to believe that there can exist a miniaturised double of a human, which (or who) then enters its double somewhere in the vicinity of the navel.58 The works of other science fiction writers have no internal consistency nor logic: in Nightfall people use torches when they have never known darkness and when the world has never previously become dark.59 The question here pertains to the necessity for torches at all if there has never been darkness. Other internal inconsistencies make the reader's supension of disbelief-often a conscious actproblematic. The point is that science fiction writers participate in the discourse of definition and apply that definition to other works, but their works do not necessarily have the qualities of science fiction that the writers define science fiction by.

Like Ellison, some contemporary film critics find science fiction a predictable and exploitative genre. To some extent the B-film tag is reflected in the tone of contemporary criticism such as the seminal essay by Susan Sontag in

\footnotetext{
Ellison 1984, 12

del Rey 1980, 11

Ellison 1984, 12

5 Harlan Ellison 1974 in The magazine of fantasy and science fiction October, 48-76

59 Isaac Asimov \& Robert Silverberg 1990 Nightfall Sydney: Doubleday
} 
the sixties, which is important in the lexicon of science fiction discourse and delineates the parameters for later critiques and the threads that might be addressed in further work. Sontag's view is that science fiction film has few redeeming features in narrative material and contains no elements of social criticism, an argument this dissertation questions, arguing that science fiction films recycled, re-formed, and re-presented the discourse of change, encapsulating discourse about the control of science and the possible consequences of scientific discoveries.

Sontag does not quite dismiss science fiction film as legitimate art, comment or entertainment but her analysis of the genre is not positive. Science fiction film is as tired and as boring as the western:

The typical science fiction film has a form as predictable as a Western, and is made up of elements which, to a practiced eye, are as classic as the saloon brawl, the blonde schoolteacher from the East, and the gun duel on the deserted main street. 60

Sontag's classification of the structural models of fifties science fiction film has three basic 'scripts', three basic plots from which all science fiction films derive. One model has five phases: the arrival of the thing, observed by the scientist who is hero; confirmation of the hero's initially disbelieved story by other witnesses of the destruction caused by the thing; conferences replete with consternation and drama involving the military and politicians; further attacks by the thing(s), including uncalled-for attacks on the hero's beautiful girlfriend and consequent and unsuccessful attacks by the latest technological weaponry; further conferences while the hero scientist works methodically and scientifically on a nuclear device which is finally successful. 61

A derivative of this model involves the discovery of the negative consequences of nuclear testing on the environment of the planet, which will quickly but inexorably lead to the extinction of human life.62 Sontag's general tone in the article is dismissive; most scenarios she refers to are in the realm of fantasy. Irony abounds-atmospheric nuclear testing has been discontinued by most nations because of the possible consequences; Chernobyl has realised the fears of many about nuclear fallout.

60 Susan Sontag 1976 'The imagination of disaster' in M Rose (ed) Science fiction: a collection of critical essays Englewood Cliffs, NJ: Prentice Hall 116, taken from Sontag 1966 Against interpretation New York: Farrar, Straus \& Giroux; 209-225

61 Sontag 1976, 116,117

62 Sontag 1976, 119 
A second model has four phases.63 The hero, attended by girlfriend or wife and, as it is a typical nuclear family, two children, are involved in some middleclass family activity when some aberration occurs. The aberration may manifest as strange behaviour by a person or vegetable matter. In the second phase, the hero makes a rudimentary investigation of the phenomenon and tries to warn the local authorities, who disbelieve him. The hero, knowing the real and malevolent intentions of the thing, takes appropriate measures to protect the girlfriend or wife and property. The third phase creates the general helplessness in the local community caused by the inexorable progress of the thing in the face of failed deterrents. In the final phase the hero discovers the vulnerability of the thing and is able to destroy it or he is able to escape in order to explain the situation to previously unaware outside authorities who repel or destroy the invaders through advanced weapons technology.

Sontag's third model describes a journey to the moon or a planet, where the inhabitants are in a state of crisis caused by some threat to their livelihood, either in the form of aliens or through nuclear war.64 Against this background are played out the features of the first and second model.

One element of Sontag's analysis of fifties science fiction films is accurate: the fifties science fiction genre contains some of the worst films ever made, by any criteria. Many such films are strongly represented in awards for 'bad' films made by some commentators. The Medveds' catalogue of Hollywood's worst films contains many examples from science fiction.65 The category "The most ridiculous monster in screen

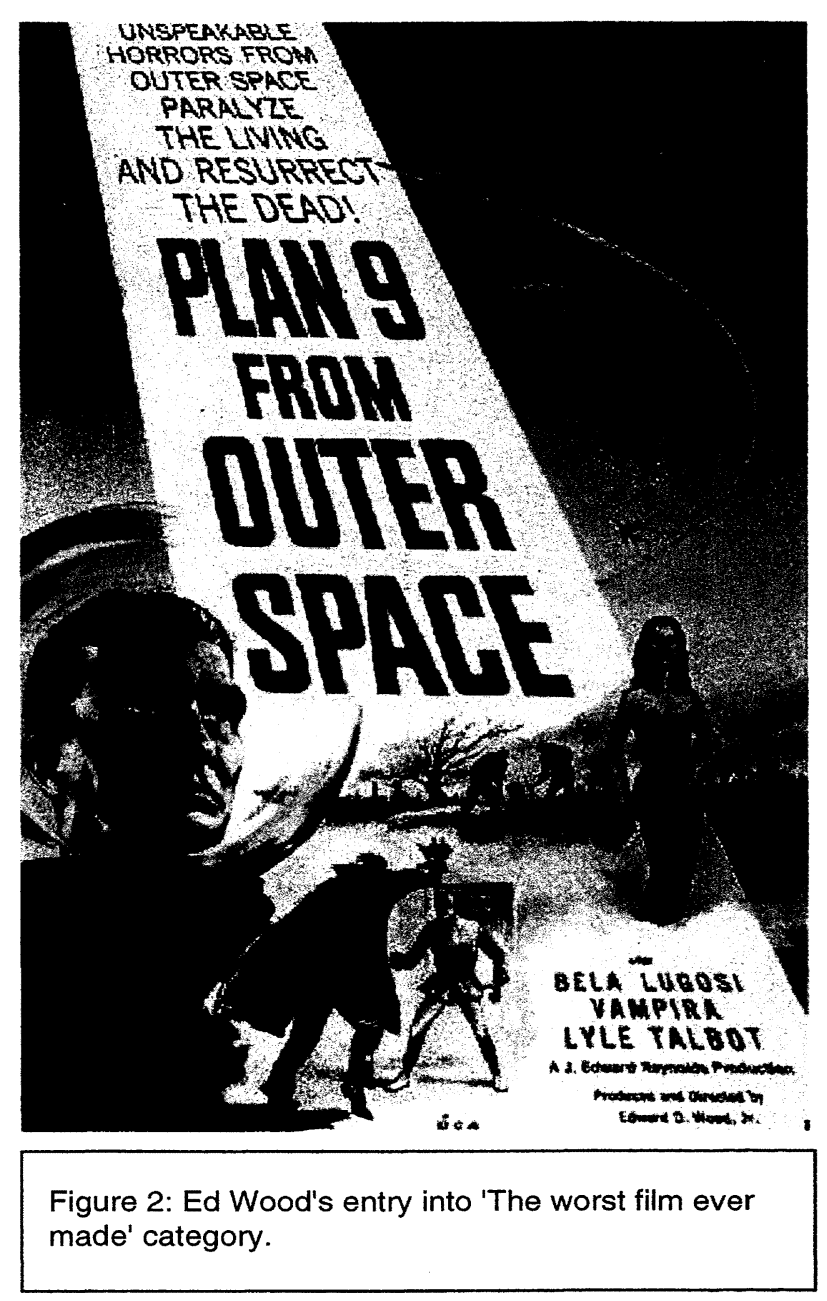

63 Sontag 1976, 117,118

64 Sontag 1976, 118

65 Harry \& Michael Medved 1980 The golden turkey awards Sydney: Angus \& Robertson 
history' contains 5 nominations from science fiction-bordering on horror-from the 50s: The Alligator People (1959), Attack Of The Fifty Foot Woman (1958), From Hell It Came (1957), Robot Monster (1953) and Teenagers From Outer Space (1959). The winner was Robot Monster. The Grand Prize-Sweepstakes Award went to the people's choice for the worst film of all time: Plan Nine From Outer Space (1959). The presence of extremely bad science fiction films is not in doubt but even in those films are significant elements in the discourse of science, of power, of change and those discourses legitimate the films as useful cultural products.

\section{The boundaries of the science fiction film: horror and fantasy}

Horror and science fiction have an uneasy relationship, assuming that the difference can be so clearly ascertained that the text can be easily categorised without further argument. And that assumption is not always valid. Many films can be classified as either horror or science fiction, while some science fiction films, such as those thematically oriented to the destruction of the world, cannot be horror, and by some definitions may not be science fiction either. This grey area between horror and science fiction is one of the reasons for the exasperation in the tone of John Brosnan's quote at the beginning of this chapter. The debate is endless and has been entered into by most writers about both genres. Vivian Sobchack teases out the many threads of similarity and difference that might be used, that seem to be used, to classify texts.66 Donald Willis claims that science fiction was a genre-without-a-name before 1950 and the dominant genre revolving around 'science fantasy' was horror. The argument that science fiction grew out of the horror genre is useful in tracing elements of the emergence of SF.67 In one sense, SF is horror film 'technologised' for modern audience who were, in the fifties, becoming increasingly pragmatic and materialistic. 68

Welch Everman chooses many films that others have classified as science fiction in his Cult horror films, yet he neatly sidesteps discussion of his selection criteria apropos 'horror', focusing instead on the question of the cult status of the films. 69 He includes films like Fiend Without a Face (1957), The Giant Gila Monster

Sobchack 1987, 26-58

Donald Willis (ed) 1985 Variety's complete science fiction reviews New York: Garland, x

68 Sobchack 1987, 29

69 Welch Everman 1993 Cult horror films New York: Citadel, 1-8 
(1959), Hideous Sun Demon (1959), Invasion of the Body Snatchers (1956) and others, within the parameters of 'cult horror', yet, as with other films in his collection, they are included in other collections as examples of the science fiction genre. 70 It is worthwhile to tease out some of the differences and similarities in the genres, and the grey areas between the two.

First, one marker of the horror text-whether it is film or print-is its concern with individuals and their quest for knowledge, and the construction of their relationship with nature. The quest for knowledge is an individual quest, that is constructed as oppositional to the laws of nature that stand as reified constructs, often of an impersonal creator. The quest is in defiance of these laws and the scientist who breaks those laws is judged by the text as guilty even if he-and the scientist is always male in these films-is reconciled and sees the error of his ways. Punishment in an abstract sense is always suffered; the fulfilment of the laws of nature takes precedence over the compassion people might feel for others. In Dr Cyclops (1940), Dr Thorkel experiments on molecular cell tissue with human subjects to gain knowledge and power over the processes of nature. Thorkel investigates domains of knowledge that should not be investigated. When told this he kills the person-his student-who tells him. The sub-genre of scientist searching for dangerous knowledge has easily traceable links to earlier filmic and literary characters. Goethe's Faust is the model; the latest incarnation of the story of Saint (Satan) being cast out from Heaven because he wanted more knowledge. Shelley's Frankenstein is a relatively recent literary incarnation, but so too are films like Dr Cyclops, The Fly and so on. In these films the scientist is of course the focus of the film; he plays the lead. In some films the scientist is portrayed as evil, as in Dr Cyclops, and in the fifties, The Thing (1951), whereas in other cases the tragedy of the search is the death of the scientist who causes harm to no one but himself. In The Fly Andre is the happy, upper middle class family man who is devoted to science, and who believes in the sacredness of life. Yet his obsession with the transmission and rebuilding of organic 'atoms' is the cause of an irreversible accident requiring his death. The knowledge is dangerous; he opines:

(t)here are things man should never experiment with. Now I must destroy everything, even myself. No one must ever know what I discovered; it's too dangerous.

70 for example, Jeff Rovin 1993 Classic science fiction films New York: Citadel 
This transgression of the laws of nature is localised and impacts only on people in the immediate 'ground zero' of the event. The consequences are confined to the local, rather than the global. In science fiction the consequences expand into the global domain. Thus Amazing Colossal Man (1957)-while it theorises that the boundaries of 'natural' knowledge have been transgressed, causing Colonel Manning to cry out in his desolation: 'What sin can man commit in a single lifetime to bring this on himself -is classifiable as science fiction because it infers the global consequence of exposure to radiation from an explosion of plutonium. The individual is a metonym for humanity, in a kind of replay of the myth of original sin.

The discourse established about nature and its relation to science sections science fiction from horror. A recurring theme in science fiction films is the primacy of science as derived from rational thought and experiment-whether that primacy has positive or negative consequences is sometimes the issue-over a materialistic and essentially 'non-sacred' universe. The lesson of horror films, on the other hand, is that an anthropomorphised nature has drawn a set of boundaries that may not be transgressed, as to do so mobilises a set of personalised recriminations that cannot be reversed. Conversely, science fiction is essentially materialistic and constructs the universe on simple cause and logical effect. This paradigmatic shift in the construction of absolute meanings is part of the discourse of some science fiction films, where the construction of an anthropomorphic, personalised nature is articulated and then discarded for the rationality of science. In Night the World Exploded (1957) the woman scientist 'Hutch' opines: "The world is striking back because we're robbing her of her natural resources", but then retracts, admitting that this type of thinking is "not very scientific". But we should be careful here because another sub-set of science fiction does assert the primacy of a creator and a created universe over materialistic paradigms. War of the Worlds closes with the destruction of the aliens through bacteria that was-the omniscient narrator informs us explicitly-not a product of the process of evolution but rather a safety device from an essentially caring Creator.

The Martians had no resistance to the bacteria in our atmosphere to which we have long since become immune. Once they had breathed our air, germs which no longer affect us began to kill them. The end came swiftly. All over the world their machines began to stop and fall. After all that men could do had failed, the Martians were destroyed and humanity was saved by the littlest things, which God in his wisdom had put upon this earth... [the 
people standing on the hillside break into a hymn].

War of the Worlds is not horror but science fiction principally because of the convergence of the discourses of science and technology, the global threat and the global cooperation that is mobilised to deal with the threat.

Horror tends to conservative views of change, science fiction tends to argue for change and progress, even if that change and progress centres on the nature of a creator. The transgression in horror films as defined here precipitates judgment-most often death-on the transgressor. In science fiction even the death of an individual might be the cause for a change in ontological understanding; The Incredible Shrinking Man (1957) not only does not theorise death as some kind of punishment from an Old Testament-modelled wrathful and vengeful reified creator, but sees it as a liberating experience, a new conception of death, a vaguely non-western notion of death as simply a transformation. As Carey dies, he says:

So close, the infinitesimal and the infinite, but suddenly I knew they were really the two ends of the same concept. The unbelievably small and the unbelievably vast, like the closing of a gigantic circle. I looked up as if somehow I would grasp the Heavens, the universe, worlds beyond number. God's silver tapestry spread across the night. And in that moment I knew the answer to the riddle of the infinite.

I had thought in terms of man's own limited dimension. I had presumed upon nature. That existence begins and ends is man's conception and I felt my body dwindling, melting, becoming nothing.

My fears melted away and in their place came acceptance. All this vast majesty of creation, it had to mean something. And then I meant something too. Yes, smaller than the smallest, I meant something too. To God there is no zero. I still exist.

Sobchack notes that both horror and science fiction are genres of chaos: horror is threaded with chaos of the moral order and a threat to hearth and home; science fiction is threaded with disruption to the social order and threat to civilised society. 71

A further difference Sobchack notes is that of geographical site. The arena for horror is often a small village, a localised area; thus the Transylvanian castle in the Frankenstein stories, the stone aristocratic gated residence in Unnatural: the Fruit of Evil (1952) in an unnamed village. The site jigsawed with the age; the battle, and the consequences of the battle were local. Science fiction operates on the global scale, even when the site of contestation, the site of chaos is local, as it very often is. The Thing's intellectual carrot landed near an Arctic station, the blob

71 Sobchack 1987,30 
took over a small town in middle USA, the saucer men invade a small town in the USA. But while the site might be local, the implications are always global. This is significant to a crystallisation of the genre of science fiction.

Prior to the fifties, prior to the nuclear explosions that announced clearly the ability of humanity to destroy all life on the planet, consequences of disturbance, of chaos, were local. In addition, the emergence of globe-enveloping communications links via, most recently in contemporary terms, television, established what came to be known as Mashall McLuhan's global village, at least in the sense of global communications. Thus in The Thing the newspaperman was a significant character, as was his use of radio communication to warn the world: "Watch the skies". The global threat of a local incident, as well as a global response, is a recurring thread in fifties science fiction and guides the narrative of The Day the Earth Stood Still, Earth Versus the Flying Saucers and Invasion of the Body Snatchers, and from Japan, The Mysterians (1959). Less effective is The Giant Claw (1957) and Devil Girl From Mars (1954), for example, but the point is that even in such low-budget films the theme recurs. The giant bird from The Giant Claw appears in the Arctic from an 'anti-matter' universe and then proceeds to instil fear and panic in the nations of the world. While the suspension of disbelief is almost impossible the film does follow the model of a global threat emerging from a local incident.

Without the technology afforded through the technological exploitation of science, global destruction could not be considered, global threats could not be conceived, global communications could not facilitate a global response. Further, the global incident creating an effect at the order of the solar system and beyond is the logical extrapolation of this model.

For Sobchack, a very unclear difference between science fiction and horror is that between 'the monster' and 'the creature' film. In brief, the monster is most often recognisably human, and undergoes a transformation that uses its similarity to the human form to emphasise the effect of 'horror'. But in science fiction, the Monsters, or Creatures as Sobchack terms them in defining their difference from the Monster of horror, are decidedly alien. The creature is constructed as impersonal, as non-human, and the battle is joined against the alien. In horror though, the Monster resembles the human or a transformed human and evokes in some way empathy and sympathy. The demarcation is, once again, not clear. In It Came From Outer Space (1953) the POV shots from the 
alien to the earthman are unparalleled. Interestingly, there is no creation of fear or menace in such a shot, simply a benign observation of the earthman Putnam's actions.

Sobchack generally defines the territory clearly in summarising the polarities of horror and science fiction. Traditional horror film is about an individual's fall from grace, the expulsion from Eden, the human dependence on the redemptive power of love, the individual struggling with evil. No such sense of predestination pervades science fiction. The science fiction creature is a threat that exists apart from collective guilt. Its relationship to humanity is non-existent; it is an accident. In science fiction, however misguided the actions are and no matter how the accidents occur, people have control over their destinies. Science fiction films differ from horror in their focus of attention, their thematic emphasis, their visual way of looking at their subjects, their total intensity.

At the other end of the spectrum to horror is fantasy. It is even more difficult to separate many recent films into science fiction and fantasy as separate categories. In the fifties, where science fiction was constructed in part as a pure extrapolation on science, fantasy was anything that involved the magical, or events that transgressed known physical laws. Like Ellison, the biologist, academic, author and science fiction writer Isaac Asimov saw some science fiction films as fantasy in that they broke universal physical laws.72 To a scientist, space travel to the far end of the galaxy is impossible as is time-travel, as these figments of the imagination contravene laws which scientists hold as fundamental. Other older-in the sense that they were described earlier-and self-evident laws such as that relating to inertia are contravened in the scene from Return of the Jedi (1983) in which ground vehicles manoeuvre at breakneck speed through a forest. In a real world the passengers would be battered and bashed at every turn. These views were reflected by John Brosnan; science fiction films 'annoyed' him because of their scientific inaccuracy. 73 Of course, all films are more or less scientifically inaccurate or historically inaccurate; for example, early westerns depicting bullet wounds without any blood-pre-Peckinpah-are scientifically inaccurate. However science fiction was supposed to foreground science, and for that reason people like Ellison and Brosnan find fault where

72 Isaac Asimov 1984 'Movie science' in Danny Peary (ed) Omni's screen flights/screen fantasies New York: Doubleday, 50-54 
others might not.

Yet, Brosnan claims, as time passed the scientific inaccuracies concerned him less. So too with del Rey in his treatment of written science fiction. Observing that science fiction and fantasy are less easy to separate, his definition of science fiction embraces science fantasy: 'Science fiction accepts change as the major basis for stories. 74 Although problems abound in the classification of science fiction, and in the circularity of the argument that makes the classification less than rigorous, an identification of the elements of science fiction reveals that it is dissimilar to other genres in important ways just as it is similar in other ways. The next section investigates those areas of difference.

\section{The genre web and genre threads}

As we have seen film genres, as with other texts, mobilise tacit and dynamic understandings between filmmakers and audiences. These understandings and links may be imagined as a web, woven with threads comprising the text, the audience, the filmmaker and the intertexts. The text exists within a context but the text feeds into and modifies that context, at the same time deriving from it. The web is a dynamic structure that is constantly in the act of renewal. The act of viewing or reading and the dynamic established between viewer/reader and text is mobilised by coding conventions within the text and material external to the text on the one hand and reader expectation on the other. Delany exemplifies this intertextuality using lines from Kafka: "One morning, waking from uneasy dreams, Gregor Samsa, still in bed, realized he'd transformed into a huge beetle.'75 The questions the reader might have emerge from the knowledge that the book is literary: what is it saying about human personality? Is Samsa insane? Is this situation a metaphor? Possible intertextual references a reader might bring to the reading are Conrad's Kurtz or Sartre's Roquentin from Nausea. On the other hand another text-that is obviously massproduced, has giant cockroaches on the front cover laying waste to a city, has "Nebula award winner" emblazoned diagonally across it, with 'SF' in the top corner-animates another set of questions in the "SF-aware" reader. Questions arise like "What, in the world that the narrative covers, causes such a 
transformation?" Answers to this and similar questions revolve around the reader's desire to know not only the agents of the transformation, but also the set of social or scientific conditions where such a transformation might occur. What is the alternative world-alternative perhaps in only small, but influential ways-where such a transformation is either logically or narratively possible and indeed, even essential?

Intertextuality takes into account pre-existing knowledge constructs which the audience may have negotiated from films and other texts. In addition, audiences exist within and negotiate contexts and meanings generated not only from the intertextual knowledge of other texts but also from those cultural contexts. Textual elements are not sufficient in themselves to account for the negotiation of meaning, for, as noted above, genres are historical and cultural artefacts and practices as they are always being used and developed. They exist within and contribute to these contexts, neither simply reflecting nor causative of them:

Film does not reflect or even record reality; like any other medium of representation it constructs and 're-presents' its pictures of reality by way of the codes, conventions, myths, and ideologies of its culture as well as by way of the specific signifying practices of the medium. Just as film works on the meaning systems of culture - to renew, reproduce, or review them - it is also produced by those meaning systems. 76

Thus the threads that indicate and comprise genre coded into the expectations that an audience brings to bear on a film are not defining, unchanging or disparate elements and any film might be treated using a different set of elements to frame the discussion. These elements organise the social ideas and practices and trigger cultural knowledge in the audience about those ideas and practices. But cultural knowledge is not only triggered, it is recreated in the site where the viewer's knowledge and perceptions are influenced by the constructs represented in the film. Where the viewer's knowledge and perceptions are confronted by those of the film then this site is one of contestation. The influence of a film then, lies in part in its ability to recreate the viewer's social knowledges in such a way as to extend that cultural knowledge; that is, to confirm through this extension the knowledges of the viewer. A genre is picked up and transformed, both by the specific socio-historical contexts and intertextual borrowing from other texts of the same genre, as well as texts from

76 Graeme Turner 1988 Film as social practice London: Routledge, 129 
other genres that are themselves undergoing transformation. The contexts are relevant historical and cultural elements of the fifties, including aspects of science, and the industrial context in which fifties science fiction films were made. Those elements frame the next two chapters of this dissertation.

This section continues with a discussion of the textual threads of genre although it is understood that science fiction films cannot be deconstructed to find meaning only through an analysis of the individual textual elements. The whole is greater than the sum of the parts so in any separation of the parts some distortion of the whole occurs; neither is that whole in some sense absolute and exterior to the viewer or reader. But allowing for that fluidity of elements of the text across genres and the differing structural function and meaning of those elements, it is both valid and possible to examine the textual elements to discuss their significance to an idea of genre. One set of threads are those of narrative, spectacle (including the notion of iconography), technical codes relating to filmmaking, the discourse of science and the character of the agents of science. Narrative, discussed in an introductory way below, as an element is included across most chapters of this thesis, as it is through narrative that other elements, such as the nature of science, can be discussed. The industrial context of filmmaking, including technical codes, is only briefly mentioned here and elaborated on in chapter three. The last two threads, of science and the scientist, are mentioned briefly here and are further unravelled in chapters four and five. The final section of this chapter focuses on the thread of iconography and its subset, special effects. The functions of human stars and special effects, and the unique- to the genre-interrelationship between the idea of 'star' and special effects concludes the chapter.

In general, science fiction as narrative is the realm of print whereas science fiction film is not just a story on screen, not just a narrative in a new medium but a completely different medium, spectacle as much as story. Both are important, and this thesis balances elements of narrative with Landon's focus on the importance of image, or iconography, in science fiction film.77 While iconography is a difficult concept to engage with as it applies to science fiction films, it is foregrounded in any comparison of film with novel, and the immediate representation of the extraordinary is unique to film-physical deformity and

77 Brooks Landon 1992, xiv 
mutation, missile and rocket combat, toppling skyscrapers -providing something that print cannot supply, that 'sensuous elaboration' that is associated with film in general.78

Additionally, science fiction is different in iconography from other genres. Sobchack makes the point perfectly when she argues that iconography in the western is limited because the genre is limited in time and space dimensions. 79 In contrast, the iconography of science fiction exists to code unbounded future time and different dimensions of space and, since The Time Machine (1960), of time also. A defining character of science fiction iconography is this change, is the representation of change in the mise en scene. Thus a science fiction film has a visual texture that, coupled with other elements mentioned above, inscribes the film into the panoply of the genre. It is the visual feel-Sontag's sensuous elaboration - of the film that assists in the recreation of the 'idea of' science fiction. 80 The visual feel comprises icons like space ships, robots, aliens, earthbound monsters, technical and technological power, global destruction, attachments to human bodies, weapons of mass (nuclear) and personal (some form of ray) destruction, different (often future) worlds, special effects and so on. None of these items in itself marks the film as science fiction, but one of more of these icons of strangeness suggests science fiction. The icons recreate strangeness but not disbelief, for science fiction functions on the premise of a very possible reality. At the same time the icons function as metonyms for science and technology, for progress, for the future, for possibilities, for a world that is in some way changed, in some complex and significant way different from today's world. It is the real, the now, but with consequence, with possibility factored into its creation.

The plot and narrative elements identify the various sub-genres of science fiction and are the determinants of Sontag's critique earlier in this chapter as well as various comic treatises on science fiction:

Earth scientists invent or discover tiny or giant bugs or reptiles or mechanical devices or super persons or icky things which or who want our women, or who are friendly (The End) or who are friendly but misunderstood or who misunderstand us or understand us too well, or look upon us only as a source of nourishment and are not radioactive and cannot be killed by the Army, Navy, Air Force, Marine Corps and/or Coast Guard, but a cute little kid convinces them people are OK or a priest talks to them of 
God or they fall in love with this beautiful girl and they die (The End) or they leave (The End) or they turn into disgusting lumps (The End) or they get married and live happily forever after (The End). 81

The plot and narrative contain those elements that have also been made the subject of comedy: a nuclear explosion causing mutants or releasing some longfrozen form of life; the effects of nuclear accidents on human beings or a similar sub-genre, the transmogrification of men into monsters; the effects of nuclear war; the exploration of space; alien visitation for some purpose such as conquest or warning. But the sub-genres are not mutually exclusive: another sub-genre might be 'brainfilms', where those films dealing with disembodied brains are classified and similarities in their narrative concerns are identified.82 That subgenre might cut across other sub-genres: Fiend Without a Face for example, constructs a story around the seemingly unlimited power of nuclear energy and speculates on its effect; the effect is disembodied brains that are manifestations of the power of mind. This theme occurs as well in such diverse films as Forbidden Planet (1956) and Invaders From Mars (1953). Many films can quite easily slide from one sub-genre into another depending on the interest of the critic, or reader/viewer as would be expected when generic classification is dependent to a high degree on the interaction between text and audience.

The character that science fiction constructs most significantly (for this dissertation) is the scientist. The scientist is not exclusive to this genre, nor does every film of the genre revolve around a scientist. Yet in a group of films that involve, in whatever form, some element of science or parascience, the scientist is both the functionary of science and the embodiment of a representation of science. Scientists are constructed in as many forms as there are attitudes and positions about science; that is, on a spectrum ranging from the almost godlike through to the devilish, the scientist might be located at any point, exhibiting any of the characteristics associated with the position of the node in the web.

A second axis, a second dimension to the scale perpendicular to the other, will indicate the importance of the scientist to the unfolding of the narrative. At the top end of the scale might be those scientists that are foregrounded by the narrative and are crucial to it. On the lower end of the axis are those scientists who are unimportant to the unfolding of the plot, no matter how important their

81 Gahan Wilson 1971 'Science fiction horror movie pocket computer chart' The National Lampoon November, 22

82 for example Jeffrey Sconce 1995 'Brains from space: mapping the mind in 1950s science and cinema' Science as culture 23, 277-302 
science is. The ultimate point for this side of the scale are those films where scientists are absent from the narrative.

Science is not just the subject of the narrative, but underpins the filmmaking as well. The significance of the technical codes lies in the foregrounding of the possibilities of film technology, that is itself a product of the science that is the subject of the genre. The earliest filmmakers-Louis and Auguste Lumière, George Méliès, Edwin S Porter for example—made films that foreshadowed later significant genres of filmic endeavour: the documentary, science fiction, the western. The Lumière brothers filmed real life events: The Gardener (1895), Paperhangers (1897), Workers Leaving the Lumiere Factory (1895), for example. 83 Méliès continued his fascination with illusion, which he brought from the theatre of magic, in films containing the themes, special effects and narrative concerns that were later developed in the genre of science fiction. The first western was Porter's The Great Train Robbery (1903), which is, in retrospect, identifiable as a western through its settings, iconography and narrative.

Special effects as a discrete entity, as a category of technical code, as an element in the generic array is very significant in science fiction film, yet special effects in science fiction has another function in that it usurps the practice of using known (human) stars. The importance of this function of special effects is so central as to require discussion in advance of any general discussion on the technical significance of special effects.

\section{Stars in science fiction}

Turner argues that the casting of known stars in a film carries with it a set of meanings for an audience; these meanings are determined in changing ways by the characteristics which the audience attributes to the stars of the films. 84 In the western, for example, John Wayne was the all-American hero, individual, a loner, tough, macho, protective of and different from women. In real life Wayne was this character; anti-intellectual and distrustful of governments and smoothtalking representatives of business and government. His off-screen persona was

83 the Lumiere collection was available at

http://www.discovery.com/DCO/doc/1012/world/technology/lumieres/lumieres1.1.html. The site has since been dismantled, although the films are linked from Errol Vieth 1998

'Introduction: the pioneer filmmakers' CQU Screen Studies unit http://infocom.cqu.edu.au/Study/Winter Units/51215 Screen Studies/Intro/intro prims.ht $\underline{\mathrm{ml}}$ (accessed 28/12/98)

84 Turner 1988, 102-109 
the archetypal outdoorsman, the hard-living, hard-drinking man whose attitude to the cancer that finally killed him was that he could 'lick it'. In a similar way Bennett and Woolacott draw parallels between the attitudes and Weltanschauungen of James Bond and Sean Connery, which are similar to those of Wayne in their individualistic and anti-welfare state elements. 85 Hence the audience viewing a western starring John Wayne creates meanings that are influenced by the pre-existent character set that the audience may know the star represents and creates. For John Wayne the western was the ideal vehicle, as it was for Clint Eastwood whose attitudes parallel Wayne's in many respects.

Given this attraction of an audience towards stars, it is significant that one of the most financially successful science fiction films, Star Wars has few recognisable stars. Harrison Ford became famous because of Star Wars although he was known from Getting Straight (1970) and American Graffiti (1973); other players have not been accorded the same superstar status, but any success that is attributed to them came about because they played in this film; they had no prior fame. Mark Hamill was unknown, Carrie Fisher had appeared in Shampoo (1975), while most others characters have had few appearances before or since. The two exceptions are Alec Guinness as Ben (Obi-Wan) Kenobi and Peter Cushing as Grand Moff Tarkin; and Peter Cushing's part was minor.

That pattern of unknowns playing in science fiction films is a general characteristic of the fifties, yet there are exceptions. In Forbidden Planet Walter Pidgeon played Dr Morbius and Anne Francis, who had performed in many films, played Altaira. Leslie Nielsen established a film reputation with this film but had acted in many TV productions in the early fifties, appearing in some 45 live TV dramas in 1950.86 Rod Taylor was already a rising star when he appeared in The Time Machine, Gregory Peck, Anthony Perkins, Fred Astaire and Ava Gardner were stars before their appearance in On The Beach (1959). Pat Boone was already famous for his singing when he starred in Journey to the Centre of the Earth (1959) while James Mason was at another, lower, pinnacle of his career.

Other actors were less well known, and some began their careers with parts in science fiction films. Lee van Cleef began his productive screen career with at least two fifties science fiction films: The Beast From 20,000 Fathoms and It

85 Tony Bennett \& Janet Woollacott 1987 Bond and beyond London: Macmillan

86 Microsoft CD 1995 Cinemania '95 Biographical details for Leslie Nielsen, Microsoft Corp 
Conquered the World (1956). He was a small-part performer initially, playing the soldier who fired the bazooka in the final scenes at Coney Island in The Beast. In It Conquered the World he graduated to the lead role. His opposite in that film was Peter Graves, who had played in the science fiction films Red Planet Mars (1952) and Killers From Space (1954) before It Conquered the World and Beginning of the End (1957). Michael Rennie had appeared in British films since the 30s, but his second wholly US production The Day the Earth Stood Still helped to shape and cement his reputation in Hollywood. James Whitmore played leads in films before Them! but was not a renowned star until his Oscar-nominated role as President Truman in Give 'em Hell, Harry (1975). Mirroring the later career path of Harrison Ford, Steve McQueen was practically unknown before he played the lead role in The Blob, and in that year also won the starring role in the TV series Wanted: Dead or Alive. Forrest Tucker, playing the lead of Alan Brooks in The Trollenberg Terror (1958)—released as The Crawling Eye in the UK-was not a star in the same league as John Wayne, but he was a second-order star and had played numerous leading roles. Barbara Rush began her thirty year film career in 1950; in When Worlds Collide (1951) and It Came From Outer Space she played strong supporting roles.

Other names re-appear in the cast lists of fifties science fiction films but are not considered significant enough to warrant an entry in such databases as Cinemania '95, for example. Morris Ankrum played sometimes significant roles in four films selected for this dissertation: 'Sparks' in Red Planet Mars, Colonel Fielding in Invaders From Mars, General Hanley in Earth Versus the Flying Saucers and in The Giant Claw. Paul Birch played in Beast With a Million Eyes (1955) and Day the World Ended (1956). Faith Domergue played Dr Adams in This Island Earth (1954) and The Atomic Man (1956), as well as Dr Joyce in It Came From Beneath the Sea.

As a general rule, big-name stars were absent from science fiction films. There may be relevant social reasons for this absence of stars, as well as reasons deriving from the nature of science fiction films. Both westerns and film noir return to the past for their reconstitution of meaning. The viewers require a sense of the past, an historical awareness of 'the west'. Sobchack says of this limiting factor:

(i)t is also highly significant that both these genres [Gangster and Western] are visually circumscribed by an awareness of history, the Western even more so than the gangster film. This linkage of situation and character, 
objects, settings, and costumes to a specific past creates visual boundaries to what can be photographed and in what context. 87

This is not to say that the historical knowledge must be authentic, but the re-presentation and revision of history is dependent on an historical awareness:

This historical awareness, which leads at least to an imaginative if not actual authenticity, demands repetition and creates consistency throughout these genres. 88

Unlike westerns and film noir, science fiction films do not necessarily return to a specific past. They are fluid in both time and space. They may turn to the future, to the unknown, and in so doing they require new and non-limiting time and space configurations, to evoke new and different meanings. New meanings are difficult to elicit if a viewer brings to the viewing act a meaning set he believes the star or stars have about 'life'. Hence the meanings she might generate are not dependent on pre-existing knowledge sets she believe the stars might have. The viewer then has a greater degree of latitude to create the new meanings the film might suggest.

Dyer observes that stars were used to sell the film to an audience and to organise that audience. 89 Stars were portrayed in large reproductions on promotional posters for films in which they performed. They were used to sell the film to an audience and to organise that audience. They were a marketing strategy.

In this context of stars it is revealing to examine the promotional posters for 50 s science fiction films. What such an examination suggests is that the stars for some films were the invidious BEMs-bug-eyed monsters. Many posters foregrounded the hero's beautiful girlfriend in a state of semi-undress, swooning in the claws of the monster whose image overwhelmed and dwarfed normal humans. The woman was evidently being threatened with ravishment although the mechanics of such an act, given the other physical characteristics of the monster, are left to the imagination of the viewer.90

The poster for Creature With the Atom Brain (1955) depicts a woman in some form of bedroom apparel ending at her thighs, lying under the demonic gaze of an oversized man with the remnants of stitching from cranial surgery emblazoned on his follicularly challenged head. One poster (which is not quite

87 Sobchack 198766

88 Sobchack 198766

89 Richard Dyer 1979 Stars London: British Film Institute, 11

90 for example, see the poster for Creature from the Black Lagoon in Phil Hardy (ed) 1984 Science Fiction: The Aurum film encyclopedia London: Aurum, 144 
the same as this illustration) for Forbidden Planet has a mid-frame shot of Robby the Robot carrying an apparently comatose, short-skirted and large-breasted woman with long blonde hair, who might be Ann Francis, except that the said Francis is in the foreground. 91 There were no other women in the film, and Robby carried no comatose, semi-clad women anywhere. These posters derived in part from the covers of the myriad magazines that were published during the golden age of science fiction magazines, but in many instances reflected a different awareness of sexuality. 92

Instead of known human stars, these posters depict two types of creature: those constructed by humans, and more commonly in fifties science fiction those of definite non-human ancestry but close enough to effectively invoke reactions of fear, of awe. These creatures take the

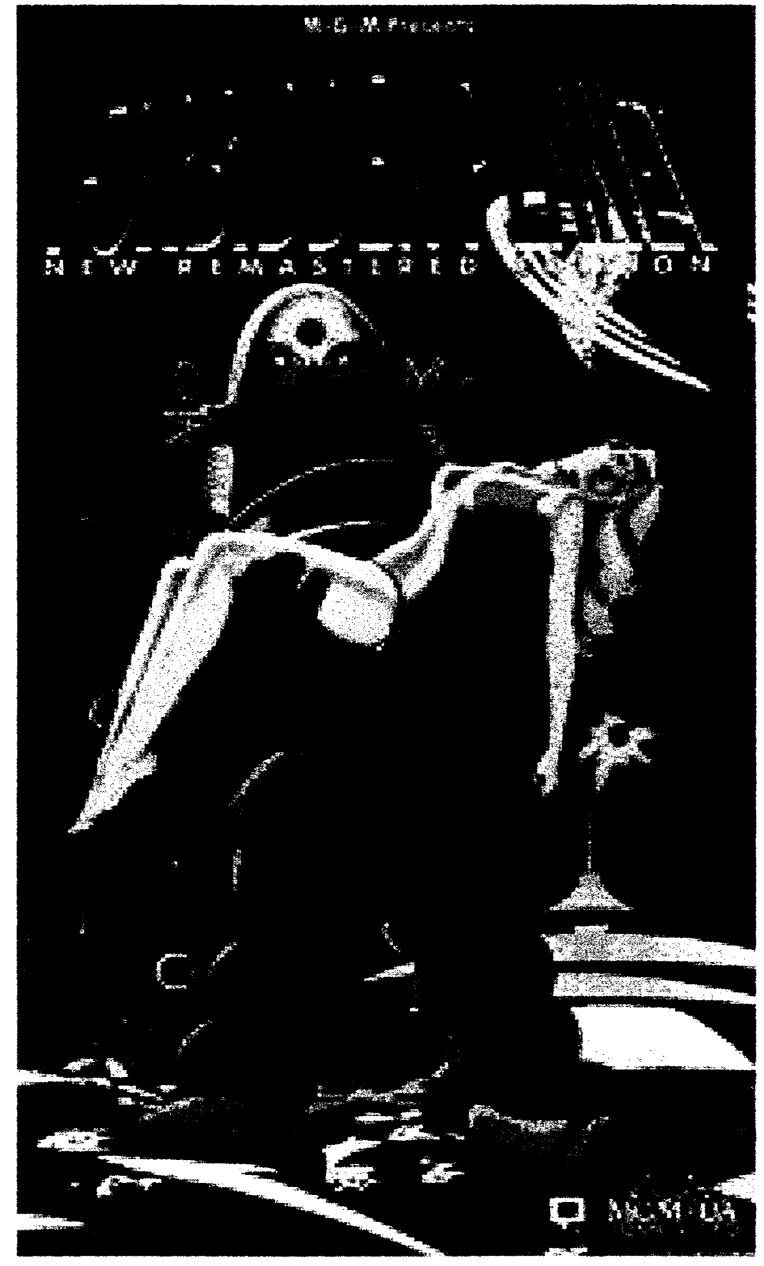

Figure 3: Robby is the malevolent alien, with grinning visage and evil intent.

place of stars on the poster, and are signifiers of codes common across the various sub-genres: humans creating or interfering with life, alien invasion, science gone wrong resulting in mutated insects and humans, monstersfunctioning as threat, as fearful, as 'the other', the aberration of the human, the primeval that resides in all people, threatening to take over the consciousness of humanity - perhaps only 'man' - and reduce it to its pre-civilised state. Golding postulated such a scenario in The Lord of the flies 93 and the thread is echoed by Commander Adams during his struggle with Dr Morbius in Forbidden Planet:

We're all part-monsters in our subconscious. And so we have laws and

91 Rovin 1993, 79

92 see Frewin, Anthony 1988 One hundred years of science fiction illustration 1840-1940 London: Bloomsbury 116 and Kyle 1976 for examples of such covers

93 William Golding 1954 Lord of the flies: a novel London: Faber \& Faber 
religion.

In this instance the narrative marks Robby as friendly but the poster is ambivalent and suggests a fear of the 'other' discussed in the next chapter. In the case of Forbidden Planet Robby the Robot became a familiar star in his own right and appeared in other films and various television series. 94

The images on posters were not isolated cultural icons; intertextual references to similar monsters abound in cartoons and texts. Cartoonists drew muscular genies escaping from bottles or brutal giants labelled "atomic power" looming over hapless scientists or politicians. 95 On the day the atomic bomb was dropped on Hiroshima the metaphor of Frankenstein, used to connote the power of the 'unleashed' atom, was broadcast on NBC and recycled everywhere 'from street corners to the United States Senate'.96 This dissertation will revisit the implications of this Frankenstein in the following chapter.

In effect, then, these creatures functioned as stars, and were themselves a product of special effects as well as foregrounding the special effects as 'star'.

\section{Special effects and science fiction film}

All cinema is illusion; our eyes and optical centres construct life from the flicker of countless still images and we believe in that flow of life that is so constructed. 97 But the life we see is sometimes of a very unnatural kind and it is here that the skill of the effects makers turns that unnatural into believable life. Special effects in science fiction film is different from special effects in other genres in that its ability to transmogrify the unreal into the real is central to the film's ability to induce the willing suspension of disbelief in an audience. In this genre special effects are not just additional to the mise-en-scene, but are integral to it and special effects assume star status in the same way that humans assume star status in other genres. I am not talking here about the iconography of spaceships, for example, but the functioning of special effects in transmogrifying the unreal to the real.

Special effects was a major determinant for the prediction of a successful

94 J P Telotte 1995 Replications: a robotic history of the science fiction film Chicago: U Of Illinois Press, 18

95 Spencer Weart 1988 Nuclear fear: a history of images Cambridge, Mass: Harvard University Press, 104

96 Weart 1988, 105

97 Clive Baker in the Foreword to Anthony Timpone (ed) 1996 Men, makeup and monsters New York: St Martin's Griffin, ix 
film. Of an early science fiction film of the 50s, Rocketship XM (1950), Variety film review wrote:

The sight of the rocketship taking off, the jettisoning of its booster equipment to the near doom of the ship; the flight of meteors that endanger the adventurers; the use of color for the Martian sequences... are among the calculated means used to thrill. 98

In addition, 'the very realistic rocketship and gadgets' contributed to 'a topnotch, small-budgeted exploitation feature'. In its review of Destination Moon in the following month, VFR suggested both that the stars of the film are the special effects and that these special effects transmogrify the unreal into the real:

Stars of "Moon" are the technicians, and the array of devices should delight the gadgeteer. The ship itself, the technically perfect models of earth, moon and the heavens, and the space suits and equipment used by the cast all contribute to the flavor of authenticity....99

By August 1951, comments on convincing special effects had moved up to the second paragraph of the review and seem to evoke even more laudatory comments from the reviewer, while reiterating both the star function of special effects and the transmogrification function:

Top honors for this inter-planetary fantasy [When Worlds Collide] rest with the cameramen and special effects technicians rather than with performances of the non-name cast. Process photography and optical illusions are done with an imaginativeness that vicariously sweeps the spectator into space....Departure, actual flight and landing upon Zyra represent the highpoint of the picture. It's a triumph for the technicians whose artistry, along with the hues of Technicolor, make the sequence a fine piece of realism. 100

The stars in these films were the special effects; the people creating them were to become famous: 'Actors, writers, and directors all played second fiddle to the technicians who engineered the destruction'.101

In 1953, VFR suggested that stars in science fiction films were not only unnecessary, but could act to confuse the transmogrification function of special effects. Of the 'Socko science-fiction thriller with big b.o. potential' War of the Worlds, the reviewer wrote:

The film wisely uses no established marquee names to detract from the feeling that what is being seen is real. Instead, what starring honors there are go strictly to the special effects, which create an atmosphere of soul-chilling apprehension so effectively audiences will actually take alarm at the danger posed in the picture....

Into this setup, the special effects group headed by Gordon Jennings loosens a reign of screen terror, of futile defense, demolished cities, charred landscapes and people burned to ashes by the invaders' weapons....

98 Variety Film Review 1950, 3 May

99 VFR 1950, 28 June

100 'When worlds collide' 1951 VFR, 29 August

101 Les Daniels 1977 Fear: a history of horror in the mass media Sydney: Paladin 
The special effects miniature work is outstanding....102

When the special effects do not function to transmogrify, the review is not enthusiastic-'Prehistoric animals look like the mechanical creatures they are'but even so, VFR șuggests the film, Lost Continent (1951), has an 'exploitation' potential that could be built around these effects:

Exploitation chances are built around the prehistoric animal gimmick, an atom-rocket flight and a lost island that blows up for the finale. Sequences showing the valley where the prehistoric creatures live is done in green hues to heighten the weird effect....103

In films where special effects are not impressive, they are mentioned briefly - '...other technical assists are standard'104_or not at all. Such lack condemned the film to mediocrity: of Spaceways (1953), the reviewer headed the review with the less-than-enthusiastic 'Mild science-fiction programmer...for routine bookings.'

The pattern of attributing star quality to special effects continued through the 50s. Of The Blob the reviewer said:

(s)tar performers, however, are the De Luxe color camerawork of Thomas Spalding and Barton Sloane's special effects. 105

Worthy of note is the introduction of a 'special effects' credit in the VFR reviews where this was warranted or had been screened.

Of the function of special effects in this first golden age of the science fiction film, Sobchack wrote in 1987:

...special effects generally functioned to symbolize the "rational coolness" (and fearsome "coldness") associated with high technology and scientific objectivity, and were "authenticated" and made credible by the genre's "documentary" visual attitude.

Some films had this "documentary" attitude, and there they did function to symbolise a rational coolness associated with scientific discourse, as the review of When Worlds Collide suggests. Even here, the special effects were not authenticated by a narrative or other device: they themselves authenticated, made real, the discourses of science. And certainly, the reviews of The Blob and War of the Worlds contradict Sobchack's assertion that special effects 'functioned to symbolize the "rational coolness" (and fearsome "coldness")' of scientific discourse. What the reviewer saw in War of the Worlds was special effects used to create an 'atmosphere' in the audience, and it was an atmosphere of 'soul-chilling

102 VFR 1953, 4 Mar

103 'Lost Continent' 1951 VFR, 25 July

104 'Spaceways' 1953 VFR, 8 July

105 VFR 195810 September 
apprehension' caused by special effects. Special effects are not authenticated by some other filmic operation, they authenticated other operations. Special effects function then to make credible the incredible and while the function of the incredible changes across films in any era the function of special effects does not.

Special effects and science fiction film cannot be separated. Except for films thematically organised around a nuclear holocaust, science fiction films are peppered with special effects. Ellison reviles the preoccupation with special effects:

So for all its vaunted SFX, the Star Wars trilogy ...has no more importance in the concern of the maturation of the sf cinema than does John Carpenter's odious and unnecessary remake of The Thing [1982]...

Talented creators like Lucas, Spielberg, and Carpenter seem to have lost their way....they languish in the thrall of camera tricks and plastic moldmakers and SFX wunderkind.106

forgetting, of course, that the films of the 50 s were remarkable at the time because of their special effects, which were, in relative terms, just as spectacular as those of Lucas, Spielberg and Carpenter: 'not many rotoscoped creatures creep better than Ray Harryhausen's' 107

There is no consensus about the issue amongst science fiction writers. Special effects are integral to science fiction films, says Isaac Asimov, and like the $V F R$ reviewers he foregrounds special effects in accounting for the success of some science fiction films:

Think of the hundreds of millions of people the world over who have seen 2001: A Space Odyssey (1968), the Star Wars trilogy..., the Star Trek movies, and all the other blockbuster science fiction films of the last few years. Each portrays worlds in which some aspects of technology are advanced far beyond anything we have today. (That's why we need "special effects.")108

Solman argues that special effects and narrative are inextricable in many films, and that the special effects on their own are meaning generating. Further, he suggests that special effects allow the filmmaker to escape from the 'collective' of filmmaking. He maintains that '...the anonymous artisans of craft always supported the great auteurs in this way...'109 As proof he compares the first two of the Star Wars trilogy with the third, indicating that the use of special effects is the difference between the first two and the last.110

If science fiction films are in part about the application of scientific

106 Ellison 1984, 12

107 Gregory Solman 1992 'The illusion of a future' Film comment 28, March/April, 32

108 Asimov 1984, 50

109 Solman, 32

110 Solman, 32,33 
knowledge as technology, then special effects are the epitome of this technology. All film contain special effects, to create an ambience, for example, in film noir. All film is manufactured from effects; 'special' effects are different in that they create the impossible-at the least, implausible-and make it real within any context. As technology changes and improves on what went before, so does the technology in special effects. The parting of the water in The Abyss (1989) and the transmogrification of the human arm into metallic clasps in Terminator 2 (1991) reach special effects standards that continue to be improved on. Special effects create awe for the audience, which is an awe of science and its technology, with technology being both the subject of the film and the creator of the awe.

Science fiction is as much a product of film technology as of any other influence. Genres are in part defined by the application of available film technology, albeit in ways constituting a departure from what had gone before, and science fiction is characterised partly by the application of contemporary film technology. This iconography, this cinematic code of special effects is a signifier of science fiction. McLuhan's 'the medium is the message' is called to mind:

Since the films themselves are often about new or imagined future technologies, this must be a perfect example of the medium fitting, if not exactly being, the message.111

The genre of science fiction is a complex web that comprises varying threads in varying sizes and proportions that together weave what is very often unmistakably science fiction film. While films might easily fit into other genres, especially those at the boundaries of the science fiction genre spectrum, the broad 'definitions' of science fiction allow for many contenders. But Brosnan's claim that the best way to classify films is to simply use one person's criteria is also inadmissible, as the genre is, within broad boundaries, quite distinct. On the other hand, the motive for his claim is to simply suggest the futility of arguing about the generic home of individual films. This chapter has shown that an examination of science fiction films from the perspective of genre is a legitimate method of teasing out what they are 'about', and what they might suggest about the film industry and the concerns of the time in which they were made.

The following two chapters focus more closely on those historical and

111 Kuhn, A 7 
cultural contexts, and the industrial contexts. The threads they seek to examine are those historical, cultural and industrial contexts in order to develop an understanding of the part those contexts played in the making of the films as well as their content. 


\title{
Two
}

\section{Cultural and historical contexts}

\begin{abstract}
Not surprisingly, in retrospect the pace of the fifties seemed slower, almost languid. Social ferment, however, was beginning just beneath this placid surface. ${ }^{1}$
\end{abstract}

Films are enterprises of culture, and are constitutive of that culture; alternatively they define, construct and recycle into that culture. Films are not simple reflections of the threads that constitute 'the era', but filmmakers and audiences contribute to the discourse of science and science fiction through making and viewing films. Thus films are both a product of and contributing to that discourse and the genre of science fiction film can be, in part, explained and theorised in relation to this historical and cultural context.

The chapter opens with the broad historical and existential explanations of the emergence of science fiction as a response to an assumed deeper quest in the human consciousness. A subset of that discourse is the argument that technology-through its promised conversion of those theories, relating in some way to the creation of life, into practice-promised the manufacture of creatures that were like humans, thereby displacing the certainty of the fabric of the human into the shifting realms of problematic. From the broad explanation related to the condition of humanity, this chapter then focuses on the context of the fifties, suggesting that the 50 s context is both threaded through the science fiction films of the decade and that those films played a part in spinning those threads and weaving the material of the context. The focus moves to the immediate history of the perceived communist threat and issues surrounding nuclear fission and, later, fusion. Related to those issues, especially that of nuclear science, are those surrounding the discourse of science and scientists, which are dealt with here, while chapters four and five focus on certain elements of the discourse. Other

1 David Halberstam 1993 The fifties New York: Fawcett Columbine, ix 
relevant contextual items, such as the apparent appearance of UFOs and the relationship of the military with Hollywood, are mentioned.

Following those political and historical threads is an elaboration of the relevant social changes and events associated with them. I argue that the fifties were in fact superficially comfortable but subverting that comfort were powerful seismic shock waves that jarred and threatened that comfort and stability, making it even more precious in the process. An important component in that weaving was the economic and cultural impact of teenagers, who comprised a significant element of film audiences. Those audiences are described as far as possible by reference to contemporary surveys and the emergence of the drive-in, and to the special audience group unknown to other genres; that is, fandom. This broad coverage of the cultural contexts of science fiction gives way to the specific production contexts-meaning the rhizome of threads broadly encompassed by the term 'Hollywood' - of science fiction film in the next chapter.

\section{Grand narratives and the emergence of science fiction}

Genres are intimately connected not only with the immediate social and historical context in which they are apparent but also with the genealogy that precedes those contemporary contexts. A pertinent issue is the extent to which science fiction is specific to the 20th century, or whether its traces can be found in social and historical contexts from earlier epochs.

Robert Scholes does not see the dilemma, describing science fiction as both old and new, rooted in the past but distinctly modern, oriented to the future but not bounded by it.' 2 He locates science fiction firmly within a contemporary ontological and scientific paradigm, linking it with the changes in the conception of man from historical to structural. Since the eighteenth century, says Scholes, the two great schools of fiction have been realism and fantasy. The tradition that leads to science fiction is romance, and a special case of romance in which there is 'a radical discontinuity between its world and the world of ordinary human experience' 3 The special case is that in which the romance informs the current situation so that there is a meeting between the fantasy and the reality:

When romance returns deliberately to confront reality it produces the

2 Robert Scholes 1976 'The roots of science fiction' in Mark Rose (ed) Science fiction: a collection of critical essays Englewood Cliffs, NJ: Prentice-Hall, 46

3 Scholes 1976, 46-47 
various forms of didactic romance of fabulation that we usually call allegory, satire, fable, parable, and so on-to indicate our recognition that reality is being addressed indirectly through a patently fictional device. 4

The meeting of romance and reality produces fabulation: 'a world clearly and radically discontinuous from the one we know, yet [it] returns to confront the known world in some cognitive way'. Of the two strands of fabulation, speculative and dogmatic, speculative involves the romance of science. Speculative fabulation is 'a creature of humanism, associated from its origins with attitudes and values that have shaped the growth of science itself ${ }^{\prime} .5$ There is here an excruciating irony in the positive association of humanistic philosophy with what has become the instrumentalism of science.

Scholes continues by investigating the link between the development of speculative fabulation and the 'revolution in man's conception of himself [that] was begun by Darwin's theory of evolution' and 'continued by Einstein's theory of relativity'; the far-reaching effect of this revolution is to replace 'Historical Man with Structural Man'.6 The essence of the scientific revolutions pertaining to the nature of reality is that the instrumental constructions of reality are no longer valid: 'At every turn we run into patterns of shaping force that have gone unobserved by our instrumental approach to the world'. ${ }^{7}$ Because of the new uncertainties about what is, and indeed, that there is no certainty about what is, speculation is a logical and valid method of expression in a world where humanity is grappling with relativities and possibilities rather than absolutes. Speculative fabulation, then, is not only a product of the post-Darwin and postEinstein era; it is called into existence by that era. Scholes names the child of speculative fiction and the post-Darwin, post-Einstein era, structural fabulation:

Considered generically, structural fabulation is simply a new mutation in the tradition of speculative fiction. It is the tradition of Moore, Bacon, and Swift, as modified by new input from the physical and human sciences. 8

Yet structural fabulation is neither scientific in its methods nor a substitute for actual science. It is a fictional exploration of human situations made perceptible by the implications of recent science. Its favourite themes involve the impact of developments or revelations derived from the human or the physical sciences upon the people who must live with those revelations or developments. 9

\footnotetext{
Scholes 1976, 47

Scholes 1976, 48

Scholes 1976, 51

Scholes 1976, 52

Scholes 1976, 53

Scholes 1976, 55
} 
The importance of Scholes' argument for this thesis is that he both traces the historical development of the genre to an earlier epoch in scientific constructions of humanity and notes the disjuncture between that earlier epoch and the later. Hence science fiction-accepting that science fiction equates with structural fabulation-is both an evolution and a revolution.

Mark Rose agrees with Scholes' fundamental argument that science fiction could only emerge as a consequence of new discoveries in science and the implications of those discoveries for the way humanity considered itself in the vast schemata of existence. 10 But he introduces the element of alienation into the discussion, arguing that the conditions of the nineteenth and twentieth century display humanity's alienation, whereas in contrast, the world of Galileo, Copernicus and Newton was a unified world where 'the cosmos was still a sacrament'.11 (Although the problems associated with grand narratives are considered, generalising about historical periods does have validity. For example, the grand narrative of 'progress towards liberation' is a Marxist discourse that was, for a time, hegemonic, as Pippin highlights.12 Following Hegel, Pippin argues that a particular effect of fragmentation and anomie is an element of the historical period or cultural geography called modernism.13 Similarly, an original application of the term 'postmodern' was as an historical period, used by the historian Arnold Toynbee to describe the fourth and supposedly last phase of capitalism, beginning at the end of World War II.14)

If Scholes argued that the emergence of a 'structural human' was a precondition for the writing of science fiction, or structural fabulation, then for Rose the emergence of the 'existential human' was the necessary pre-condition.

...the kind of alienation from the natural world that science fiction presupposes really only comes into being in the nineteenth century, and it is intimately associated with both industrialization and urbanization and with the Victorian crisis of faith, with the disappearance of God that marks the beginning of the modern sense of radical disconnection. 15

His analysis of the social context focuses on the loss of meaning in the scientific age, and his metaphors conjure images reminiscent of Kafka and the grotesque

10 Mark Rose 1981 Alien encounters: anatomy of science fiction Cambridge: Harvard University, 5053, 96-176

11 Rose 1981, 51

12 Robert Pippin 1991 Modernism as a philosophical problem Cambridge, Mass: Blackwell

13 Pippin 1991, 159

14 Pippin 1991, 156

15 Rose 1981, 52 


\section{Gothic of Mervyn Peake16:}

Later in the century, however, the melancholy, long withdrawing roar of the Sea of Faith left exposed the naked shingles of the world, revealing a desert or, worse, a monstrous battleground in which individuals and species fought for survival in a world empty of comfort or meaning. 17

And again, using a metaphor which pre-figures the prison imagery of ET by one year:

The Victorian situation of urban man disconnected from God, cut off from nature, separated from other men, is of course our own; it is in the nineteenth century that the modern age of alienation begins. Science fiction can be understood in the context of nineteenth- and twentieth-century spiritual loneliness as a manifestation of our culture's longing to escape the prison-house of the merely human. It might be considered as an attempt to re-establish, in some way that will sustain conviction even in our technological and post-Christian culture, the channels of communication with the nonhuman world.... What is important is the attempt to replenish the void, to fill the immense absence with meaning, even if this is accomplished by turning emptiness itself into an antagonist that can be confronted in human terms. 18

While such a broad-brush approach and analysis of the elusive notion of the human 'condition' is both a generalisation and difficult to prove, Robert Heinlein focuses on the subject of an alien existence in Stranger in a strange land,19 and echoes Rose's sentiment in a letter he (Heinlein) wrote to his agent, Lurton Blassingame, about the novel:

But ...the two major things which I am attacking are the two biggest, fattest sacred cows of all, the two that every writer is supposed to give at least lip service to: the implicit assumptions of our Western culture concerning religion and concerning sex. Concerning religion, our primary Western cultural assumption is the notion of a personal God. You are permitted to argue every aspect of religion but that one. If you do, you are a double-plus ungood crime-thinker....

But I don't offer a solution because there isn't any, not to an intellectually honest man. That pantheistic, mystical "Thou art God!" chorus that runs through the book is not offered as a creed but as an existentialist assumption of personal responsibility, devoid of all godding. It says, "Don't appeal for mercy to God the Father up in the sky, little man, because he's not at home and never was at home, and couldn't care less. What you do with yourself, whether you are happy or unhappy-live or die-is strictly your business and the universe doesn't care. In fact you may be the universe and the only cause of all your troubles. But, at best, the most you can hope for is comradeship with comrades no more divine (or just as divine) as you are. So quit snivelling and face up to it - "Thou art God!"20

Arguably such a notion prefigures John Lennon's Imagine (1971): 'Imagine there's

16 Mervyn Peake 1969 Gormenghast Harmondsworth: Penguin

17 Rose 1981, 52, 53

18 Rose 198153

19 Robert Heinlein 1961 Stranger in a strange land Putnam

20 Robert Heinlein 1989 Grumbles from the grave Virginia Heinlein (ed) New York: Ballantine, 228,229 
no heaven, it's easy if you try, no hell below us, above us only sky'. But while Lennon hints at a peaceful reconciliation with an atheistic universe, writers like Camus, Sartre and Kafka wrote of individuals toiling ineffectually in an overwhelming, alien universe. 21

Given the necessary precondition of alienation for the emergence of science fiction, argues Rose, it has few links with earlier literature. Because the Platonic identification of the real with the eternal and unchanging has dominated the history of Western thought, then the notions of uncertain time and change have not been prevalent, and 'in such circumstances science fiction, dependent upon the radical sense of alienation from the cosmos, could not appear'.22

Like Scholes, Rose traces the scientific discoveries and theorising that transformed medieval certainties about time, space and man.23 These certainties were shown over time to be mythical; for example, Charles Lyell's Principles of Geology seriously shook the certainty about biblical time frames in the early part of the nineteenth century. The discovery of Neanderthal Man in 1856 followed by Darwin's Origin of species necessitated a self-reflexive human being thinking of himself or herself as a natural phenomenon developing and evolving over unimaginable eons rather than as the creation of a personal God. These scientific paradigmatic shifts undermined the sense of certainty about the nature of the universe and humanity's place in it, substituting that certainty with a paradigm that foregrounds change as the universal principle, toppling the edifices of certainty of the biblical world. Change is a feature of the paradigm of science and appears, as I have and will further illustrate, in science fiction; change as a legitimate-and in some instances, illegitimate-element of social practice features in the discourse of science fiction film.

A primary feature of change relates to the conception and construction of a human as the binary to the non-human creature, foregrounding that non-human as a product of technology. The space between the binaries is the area of contestation and the problematic science fiction examines is the boundary between the two.24 Science fiction explores the changing discursive space between non-humans and humans, speculating on the qualities that distinguish

21 Albert Camus 1978 The collected fiction of Albert Camus (trans Stuart Gilbert) London: Book Club Franz Kafka 1974 The castle (trans Willa \& Edwin Muir) Harmondsworth: Penguin Jean-Paul Sartre 1965 Nausea (trans Robert Baldick) Harmondsworth: Penguin

22 Rose 1981, 96

23 Rose 1981, 96-109

24 J P Telotte 1995 Replications: a robotic history of the science fiction film Chicago: U of Chicago Press 
the two; additionally, when humans create that 'other' the boundary becomes even more blurred. The fascination for this act of creation is not another aspect of the mythology of creation but rather a chapter in the development of technology. 25 Technology allows for the construction of the proto-human through mobilising the fascination with creation in a concrete, or rather more fittingly, metal form. While Metropolis is the outstanding example of such a creation in the pre-fifties film era, Forbidden Planet is the fifties parallel, constructing a persona of Robby the Robot that was to become a familiar cultural icon. While he-or is it she, given that his activities cross all kinds of gender roles and pose interesting questions pertaining to cross-gender roles-is fundamentally a fascinating and ingratiating creature, he embodies in part the fears and concerns about the ability to create life through an increasingly sophisticated technology.

\section{Change and Fear}

While the idea of the grand narrative is useful in locating and perhaps explaining science fiction, other threads (that might create the conditions for the description of the grand narrative but are not necessarily causative) are specific to the culture of the fifties, at the same time contributing to the grand narrative in significant ways.

Two significant and interrelated threads that weave through the fifties and occur in different texts, different discourses, are change and fear; both are impossible to prove in any empirical sense. The fifties was a period of change and instability that manifested in different cultural features: for example, the split of the globe into the armed camps of East and West, the tension of the cold war between these two camps and the fear of communism on the part of the west, the knowledge of the power of nuclear weapons, the re-emergence of antiintellectualism. But there were other significant changes that add further threads to the web: consumer credit, the suburbs founded on the mobility and 'freedom' brought about by the car and consumer credit, the 'maturing', into the new marketing target and socially constructed group, of 'teenagers' emerging from the mini-baby boom of World War 2 and the second 'boom' from the end of that

25 Harry Geduld 1978 'Genesis II: the evolution of synthetic man' Geduld \& Ronald Gottesman (eds) Robots robots, robots Boston: New York Graphic Society, 5 
war. Associated with these changes is a deep insecurity and fear, reflected in various social indicators that this chapter will trace by examining the divergent threads and connecting them to science fiction films of the decade. The first of those threads entwines the politics and discourse of nuclear fission and fusion.

Nuclear physics had unleashed the power of the atom in nuclear explosions that ended World War 2. This source of power was the node around which was generated both extreme pessimism and extreme optimism. The hope-constructed in part by nuclear-observer and official journalist to the nuclear tests, William Laurence-was that harnessing the atom would lead to a utopia that included air-conditioned jungles, livable paradises transformed from arctic wastes, revolutionised transport fuel needs and world peace. ${ }^{26}$ In short, atomic energy could "make the dream of the earth as a Promised Land come true in time for many of us already born to see and enjoy it". 27

But such beliefs were counter-balanced by the fear of the Frankenstein of nuclear apocalypse if not from war, then from associated cataclysms. Robert Heinlein wrote that a disastrous atomic war which 'will destroy for a long time the present technological structure' was one of two possibilities for a period of 'extreme change'.28 Even so soon after the development of nuclear weapons one quarter of US citizens polled thought that the atom-smashing experiments would in some way destroy the world, and in a French event paralleling the panic caused by the 'War of the Worlds' broadcast on CBS in 1938,

an announcer, imitating news flashes, cried that "atoms from radium used for research in America have broken loose" and a doomsday atomic storm was sweeping around the world. Parisians went into a panic, jamming switchboards with terrified calls; the scare cost the director of the French national radio his job.29

The similarity in language and metaphor that commentators from across the social spectrum used to describe the first nuclear explosion attests to its power but more significantly, those references were recycled in the various metaphors of nuclear holocaust used in social texts. The contemporary significance of the nuclear issue lies in the realisation that the power that might be invoked was of such an order to destroy all sentient beings, and this was a new thread in the cultural web. Previously world destruction was the province of

26 Spencer Weart 1988 Nuclear fear: a history of images Cambridge, Mass: Harvard University Press, 105

27 Weart 1988158,159

28 Robert Heinlein to Lurton Blassingame, 16 March 1946 in Heinlein 1989, 41

29 Weart 1988, 106 
a vengeful and wrathful God but now such power was in the hands of people or perhaps worse, computers. Army engineer General Thomas Farrell, at the site of the first nuclear explosion, wrote that the sound of the explosion 'warned of doomsday and made us feel that we puny things were blasphemous to dare tamper with the forces heretofore reserved to The Almighty'. During the explosion and significantly with reference to an anti-intellectual milieu-and to today's audience, more humorously-he had opined, 'Jesus Christ, the long-hairs have let it get away from them' 30 But such images of absolute power were not the domain of military personnel only; the 'long-hair' Robert Oppenheimer invoked apocalyptic verses from the Bhagavadgita as his metaphor in a surprisingly poetic conversation recorded by Laurence:

As Oppenheimer watched the cloud boil miles up over his head, multicolored and radiant, he had recalled a passage from an ancient Hindu scripture that described a vision of the divine Krishna suddenly growing to reach from earth to heaven, taking on a dazzling multicolored form with numberless arms and eyes, numberless flaming jaws that swallowed whole armies: "I am become Death, the destroyer of worlds". 31

The Judeo-Christian vision of the apocalypse was present in the language of 'presidents and popes' from 1945 moving from the fringes into mainstream society, such that the fear of an 'irrational death' and the loss of a sense of security and certainty became the subject of comment: 'The fear of irrational death...has burst out of the subconscious and into the conscious, filling the mind with primordial apprehensions". 32 President Eisenhower for example, in a speech to the General Assembly of the United Nations on 8 December 1953, indicated the power of nuclear weapons in divulging that the USA nuclear armoury far exceeded the force of all explosives used by all sides in World War 2.33

Oppenheimer's sense of pessimism at the first nuclear explosion was an attitude reflected in the work of other scientists involved in nuclear weapons both during and after the war. Physicist CP Snow in an editorial in Discovery in September 1939 wrote that the discovery of the physics of the atom as a new means of destruction meant that the world had changed. 34 Yet the threat posed

30 Weart 1988, 101

31 Weart 1988, 101. The fundamental difference between Judeo-Christian and Hindu apocalyptic visions. The Judeo-Christian version is of a once-only end of the world, just as creation was a once-only event. The end of the world is just that. The Hindu scriptures describe a cycle of birth, death and rebirth, in which one end is the beginning of a new existence.

32 Norman Cousins in Weart 1988, 106

33 Weart 1988, 158

34 C P Snow 1981 The physicists London: Macmillan, 10 
by Hitler for the Allies and the real understanding that Nazi Germany and Japan were also working on the development of nuclear weapons united scientists in support of the development of nuclear weapons. While physicists generally supported the explosion of the nuclear warhead at Hiroshima, the subsequent detonation at Nagasaki was not justified in the eyes of many physicists. 35 The scientists' misgivings about nuclear weapons were not reflected in the nuclear brinkmanship of President Eisenhower who saw the use of the H-bomb as a way to regain the initiative lost when the USSR exploded its own A-bomb in 1949. Eisenhower's policy of 'compellence' became official policy in 1953, and broadly stated that the US would consider nuclear weapons as available as other munitions, and included the use of tactical atomic weapons in local wars. 36

The history and impact of nuclear power cannot be appreciated outside of the context of the cold war. Without delving too deeply, the Cold War grew out of long-standing antagonism between Great Britain and the US on the one hand and the USSR on the other. Prior to the end of World War 2, the leaders of these three nations met at Teheran and Yalta to coordinate strategy for the remainder of the war and determine where the spoils of war would go. Josef Stalin won significant concessions from US President Roosevelt and (reluctantly) from Prime Minister Churchill, allowing the Soviet Union to fill the power vacuum in Central Europe, the Balkans, and Asia left by Nazi Germany and Imperial Japan. After the war Communist influence spread from Europe to Asia, providing the impetus for the Cold War. Communist governments were established across Eastern Europe and became known as the Communist or Eastern Bloc. An 'iron curtain' was drawn across the centre of Europe, but outside the curtain other communist parties were powerful in France, Italy, and Greece, raising fears that they too would fall behind the curtain. In Asia, communist support was growing in China and Indo-China. Because her history is the history of succeeding invasions, the USSR wanted buffers and so had an expansionist policy to keep the area around the Soviet Union as large as possible and to ensure the governments of those countries remained communist. The Soviet Union exported communism, helping to subvert other countries and hopefully bring them under Soviet influence and domination. In turn the countries of (West) Germany and Japan became bulwarks against this spreading scourge of communism, helped 
enormously by US loans.

The geographical area behind the Iron Curtain became the Dark Regions, closed to all outside eyes and thus the focus of all evil, even more so because its tentacles were spreading (the Domino Effect) the evil religion further afield. This is not to suggest that communism was not a perceived threat before WW2, as the history of the US since the twenties must take into account the hatred (in some quarters) of communism and its influence in labour unions, Congress, the Executive and-significantly for the film industry-Hollywood. The House UnAmerican Affairs Committee (HUAC) was the institutional mechanism of anticommunist activity on a national level, and the focus of anti-communist fervour. 37 With the drawing of the Iron Curtain the threat became more sinister than it was when Russia was, to some extent, open to dialogue, and fear was added to hatred as a significant thread in the culture of the fifties.

The cold war and nuclear issues were the launching pad for numerous science fiction films of the fifties. Fiend Without a Face, for example, is set in a nuclear powered (!) radar station in Canada, the nuclear power providing penetration of 2,500 miles into the USSR across the North Pole.38 Constructing the argument of universal government, Day the Earth Stood Still warns the people of the planet to use their new-found power wisely, under an authoritarian threat of annihilation by the cosmic leaders. At the 'bad' end of the spectrum of 'good versus bad' films, Astounding She Monster (1957) too mobilises the theme of galactic warning to an errant earth people. The space visitor, a female space person, leaves a message from the Master of the Galaxy of Stars warning the planet that the Universal Governing Body of the New Galactic World Order might retaliate if the people of Earth continue to disturb the cosmic peace. A similar cause urges the Martians to invade the Earth in Invaders From Mars: Earth's exploration of space is causing disequilibrium in the galactic balance.

The fear of internal communist infiltration and external communist aggression meshed with the fear of nuclear holocaust in the events surrounding the Korean War. The fear of a perceived external communist threat fed into the

37 The HUAC was previously the Dies Committee, formed in 1938 by an alliance of Republicans and Southern Democrats who were united in their distaste for the New Deal.

38 A sidebar of interest is that the commander of the station openly takes benzedrine to maintain his efficiency. His subordinate says: "Did you ever think of trying sleep instead of benzedrine. You know you might like it". This is the only reference 1 have been able to find to the sanctioned use of amphetamines in fifties science fiction films. 
Truman policy of containment, leading to the US involvement in Korea and the threat of nuclear holocaust. In the northern summer of 1950, north Korean soldiers took Seoul and US soldiers were then committed to combat duties. China committed 33 divisions to the war by the end of 1950 and in the face of this opposition the war was going badly for the inexperienced and outnumbered US troops. One reaction in the US was to advocate the use of nuclear weapons. 39 Truman and most US allies were initially reluctant to employ nuclear weapons but there was some pressure for their use within the US: a draft board in Montana 'refused to induct additional young men until Truman had granted General Macarthur atomic weapons and the power to employ them at will'.40 By 1953 President Eisenhower announced that he was willing to consider using nuclear weapons in Korea. 41 In this he was supported by 51 percent of Americans, polled on 1 November 1951, who indicated their support for the deployment of atomic bombs against military targets in Korea. Significant too was both the $49 \%$ who did not support such a deployment and the potential polarisation of social groupings over this issue.

However, those statistics do not allow for extrapolation into the extent of nuclear fear. While the quantitative measuring and tracking of nuclear fear as a response to the events of the fifties might be an impossible task, the conscious response towards nuclear weapons across the US was described by a US Congressman as 'Lock the bomb in a burglar-proof safe and not discuss it'. 42 Avoidance of considering the spectre of nuclear destruction seems to permeate the fifties; for example, two analyses of national opinion polls agreed that the norm was a lack of concern underpinned by ignorance and apathy about such issues as fallout. 43 Of greater concern was the necessity of competing with and equalling the capacities of other nations. These analyses also showed that this position changed during the fifties so that by the late fifties moral concern about nuclear issues was gaining ground and in the early sixties nuclear testing was becoming an item of serious debate.

Weart concedes that quantitative measuring of the degree to which nuclear

39 Robert Torry 1991 'Apocalypse then: Benefits of the bomb in fifties science fiction films' Cinema journal $31: 1,14$

40 Torry 1991, 14

41 Bryan Fruth et al 1996 'The atomic age: facts and films from 1945-1965' J Popular Film E Television 23:4, Winter, 157

42 Gregg Herken 1982 The winning weapon New York: Vintage, 136

43 Strada 1986, 191 
fear pervaded and influenced the history and cultural context of the fifties is not possible.44 To ignore it because it can't be measured would suggest that it did not exist, yet the discourse of nuclear fear manifests in some science fiction films of the period and indirectly in other texts:

The groups of the left and right who spread nuclear imagery understood that they were provoking emotions, but they did not recognize how powerful and ambiguous a force they were using. All the talk about secrets, control and security was less likely to reassure citizens than to remind them of their most intimate problems. Nuclear fear was like a Chinese finger-trap: the harder people tried to pull out of it, the tighter it gripped them. 45

While psychological explanations for events has not been a feature of this dissertation the concept of psychological defence is a possible explanation for the production of films about nuclear war in the light of the ambivalence of social concern. Because of their lack of skilled defence mechanisms children experienced-partly through exposure to science fiction books and filmsnuclear anxiety in a way not experienced by their psychologically well defended parents. 46 Certainly the scenes from science fiction films, even if the parent-aged production people were unaffected by it, reproduce images of the awesome destructive power of nuclear fission and later, fusion.

Many science fiction films screened the logic and images of the power-and the fear of the power-of nuclear weapons. Killers From Space opens with stock footage of A-bomb testing, its effects, the iconic mushroom cloud while the film's narration lurches into a possible consequence of this testing. The Amazing Colossal Man has a similar narrative structure, although here the weapon is a plutonium device and while the effects are different, the evocation of fear is similar. While not specifically invoking apocalyptic visions of power for their effect, other films weave the emotion of fear through an exploration of other, less cinematic but narratively effective, logics involving the unknown effect of nuclear isotopes, for example. Hideous Sun Demon retells the fate of a nuclear scientist who is not careful enough in his handling of atomic material, while The Time Machine uses different images of a devastated London, images that are not quite as exploitative of the power of nuclear destruction. In the sub-genre of films about nuclear destruction the fear was made subject, was rekindled quite openly and as such both built on pre-existent fears and added to them.

\footnotetext{
Weart 1988, 127

Weart 1988127

Douglas Miller \& Marion Nowak 1977 The fifties: the way we really were New York: Doubleday 54
} 
Fear of the apocalypse was the underpinning link for the constructed fear of the decade and was an acceptable and viable narrative to hang a film on. MGM made the first semi-documentary-The Beginning or the End (1946)detailing the development of nuclear fission, climaxing with the first nuclear explosion in 1945 and posing the question that underpins later films: Is this the suicide of the human race or a new era of progress?47 (Importantly, both elements of spectacle and humanitarian concerns are present in this first project.) The Day the World Ended, one of the first (after Five (1951)) of the sub-genre imagining a world after nuclear holocaust, begins with on-screen text:

What you are about to see may never happen, but to this anxious age in which we live, it presents a fearsome warning...Our story begins with...THE END.

In keeping with this nondiegetic text the stock footage of a nuclear explosion and accompanying mushroom cloud follow diegetically and the narrator, adding the spoken mode to both print and image, assumes the role of the prophet of the Judeo-Christian apocalypse:

And the elements shall melt with fervent heat. The Earth also. And the works that were therein shall be burned up. This is T.D Day. Total Destruction by nuclear weapons.

On the Beach is an interesting closure to the decade and diegetic conversations revolve around the place of optimism and hope, balanced against the total hopelessness in a post-apocalyptic planet. That hopelessness is not constructed from images of power but from the total absence of human beings in the city of San Francisco, an environment where human activity is foundational. Fear is constructed through the presentation of environments operating on different logics, where everything is so different from the 'normal'. Impending death is relentless; the normal logic of a civilised world is upturned and then returned to confront the human beings remaining alive.

Nuclear war was one effect of experimentation with splitting the atom yet there were other elements of nuclear fear that did not involve destruction by nuclear weapons but rather some other effect. The power of nuclear explosions was such as to generate a new sub-genre of films where a human or animal monster was created, released, or in some other way animated by nuclear explosions. Those where the monster that was released or created is animal 47 John Douglas Eames 1975 The MGM story: The complete history of fifty-seven roaring years London:
Octopus 209 
rather than human is the larger group: Beast From 20,000 Fathoms, Godzilla (1954) — from Japan but with similar interests and marketed in the US - It Came From Beneath the Sea, Them!, Phantom From 10,000 Leagues (1956), The Black Scorpion (1957), Fiend Without a Face-exceptional in this field because of its different plot-and Attack of the Giant Leeches (1959). Films where the nuclearaffected being is human comprise a significant proportion of this sub-genre: Amazing Colossal Man and its sequel, War of the Colossal Beast (1958), focused on a man who had been exposed to radiation from a plutonium bomb; Hideous Sun Demon involves a scientist affected by a radioactive isotope as does The Atomic Man. The alien invader, or the released beast, is a metonym for nuclear devastation and both the nuclear and alien threats have similar characteristics: an immense, uncontrolled power; other worldly, alien or non-human representations; a similar range of responses is called into play on the part of the humans; an apparent powerlessness is evinced in the face of this alien power followed by panic.

Thus the negative effects of nuclear power are constructed, argued and recycled through the images and logics of Hollywood film. But it would be wrong to assume that this overwhelming negativity is the only discourse surrounding nuclear power, as I have suggested above. Other films pose the antidote to nuclear fear as being global cooperation and global government, marking a new formation of world unity. These films suggest a united world, but not necessarily aligned to a contemporary governmental structure; that is, the suggested paradigm of government has moved beyond the national to the international, aligned perhaps with a Platonic notion of government by scientists rather than the military-industrial-political axis. The dominant imperative here is survival: in the Day the Earth Stood Still the imperative to address the problems of total devastation is brought home by Klaatu, who warns that the galactic police force will be forced to cataclysmically intervene if the people of Earth can't solve their problems. The earth's scientists-as distinct from politicians-are the only group with an existing communications and cooperative network and, as a response to the threat of an alien invasion, the world must unify under the leadership of these networked and internationally aligned scientists to survive. Earth Versus the Flying Saucers also documents the tension between the paradigm of the national and that of the global: the military and the political governments are not able to deal with the situation and the solution to the problem lies in the 
ability of scientists world-wide to address the problem, and work cooperatively towards a solution. But the contemporary political structures are applauded as being the most useful coordinating body for the efforts of the world's scientists in The Crawling Eye. The newly established United Nations has the resources to deal with global problems and it is the international team that has the organisational and scientific resources to deal with the invader.

These globalised teams generally comprise at least one scientist or engineer, or both. The difference between those vocations is marked and represents a significant difference in the weavings of those characters and their status within US society during the fifties. The cultural and social climate, the 'milieu', of the early 50s was anti-intellectual to the extent that during the fifties the term 'antiintellectualism' had become part of the national language; in contrast, it had not been widely used before although the seeds are found in such works as Verne's From the Earth to the Moon.48 Anti-intellectualism is 'a resentment and suspicion of the life of the mind and of those who are considered to represent it; and a disposition constantly to minimise the value of that life'.49 To support his contention, Hofstadter outlines twelve cases from the 50 s where negative views of the intellectual are expounded. For example, egghead was the term used to refer to anyone who displayed 'intellect' on its own; that is, without 'intelligence'. Or to put it in concrete terms, the divide between the scientist and the engineer:

During the campaign of 1952, the country seemed to be in need of some term to express that disdain for intellectuals which had by then become a selfconscious motif in American politics. The word egghead was originally used without invidious associations, but quickly assumed them, and acquired a much sharper overtone than the traditional highbrow. 'The recent election', Bromfield remarked, 'demonstrated a number of things, not the least of them being the extreme remoteness of the "egghead" from the thought and feeling of the whole of the people.'50

The label of 'intellectual' applied not only to scientists but also to anyone whose work involved thinking on an abstract level without foundation in some practical activity. Thus the left-liberal was something less than the honest American, and civil libertarians and inhabitants of universities were also known by other epithets: 'those fags in striped pants who lost China for us'. 51 As

48 Richard Hofstadter 1964 Anti-intellectualism in American life London: Jonathan Cape, 3

49 Hofstadter 1964, 7

50 the quotation is from Louis Bromfield, 1952, 'The triumph of the egghead' The Freeman vol 3, December 1, 158 in Hofstadter 1964, 9, 10

51 Nora Sayre 1982 Running time: films of the cold war New York: Dial Press, 11 
General Thomas Farrell stated (above), scientists were part of the intellectual group known by the appellation 'long hairs', a term that can be found in diverse contexts with similar connotations to 'egghead'. For example, Manny Farber blames the 'long-hairs' for the apparent poverty in Hollywood film production in 1952:

There is plenty of justification for trying to find what is causing this plague, and I point my thumb accusingly at the audience, the worst in history. The present crowd of moviegoers, particularly the long-haired and intellectual brethren, is a negative one, lacking a workable set of values or a sense of the basic character of the medium, so that it would surprise me if any honest talent in Hollywood had the heart to make good pictures for it. 52

The spaceship 'astronaut' in Asimov's Escape has a similar, although less stridently negative, opinion of the scientists who explained a particular event in scientific terms. Donovan says

Listen, this junk about the space warp knocked out Consolidated's robot, and the longhairs said it was because interstellar travel killed humans. 53

The division was in part between the impractical scientist, who functioned in the realm of theory, and the practical engineer or technician, who practised rather than theorised, who acted rather than, like Hamlet, vacillated.

Longhair Liberalism was often seen as little more (or less) than communism and the ambience of distrust was signified by the activities of official anti-communist committees in politics, the public service and education and HUAC in the film industry. But this culture of neo-official anti-intellectualism also changed during the fifties, in that, towards the end of the decade education was perceived to have failed the US because not enough scientists and technicians were being educated and trained. Earlier, Vice-Admiral Hyman G Rickover had insisted that the 'United States lagged behind the Soviet Union in the arms race' and this was a result of the schools' failure to turn out enough scientists and technicians. 54 Of course, these scientists and technicians were to be employed in the armaments and other defence-related industries.

One of the causes for the re-examination of science issues at the political level was the launch of Sputnik on 4 October 1957 by the USSR, evincing the surprise lead that nation had over the US in the space race and causing consternation as well:

52 Manny Farber 1952 'Blame the audience' McCarthy \& Flynn 1975 Kings of the Bs New York: Dutton, 45

53 Isaac Asimov 1945 'Escape' in Asimov 1968 I, Robot Herts: Panther, 148

54 C Lasch 1978 The culture of narcissism New York: W W Norton, 139 
(t)he United States went into a dreadful crisis of confidence over the fact that the Soviet Union had gotten there first and berated itself for not being interested enough in science. 55

Sputnik revealed the extent to which the USSR had surged past the US in the race for space and the loss of the lead in this race was sheeted home to the negative attitude in the US to science and intellectual pursuits prevalent in some quarters:

The Sputnik was more than a shock to American national vanity: it brought an immense amount of attention to bear on the consequences of antiintellectualism in the school system and in American life at large. Suddenly the national distaste for intellect appeared to be not just a disgrace but a hazard to survival.56

The hazard to survival lay in part in the belief that whoever conquered space, whoever controlled space, would be able to launch attacks on the US. Films like Destination Moon, one of the first science fiction films of the 50 s and based on Heinlein's 1947 novel Rocketship Galileo, had already presented this as an important reason for colonising the moon and it was a recurring theme in Heinlein's writing. That the view continued to be held is evinced by the Reagan administration's support for the Star Wars program in the 70s and 80s, predicated on the belief in the importance of 'battleships in space' as a national defence strategy.

Sputnik caused a resurgence of interest within the US in the significance of space and highlighted the attitudes of a section of the US public about the issues of science and space. Various groups wanted to know more about science and its contribution to space exploration:

Sputnik also served to increase the importance of any known public speaker who could talk on science and, particularly, on space, and that meant me. I was hunted down, for this reason, by a lecture agent named Harry Walker. 57

Asimov's first engagement was with a group of 'bankers, lawyers and industrialists' to whom he talked 'on the significance of Sputnik',

and it went over very well, all the more so since on the day before [3

November 1957], the Soviets had put up Sputnik II. 58

This resurgence of interest came on top of an existing interest in space and its exploration. During the fifties, science had an audience not limited only to those who read and viewed science fiction, but comprising these other community groups (who may, in passing, have 'read' and 'viewed' science

55 Isaac Asimov 1980 In joy still felt: The autobiography of Isaac Asimov, 1954-1978 New York: Avon, 106

56 Hofstadter 19644,5

57 Asimov 1980, 106

58 Asimov 1980, 107 
fiction). The knowledge and discourses of science, and its application to technology, became of more general interest before 1957, and became of national importance after Sputnik. This change in attitude and interest occurred over the period from 1952 to 1958 :

In 1952 only intellectuals seemed much disturbed by the specter of antiintellectualism; by 1958 the idea that this might be an important and even a dangerous national failing was persuasive to most thinking people. 59

If there was a growth of interest in science and its extrapolations, it is in part explained by the convergence of science fiction with science fact. These two poles had been moving closer together since the nuclear explosions of the Manhattan project. For example, the Complete book of outer space contains a factual article by science fiction writer ('Conquest of space', 'Across the space frontier') Willy Ley on 'Development of the spaceship'; another, by physicist and V2 Rocket designer Dr Wernher von Braun, discusses the possibility and necessity of an artificial Earth satellite in 'Station in Space'; Dr Heinz Haber of the Department of Space Medicine writes about the predicted effects of space travel on the human mind and body; Dr Donald H Menzel of the Harvard College Observatory discusses space suits; the 'pioneer of science fiction and outstanding science prophet' Hugo Gernsback writes about the exploitation of the moon. 60 Other articles discuss the Air Force high altitude program, history of the rocket engine, legal aspects of space travel, interstellar flight and the spaceship in science fiction. Article writers were scientists and science fiction writers and there are few discernible differences between the two, reflecting the imperceptibility of the gap between science fact and science fiction. The appendices include charts of possible moon and Mars voyages, timetables of travel, weights on various planets, and a space-travel dictionary. The science fiction here is simply an extrapolation of science fact; there is no question that the events described will occur as a continuation of those that have occurred. Fact and fiction are synonymous even to the extent of the photos used to illustrate the factual text: the discussion of space medicine, for example, uses unattributed stills from Destination Moon to illustrate the factual effects of g-forces on the human body. 61 Both Isaac Asimov and Robert Heinlein wrote not only science fiction but

59 Hofstadter 1964, 5

60 Jeffrey Logan 1953 The complete book of outer space New York: Maco

61 Logan 1953, 32, 128. Stills from other films, generally acknowledged as such, populate this book along with 'factual' photos. The attributed stills are from War of the Worlds, Dream of the Stars (1949), When Worlds Collide (1951) and the earlier serial Buck Rogers. 
also science fact; they were science writers as well writing for readers who were interested in both science fiction and science fact. Fact and fiction moved in parallel with threads of both entwining as fiction became fact and different possibilities were explored. Heinlein wrote for an audience of science fiction fans and more general readers and those with some technical expertise: in a letter to the Saturday Evening Post he claimed that many of the letters he received were from 'technical men' and none from 'crackpots'.62 Between 1941 and 1956 he wrote factual science articles for science fiction magazines with titles like 'Discovery of the future', 'Where to?' and 'The third millennium opens' as well as speeches on science, while for general audiences he wrote 'Man in the moon', 'Flight into the future' and 'Ray guns and rocket ships'. Isaac Asimov also wrote non-fiction for audiences other than science fiction fans: by 1954 he had published five articles in the Journal of chemical education and had written many

\section{SF films each year}

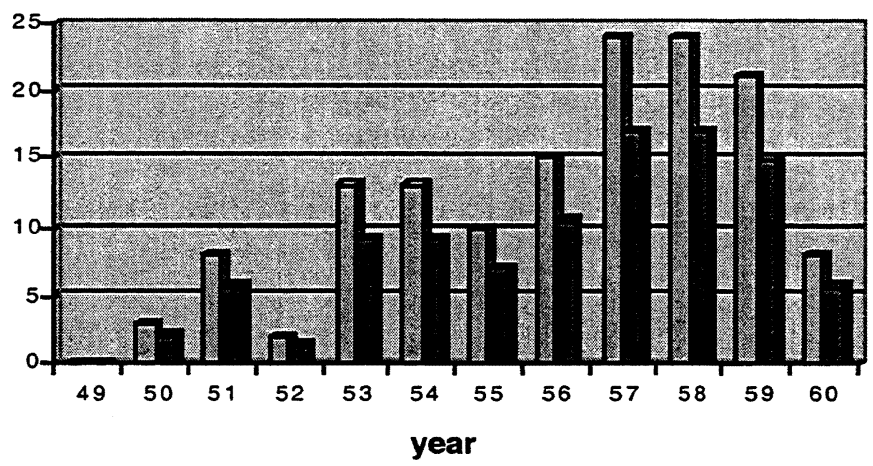

Table 1: Number of science fiction films made each year (author's criteria)

general educational texts. 63

The launching of Sputnik dissolved further the space between science fiction and science fact. Sputnik edged the perimeter of science fiction into that of science fact; for example, if science fiction had predicted that people could escape the gravity of Earth and enter space, and the prediction had proven correct, then other predictions were just as likely to become reality. The growing interest in space and the real possibility of its exploration is correlated with a surge in the production of science fiction films. The number of science fiction films produced 
every year is open to debate, as such a calculation is dependent on the definition of the genre. A cursory glance at the films I chose as science fiction from Variety film review tends to support the argument that the growing interest in space is reflected in the numbers of science fiction films produced around the time of Sputnik's launch.

Donald Willis searched Variety's reviews for those films he considered to be science fiction, and his parameters were very wide, including films like the Red Skelton comedy Yellow Cab Man (1950). 64 Nevertheless, even those films collected by Willis' criteria show a rump in the 56-59 period.

\section{SF films each year (Willis)}

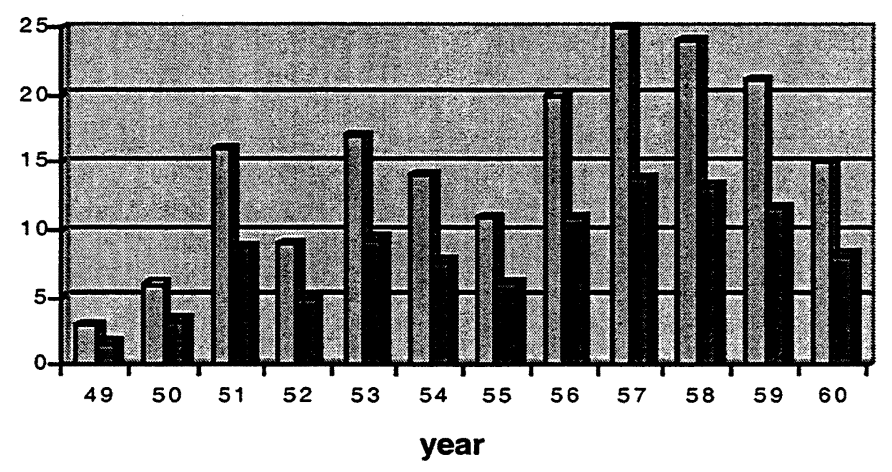

Table 2 Number of science fiction films each year (Willis)

Some films mentioned in this thesis are not included in this second table, as they were not reviewed by Variety, possibly because they were not seen to be mainstream theatre releases, but rather, specifically targeted to the drive-in market.

\section{The appearance of UFOs}

Another thread in the web of the cultural and historical context, espcially that thread of space exploration, is the UFO phenomenon. Although the first major UFO wave in the US was in the late 1800s, these sightings were generally ascribed to the work of a secret inventor. In June 1947 civilian pilot Kenneth

64 Donald Willis (ed) 1985 Variety's complete science fiction reviews New York: Garland 
Arnold spied nine peculiar craft with wings but no tails, flat, with a reflective surface, travelling at $1600 \mathrm{mph}$ with flight characteristics he likened to a saucer being skipped across the surface of water.65 Throughout the fifties were numerous sightings of UFOs, to the extent that the US Air Force established Project Blue Book to investigate these sightings and to attribute them to known and identifiable causes. Yet it was the sightings that cemented the possibility of other life outside planet Earth, while the purpose of such visitations was the stuff of some science fiction films of the decade with a metaphor for Project Blue Book being used in Phantom From Space (1953).

The UFO phenomenon was of such significance that Carl Jung wrote a book on their meaning, suggesting that the normalcy and peace of the fifties was something of a charade. He likened the conditions for UFO 'visions' to those he experienced before World War 2. For Jung, the fifties were the stressful end of an era, an end on a 'cosmic', 'grand narrative' scale:

These rumours, or the possible physical significance of such objects, seem to me so significant that I feel myself compelled, as once before, when events were brewing of fateful consequence for Europe, to sound a note of warning. I know that, just as before, my voice is much too weak to reach the ear of the multitude. It is not presumption that drives me, but my conscience as a psychiatrist that bids me fulfil my duty and prepare those few who will hear me for coming events which are in accord with the end of an era. As we know from ancient Egyptian history, they are symptoms of psychic changes that always appear at the end of one Platonic month and at the beginning of another. They are, it seems, changes in the constellation of psychic dominants, of the archetypes, or 'gods' as they used to be called, which bring about, or accompany, long-lasting transformations of the collective psyche. This transformation started within the historical tradition and left traces behind it, first in the transition from the age of Taurus to that of Aries, and then from Aries to Pisces, whose beginning coincides with the rise of Christianity. We are now nearing that great change which may be expected when the spring-point enters Aquarius. It would be frivolous of me to conceal from the reader that reflections such as these are not only exceedingly unpopular but come perilously close to those turbid fantasies which becloud the minds of world-improvers and other interpreters of 'signs and portents'.66

While Jung's 'new age' interpretation of the times is problematic, his thesis concerning the 'end of time' is relevant, linking with the broader Judeo-Christian teaching that there will be such an apocalyptic end, a time of judgment.

Jung does not suggest he can add anything to the debate over the physical reality of UFOs, but he is concerned with the phenomena as a manifestation of a

65 Chris Bader 1995 'The UFO contact movement from the 1950s to the present' Studies in popular culture 17:2

66 C G Jung 1959 Flying saucers: a modern myth of things seen in the skies trans. RFC Hull London: Routledge \& Kegan Paul, xi, xii 
psychic state or states. UFOs are a 'visionary rumour', which is more than a rumour. It is an 'unusual emotion' which intensifies into a vision and delusion, which 'springs from a stronger excitation and therefore from a deeper source'.67 The agent of this excitation is a situation of emotional tension caused by collective distress or danger, which, Jung believes, accurately describes the 50s, when 'the whole world is suffering under the strain of Russian politics and their still unpredictable policies'.68

Projection is another mechanism Jung uses to explain UFOs. The world of the 50 s is threatening, and 'everything' is being threatened and 'everything' is at stake. In this earthly world, 'split into two halves', the 'projection-creating fantasy soars beyond the realm of earthly organizations and powers into the heavens, into interstellar space, where the rules of human fate, the gods, once had their abode in the planets'.69 For Jung, the 50s are a time of stress for American culture, accepting for a moment the problems of generalisation, problems with which Jung did not become entangled. He wrote about the fear and uncertainty implicit in the phenomenon of change itself, as an uncontrolled influence, a phenomenon that will be further addressed in this chapter.

It is impossible to determine whether the appearance of UFOs caused the making of films about them, or whether the films made people receptive to the possibility that what they were seeing were UFOs. Perhaps more easily suggested is that both events ran in parallel, each supporting and recycling the other. But while that process remains problematic, the involvement of the military in science fiction is not. This section examines the relationship between Hollywood and the military as another thread in the cultural web in which science fiction films were made.

\section{Hollywood and the Pentagon}

The historical and political context had an effect not only on the themes, plots and narratives of science fiction films, but on the context of production as well. This section, then, would fit almost as neatly into the next chapter that deals with this context of production. Yet the subject is intertwined with the historical and political events of the decade and springs from that, so the discussion at this

67 Jung 1959,3

68 Jung 1959, 8

69 Jung 1959, 10-11 
point is appropriate.

The mise-en-scene and the 'textual feel' of science fiction films of the 50s can be explained partly by reference to the contemporary culture described to date and partly by reference to explicit transactions between the military and Hollywood. Denisoff and Romanowski suggest 'a symbiotic relationship' between the Pentagon and the motion picture industry. 70 This relationship began with the production of D W Griffith's Birth of a Nation (1915) and America (1924):

In shooting Birth of a Nation D W Griffith relied on West Point for technical advice and authentic weaponry to recreate Civil War battles. Nine years later, Griffith was provided 1,000 mounted soldiers and a marching band to aid in the making of America. 71

This relationship between the military and Hollywood continued in various formal and informal ways, and propaganda was one outcome. In 1942 the OWI (Office of War Information of the Bureau of Motion Pictures) was created and firstly, published a manual for the film industry titled "Will this picture help win the war", and secondly, monitored the content of every feature film coming out of Hollywood.72 Both film producers and the Pentagon saw film's function as 'educating' the 'masses', and this implies propaganda. In 1942, the producer-director Walter Wanger, who was an intelligence officer in WW1 and a staff member of President Wilson's negotiating team at the Paris Peace Conference, and later producer of Invasion of the Body Snatchers, wrote to the OWI domestic director Gardner Cowles Jr:

The American film is our most important weapon as no country has developed its film industry to compete with ours. The problem of enlightenment of the masses is a major problem and admittedly the film is the greatest visual educational factor accepted by the masses. 73

The term 'education' may be read in two ways, one is to equate education with pedagogy. In many science fiction films of the 50 s this pedagogy is a significant and explicit aspect of the film. Destination Moon and Invaders From Mars, for example, contain scenes where the audience is being 'taught' physics, rocketry and astronomy. Science fiction writer, editor and critic Judith Merril, using a different order of classification to those in chapter one of this dissertation, categorises some science fiction films as the subgenre 'the Teaching Story',

70 R Serge Denisoff \& William Romanowski 1989 'The Pentagon's Top Guns' Journal of American Culture 12 (3), 67-78

71 Denisoff \& Romanowski 1989, 67

72 David Culbert 1988 'Our awkward ally: Mission to Moscow (1943)' in John O'Connor \& Martin Jackson (eds) American history/American film New York: Ungar, 137

73 Denisoff \& Romanowski 1989, 76 
'whose function seems to be the popularisation of science and technology'.74

The second is to treat 'education' as 'propaganda', and, in its broadest sense, 'propaganda' here means the hortatory functioning of a film to 'persuade to' a particular viewpoint. Novelist Leo Rosten's argument about the propaganda value of films was uncontested by both the military and the studios:

The movies can give the public information...They can clarify problems that are complex and confusing. They can focus attention upon the key problems which the people must decide, the basic choices which people make. They can make clear and intelligible the enormous complexities of global geography, military tactics, economic dilemmas, political disputes, and psychological warfare. The singularly illuminating tools of the screen can be used to give the people a clear, continuous and comprehensible picture of the total pattern of total war. 75

The dividing line between education and propaganda is, at best, blurred. In fact, the two readings of 'education' is most clearly realised as the two ends of a spectrum, with most films lying between the two extremes, and even the apparently non-controversial information-giving end of the spectrum is arguably persuasive.

David Culbert's analysis of the context of production of Mission to Moscow (1943) leaves no doubt that the film, and other films, was a direct consequence of political influence that wanted to cement pro-Russian (read allied) sentiment.76 The film was propaganda as well, as John Dewey noted:

[It] is the first instance in our country of totalitarian propaganda for mass consumption - a propaganda which falsifies history through distortion, omission or pure invention of facts. 77

Although the film was made to 'wed the home-front citizen to official war aims', it did not 'reflect' the universal perception of Russia. During the late 1940s and 50s, the war would be of a different kind, but still a war with the same need to unify the country against the earlier wartime ally and the purpose of the propaganda was the same: to unify. The HUAC would create the enemy against whom unification was more readily possible. Thus any films produced in the late 40 s and 50s that involved the military were partly devices of propaganda. The submission of film screenplays to the Pentagon for approval and advice was a continuing practice and this 'censorship' was not regarded by the film industry as inappropriate. 78 During the cold war, Suid argues, the

\footnotetext{
74 Vivian Sobchak 1987 Screening space New York: Ungar, 18

75 Denisoff \& Romanowski 1989, 68

76 Culbert 1988 121-145

77 Culbert 1988, 134

78 Lawrence Suid 1988 'The Pentagon and Hollywood: Dr Strangelove...' in O'Connor \& Jackson
} 
military preserved the peace against an enemy who wanted to take over the world, at least according to the conventional teachings which bombarded the nation.79

It was not only through the submission of screenplays, but also the provision of equipment and film footage that the military exercised influence. In return for a script showing the military in terms deemed appropriate by that military, the film maker could count on hardware-tanks, planes, men-and in science fiction movies, footage of the military in action as well. Films which constructed a paradigm that was in some way oppositional to the doxa were not supported, and so producer and director Stanley Kramer was not given a US submarine for On the Beach, because the military argued that there could be no total destruction through nuclear weapons; they were a deterrent to nuclear war, thus the tenet of the film was inaccurate. 80 Kramer reported that he was not allowed to photograph a nuclear submarine at Pearl Harbour because the theme of On the Beach was the world's end. He [a State Department official] thought I was taking myself and the film too seriously. There might be four or five hundred million casualties, but it wouldn't be the end of the world. I said then it was as near to the end of the world as I'd like to get - I didn't get the submarine. (We used instead a British "Guppy" sub, revamped to look like the then-new atomic subs.) $)^{81}$

But Kramer's experience was not usual: most films of the 50 s did have approval and this is apparent in the never-ending stream of military footage as the US sets itself to battle aliens, creatures, or mutated humans. Indeed, some films used such footage as filler to cover for lack of narrative or finances.

Science fiction films of the 50s were not made to simply 'entertain' audiences; there are elements that persuade audiences that the military and the military culture is both the saviour of the USA-and the metaphors associated with that term-and a worthwhile expenditure in the national budget. Other threads in this particular web are analysed in the next chapter.

\section{The social context}

The political context is jigsawed with the social context and they are elements of a larger whole, which comprises these parts but is more than just

219-235, and .... 'Hollywood and Vietnam',....,20-25

79 Suid 1988, 220

80 Suid 1988, 224

81 Stanley Kramer 'On' the Beach: A renewed interest' Danny Peary (ed) 1984 Omni's screen flights/screen fantasies New York: Doubleday, 118 
their sum. An appropriate metaphor is that of inter(con)textuality, where texts -in this case the (con)texts of social life-are influenced by the (con)texts of history and politics.

At the same time are acting, contiguous with the social context, contradictory threads to those of fear and change that we have traced in the first part of this chapter through the events surrounding nuclear fission and fusion. The dominant threads are those of optimism and conformity but interfering with and subverting those are discourses of change acting like waves riding on and inseparable from the deeper moving seas of optimism. This optimism was not generated from a void but resulted from contiguous social and historical events and government policies. The threads of this optimism comprised the growth of credit, the optimism of a post WW2 USA that faltered for a few years during the Korean War, the New Deal welfare programs of the Truman and Eisenhower presidencies, the Full-Employment Bill of 1945, and the rise in significance and availability of the automobile which is itself a result of the full-employment and high wages explicit in a planned consumer society, and the explosion of developing suburban life.

The argument surrounding the Full Employment Bill highlighted the issues of post-war politics, society and economy. The bill was a Keynesian document that would establish "a national policy and program for assuring continuing full employment" by the intervention of government in the market system, through planning, direction, and most importantly, spending, which was to become a tool of government policy to ensure social objectives were met.82 A modified version of the bill became law in 1946, and with that came the implementation of the liberal democratic theory of economic oversight and increased government spending as an economic tool to achieve planned social objectives that were consensually agreed. The economic theory of Keynes became, in practice, focussed on ensuring economic growth, low inflation, full employment in the production of consumer goods, and consumer income.

Other initiatives of the federal government were designed to assist people into homes and therefore the emergent suburbs. Veterans benefited from government-sponsored loan programs, allowing them to build in the suburbs. This perception of economic well being was one cause for the optimism of $50 \mathrm{~s}$

82 Norman \& Emily Rosenberg 1991 In our times: America since World War II (4th ed) Englewood Cliffs: Prentice Hall, 27 
USA; albeit a white colour, white and blue collar optimism. In addition to the programs designed to ensure a consumer spending capability, the wider use of credit allowed families to buy without having the immediate funds. Credit was an integral factor in the fabrication of optimism: 'Instalment buying, finance agencies, charge accounts, and credit cards helped many consumers buy whatever they wanted, whenever they wanted $i^{\prime}{ }^{\prime} .83$

This optimism is evident in the sudden increase in people marrying at a young age and having larger families. Optimism was partly economic:

The bright economic picture after the war provided couples with the selfconfidence and optimism that are important ingredients in decisions to marry and have children. 84

The meteoric rise in the birth rate was to some extent a reaction against the decline in confidence that was an integral aspect of the 1930s Depression and the economic invigoration in the US at the beginning of World War 2 and the industrial re-tooling as a result of the US entry in the war in 1941. Birth rates during the war years increased, producing a relatively smaller baby boom than the great baby boom of 1946-57.85 From 1940 to the mid 1950s, people began marrying and having children at a much earlier age than their parents. ${ }^{86}$ Early marriages and greater numbers of children are always correlated, and from 1945 to 1955 the number of children born each year rose by nearly 50 percent, 'the biggest increase in births ever recorded anywhere' .87 The baby boom was really that, and its confluence with the emerging suburbs contributed to its occurrence. But it is the children of the wartime baby boom who reached adolescence from 1953 to 1958 who were the original teenagers, and who were the first to benefit from the general wealth of the post-war period.

Another divergence from the Depression concerned the place of work in the legend of life. In the suburbs, the home and the immediate community assumed a greater importance than work. 88 The suburbs were the new paradise for credit-wealthy couples. They were accessed by car, they could accommodate larger families, they could remove the family from urban problems, and contribute to status and material comfort. The California-style houses, and

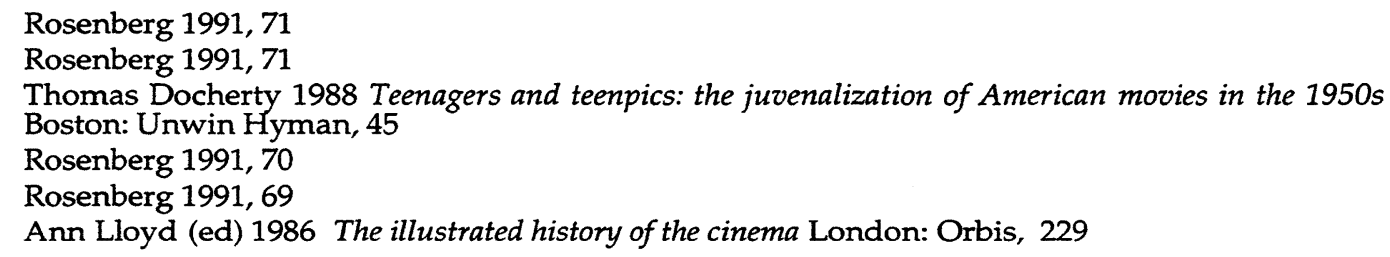


informal, family-oriented lifestyles were accessible to many through FHA and VA loans programs. But technological advances helped too; innovations in building allowed for cheaper housing. One-fourth of all the housing that existed in 1960 had been built since 1950.89 The one-quarter acre blocks, separate, single storey houses, curbed and paved streets with vehicle access in the form of paved driveways leading to a separate house for the automobile was the 50 s gift to some sectors of subsequent US generations.

But 'the burbs' was not only a physical location; it was a world-view, a value system centred on the family, not yet nuclear in its limitation of two children, but approaching that. It was materialistic; focused on technical devices and their production that were developed in part because of scientific discoveries and surplus post-war production capacity. The meaning of life was shared with others in the community and conformity of the suburbs. 90 Life, it appeared on the surface, assumed a new normality, but in that normality were the seeds of change. 91

On one level, then, the fifties were a time of some certainty. Externally, the suburban values of home, hearth and apple pie were paramount with suburbanites and their two or three children firmly ensconced in their detached house, one or two cars in the garage and the belief that their children would have an even better life than they did. This extreme generalisation was not applicable to all groups comprising the US population; those of colour, for example. The sense of complacency was not universally apparent and the burbs were not always positively represented, even in the fifties. The possibility of the awfulness and ordinariness of suburban life is foregrounded in The Incredible Shrinking Man, for example, against which is juxtaposed the weirdness of the life of one individual. Tension manifested in various cultural activities and historical events; for example, the writing of science fiction authors, the change in the formation of screen stars, the dialogue of science fiction film, the emergence of a civil rights campaign amongst the Negro population of the US and the rise in the inmate population of state mental hospitals. Inmate numbers grew to such levels as to cause severe overcrowding and inmate growth was almost twice that of

Rosenberg 1991, 74

90 William Whyte (first published 1956) 1963 The organisation man Mitcham, Victoria: Pelican, 246372

91 Whyte 1963 establishes clearly the mores and lifestyles of the suburban communities, including their credit-purchase habits. 
population growth. 92

Thus the threads of change wove through the decade. That change did not begin in the fifties; indeed, the Depression, World War 2, the Cold War, were all periods of change; what is marked in the fifties is the continuous and potentially very destructive change. Robert Heinlein wrote in 1946 that 'we [the USA] have entered a period of extreme change' in which there were two possible futures, one of which was 'a period of peace in which technical progress will be so enormously accelerated that only short range predictions can hope to be reasonably accurate'. 93 Once again it was the immense gulf and lack of some compromise between the two ends of the range of possibilities (total destruction and Paradise) that was instrumental in the formation of tension. As noted previously, at the end of the decade Jung spoke of the effects of change.

Lloyd sees the period as one of normalcy, of mediocrity, marked by the striving for conformity on the one hand but underlying this was 'an unarticulated and widespread sense of dissatisfaction'. These opposing discourses were evident in the construction of 'stars'.94 On the one hand the fifties were 'the great period of the star-as-ordinary person'. For ordinary, read average: 'They were no longer the special beings of the past but straightforward, uncomplicated, average humans'. They were the signs referring to normality, and normality was the predominant discursive formation. Dyer concurs with Lloyd in this differentiation in the perception of stars: in the 'early period', with the introduction of sound as the possible watershed, stars were 'gods and goddesses, heroes, models-embodiments of ideal ways of behaving. In the later period, stars became identification figures, people like you and meembodiments of typical ways of behaving'.95 Some stars were inscribed in the 'chilling conformity' of the 50s such as the early male archetype of Douglas Fairbanks, a good 'all round chap, just a regular American'.96 On the other hand, other less ascendant stars signified an opposing discourse, a discourse marked by a concise critique of normality:

Beneath the plastic, antiseptic, streamlined conformity of the Fifties, there was a unarticulated but widespread sense of dissatisfaction, a realization,

92 Pressman, Jack 1988 Uncertain promise: Psychosurgery and the development of scientific psychiatry in America, 1935 to 1955 AnnArbor: University Microfilms International, 81

95 Richard Dyer 1979 Stars London: British Film Institute, 24

96 Alistair Cooke 1940 Douglas Fairbanks: The making of a screen character in Dyer 1979, 36 
though still unformulated, that the status quo was not the best way things could or should be. 97

In terms of the parameters of stardom, this dissatisfaction with the status quo is evinced by the scandals and the positive treatment metered out to the stars who were involved in them, in contrast to the thirties and forties, when these scandals were a distortion in the fabric of the normal. The fifties scandals were fascinating to those who read about them, precisely because they were scandals; the stars were 'stepping outside the cosy, stifling atmosphere of the mainstream', and this made them even more popular.98 But it was not only the scandals as issues that were accepted, but stars' scandalous behaviour. Scandals had become marginally acceptable, scandalous behaviour was now construed as marginally acceptable; one obvious example is Marilyn Monroe. She is firmly inscribed in

the flux of ideas about morality and sensuality that characterised the fifties in America....She seemed to "be" the 'very tensions that ran through the ideological life of fifties America'.99

Similar changes in the characteristics of the star are to be found in the music industry where stars like Elvis Presley challenged the purity of the image of popular musicians.

What is important in this discussion is not so much the study of stars, but their significance in describing the social context of the 50s. As I have argued in chapter one, science fiction film audiences did not consider human stars all that important, and science fiction films were generally characterised by a dearth of human stars.

The social context, then, has elements of a strict conformity that is in opposition to change yet is in some way dependent on a fear of change. Those threads of change and anxiety that subverted the culture of the fifties were voiced in elements of science fiction film of the decade. The degree to which this fear of change permeated society cannot be measured and it is a minor, yet significant element of some films. Often articulated by women, the declarations concern the pace of change in the technologies associated with fifties progress; for example, in The Fly the scientist's wife Helene expresses these concerns as:

I get so scared sometimes. The suddenness of our age: electronics, rockets, earth satellites, supersonic flight, and now this....Everything's going so fast.

This element of 'speed' in the discourse of change is significant. Heinlein

97 Lloyd 1986, 253, 254

98 Lloyd 1986, 254

99 Dyer 1979, 36 
drew attention to accelerated technical progress (mentioned previously in this chapter) and the notion of haste was factored into the implementation of social change as well, with the notion of 'deliberate speed' being sanctioned as government policy by Chief Justice Earl Warren in the 1954 schools desegregation ruling, Brown v Board of Education.100 Significant was Warren's valorisation of both significant cultural 'change' and judicially mediated 'haste' when he ordered

the District Court to take such proceedings and enter such orders and decrees consistent with this opinion as are necessary and proper to admit to public schools on a racially nondiscriminatory basis with all deliberate speed the parties to these cases. 101

The argument that the speed of social change threatens a particular social order articulates closely with the idea of impending natural or human-contrived disaster threatening to overwhelm civilisation as well. The fear of disaster is embedded in a fear of technology, and this fear of technology, fear of the consequences of a science out of control, is clearly articulated in Red Planet Mars. Linda Cronyn, wife of the radio astronomer and leading character Chris Cronyn, voices the antithesis to the 'scientific progress' argument. She situates herself with all women who are mothers who endure the fear associated with some consequences of scientific 'progress'.

Linda: Fear Chris. Always eating fear. The whole world's scared. Why shouldn't I be. Every woman in the world; we all live in fear. It's become our natural state. Fear our sons will have to fight another war, or fear they'll face worse. We've lived on the edge of a volcano all our lives. One day it has to boil over....Science has made the volcano we're sitting on. Nobel invented dynamite to ease man's life. It's eased a good many into annihilation. Einstein split the atom to create energy. Is terror energy?!

Significantly, women are participating in these debates. While in films like The Thing, the expression of no-confidence comes from males with the females not taking any part in that debate, the emergence of women in a different, active role is prefigured in these films. That topic will be mentioned later in this thesis.

Another heavy cord-as distinct from the invisibility of a thread-in the weaving of change, both as an indicator of change but also as a catalyst for change, was the social grouping known as teenagers. Teenagers were significant as a market, because of the power of their disposable income; because of their

100 WT Lhamon Jr 1990 Deliberate speed: the origins of a cultural style in the American 1950s Washington: Smithsonian Institution, 7

101 Lhamon 1990, 33 
mobility and hormonal flow that took them to the flourishing drive-ins; and because of their potentially disruptive influence in the sea of conformity. The wartime mini-baby boom meant a new market in products aimed at youth. Thus was consciously constructed - as a market-an homogenous culture of youth, which could then function as the shaping force for new markets. The wartime baby-boomers were reaching the ages of increasing independence, with the benefit of material possessions and disposable income.

According to Scholastic magazine's Institute of Student Opinion, by early 195613 million teenagers had a disposable income of $\$ 7$ billion a year, which was a $26 \%$ increase on that from 1953, and represented an average weekly income of $\$ 10.55 .102$ The youth culture was driven by this disposable income and mobility brought by the second family car, the teenager's own car, or in some instances, a motorcycle. As early as 1944 the magazine Seventeen appeared as a vehicle for a youth consumer lifestyle and recycled to that consumer group 'a sparkling, constantly up-dated array of consumer products and mass-consumption lifestyles'. 103 The spending power of this new market was not lost on marketing consultants who could see the potential in the manipulation of this consumer power:

Monitoring the burgeoning teenage consumer market, they [magazines] consulted with companies about what to produce and, at the same time, advised teens about what they might consume.104

The same consultants were responsible, albeit unknowingly, for the term 'teenagers'. The term emerged in embryonic form in 1945 when Eugene Gilbert established the 'Gil-Bert Teen Age Services' to advise firms on ways to exploit the new Eldorado of marketing to this in-between age.105 During the fifties the term became the common one applied to people in their in-between years, and this change is apparent in the film reviews of Variety. 106 As with many words in the English language the two words were at first separate then later joined by a hyphen until they merged to become a single word.

The connotation of 'teenage' was a separate niche, a marketing fabrication. 'Teenage' was not the beginning of adulthood; it was not the 'flowering' of the

102 Halberstam 1993, 473

103 Rosenberg 1991, 84

104 Rosenberg 1991, 84

105 Rudolph Kenna \& William Grandison 1989 Somethin' Else: 50s life and style Glasgow: Richard Drew, 76

106 see the extracts from Variety Film Reviews in chapter one, for example 
child as was implicit in the German 'Erwachsene'. The new term 'teenager' signified not only an age group, but defined the group as being separate from adults. The term used in Variety initially to signify 'a young person' was 'juvenile', connoting not an age in itself, not a person as person, but a person in the state of becoming an adult, a person in transition. On the other hand, 'teenager' has no such connotations, signifying an end in itself rather than a becoming, rather than a transition to something else. The focus was on the individual at a concise and separate point in time, the teenager, rather than the life-period or the suggestion of a transitional life-period within a continuum. The culture foregrounded the individual within the group, as different from other groups, and different from each other in marked ways, but still of the same mould. The irony of the positioning as defined by difference from other groups,

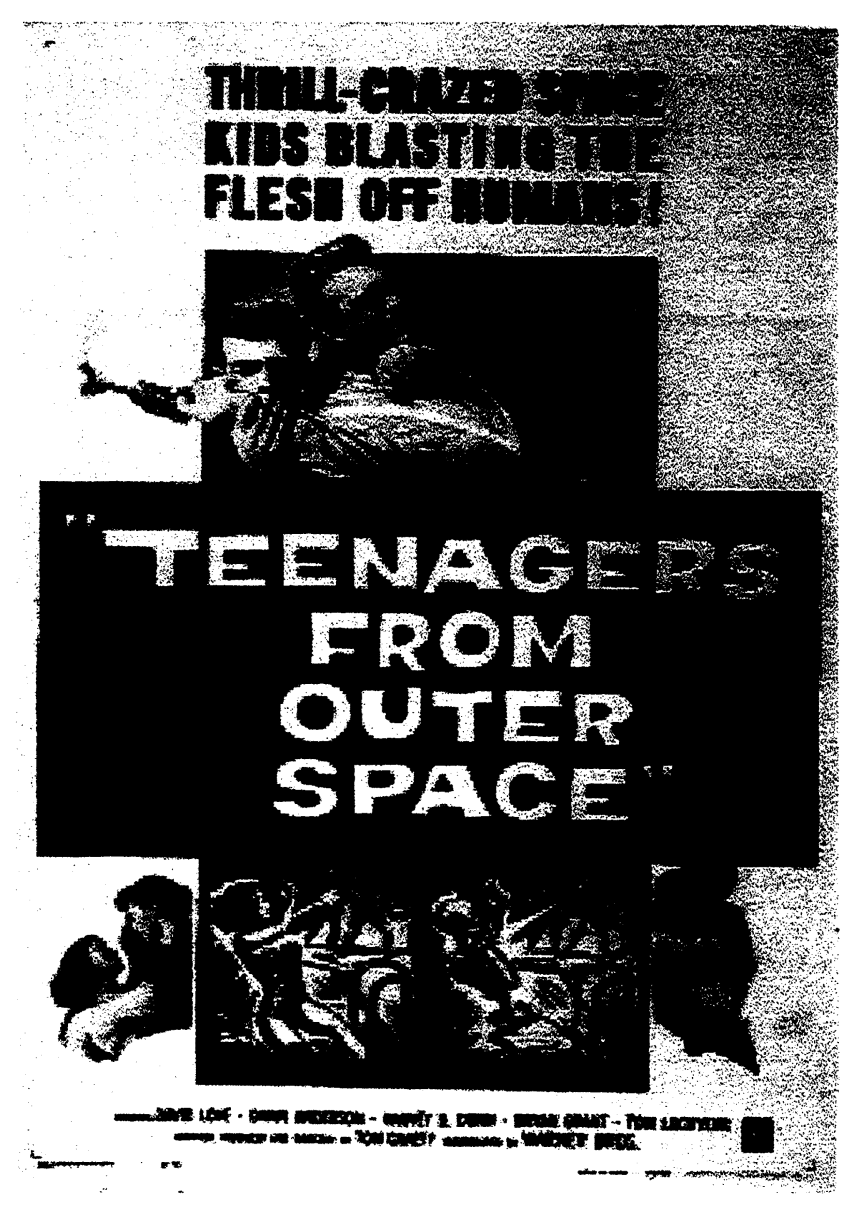

Figure 4 Teenagers were aliens! yet startlingly homogenous within the group, is legendary.

In the 50s, teenage culture became, according to Lhamon, one of the most significant cultures of US life with a sometimes different and unique set of characteristics. 107 Teenage culture signified fullblooded consumerism, in contrast to the poverty of the Depression and, to a much lesser extent, the poverty and tension of World War 2. The referents of 'teenage' were 'leisure, pleasure and conspicuous consumption', rock 'n roll and perhaps delinquency, adolescent gangs, motorcycle worship and various music halls.108 At one

107 Lhamon 1990, 8

108 Lloyd 1986, 244 
extreme it was a culture of rebellion against the conformity of the status quo. Radio stations would not initially play Buddy Holly music, but it became commercially successful because teenagers had the money to support the star. The record producers saw the opportunity to make money, and the rebellion entered the homes of millions and was assimilated into it becoming, according to the dialectic, changed in the process.

On the one hand this culture mirrored, perhaps caricatured, the rest of society in its crass commercialism and unabashed materialism. On the other it deformed - through its caricaturing - the icons of commercialism and materialism, so prefiguring the iconoclastic revolutions of the 1960s. The seeds of rebellion were in the music and films of that youth culture; stars like Marlon Brando, James Dean and Marilyn Monroe constructed and were a construction of a rebellion in the process of articulation. It was a rebellion against a status quo (a status quo that was founded on criteria of race) kick-started through the rock'n roll that was an acquisition from black culture. Black New York audiences were astounded that Buddy Holly and the Crickets would play before them; astounded because they were white. Radio stations, even in the north of the US, would not initially play the 'nigra' music of Buddy Holly and Elvis Presley. The wild 'jungle' sounds and lyrics with alleged sexual innuendo were a concern for many parents:

So many people, so many films, novels, plays, movies, ministers, mayors, and mothers were angry at the manners and values of the youth culture that for a while it seemed the ideal of Eternal Youth was the most obsessively threatening theme of our time. 109

Technology assisted in this undermining of traditional parental and elder authority. The stately family valve radio that could be controlled by those figures of authority was miniaturised into the mobile and cheap transistor radio, that sold for $\$ 25$ and could be purchased on credit by teenagers, and which subverted the monitoring of teenage listening by elders. 110

The role of teenagers as a specific audience group for science fiction film is discussed later in this chapter. While they were an emergent social group in the fifties the social movements that were significant in their production contributed to the demise of other audiences, namely returned servicemen and women who had worked in war-related and other industries. It is to these other audiences

109 Lhamon 1990, 8

110 Halberstam 1993, 474 
that this chapter turns, after a brief excursion into the causes of the dwindling film audiences and the plurality of those audiences. The drop in audience numbers is crucial to an understanding of the industry and its responses discussed in detail in the next chapter.

\section{Audiences}

During World War 2, servicemen and the fewer numbers of servicewomen in the US army were well used to viewing films, via the Army Motion Picture Service. These men and women were to continue their viewing until they returned home, and in subsequent years joined the mass migration to the suburbs where they had babies. Demobilised soldiers were a significant part of the exodus to marriage and the suburban lifestyle in a reaction to the pre-war Depression and the war that had denied many the lifestyle they now so eagerly pursued:

Lifestyles that had been denied by the Depression and the war were now embraced with wild relief. The women, who had worked in the munitions factories went home, settled down, had babies and stopped going to the movies. 111

In addition, it was possible to remain at home and still see moving images on the television. Whether television caused a drop in the number of theatre patrons, or whether other factors-for example, lower disposable income because of family commitments - caused this decrease is problematic. Certainly the drop in patrons paralleled the rise in television penetration. In $194690,000,000$ patrons attended the cinema every week, on average. This represented 2.35 attendances per household per week. In 1948 the number of patrons remained stable at $90,000,000$, but this represented a drop to 2.22 attendances per household per week. Two years later, the drop was huge: A reduction of $33 \%$ to $60,000,000$ in weekly attendees, and a even bigger drop to 1.38 attendances per household per week. 112 The decline in the number of weekly household attendances began in 1947, 'long before most American cities had television'.113 By 1948 the number of television sets sold was just one million and film audiences remained stable in numbers, but decreased in relative terms.

The audiences were both a product of and contributors to the social and

111 Lloyd 1986, 203

112 US Bureau of Census data quoted in Garth Jowett 1976 Film: the democratic art Boston: Little, Brown, 475

113 Lloyd 1986, 229 
historical context. This cannot be translated to mean that the audiences for films are only subjects inscribed in the discourses of the 50s, as this omits the important element of reflexivity; that is, it suggests the audiences, while not empty sponges, were determined by those discourses in which they were inscribed. If this were the case, it would not allow new discourses to be developed; no new signs can be developed if users are simply passive receptors.114 The dynamic is between audience and film, and the contexts of both.

For any film audience the signs are the same, but individuals place different emphasis on those signs. The audience selects those that are useful and locates them within structures of meanings that therefore undergo changes. The referents depend on the user, and the referents depend on which signs the user selects while those signs may be selected because they reinforce, or reinscribe, the user within a discourse or they may be selected because they challenge preexisting relationships between the sign, the referent and the user.

Thus the different audiences are likely to exit the film with different meanings that are not necessarily contradictory, but meanings which are, for whatever reason, a product of the interaction between the film and the particular audience. This is not to say that all meanings are the result of conscious processes. Doubtless the production of meanings within an individual is difficult, if not impossible to determine. But it is useful then to consider the audience of films in the $50 \mathrm{~s}$, to attempt to understand the possible meanings they might have drawn from 50 s science fiction film, given the demographic structure of these audiences.

The survey conducted by the Motion Picture Association of America in 1957 is 'one of the most comprehensive analyses currently available', surveying 5,000 people. 115 The age survey of the estimated 54.2 million filmgoers revealed that half (28.1 million) were children of the immediate pre-war to the post-war years; that is, they were born between 1937 and 1957. More specifically: 11.2 million (21\%) were 15-19 years, that is, they were born between 1938 and 1942; 8.4 million (15\%) were 10-14 years, that is, born between 1943 and 1947; and 8.5 million (16\%) were 0-9 years, that is, born between 1948 and 1957. A further 11 million (20\%) were between 20 and 29, born between 1928 and 1937. Seventy-two

114 David Sless 1991 'Communication and certainty' Australian journal of communication18:3, 19-44

115 Jowett 1976, 375, 476-479 
percent were below the age of 30 .

$\begin{array}{cccc}\text { Age } & \text { Born between } & \text { number in millions } & \% \text { of total audience } \\ 0-9 & 1948-1957 & 8.5 & 16 \\ 10-14 & 1943-1947 & 8.4 & 15 \\ 15-19 & 1938-1942 & 11.2 & 21 \\ 20-29 & 1928-1937 & 11 & 20\end{array}$

Table 3: Age and attendance survey, 1957

That audiences comprised $50 \%$ of young people (below 19) is significant to the remainder of this discussion of audiences. Men accounted for $51 \%$ of admissions, and were $49 \%$ of the population. Films, then, were just as popular for men as women, indicating that they-women-did not feel they were marginalised as film audiences; that is, they were not constructed in ways they objected to. There were, the statistics indicate, no structural impediments to their viewing. In Bond and beyond, Bennett and Woolacott argue that males dominated the Bond film audiences. 116 Yet there is no evidence of this in general filmviewing habits in the US. The implications are many: first, the possibility of multiple meanings is obvious. How would women read (as distinct from men and assuming homogeneity within the group) Linda Cronyn's plea in Red Planet Mars to slow down the rate of change and divert the apocalypse? How would men read those same signifiers? More interestingly, what would the effect be on the individual of those readings? These questions are interesting, but must remain in the realm of worthwhile speculation.

Both men and women, children and adults, believed that people went to the cinema for both entertainment-however the respondents conceived of 'entertainment' - and to get away from the routine of daily life. In answer to the question "What do you think are the main reasons people go to the movies?", $57 \%$ of respondents answered 'for recreation or entertainment', $39 \%$ believed patrons wanted to get away from everyday routine, and $23 \%$ believed patrons wanted to pass time, to give them something to do. (The total is greater than

116 Tony Bennett \& Janet Woollacott 1987 Bond and beyond: the political career of a popular hero London: Macmillan 
$100 \%$ as many people gave more than one reason. Nevertheless, these were the only answers that totalled double-digit percentages; all other answers were each below 10\%.)

Earlier in this chapter I used the notion of stars as evidence of both a status quo and an underlying conflict and used this as evidence of flux in the social and historical context of 50s USA. But stars were not necessarily important in determining viewers' attendance at a film: only $18 \%$ of respondents indicated that who was in the movies was important to them. Forty-five percent stated that they were more interested in what the movie was about.

The education of the audience was also of interest to the MPAA. Although $47 \%$ of the total population had completed high school or better, $58 \%$ of the audience was from this group. Given that the census was taken of people 15 years and older, (these could not have completed high school), these results showed that a far greater proportion of 'educated' people viewed films than were in the total population.

As the survey suggests, no analysis of 50 s audiences could be complete without some mention of the impact of the burgeoning teenage culture. This was not just a during and post-war baby boom, in terms of numbers, but a new and different culture from the older and is noted in the language of the VFR; for instance, in reviewing early 50s film reviewers make comments to the effect that the film would be appreciated by 'juves', replaced later by the term teenagers. VFR notices this new culture and remarks on a film's potential with that audience. Invaders from Mars caters to 'juveniles and action fans'117; 'even juve audiences' won't accept Project Moonbase (1953)118; Cat-Women of the Moon (1953) had 'enough novelty...to attract both juve and adult spectators who lean towards this form of entertainment'.119 A term to describe even younger audiences was 'moppet': It Conquered the World had 'a number of fairly gruesome sequences', which might have been viewed censoriously by some groups, '[b]ut it must be admitted that the packed house of moppets at the show caught loved the gore, and continually shrieked avid appreciation'.120 By 1957 VFR had begun using 'teenager' rather than 'juvenile': 'Another in the cycle of regression themes is a

117 VFR 8 April 1953

118 VFR 2 September 1953

119 VFR 16 December 1953

120 VFR 12 September 1956 
combo teenager and science fiction yarn...'.121 The Brain from Planet Arous (1958) was 'certain to attract teenage attention'122; 'the dialog and most of the situations [in The Blob] are tailored to the teenage set...'123; and finally, 'The Hot Angel [1958] is a low-budget feature about and for that category called teenagers'124. 'Juve' was still used, but 'teenagers' made its appearance and stuck. The new youth culture was different from that of the years of the Depression and the war. It was a symptom of 50 s change and was a culture of numbers: the baby-boomers of the war and post war years.

As might be expected when a proportionately large, easily identifiable group constitutes an audience, they are represented in the films that are targeted to that audience. Hence teenage audiences and their pre-occupations were a thread in science fiction films such as Invasion of the Saucer Men (1957), which focussed on the teenage culture of Hicksburg, a small town in the US. Teenagers hang out at the 'soda pop shop', with their cars parked in the street outside and discuss girls and flying saucers. They 'neck' in their cars at Lovers point; young males have discussions like "She's got a lot of the right things in the right places" / "Yea, and they're all mine", while Joan, focussed on her marriage, views the saucer men with fear: "I expected to be frightened on my wedding night, but nothing like this". Teenagers are the heroes of the film, overcoming the aliens with a cavalry-like car-charge, and it is this recognition of teenagers as providing the solution to the problem, the heroes of the event, which is a new thread in the discourse of heroism. This foregrounding of teenagers as not only the chief protagonists, but also the clearest thinkers and problem-solvers continues in The Blob.

Yet the conservative thread is just as evident in science fiction films aimed at a teenage audience. The McLendon Radio Pictures production of Giant Gila Monster was filmed near Cielo, Texas, a small town with only a milk bar, it seems. The hot rod crowd inhabiting the milk bar are fine, upstanding Christian folk, who are generally misunderstood as hoons when they are actually clean living, hot-rodding and drive-in attending. Their leader, Chase Winston, is a 19year old mechanic who works to provide for a fatherless family. He has worked

121 VFR 10 July 1957

122 VFR 8 January 1958

123 VFR 10 September 1958

124 VFR 10 December 1958 
to provide money for operations on his disabled sister and he also sings his own compositions about God. In films where sexual sub-texts are common, this films differs in that there is no kissing, no legs, no mention of anything vaguely sexual. The hero, Chase, sacrifices his all-his car, not his life-and saves the community by driving his hot rod into the Gila monster. The end of the teenage years, the early years and traditions of adult life comprise the material for I Married $a$ Monster From Outer Space, a narrative woven around marriage and its consequences for issues like careers, where the basic ideology is that a career is an option only for those who cannot get married and have children.

These audiences enjoyed being scared, evinced by the anecdote of Harlan Ellison in chapter one. In addition to those above is the review of 20 Million Miles to Earth (1957): 'Another "monster" to scare the kids the way they like to be scared'.125

The audience of science fiction films also comprised 'fans' of the genre, obviously drawn from the groups above. The strength of 'fandom' within the US should not be underestimated but the problem lies in determining its impact in describing a film audience. Doubtless there were many who viewed science fiction films simply because they were 'scary', as the VFR material above suggests. At the same time, the reviews mention another audience: those who were intrigued by 'gadgets' or by the genre in terms of its extrapolative, predictive or pedagogical function. These fans of science fiction were so because of their interest in the genre, as distinct from those now included under the rubric of 'fandom' - a smaller group, often focussed on a particular series of productions, such as 'Trekkies'.

The fans of science fiction already existed in the fifties, evinced by the popularity of pulp magazines. The first of these was published in 1926; Hugo Gernsback's Amazing Stories.126 But the real boom in pulp science fiction came after 1938, the year in which John W Campbell Jr assumed editorial control of Astounding Stories, which he changed to Astounding Science Fiction.127 Pulp magazines were of all genres: love and romance, detective stories, Western stories, war stories, jungle stories and sports stories. At the same time (the late 30s) comic books appeared and pulps began to disappear, and by the late 40 s,

125 VFR 12 June 1957

126 Isaac Asimov 1984 Asimov on science fiction London: Granada, 115

127 Asimov 1984, 117 
only the crime, western and science fiction genres remained. In itself, this resilience of science fiction magazines is qualitative evidence of the popularity of the genre, but not only did the genre survive the popularity of the comic book, it flourished. Science fiction magazines proliferated, to such an extent that the period 1938 to 1949 is now known as the Golden Age of print science fiction.128

The audiences for these magazines was no doubt relatively small, but not insignificant. Asimov believes that the audiences in the 1920 s and 30 s comprised, in part, young people who were interested in science and its applications, and he believed that these people were to become the leaders in later life in these disciplines:

...the youngsters who read those magazines in the 1920 s and 1930s were, for the most part, keen-minded, imaginative, and feverishly interested in science. They might have made up no more than a tenth of one per cent of the population, but they grew up to form far more than a tenth of one per cent of the scientists, engineers, and, in general, the intellectual leadership of the nation. 129

Asimov's claims are difficult to prove. His first claim can be supported by the fact that his first science fiction story was published in 1938, and as a writer, he must have had some idea of his audience and it is likely his notion of audience is accurate given his success. But there are other indicators of audience that support Asimov's view. In 1947 Robert Heinlein, in a letter to the Saturday Evening Post, described his mail in response to Green hills of earth. First, the volume of mail was a 'flood'; second, none of it was from 'crackpots' and half of it was from 'technical men'; namely, those interested in science and engineering. ${ }^{130}$ Heinlein mentions this volume of fan mail again in letters of 4 September 1952 and 1969, indicating that fans were really 'fans' of the genre in that their interest was not just in reading, but for some, entering into dialogue with the writer. 131

It may well be that the audiences of fifties science fiction were interested first and foremost in technical developments, extrapolations of science principles and the social consequences arising from them. But elements of beauty, of sensual appreciation, were also canvassed. Heinlein's Green hills of Earth postulates an almost Gaia-like appreciation of the planet Earth, and its

128 Lester Del Rey 1980 The world of science fiction London: Garland, 91-160

129 Asimov 1984, 116, 117

130 Heinlein 1989, 131

131 Heinlein 1989, 131-145 
significance as 'home', which is a recurrent theme in Heinlein.132 The theme is the beauty of the planet Earth, not necessarily the built environment, but natural beauty and the sense of home amongst that beauty. The emotion, the appreciation, appears in the generally unemotional Destination Moon where the astronauts look at the earth from the moon and are entranced by the globe's beauty. While science fiction is about prediction in terms of scientific advances, no one has commented on the fact that the first astronauts were astonished, and in some cases deeply affected, by the emotional experience of viewing the earth from space. Heinlein predicted this emotional experience, as well as many scientific experiences.

In addition to 'technical men', juveniles were a new market for print science fiction from 1945, as evinced by the appearance of science fiction novels for juveniles alone.133 Both Heinlein and Asimov, for example, wrote for a juvenile audience. Heinlein wrote a number of juvenile novels: Rocketship Galileo (1947), Red planet (1949), Space cadet (1950), Farmer in the sky (1949); Between planets (1951); The rolling stones [!] (1952); Starman Jones (1953); The star beast (1954); Tunnel in the sky (1955); Time for the stars (1956); Citizen of the galaxy (1957); Have space suit-will travel (1958); Starship troopers (1959); Podkayne of Mars (1963).134 Some of these stories were serialised in boys' magazines, such as Boy's Life, and other short stories were written for publication in these juvenile magazines. 135 Perhaps unwittingly, authors such as Heinlein were building a subsequent generation of science fiction fans in writing for children. Those readers in the late 40 s and early 50 s would be one of the audiences for the celluloid golden age in the 50 s.

Further evidence that science fiction was not limited to audiences of small social groups is provided by the acceptance of science fiction in the immediate post-war years, which mirrored both the growth in production of science fiction films in the decade and the convergence of science fiction and fact. Science fiction

132 Robert Heinlein 1956 (first published 1954) 'The green hills of Earth' The green hills of Earth London: Pan, 131-141

133 Ash 1977, 289

134 Heinlein 1989, 37-89, 268-272

135 Interestingly - in the light of the debate about constructions of gender, and the arguable dominance of men - Heinlein's editor at Scribners was a Miss Alice Dalgleish. Heinlein railed at the many editorial changes Dalgleish suggested. The allusions, she said, were 'Freudian' and talked about sex. The influence of women librarians was marked in Heinlein's writing. For example, Virginia Heinlein noted that Red planet had to be edited to suit the sensibilities of librarians who were mostly elderly ladies.(p57) Heinlein wrote novels for boys, but these had to pass through the censorship of women. 
became a mainstream genre in the 50 s, evinced by the publication of stories in major newspapers and magazines and in the growth of science fiction publishing beginning in the immediate postwar years. Robert Heinlein had these short stories published in mainstream and influential magazines: 'The green hills of Earth', in Saturday evening Post (8 February, 1947); 'Space Jockey' in the Saturday Evening Post (26 April 1947); 'It's great to be back' in Saturday Evening Post (26 July 1947); 'The black pits of Luna' in the Saturday Evening Post (10 January 1948); 'Ordeal in space' in Town and Country (May 1948); 'The long watch' in American Legion Magazine (December 1949).136 Isaac Asimov had his first story published in the New York Post on 6 March 1955.137 Obviously, magazines such as the highly influential Saturday Evening Post and the New York Post contributed to the canonisation of science fiction as a mainstream genre.

Science fiction fans discovered that the publishing of science fiction books and anthologies could be a profitable venture. In the 1930s, fan publications or fanzines already existed to supply and fan the growing demand for science fiction material.138 At the end of World War 2 some returned servicemen turned to publishing science fiction. Shastra Publications in Chicago was incorporated to produce 'serious reference works on science fiction', but later included novels such as John W Campbell's Who goes there-the story on which the 1951 film The Thing was based-L Ron Hubbard's Slaves of sleep and novels by Robert Heinlein. 139 Other specialist fan publishers were Thomas Hadley, who published John Campbell's work, and Lloyd Eshbach, who, established Fantasy Press in 1947 and later a second publishing house, Polaris Press. Eshbach published most of Campbell's work, and all of E E Smith's.140 Other specialist publishing houses established in the late 40s were Fantasy Publishing Co Inc, Prime Press, the New Era Publishing Company, the New Collector's Group, and the influential and successful Gnome Press, which published Isaac Asimov's I, robot in 1950 and the Foundation trilogy between 1951 and 1953.141

These specialist publishers filled a demand that was seemingly profitable so that, in 1950, major US publishers began to include science fiction in their lists.

136 Heinlein 1989, 270, 271

137 Asimov 1980, 28

138 Ash 1977, 313

139 Ash 1977, 313

140 Ash 1977, 314

141 Ash maintains that these are the dates over which the trilogy was published. Asimov dates the trilogy as published in 1951 and 1952, in his autobiography In joy still felt, 799. 
This acceptance of science fiction as a profitable and popular genre in novels parallels the acceptance of science fiction stories by mainstream magazines. By 1953, the major publishing houses had forced many specialist publishers out of business, with the exception of Gnome Press. Doubleday, for example, published all of Asimov's science fiction novels except for those mentioned above and Fantastic voyage, published by Houghton Mifflin in 1966, and many of his short story collections and anthologies.142 Under David Wolheim from 1952, Ace paperbacks became the largest science fiction publisher in the US, 143 reprinting many of Heinlein's stories and novels.144 Other publishers included Ballantine, Avon and Berkley. In Britain, publishers included Gollancz, Sidgwick \& Jackson, New English Library, Weidenfeld \& Nicolson, Granada (Panther), Sphere, Futura, Coronet, Corgi and Pan. By 1955 science fiction print had established a significant place in mainstream popular literature, read not only by many fans dedicated to the genre, but by many who were outside the initiates of fandom.

While the threads described in this chapter in the web of the social and historical context are diverse, they are closely related to the production of science fiction film. Undoubtedly other elements played a part; those discussed here are those having a major role in the production and exhibition of science fiction film. The discussion will now turn to the industrial context to examine elements of Hollywood with the purpose of suggesting that science fiction films should also be seen in part as Hollywood's response to changing conditions in the production, distribution and exchange matrix.

142 Asimov 1980 799-801

143 Ash 1977, 315

144 Virginia Heinlein, 268-273 


\section{Three}

\section{Industrial contexts}

But the industrial structure of Hollywood, already rocked in the Forties by the antitrust laws and by social changes, was radically altered in the Fifties by a declining demand for movies and the increased independence of stars, directors and writers...

In place of the comfortable process of making assembly-line product for tied houses, uncertainties abounded. A movie might disappear soon after shooting or make a wholly unexpected profit. Nobody knew. The panic of men like Jack Warner may have reflected the visible threat of television, but it also testified to an informed awareness that the industry was becoming a game of chance. 1

This chapter examines the emergence and development of science fiction film in the 50s from a different perspective to that of the previous chapters: the perspective that distinguishes Hollywood as industry from the idea of both Hollywood films and Hollywood auteurs, and sees both these last two classifications as in some way a mystification and reification of the term Hollywood.2 The perspective arises from the question, 'How can we understand 50 s science fiction films in an industrial context?' Are there features of the industrial context that caused, or at least encouraged, the making of science fiction films? In other words, how did these films arise out of the context of the film industry? These questions surround the genre of science fiction, arising as they do from Gomery's contention that the film industry has one goal in common with other industries; that is, making the highest possible profits. ${ }^{3}$ In science fiction films, was there some element that allowed corporations to make more money? Was there some element that enabled corporations to make money at a time of upheaval in the industry in a number of different areas?

These considerations are additional threads to those already discussed that comprise the web of influences that enmesh the science fiction film genre. This

\footnotetext{
Lloyd 1986, 229

Paul Kerr (ed) 1986 The Hollywood film industry London: Routledge \& Kegan Paul, 2.

Douglas Gomery 1986 The Hollywood studio system London: Macmillan, 1
} 
chapter owes much to the work of Paul Kerr, who, in The Hollywood film industry4 and the essay 'Out of what past?: Notes on the B film noir' reprinted in that book, 5 argues for the demystification of the catch-all term 'Hollywood' and its redefinition as an industrial site of production, distribution and exhibition. The exact nature of that relationship between the text-the science fiction film-and its industrial context is not easy to define. Kerr admits the problem, but argues that many critics have simply ignored the problem as being 'too hard' in favour of arguments such as those based on psychoanalysis, for example. 6

This chapter is, then, in Kerr's words, 'an attempt to refocus the debate on the specifically film-industrial determinants of the genre...'.7 Those determinants are the events and shakeouts surrounding the anti-trust ruling known as the Paramount Decree, the challenge of television, the thriving success of the driveins and the changing nature of the audience. 8 In addition the chapter examines two studios by way of case studies, and two artist-technicians in the area of special effects, an area crucial to the genre of science fiction.

\section{Changes in the industry}

The previous chapter described the cultural context in the USA in broad terms and the relationship between science fiction film and that cultural context. But those same historical events impacted on Hollywood-as-industry and Hollywood-as-people, and to establish different outcomes from the same events some of those events are here iterated. As we have seen, nineteen forty-five marked the end of open warfare between the United States and Germany, but in the years after 1945 a different Cold War was fought-in a manner unlike previous wars in that battles were of the mind rather than the body-between the USSR and the US that continued until the late 1980s. The fear of communism and hatred of communists may not have been shared by every person but the fear and hatred certainly played a significant role in the cultural history of the

4 Kerr 1986, 1-30

5 Paul Kerr 1979/80 'Out of what past?: Notes on the B film noir' Screen education Autumn/Winter, 45-65

6 Kerr 1986, 12.

7 Kerr 1986, 45

8. Some description of the audience has been mentioned as part of the cultural context of the previous chapter. It is used in this chapter to suggest a partial explanation for the emergence of science fiction films. 
US. President Truman's federal loyalty program of 1947 and Eisenhower's harsher 1953 version investigated the political beliefs and associations of all federal employees and fragile accusations of disloyalty saw 'security risks' lose their jobs. ${ }^{9}$ Such events and attitudes impacted on Hollywood: 'Much that characterized Hollywood during this decade can be seen as a response to anticommunist hysteria and the blacklist...'10

The atmosphere in Hollywood was 'fiercely anti-communist but not yet paranoid'.11 The House Un-American Activities Committee (HUAC) investigated in a very public way the activities and 'leanings' of those involved in the studios. Significantly, the 'communist sympathisers' HUAC found in Hollywood included 'intellectuals', or anyone who was rumoured to have slightly leftist leanings. In order to work in Hollywood an actor, writer or producer whose name was on a black list-or from 1951 a grey list as well-had to admit their guilt, reveal the names of friends and colleagues who might have shown some leftist sympathies, and then beg patriotic organisations like the American Legion for clearance letters. 12 The film studios and the principals of some did actively support the HUAC through the Association of Motion Picture Producers, which met at the Waldorf-Astoria Hotel in New York on 24 November 1947 and resolved to not knowingly employ a communist and, after 1951, anyone who took the Fifth Amendment.13 In addition, to prove they were not communist, to feed on and recycle the anti-communist fervour, the studios made a series of anticommunist movies: The Iron Curtain (1948), The Red Danube (1949), Conspirator (1949), I Married a Communist (1949), I Was a Communist For the FBI (1952), My Son John (1952) and Red Planet Mars. While these films were in part an obvious response to the blacklist and the anti-communist fervour, the demise of any suitable forum for social comment in mainstream film encouraged the use of the science fiction film as an alternative genre for social comment because of its apparent focus on the unreal.

Films directly critical of American institutions such as the realist 'problem

9 Nora Sayre 1982 Running time: films of the cold war New York: Dial Press, 10

10 David Cook 1996 A history of narrative film New York: Norton, 461

11 Ann Lloyd (ed) 1986 The illustrated history of the cinema London: Orbis, 232

12 Sayre 1982, 21. The irony is that such a star chamber process was common in that most feared evil empire, Soviet Russia.

13 Sayre 1982,23 
pictures' and semi-documentary melodramas-genres that were generally of liberal or left-liberal ideology-were no longer produced, displaced by genres that were uncontroversial and sanitised of any social comment like the western, the comedy and the epic, genres that were unlikely to attract the attention of the anti-communist vigilantes. In an anti-communist context such as this science fiction films were one of the few sites where different social and cultural formations could be suggested and canvassed. Differing political formations are argued for in many films like Earth Versus the Flying Saucers but perhaps in none so strongly as Day the Earth Stood Still. On the other side of the political coin, Invaders From Mars constructs a powerful State that is essentially just, in opposition to families that are prone to evil and violence, and Destination Moon and Missile to the Moon (1959) define a business sector that should not be interfered with by government as business is better able to explore and colonise space. But then Angry Red Planet suggests that such progress may be dangerous, while The Fly, Hideous Sun Demon and Amazing Colossal Man suggest that the knowledge that leads to various contemporary manipulations of nature could be intrinsically damaging to sentient life. While women are sometimes the voices calling out for some sanity in a world of unnatural progress (for example, The Fly, Red Planet Mars), other films refocus on gender and the roles of women in ways that are different from the norm, such as Devil Girl From Mars, The Wasp Woman and Angry Red Planet, as well as those discussed in the next chapter. Invasion of the Saucer Men foregrounds a military that, as a matter of course, lies to the public to keep secret matters it considers to be inessential for the public to know. A similar situation arises in The Blob, and in Amazing Colossal Man the normality of covert operations in the US is argued. Not only the military but also the government conspires against its own citizens in Killers From Space where the FBI administers truth drugs to and keeps files on normal citizens of the US. The 'difference' of the intellectual in society is represented in It Came From Outer Space where 'the town doesn't understand you [the intellectual]' but it does understand the flying saucers that populate many of the alien invasion sub-genre of science fiction films, such as Astounding She Monster. Even a forgotten and forgettable film like Beast With a Million Eyes moralises that love is the binding force that must hold the isolated, nuclear family together in the face of external threats that only make it (the family) strong, while the father argues that the daughter should 
receive a college education against the mother who argues she should remain at home. While Day the Earth Stood Still is a well-known film where mankind is warned about following contemporary trends, It Conquered the World has a similar theme. Similarly, On the Beach constructs a story about the end of humanity, but so does Day the World Ended, while The Time Machine goes further in that it hypothesises catastrophic, but not totally life-destroying, nuclear holocaust.

The end of the 40 s saw significant changes within motion picture companies and in the matrix of production, distribution and exhibition. These changes came at the end of a period of unprecedented growth in revenues of film corporations during the war and in the few years after, and the changes threw those corporations into a situation where they had to 'downsize', to innovate, to deal with a different playing field, to use the current metaphors of economic rationalism. At the same time new audiences appeared, specialised audiences such as young people, the newly-defined teenagers, who, along with nuclear families, often viewed films at drive-ins. New parameters of production, new audiences and new contexts of distribution and exhibition did not directly cause a focussing on science fiction, yet they did cause the corporations to try new strategies to make money. Science fiction film was a minor strategy in this new ball game.

Through the forties, eight companies dominated the production, distribution and exhibition sectors of the US film industry. Paramount, 20th Century-Fox, Warner Bros, Loew's Inc (MGM) and RKO were the major players - the Big Five-in that they produced film in their studios, distributed them through worldwide distribution networks they owned, and exhibited them in theatres they owned. Significantly the nomenclature of the term studio masks the profit motive of these large corporations and instead gives them some kind of creative and artistic ambience, so in this chapter I will refer to them as organisations or corporations or companies, and as studios only when I refer to that site of filmmaking. On paper at least, these corporations made most revenue in the exhibition sector. However, in one sense it is irrelevant to the vertically integrated company where the profits come from, as it is able to manipulate any sector to show a profit there and a lower profit or even a loss in other sectors. Vertical integration allows for profits to be made that might otherwise not be 
made because, in the orthodox theory of supply and demand, supply is controlled and even demand can be manipulated. In the 1930s the Big Five owned three thousand of the twenty-three thousand theatres in the US, but the telling factor was not the number of theatres, but their strategic location in the market. These theatres were both the largest and best first-run theatres, situated in metropolitan areas where they accounted for 50 percent of domestic film rentals. 14 The film industry was, then, for the most part vertically integrated. The smaller Columbia and Universal corporations focussed on production and distribution, and United Artists distributed for independent producers. Universal and United Artists were affiliated with small chains of theatres for a short time, but none of the smaller three owned theatres. 15 Distribution was most often through affiliations of independent exhibitors who could operate under States Rights legislation.

This vertical integration of production, distribution and exhibition on the part of the majors was the subject of an historic anti-trust action in the US Supreme Court that lasted from 1938 to 1949, culminating in the 1949 Paramount Decree. In that ruling the US Supreme Court found the Hollywood corporations guilty of anti-trust violations, in that the Big Five had conspired to monopolise the exhibition of motion pictures-not the production nor distribution-and the large film companies were forced to divest themselves of their exhibition sectors. This divestment was completed in 1957 when Warner Brothers entered an agreement to finally excise its theatre chain into a separate company.

In addition, the procedure known as block booking was prohibited. Prior to 1949 , independent exhibitors were forced to obtain first-run, big budget film on the condition that they agreed to a block of films from that company without having seen them. Doubtless many of these films would not have been chosen by the exhibitors if they had been offered them as single items. Additionally, runs that were artificially long in corporation theatres to prevent independents receiving new films were judged to be illegal restraints of trade.

As a result of the ruling the corporations had to enter into consent decrees providing for the renting of films as single entities supposedly without regard to

14 Tino Balio 1990 'Introduction to Part I' in Tino Balio (ed) Hollywood in the age of television Boston: Unwin Hyman, 4

15 Gomery 1986, 2 
other films and without regard to the ownership of the theatre; they also had to agree to the excision of the exhibition sector from the production and distribution sector so that separate companies would control those sectors. This was guaranteed by voting trusts so that stockholders in a production/distribution company could not control an exhibition company. By the end of the fifties these companies-the Big Five and the Little Three-were somewhat more equal in that none had exhibition sectors, at least on paper. Although there were still eight a couple of players had changed: RKO had effectively ceased filmmaking and the Disney Corporation was now in the same league as the others through its success with animation. All eight distributed films and found independent producers to make them. They all expanded into television. However, the new eight still controlled the box-office almost as tightly as did the Big Five.16

The Paramount Decree was not the only unsettling element of the late 40 s and early 50s. The loss of audience coupled with the divorcement process of the Paramount Decree caused significant change within the Hollywood industry through the dismantling of the studio system. In the studio era, the mass production of films meant the division of labour into departments-such as script development and direction - that came into play at appropriate points in a film's production and performed their work on the film before moving on to the next film. Television and changing audiences decreased demand for motion pictures, and thus demolished the rationale for the studio system. Studios retrenched on a massive scale in all areas of film production. To make fewer big budget films, the most efficient structure for the film corporation was to contract the particular piece of labour out to the most-suited people in the field, thereby avoiding the fixed, long-term salary costs that were a feature of the mass production of the studio system.

Thus as studio production decreased, independent production grew. In 1949 independents produced about $20 \%$ of the 234 pictures released by the eight majors. 17 By 1957 independents produced 170 of 291 productions, or $58 \%$. Importantly, stars were possibly more significant than they were in the thirties and forties, although they were no longer on contracts. Producing a film in the fifties without some kind of star-whether human or special effect alien-was

16 Douglas Gomery 1991 Movie history: a survey Belmont, Calif: Wadsworth, 296

17 Balio 1990, 10 
not conducive to success.

While the majors did focus on high quality, high cost productions, it would be a mistake to construe all films as of this calibre. The industry was in a state of flux and cheaper films were made-although there were fewer of them-to be exhibited in suburban and rural theatres and the drive-ins. In this sense the new B films followed in the steps of the classical Bs. The creation of B films was a response to a demand for 'double-bills' during the Depression:

The B film was launched as an attempt by a number of independent exhibitors to lure audience back into their theatres at a time of acute economic crises in the industry. 18

The B film as the second of the double bill was common by 1935 , with $85 \%$ of theatres running them while only certain theatres in the cities still ran single features.19 This type of exhibition remained a feature even after the Depression. As I will show below, the science fiction film was, in many instances, in the tradition of the $B$ film of the 30 s and $40 \mathrm{~s}$, but the films differed from those $B$ films in many respects.

The major film companies did not establish B film production as a significant contribution to box office receipts and the method of determining the sharing of these receipts explains this. The feature would quite rightly claim the major share of the box office receipts, as it was the main attraction. The A film played with a percentage of the receipts going to the producer or film company, and the remainder going to the exhibitor, ranging from 60 (producer) $/ 40$ (exhibitor) to $80 / 20$ or even $90 / 10$ for a popular film. 20 Thus the feature could bring huge returns to the company if it were popular.

In contrast the B played for a flat, fixed rental and, while there were few risks, there was no potential for spectacular profits for the producer. A minor company such as Republic or Monogram could produce a B for, say, $\$ 75,000$ or $\$ 80,000$ and clear $\$ 10,000$ or $\$ 15,000$ profit. Because of their low income potential, the major corporations did not have a great interest in making or selling Bs, although this is not to say they did not make them at all, because corporations used Bs to ensure contract actors met their obligations and in some instances the B film was a significant-while still minor-element in the corporation. For the

18 Kerr 1979/80, 50

19 Charles Flynn \& Todd McCarthy 1975 'The economic imperative: why was the B movie necessary?' in McCarthy \& Flynn Kings of the Bs New York: Dutton, 15

20 Flynn \& McCarthy 1975, 17 
producer and for the exhibitor, programming two features together would be a waste of money, when the distributor/producer could extract two admission charges for two good films.

The smaller companies like Monogram walked a financial tightrope. Excluding 1949 when it made a huge loss, Monogram's average profit per film was \$1932.12.21 Their problem was the small profit they could make on each film because they were exhibited at a fixed rental. They could never make more than that small profit, and often made a loss if the film even marginally exceeded its budget. Although Monogram managed to survive as Allied Artists from 1953, other companies specialising in Bs were less fortunate. Prior to 1949, a definite and predictable demand for $B$ film existed because the rules of the game of distribution and exchange were fixed and predictable. The industry changes from 1948 meant that the new breed of B film was still low budget and formulaic, but not designed as the bottom of a double bill and not made by the major corporations. Nevertheless opportunities for reasonable profits existed even in this apparently impossible market, and the problem of income was overcome by American International in the mid-fifties with an innovative form of film packaging, which I study later. With the excision of the exhibition sector from the production/distribution sector in the case of the Big Five, the demand for 'classical' B films dwindled. In the 50s, Monogram metamorphosed and Republic disappeared, while new B studios, differing in style, purpose, and market-such as teenagers-emerged. The reason for the re-emergence of the B film was supply and demand. The supply of film had dwindled markedly but new markets were emerging, so companies like AIP (American International Pictures) stepped in to fill the gap.

Before I examine United Artists and AIP by way of case studies, other aspects of the industry, and the changes that occurred in the fifties, need to be examined.

\section{The challenge of television}

The history of cinema in the 50 s is, arguably, the history of a reaction to the overwhelming influence of television. In 194690 million people in the US went to

21 Flynn \& McCarthy 1975, 24 
the 'pictures' every week.22 This was some $75 \%$ of the maximum possible audience.23 By 1950 that audience had shrunk to sixty million a week, and it continued to decline; for example, by 1953 it was 46 million, a figure that remained until 1958, when it again declined to 40 million and it was at that number in 1960.24 Considering the population increase from 1945 to 1957 of $35 \%$, these figures when translated to per capita attendances are even worse. 25

Chapter two mentioned the impact of television in analysing the audience and changes in that audience. The impact of television is also significant to an analysis of the industrial context. Paralleling the decline in cinema audiences, television as a similar medium-in that pictures appeared on a screen for the purpose of entertainment-impacted on the film industry. First analyses tended to support the argument that television simply replaced the cinema; according to Stuart, statistical analysis suggests the introduction of television did cause the decline in cinema audiences. 26 He apparently demonstrated a correlation between the loss of motion picture revenues and the degree of television penetration in any geographic area.

On the other hand other evidence suggests that television did not cause the loss of box-office. Audiences began to decline markedly in 1947; it was not until 1950 that large numbers of televisions were sold and the argument can be made that television did not affect cinema audiences. 27 The decline in cinema attendances preceded the advent of television in most parts of the US, as the Federal Communication Commission issued most television broadcast licences only in 1952.28 By 1952/53, the weekly audience had plummeted from the 90 million of 1946 to 46 million, and during this time television was not available to most people in the US. Doubtless for many people the abandonment of the cinema was due to other factors than television. As I've noted in chapter two, men and women were getting married and having babies at the highest rate ever measured in the western world and this brought a change in patterns of

22 Garth Jowett 1976 Film: the democratic art Boston: Little, Brown and Company, 475

23 Barry Norman 1987 Talking pictures London: Hodder and Stoughton, 287. See also Jowett.

24 Jowett 1976, 475

25 Kerry Segrave 1992 Drive-in theaters: a history from their inception in 1933 London: McFarland, 74

26 in Jowett 1976, 350

27 Balio 1990, 3

28 Gomery 1991, 280 
disposable income. The war brought full employment and prosperity after the Depression years but little to spend it on, given the wartime restrictions on material and energy sources; after the war, cars, a home in the suburbs and a family assumed a new dominance in the scheme of things. These factors were of greater influence on cinema-attending habits than the penetration of television.

Given that the home was the castle, and that the centre of human activity had shifted to and focussed on the home as a place of entertainment and relaxation -in the garden, with friends having 'drinks', a bar-b-que, playing with the children-it is not surprising that in the latter half of the decade visual entertainment would focus on the home, in the mode of television and that technology would become almost a defacto baby- and child-minder.

Statistics relating box office receipts to personal expenditure support the contention that the transformation of many singles into fewer families caused cinema numbers to dwindle. For example, in 1950, \$1,376 million crossed box office windows, representing $0.72 \%$ of total personal consumption expenditures, but by $1960, \$ 951$ million was taken at the box office, representing $0.29 \%$ or a decrease of $75 \%$ in the proportion of personal consumption expenditure. The per capita decrease was even more depressing for theatre and studio owners, as disposable income rose from $\$ 159$ billion in 1945 to $\$ 287$ billion in 1957.29 Personal consumption expenditure was going elsewhere. 30 The baby boom after the war meant that many from the earlier audience had become parents, and this introduced a different set of spending parameters. A father explained the reasons for not going to the cinema:

There was a movie my wife and I wanted to see. Then we began to add up the price. Two tickets at $60 \mathrm{c}$ each - that's not so bad. But then there was the babysitter. Three hours at $50 \mathrm{c}$ an hour plus car fare is $\$ 1.70$. Parking the car-that would be another 50c. Figuring gas and oil would be another $50 \mathrm{c}$. Add a coke or something afterward, say another $25 \mathrm{c}$. That's over $\$ 4.00$. So we stayed home. 31

While it seems accurate to argue that television did not cause a decline in cinema attendances, it is also the case that television was a threat to those audiences and only the most obtuse film corporation executive would fail to recognise this fact. Film corporations were not slow to gauge the importance of

29 Segrave 1992, 76

30 Jowett 1976, 473

31 Robert Coughlan 1951 'Now it is trouble that is supercolossal in Hollywood' Life v31, August 13,102 , in Jowett 1976,350 
television, and the impact it would have in the entertainment industry. While it might often seem that the film corporations were unprepared for the assault of television, such was not the case. Some members of the Big Five had planned to enter the television market before the 1950s, but they had to deal with the Federal Communication Commission, and that body was hostile to the film corporations, as the FCC surmised that the corporations were entering the industry for crass profit motives, unlike the radio networks who had, allegedly, the public interest at heart. 32 Whether or not such a claim is accurate it is fact that Federal Communications law prohibited companies found guilty of monopolistic practices from holding broadcast licences, and so, when the Supreme Court found the operation of the Big 5 to be monopolistic in 1948 the FCC ruled them ineligible to be considered for television licences. ${ }^{33}$ After the Decree the FCC was less prepared to let the film corporations enter the television field:

It is important that only those persons should be licensed who can be relied upon to operate in the public interest, and not engage in monopolistic practices....It is obvious ...that violation of the antitrust laws by the motion picture companies is a matter that the Commission must consider carefully in determining the qualifications of these companies to operate in the public interest. 34

Paramount, of all the Big Five, had the biggest stake in television through two elements: its partnership in the DuMont Corporation, and Paramount's subsidiary, Paramount Television Production, which supplied filmed television programs to broadcasters. Paramount's stake was substantial. In 1938 it had invested almost $\$ 500,000$ with the Dumont Corporation, a television developer and manufacturer, who had in place an application for an experimental broadcast licence, which was the major attraction for Paramount. In addition, the corporation had access to four of the first nine television stations in the most important population centres of New York and Washington DC. For Dumont the attraction was the studios and the library of Paramount Films. The embryonic television network was a part of the strategy of establishing a nationwide television network owned by theatre chain subsidiaries and supplied with film by the Paramount-owned Television Productions Inc. Others of the Big Five applied for television broadcast licences, as did the radio networks like NBC,

32 Timothy White 1990 'Hollywood's attempt at appropriating television: the case of Paramount Pictures' in Tino Balio (ed) Hollywood in the age of television Boston: Unwin Hyman, 146

33 Gomery 1991, 284

34 Broadcasting April 2 1951, in White 1990, 147 
$\mathrm{CBS}$ and the $\mathrm{ABC}$. With the failure of these attempts to enter the television industry as broadcasters, the Hollywood companies realised that they could generate income by releasing film to the networks, and by renting vacant studio space to television producers. By 1955 the Hollywood corporations had begun making films and series for television, and by the end of the decade Hollywood companies supplied most of the prime-time material for television. 35

Television, then, did not take the corporations by surprise. They did have plans to enter that industry, but were prevented from doing so in the way they would have liked, so in order to survive they needed to be innovative both in their filmmaking and marketing. The film corporations resorted to different measures to try to again attract audiences, and one of the measures was the science fiction film.

The emergence of science fiction film was partly a response to the challenge of television, a response to the falling audience numbers-and therefore box office receipts-that I've discussed above. What could science fiction film offer an audience that could not be offered on television? Science fiction in the cinema offered more than many television genres, more too than science fiction on television. It could offer a visual and auditory experience that could not be replicated on the small screen. Special effects, for example, could not be reproduced to the same depth or in the same clarity on the small screen. Nor could the viewing context-the theatre, the darkened seats facing a large screen with life-size images above the audience-be reproduced in the viewing of television. The effect on the audience of many science fiction film was an emotional response to the film-fear, apprehension for example-that was unique to the viewing context of a theatre. Larger than life aliens, combined with musical effects, were designed to create an emotional response that could not be created on television. The extracts from Variety Film Review in chapter two indicated the importance of the creation of fear for young audiences.

For similar reasons the musical was developed: it could offer spectacle and size, and later, colour. Sound quality in film was better than television; an important selling point that was exploited in the genre of the musical, which helped to keep MGM in the black up to the mid-50s. The superproduction was

35 Gomery 1991, 291 
another genre that flowered in response to television; the Cecil de Mille biblical epics capitalised on cheaper Eastman Kodak film processes as well as widescreen technologies to become important money-spinners. These costly productions were financed in part by the injection of funds from the sale of blocks of film library to the television networks beginning in 1954.

While traditional audiences were falling away, a new and distinct teenage audience was coalescing - to partly fill the seats vacated by their parents in favour of the couch in front of the television-whose emergence as a targeted marketing niche is discussed in the previous chapter. Producers like Samuel $Z$ Arkoff of American International Pictures recognised the interests of this audience and made science fiction, horror, beach party and other films to both cater to and form those interests. Yet science fiction films were not produced to fill only this need; other producers made science fiction films that targeted more sophisticated audiences. All studios produced science fiction film, so it was not a case of one studio using it alone.

Science fiction, while in part a film industry response to the challenge of television, was, apparently paradoxically, a product of television studios in the early fifties. Juvenile science fiction novels, films and a limited number of television programs were popular with children in the years up to 1954, children who comprised the mini-baby boom that occurred during WW2 because of the rapidly expanding economy that followed the pre-war depression. Children appeared to enjoy science fiction even though, like the epic and the musical, special effects lost a great deal in the translation to the small, black and white television screen. The fear-evoking image of a rampaging dinosaur becomes something less on the small screen of television. Yet on the other hand the narrative potential of science fiction; that is, the possibilities of stories of interest, action and adventure for children were exploited to make science fiction programs that were cheap, with special effects that were less special than effectual in their narratival function of telling adventure stories. In addition, the convergence of science fiction and fact is illustrated in those adult shows like Science Fiction Theater.

While science fiction on US prime-time television was generally uncommon, some significant US-made science fiction programs in prime time in 
the 50 s were: 36

\begin{tabular}{|l|l|l|l|}
\hline title & category & first telecast & last telecast \\
\hline $\begin{array}{l}\text { Captain Video and His } \\
\text { Video Rangers }\end{array}$ & children's & 27 Jun 1949 & 1 Apr 1955 \\
\hline Buck Rogers & science fiction & 15 Apr 1950 & 30 Jan 1951 \\
\hline Tom Corbett, Space Cadet & children's science fiction & 2 Oct 1950 & 26 Sep 1952 \\
\hline Space Patrol & children's & 9 Jun 1951 & 1 Jun 1952 \\
\hline Tales of Tomorrow & science fiction anthology & 3 Aug 1951 & 12 Jun 1953 \\
\hline Out There & science fiction anthology & 28 Oct 1951 & 13 Jan 1952 \\
\hline Johnny Jupiter & children's & 21 Mar 1953 & 13 Jun 1953 \\
\hline Operation Neptune & science fiction & 28 Jun 1953 & 16 Aug 1953 \\
\hline Flash Gordon & science fiction & 1953 (39 episodes) & 1954 \\
\hline Science Fiction Theater & science fiction anthology & 1955 (78 episodes) & 1957 \\
\hline Men into space & science fiction & 30 Sep 1959 & 7 Sep 1960 \\
\hline Twilight Zone & science fiction anthology & $\begin{array}{l}2 \text { October 1959 } \\
\text { then } \\
\text { Sep 1985 }\end{array}$ & $\begin{array}{l}\text { Sep } 1965 \\
\text { 31 July } 1987\end{array}$ \\
\hline
\end{tabular}

Table 4: Science fiction on television

On average there was one television series a year and with some notable exceptions, most did not last longer than one season. Captain Video was one of these exceptions. Its prop budget was a measly $\$ 25$ per week, yet it was 'one of the most popular children's programs of the early 1950s', reaching an estimated 3.5 million children. 37 It was popular enough to have a merchandising arm of the operation that offered plastic replicas of the captain's weapons, for example, a theatrical production was modelled on the show, and the captain won awards for his short talks on liberal values. 38 The emergence and popularity of this program paralleled that of juvenile science fiction in print.

The show was popular enough to be copied by other networks. Space Patrol and Tom Corbett-Space Cadet were the imitators, although never as successful. Tom Corbett had more realistic special effects than Captain Video, but the focus of the show was the adventures of the space cadets, where they managed to instruct

36 Tim Brooks \& Earle Marsh 1992 The complete directory to prime time network TV shows, 1946-present (5th ed) New York: Ballantine, 125-928

Brian Ash 1977, 300

37 Brooks \& Marsh 1992, 144

38 Brooks \& Marsh 1992, 145 
the audience in aspects of space. As argued in the next chapter, instruction was an important element of the genre. The scientist and author William Ley was adviser to the series. 39

After 1954, there was only Captain Video for children and science fact for adults. Television science fiction had burnt itself out and science fact, rather than fiction, was the focus of the few shows that appeared in the second half of the decade, mirroring the convergence of science fiction and fact emerging in literature and film. Science Fiction Theater was 'factual' science fiction in that it took current science facts and extrapolated on those. Each episode dealt with some aspect of the strange, but possible in some degree; such as UFOs, the possibility of thawing frozen prehistoric animals, mental telepathy. 40 The series had a number of real scientists as advisers, and was respectable enough to have players like Basil Rathbone and Gene Barry. The other 'realistic' program was Men into Space, the serialised TV version of Destination Moon in the sense that it attempted to be scientific fact, rather than fiction. The series was developed as a response to the interest in space travel and concern about the space race, catalysed in the US by the USSR Sputnik success, a topic covered in the previous chapter. ${ }^{41}$ The series had the full support of the US army, navy and air force, and numerous scientific organisations in order to be scientifically accurate, but also to make visible the support of these organisations for the space program. Neither adult program was long running: Science Fiction Theater ran for two years; Men Into Space for one. Twilight Zone, however, was a favourite that ran until 1987. Its focus was less science fiction than fantasy, with narratives that were unusual and offbeat, often with ironic endings.

In one sense science fiction television for children was overtaken by events. On the one hand the children of the mini-baby boom of World War 2 were both young and old enough to watch television up to about 1955, by which time most were at least ten years old, and then to attend the exploitation films made by producers like AIP in the second half of the decade.

While it is possible to name the 50 s the golden age of science fiction films,

\footnotetext{
39 Brooks \& Marsh 1992, 904

40 Brooks \& Marsh 1992, 786

41 Brooks \& Marsh 1992, 578
} 
there is no evidence that this golden age translated to television. With its small screen, television could not evoke the fear that I have elsewhere noted was often an integral aspect of the screening of science fiction in the cinema. On television the narrative potential of the action-adventure element seemed to be the drawcard for the audience, who were, in many instances, children. In contrast, the screening of science fiction in the cinema centred around elements in addition to action-adventure such as special effects, and the fear and similar emotions that might be evoked. But other emotions were being generated in places other than cinemas, and these places were drive-ins.

\section{The growth of drive-ins}

Drive-ins developed because of the American car culture that effloresced in the post-war years, inextricably linked with other threads like consumer credit, suburbs and the baby-boom.

The drive-ins were the exception to the rule of dwindling cinema audiences. In 1951, the drive-ins represented $15 \%$ of the total number of movie houses, and $20 \%$ of receipts. 42 The significance of drive-ins was to expand during the 1950s in proportion to the mushrooming in numbers. The overall numbers suggest a gradual decline in total numbers of theatres, whereas numbers of indoor theatres declined dramatically. 43

$\begin{array}{rrrr}\text { year } & \text { indoor } & \text { drive-ins } & \text { total } \\ 1948 & 17,811 & 820 & 18,631 \\ 1954 & 14,716 & 3775 & 18,491 \\ 1958 & 12,291 & 4063 & 16,354 \\ 1963 & 9150 & 3502 & 12,652\end{array}$

Table 5: The growth of drive-ins

These statistics do not support an argument for a simple replacement of indoor theatres by drive-ins. Stuart found that there was little relationship between the opening up of drive-ins and the decline of the conventional fourwalled theatre, and a survey taken by MGM in 1949 found that hardtop

42 Jowett 1976, 352.

43 Jowett 1976, 482 
attendances were not affected by an 'ozoner' opening nearby.44 Weather and population concentration were the prime criteria for the choice of constructing drive-in theatres over indoor theatres, hence the popularity of the drive-in in the southern states. Between 1948 and 1954, hardtops in southern states were closing, but this was more than compensated for by the opening of drive-ins: 45

$\begin{array}{lcc}\text { state } & \text { net increase in theatres } & \text { new drive-ins } \\ \text { North Carolina } & 63 & 140 \\ \text { South Carolina } & 49 & 63 \\ \text { Georgia } & 89 & 115 \\ \text { Florida } & 98 & 136 \\ \text { Kentucky } & 36 & 89 \\ \text { Tennessee } & 50 & 92 \\ \text { Alabama } & -2 & 80 \\ \text { Mississippi } & 3 & 60 \\ \text { Arkansas } & -58 & 51 \\ \text { Louisiana } & -5 & 58\end{array}$

Table 6: Drive-ins in southern states of the US

Drive-ins required far less capital that hardtops, and thus profit could be greater. Some statistics indicate the impressive growth of the drive-ins, and the lower cost per patron to build those places. In 1952, sixty-five indoor theatres were built, providing seating for 35,000 people at a cost of $\$ 8.5$ million. Each seat cost $\$ 243$. In the same year some 690 drive-ins were built, providing 263,879 car spaces for a total of $\$ 52,125,800$. On the basis of 2.7 occupants per car, the cost per seat was only $\$ 73.46$ Drive-ins could be very profitable. Averaging the costs and income of 12 ozoners in 1953, George Petersen estimated that an ozoner could make a net profit of $\$ 59,961$ in 26 weeks for a seven hundred car theatre. 47

The drive-ins were partly the domain of the young, a place where the freedom and mobility promised by the automobile was transferred to the sexual experimental arena, albeit a private arena:

\footnotetext{
44 in Jowett 1976, 351

45 Jowett 1976, 376

46 Segrave 1992, 65

47 Segrave 1992, 65
} 
During its formative stage the drive-in theatre had quite justifiably acquired the reputation as a "passion-pit", where young couples could steal a few private moments in the darkened confines of an automobile. 48

Indeed, the science fiction writer Harlan Ellison was one half of one of those 'young couples', attending a drive-in to watch a science fiction film:

Invaders from Mars and Invasion of the Body Snatchers may provide Ossianic opportunities for publish-or-perish cinéastes to breathe heavily about unconscious Jungian archetypes and the basic Apollonian/Dionysian conflict, but for those of us trying to catch a cheap feel in the back seat of a Nash Rambler, them films was just some good scary shit. 49

My copy of Attack of the Giant Leeches concludes with on-screen instructions and directions for leaving the drive-in.

Initially, drive-ins were a place for suburban families and they were conceived as such by the inventor, Richard Hollingshead, in his unsuccessful patent application that envisioned families as the major audience. 50 His reasoning was that suburban families did not want to return to the city at night. The new suburbs could not have existed without the automobile, and going to a drive-in meant that the family did not have to step out of the car for the whole evening, although they could go to the playground, or the concessions. America's baby book, one of the child-rearing books of the period, advised new parents to take the opportunity the drive-in presented: 'If you have a car, baby can sleep in the back seat while both parents enjoy the movie at a drive-in theatre'.51 The drive-in allowed the family to spend time together. The formal attire of the organisation was not required for the drive-in, in an era when casual clothing was otherwise restricted to certain times in the home; and the night was a comparatively cheap evening for families. There were, for example, no inner-city parking fees, nor baby sitting fees. This upset the female teenage baby-sitters in Seattle, Washington, who picketed the Aurora Drive-In with placards reading, for example, 'Down with drive-ins, more work for baby sitters' .52

The place of ozoners in the film industry was problematic according to the practices of distribution. On the one hand, MGM Vice-President William F Rodgers argued that the industry should treat ozoners as another department in

48 Jowett 1976, 376

49 Harlan Ellison 1984 'Lurching down memory lane with It, Them, The Thing, Godzilla, HAL 9000 ...that whole crowd' in Danny Peary (ed) Omni's screen flights/screen fantasies New York: Doubleday, 6.

50 in Segrave 1992, vii, viii, 142

51 Segrave 1992, 64

52 Segrave 1992, 38. 
that industry, and that film companies should give them good service. 53 However, they didn't. Ozoners were not popular with production companies and were seen by those companies as poor cousins to hardtops. They did not often get first-run, major Hollywood films; instead their programs were second or third run, or comprised B films.54 The appearance of drive-ins, coupled with other unique problems concerned with their position or lack of it in the system of distribution created something of a vacuum that was filled by a new production industry that assumed, during the 50s, some significance because it focused on producing science fiction film.55 Of major, lasting significance was American International Pictures (AIP), coalescing in that identity in 1954 under the direction of Samuel Z Arkoff. The AIP formula of low-cost, quickly made horror or science fiction film was designed to fill the vacuum in the drive-in market. These films were not meant to be shown in hard-tops, perhaps because their lack of production values would be more closely scrutinised. Hence many were never screened in hard-tops. 56

And films for drive-ins were not supposed to be 'quality' offerings. At the end of the war, when Herbert Ochs was enlarging his chain of drive-ins, he did not advertise the name of the film in his theatre advertisements when opening a new theatre, 'believing that customers simply wanted to enjoy the outdoors along with some form of entertainment'. 57 His drive-ins marketed the concept of a night out: 'we sell the drive-in theatre to the public, not the picture. The program is secondary.'58 Specialist drive-in studios like AIP, CIP and Azalea could sell into this market with their low-cost, low quality product, where the screening context did not require films of high quality.

This context of production, distribution and exhibition, allows us to turn to science fiction films themselves and their producers and makers. The chapter continues with an examination of the corporations that produced science fiction films (to indicate the genre's appeal to the film corporations that crossed barriers of size); it looks at two studios as case studies of the effect of the changing

53 in Segrave 1992, 143

54 Segrave 1992, 174

55 Segrave 1992, 174

56 Segrave 1992, 174

57 Segrave 1992, 39

58 Segrave 1992, 39 
context and the resultant appeal of science fiction; and then profiles George Pal and Ray Harryhausen, two special effects artists and technicians who were to demarcate film and television through the development of special effects.

It is a mistake to assume that 50 s science fiction was just the domain of the small corporation. As I've indicated above, the challenges facing the industry were multi-faceted, and the making of science fiction film was a response to those challenges. The Variety film review collection of science fiction reviews contains most films released on the US market.59 Variety's own reviewers did not call some entries science fiction, and so I have culled them from this list, and added others not reviewed by Variety. What remains is an exhaustive list of the science fiction films of the 50 s, listed by releasing corporation, which was, in the 40 s, often the producer, but this situation had changed by the end of the decade.

\section{Science fiction films by corporation}

All corporations participated in the science fiction film market. This list of films is by corporation, compiled from Variety film review, my records and the Internet Movie Database.60 Thus, while extensive and as exhaustive as possible, it is not complete as inclusion depends on questions of genre. It does, however, give some idea of the distribution of films across corporations at various times.

The Big Five

Paramount

When Worlds Collide 1951

War of the Worlds 1953

Conquest of Space 1955

The Space Children 1958

The Blob 1958

I Married a Monster From Outer Space $\quad 1958$

Visit to a Small Planet 1960

20th Century Fox

The Day the Earth Stood Still 1951

Invaders From Mars 1953

The Rocket Man 1954

On the Threshold of Space 1956

Kronos 1957

59 Donald Willis (ed) 1985 Variety's complete science fiction reviews New York: Garland

60 The Internet Movie Database http://us.imdb.com/ (accessed 28/12/98) 
She Devil $\quad 1957$

The Fly 1958

Space Master X-7 1958

Journey to the Centre of the Earth 1959

Return of the Fly 1959

Warner Bros

The Beast From 20,000 Fathoms 1953

Them 1954

Satellite in the Sky 1956

$X$ the Unknown 1957

The Black Scorpion 1957

From the Earth to the Moon 1958

Gigantis 1959

Teenagers From Outer Space 1959

MGM

Forbidden Planet 1956

The Invisible Boy 1957

First Man Into Space 1959

The World, the Flesh, the Devil 1959

The Mysterians 1959

$\begin{array}{ll}\text { The Time Machine } & 1960\end{array}$

RKO (ceased production in 1953)

The Thing 1951

Killers From Space $\quad 1954$

The Other Three

Columbia

Five 1951

It Came From Beneath the Sea 1955

Creature With the Atom Brain 1955

Earth Versus the Flying Saucers 1956

The 27th Day 1957

The Giant Claw 1957

Twenty Million Miles to Earth 1957

The Night the World Exploded 1957

The HMan 1959

The Electronic Monster 1960

Battle in Outer Space (Japanese production) 1960

12 to the Moon 1960

Universal

It Came From Outer Space 1953

Creature From the Black Lagoon 1954 


$\begin{array}{lr}\text { Revenge of the Creature } & 1955 \\ \text { This Island Earth } & 1955 \\ \text { Tarantula } & 1955 \\ \text { The Creature Walks Among Us } & 1956 \\ \text { The Mole People } & 1956 \\ \text { The Incredible Shrinking Man } & 1957 \\ \text { The Deadly Mantis } & 1957 \\ \text { The Land Unknown } & 1957 \\ \text { The Monolith Monsters } & 1957 \\ \text { Monster on the Campus } & 1958 \\ \text { 4-D Man } & 1959\end{array}$

United Artists

Red Planet Mars 1952

The Magnetic Monster 1953

Phantom From Space 1953

The Twonky 1953

Donovan's Brain 1953

Riders to the Stars 1954

Gog 1954

Snow Creature 1954

The Creeping Unknown 1956

The Beast of Hollow Mountain 1956

Monster That Challenged the World 1957

Enemy From Space 1957

It! the Terror From Beyond Space 1958

Curse of the Faceless Man 1958

The Lost Missile 1958

Invisible Invaders 1959

On the Beach 1959

Other film corporations

Allied Artists

Target Earth 1954

Atomic Man 1956

Invasion of the Body Snatchers 1956

World Without End 1956

Attack of the Crab Monsters 1957

Not of This Earth 1957

War of the Satellites 1958

Attack of the 50 Foot Woman 1958

Queen of Outer Space 1958

The Cosmic Man 1959

The Wasp Woman 1960

Allied Artists Television Corp 
Lippert Pictures

Rocketship XM

1950

Lost Continent

1951

Unknown World

1951

Spaceways

1953

Project Moonbase

1953

Monster From the Ocean Floor

1954

King Dinosaur

1955

American Releasing Corp/American International Pictures

The Beast With 1,000,000 Eyes

1955

The Phantom From 10,000 Leagues

1956

Day the World Ended

1956

with Golden State

It Conquered the World

1956

Invasion of the Saucer Men

1957

I Was a Teenage Werewolf

1957

Amazing Colossal Man

1957

Cat Girl

1957

Attack of the Puppet People

1958

War of the Colossal Beast

1958

The Spider

1958

Terror From the Year 5000

1958

The Brain Eaters

1958

Attack of the Giant Leeches

1959

Amazing Transparent Man

1960

Beyond the Time Barrier

1960

Others, ungrouped

3D pictures

Robot Monster

1953

Al Zimbalist/Jack Rabin

Cat-women of the Moon

1953

Associated British-Pathe

1984

1956

Missile to the Moon

1959

BBC

Quatermass and the Pit

1959

British Lion

Seven Days to Noon

1950

20,000 Leagues Under the Sea

1954

Unnatural: The Fruit of Evil

1952

CCA [German release]

Hideous Sun Demon

1959

Criterion Films/Topaz

Fire Maidens From Outer Space

1955

Danziger/Spartan

Devil Girl From Mars

1954

Eagle Lion

Destination Moon

1950

Embassy

Godzilla

1954

Eros

Strange World of Planet $X$ 
Exclusive

Favorite

Hollywood International (related to AIP)

Howco Productions

Independent

McLendon Radio Pictures

MLC Producers Associates

Monogram (later Allied Artists)

Orion/AIP

Republic

Rex Carlton/AIP
The Trollenberg Terror

1958

The Crawling Eye

1958

Behemoth, Sea Monster

The Quatermass Experiment

The Brain From Planet Arous

Astounding She Monster

Mesa of the Lost Women

Brain From Planet Arous

Teenage Monster

The Man From Planet $X$

The Giant Gila Monster

The Killer Shrews

Fiend Without a Face

Flight to Mars

The Angry Red Planet

Tobor the Great

Beginning of the End

The Brain That Wouldn't Die
1959

1955

1958

1957

1953

1958

1958

1951

1959

1959

1957

1951

1959

1954

1957

1959

Table 7: The corporations and their science fiction films

Apart from RKO which made only two films loosely classified as science fiction before it ceased production in 1953, the other six of the seven majors (excluding Disney) realised the demand for science fiction after about 1955 and turned out science fiction films every year or two. The Little Three of these seven, who were still smaller corporations, produced relatively more science fiction. But the smallest corporation, United Artists, released the most films (17) over the decade. While the majors could produce the blockbusters of the period, given their resources of studio space and expertise, the smaller studios could do well out of science fiction, although not realising massive profits. United Artists quantity of film might be partially explained as a need for film. The case study below discusses this.

American International, focussing on the drive-in and teenage markets and operating outside the distribution system that was operated by companies friendly to the Big Five, made 15 films, but this corporation did not coalesce until 1955. Thus its 15 science fiction films in a five year period represent the highest production total. Nineteen sixty was the fin de siecle, at least in terms of numbers. While some ten science fiction films were released in 1960 , only four were released in 1961 and five in 1962. 


\section{United Artists}

I suggest that the science fiction output of United Artists was a function of two planks in the organisation. One was the need for film simply to cover fixed overheads, and the other was the unique structure of the organisation and its unique method of acquiring film for distribution.

As I have shown, during the fifties the nature of the film industry had transmogrified: audiences had changed and decreased markedly, the Paramount decrees had changed some aspects of the industry-although not to the extent that the change in audience forced re-thinking in the industry-and television had reduced the demand for B film. During this time the majors changed the way they operated, moving to independent production so that, as I've pointed out above, by the end of the decade over $50 \%$ of their output was made by independents. Still, the majors retained control of production through contracts that left control with the corporations. The corporation where filmmakers did have a greater degree of independence was United Artists. At the opening of the decade the company that Charlie Chaplin and Mary Pickford controlled had made losses for most of the previous ten years. Arthur Krim and Robert Benjamin headed a syndicate that took over in February 1951 under an arrangement whereby they could acquire a controlling interest if the company made a profit in any one of the next three years. At the same time, independent producers emerging in the post-divestment environment were looking for distributors.

In 1951 Krim and Benjamin began offering filmmakers a completely different deal from the other companies:

in return for distribution rights, UA would offer independent producers complete production financing, creative control over their work, and a share of the profits. 61

Compared to the other majors, UA was a financing, distribution and publicity company only, allowing the creative talents of filmmakers to focus on making films. The distribution network of some 90 sales offices and two thousand people required some $\$ 15$ million to maintain each year. These fixed expenses meant that the company had to turn over a certain number of films each year just to break even. The distribution costs were fixed, so any excess

61 Balio in Balio 1990 New producers for old', 168 
income was profit. The more film, the better were the company's chances of making a profit overall. Science fiction film was one element in this strategy. They did not depend on stars for their success, but rather special effects. They could thus be made with reasonable production values relatively cheaply, and hence assist the company pay its fixed expenses, and possibly contribute to total profits. Yet unlike AIP's strategy, UA did not simply produce cheap films because they were cheap. They viewed each project as a potential failure, to be carefully monitored so that costs were contained and therefore individual disasters could be avoided. Krim stated:

...we must constantly weigh and gauge how many pictures we can profitably handle, and we must make sure that we don't take undue risks. 62

So some pictures were a greater risk at $\$ 3$ million than others at $\$ 12$ million. The cost of the film was not the issue; the important judgment was cost against potential revenue.

\section{American International Pictures}

One of the most successful studios was American International Pictures. In 1975, Samuel Z Arkoff had been head of American International Pictures since its formation in 1954, when Arkoff and Jim Nicholson formed it as a distribution company, American Releasing Corp, to become subsequently American International Pictures in 1955. The formation of another low-budget company at the time could have appeared to be a misreading of the market, given the liquidity problems of the traditional B film makers, Republic and Monogram. The larger film companies were reeling from the impact of television, falling box office receipts and the anti-trust ruling that forced them to divest themselves of the vestiges of vertical integration. 63

Arkoff argued that the demise of the B films was a result of the impact of television and the development of colour in the cinema that required increased production costs. The classic B film in black and white, argued Arkoff, could be played as second features as long as there were many theatres,

But the minute that everything became color, and the cost of color prints was approximately two-and-a-half times the cost of black-and-white prints, some smart chap discovered what everybody should have known all along: namely, that you were better off with a second feature that was not a new

62 Balio in Balio 1990 'New producers for old, 171

63 Linda May Strawn 1974 'Samuel Z Arkoff' in McCarthy \& Flynn, 256 
picture.64

He was also aware that the audience had changed. He criticised the majors for making 'nice pictures' for a non-existent audience and he also believed that making program pictures-that is, the second half of a dual program for a fixed rental-was a recipe for disaster. 65 Arkoff realised that the audience for films was changing to youth and that this group were becoming the regular theatre audience often attending a drive-in. It was young people, he surmised, who were the new regular attenders and he sold to that audience, changing the themes as necessary to attract an audience. Film themes ranged from science fiction, forbidden romance, through motorcycle films (popular with men outside large cities and in drive-ins) and 'Edgar Allen Poes', to the beach films of Annette Funicello and then to rebellious youth with Wild in the Streets in 1968.66

These considerations were evident in AIP's first productions. The first film was Apache Woman (1955), and AIP sold it as the second half of a program, resulting in low returns to AIP because they received a flat fee. Realising the problems that had beset so many B film producers, AIP subsequently produced two cheap films and booked them together as a combination. AIP made one of the films, The Day the World Ended in 1956, commissioned the second, The Phantom From 10,000 Leagues, and distributed them together as a package on a percentage basis which was the significant feature that distinguishes it from the usual financial arrangements surrounding the distribution of an A and B film.67 The production values and narrative aspects of The Day the World Ended do not commend the film as a classic; but in the second-half of the package, Phantom From 10,000 Leagues, those values are non-existent. Nevertheless the popularity of their strategy was apparent in that AIP made 22 films in 1958, in 11 combinations. Significant to this thesis is the fact that many were science fiction films. A film was made in two weeks and the directions the company gave to directors were concise in terms of expenditure of funds and time. Roger Corman-who directed The Day the World Ended-reports that AIP told him to make 'a prehistoric picture for $\$ 80,000$ in ten days', so Corman made Teenage

64 Strawn 1974, 257

65 Strawn 1974, 260

66 Strawn 1974, 261

67 Strawn 1974, 259 
Caveman, although he shot it as Prehistoric World.68 By 1959 the other companies were making combinations, so AIP ceased making them; instead they imported Italian-made films, and successfully marketed those. For example, Goliath cost AIP some $\$ 20,000$, and grossed $\$ 1.8$ million.

AIP capitalised on the 'states' rights' franchise holders for distribution of their films. Accordingly, claimed Arkoff, they had subdistribution offices wherever the majors had one. AIP subsequently took over these distribution offices.

A second string to AIP's marketing was to not differentiate between hardtops and drive-ins. Unlike the major studios, AIP distributed to drive-ins and hardtops at the same time, and this strategy was consistent with the targeting of youth, and the 'exploitation' aspect of the films. Referring to the somewhat ephemeral popularity of AIP films, Arkoff explained that the film needed to be released in as many theatres as possible, as soon as possible. The strategy was linked to the nature of the films: 'You go in, you get your money, and you get out.' 69 Thus there was no differentiation between hard-tops and drive-ins, and very often the drive-ins provided greater returns.

United Artists and American International used science fiction as a successful strategy in making a profit in an industry where the rules had changed and where a new market was exerting its influence. Apart from On the Beach and Amazing Colossal Man, the films are not generally remembered as anything other than cheaply made films, that, like all films, were produced to make money, in many cases through attracting an audience of young people. The attendance of this group at drive-ins was noted and acted on through recognising the claims of these venues for newly-released material. Science fiction was, for whatever reason, one of the genres that this audience appreciated, as it was a genre where teenagers could in fact be recognised as contributing to the narrative in a way that they could not in other genres that were based substantially on an historical discourse that did not include teenagers, such as the western, the musical, the sword-and-sandal epics that were one response of the

68 Ed Naha 1984 'Cautionary fables: an interview with Roger Corman' in Danny Peary (ed) Omni's screen flights, screen fantasies New York: Doubleday, 233

69 Strawn 1974, 262 
industry to the changed environment. The other successful genre that did include teenagers as the focus of the narrative was the beach party films. It was not until the musical was woven with teenagers and their rebellious interests in West Side Story (1961) that the musical genre again enjoyed some success. Science fiction could be made cheaply (and in some cases with reasonable production qualities) and shown in an environment where the screening did not need to be as clear as in a hardtop, given the nature of the technology that produced the image. The screen was further away from most of the audience than it would be in a hardtop, and the lack of definition produced by the distance of the camera from the screen, the power of the light source, and the large screen concealed the poor quality of many films and their special effects.

So while these two corporations made films where the special effects remains eye-opening to a contemporary audience for its lack of realism, or the lack of ability to suspend disbelief, other corporations realised that good special effects were essential to attracting an audience away from television and to the established indoor theatres. The contributions of George Pal and Ray Harryhausen in this field are equal to that of George Lucas in the 70s and the work of corporate special effects laboratories like Industrial Light and Magic.

\section{Special effects artists: George Pal and Ray Harryhausen}

As I've suggested in chapter one, special effects assumed the mantle of star in science fiction films of the fifties, and the attention paid to effects was in part a response by the industry to both the declining cinema audience and the emerging audience of teenagers and their younger siblings. The technology of the cinema was further developing so that special effects could create realism in a flying saucer or a recently awakened dinosaur, or the effects of space flight and landing on the moon. Two of the most significant technician-craftsmen were George Pal and Ray Harryhausen.

\section{George Pal}

George Pal was born in Hungary in 1908, moved to Paris in 1934 and made stop-motion cigarette advertisements that made him famous and in demand.70

70 John Brosnan 1974 Movie magic: the story of special effects in the cinema London: Macdonald, 184187 
He continued his work in Holland but moved to New York in 1939 in the face of the threat of a Nazi Europe. Contacted by the president of Paramount, Pal signed up and the studio set up George Pal Productions, a workshop of some 20 artists and woodworkers, who made short animated films-such as the Jasper series-comprising up to 30,000 single-frame shots, 9,000 hand carved wooden figures and some 45 days shooting time. The models required 24 changes of facial expression for each second of action. These short films were too expensive to continue. After working on The Great Rupert with Irving Pichel, Eagle Lion financed Pal to make Destination Moon, again with Pichel.

Working with Robert Heinlein as technical adviser (the film was based on his short story Rocketship Galileo), Pal and Pichel created a film that was not essentially a science fiction film; science fact would be a more appropriate term as the film was as scientifically accurate as possible, as 'real' as possible. Other production members were rocket expert Hermann Oberth, astronomical artist Chesley Bonestell, Lee Zavitz in charge of mechanical effects, and John Abbott directing animation. $71 \mathrm{~A}$ full-scale, 150 foot rocket was prefabricated and then erected in the Mohave desert with the familiar-to those who have watched rocket launches on television-crane and associated structure. But the realism ends there. The scenes of the lift-off are animated. Prefiguring the star status of special effects, Brosnan reports that the five minutes of animation took longer to film that the eighty-five minutes of live action.

The film aimed to be scientifically accurate, and so the astronauts, lying horizontally, experience the g-forces of rapid acceleration and their faces distort, a little like a jowelled dog hanging its head out the window of a speeding car.72 To achieve this effect, the make-up person glued a thin membrane to the face of each astronaut. These membranes were attached to levers behind the actors, allowing the membrane to be stretched, distorting the actors' faces. Rapid acceleration was simulated when the actors sank back into the cushions they were lying on. These cushions were inflated rubber bags, deflated rapidly to simulate the effects of acceleration. The problem lay in the sound of the deflation, reportedly very unspaceship-like, and the film had to be dubbed later. This single illustration attests to the convergence of fact and fiction discussed in the

71 This encapsulated narrative on the making of Destination Moon is from Brosnan 1974, 188-190.

72 This is the illustration mentioned in chapter 2, page 70, from Logan 1953, 32 
previous chapter, and also evinces the function of special effects to create a reality, that was, in this case, real enough to be used as an illustration in a 'factual' text.

Many scenes were shot in the control room, but from many angles.

Heinlein, once an engineer and a stickler for realism, insisted that the room be as realistic as possible. So that camera shots could be made from the various angles with the necessary set, the control room was built in such a way that every part could be removed to make way for the camera. The set was made of steel, and in order to film what appeared to be a person floating the set had to be tilted on its side. A rig three storeys high solved this problem, with a platform around the control room and a camera on a giant boom.

During the flight to the moon an astronaut on the first space walk becomes detached from the ship, and is rescued by another crew member using an oxygen bottle to provide propulsion. Another two men were attached to the side of the spaceship with magnetic shoes. All events had to be shown in conditions representing weightlessness, and so there were many wires and safety lines, all of which had to kept invisible. The enterprise was immense:

Once again the actors had a hard time of it, often suspended for up to two hours on their wires just to get two seconds of completed films. Each man was attached to an overhead travelling crane and was guided by several men who acted as 'puppeteers', manipulating giant cradles of the type used to manipulate marionettes, only these were made out of heavy welded pipe frames. 73

But this was not all. The space suits were designed for visual accuracy, not creature comforts, and in the hot studio the situation was 'roughly equivalent to doing heavy work at noon in desert summer, in a fur coat while wearing a bucket over your head'.74 The effort, then was both immense and resembles the similar effort made in such films as Terminator 2, where film crew allegedly spent some 9 hours making scenes of a few seconds.

Destination Moon broke new ground in its attention to special effects, but with some apprehension on the part of its backers for their commitment. However, the film was a great success, causing the largest studio, Paramount, to immediately contract $\mathrm{Pal}$ to begin another science fiction film, When Worlds Collide. The special effects now had the financial resources of Paramount, and the

73 Brosnan 1974, 189

74 Brosnan 1974, 189 
technical expertise of Gordon Jennings resulting in what Brosnan calls a 'tour de force of special effects'. As today, special effects swallowed money: in Pal's next film, War of the Worlds, $\$ 1,400,000$ went to special effects and $\$ 600,000$ went to the live action. Similarly, people-action required less time to film: the special effects required six months to film; the actors only forty days. 75 And, claims Brosnan, these resources energised special effects enough for it to jump from the status of star to that of superstar, a claim made initially by Variety's reviewer, who labelled When Worlds Collide a 'socko science fiction thriller' for its ability to convince:

Just as listeners willingly mesmerized themselves into being scared half-todeath by the broadcast [Welles production of War of the Worlds], so will viewers take vicarious pleasure in the terror loosed in the film.76

That terror was created by the special effects team:

Into this setup, the special effects group headed by Gordon Jennings loosens a reign of screen terror, of futile defense, demolished cities, charred landscapes and people burned to ashes by the invaders' weapons.77

The reviewer recognised that special effects had assumed the mantle of star: the film wisely uses no established marquee names to detract from the feeling that what is being seen is real. Instead, what starring honors there are go strictly to the special effects, which create an atmosphere of soul-chilling apprehension so effectively audiences will actually take alarm at the danger posed in the picture. 78

\section{Ray Harryhausen}

The second of the special effects artists was Ray Harryhausen.79 In contrast to Pal, Harryhausen was born in the US, in Los Angeles in 1920. As a child he saw King Kong (1933) and was later to be assisted in his career by that film's special effects artist, Willis $O^{\prime} B$ rien to whom he was introduced as a teenager through a chance meeting with O'Brien's niece. He learned the art of stop-motion animation while at school, followed by two years of work with George Pal on the animation of a series of puppetoons. At the outbreak of World War 2 he joined the Army Motion Picture Unit but his real break in films came when Willis O'Brien asked him to assist with the animation in Mighty Joe Young (1949), a film

75 Brosnan 1974, 190,191

76 Variety Film Review 4 Mar 1953

77 VFR 4 Mar 1953

78 VFR 4 Mar 1953

79 Jim Rodkey 1997 Ray Harryhausen http://www3.leba.net/jrodkey/harryhausen/harryhis.html (accessed 4/2/98) 
that celebrated the achievements of stop motion animation and, because it was commercially successful, opened further opportunities for Harryhausen in science fiction where fifties audiences wanted to be thrilled by the convergence of science fiction and science fact.

Harryhausen's first film of the fifties was The Beast From 20,000 Fathoms, which was based on a short story by Harryhausen's friend, Ray Bradbury, called The fog. The potential producers were interested in Harryhausen's drawings of the beast destroying a lighthouse although that particular scene was only a brief sequence in the final film. The film's budget was very low and Harryhausen 'found it an interesting challenge to try to find new ways and less expensive ways of achieving a spectacular pictorial effect'. 80 He developed a simplified technique of combining animated models with live backgrounds. The meagre production cost of $\$ 200,000$ reflected the belief in its ability to make money, for it was up against 3-D, wide screen and Cinemascope. Nevertheless Warner Bros bought it and released it in 'glorious Sepia Tone' and it unexpectedly made huge profits, while helping to establish science fiction films as a possible revenue source for little cost at a time of substantial shifting of the ground of filmmaking.

Subsequently Harryhausen met Charles $\mathrm{H}$ Schneer who suggested a film about a giant octopus that rises out of the Pacific and threatens to destroy San Francisco, an idea that was realised in It Came From Beneath the Sea. Production costs determined that the octopus have only six tentacles. Harryhausen explains:

By necessity, we had to work on a rather tight budget and no matter how ridiculous it may sound, two tentacles less to build and animate during the long process of stop-motion photography, among other compromises, did save quite a bit of time. And in Hollywood, time is money. I sometime wonder if the budget had been cut anymore if [sic] we might not have ended up with an undulating tripod for the star villain of the picture. 81

Problems were not just those associated with special effects; the city of San Francisco did not approve the use of the Golden Gate Bridge as they thought it might undermine public confidence in the integrity of the structure. Because filming was already underway the project could not be abandoned so stock and newsreel footage was used for full shots of the bridge.

In association with Charles Schneer again, he worked on Earth Versus the Flying Saucers. The challenge for Harryhausen was to make interesting an

80 Ray Harryhausen 1974 Film fantasy scrapbook London: Tantivy, 33

81 Harryhausen 1974, 37 
inanimate object such as a rounded metal spaceship, using stop-motion photography. Another challenge was to create the disintegration of falling buildings resulting from the alien death ray, where each shot required the movement of bricks suspended by invisible wires. Production costs barred the use of high speed photography even though this process would have been more effective than stop-motion photography. A further challenge was to keep the film narrative within the bounds of possibility, so Harryhausen had the topic carefully researched so that this particular event was similar to reported sightings and therefore within the bounds of credibility, once again evincing the convergence between fact and fiction. The scenes of destruction to Washington DC were used again in a later film The Giant Claw, and here they stand out in stark contrast to the fairly appalling special effects of the rest of the film and therefore stand as a testament to the ability of Harryhausen.

In these three films the narrative includes and is in some way dependent on the destruction of famous US landmarks. In Beast the octopus attempts to destroy Coney Island, in It Came From... the targets of destruction include the Golden Gate Bridge in San Francisco, and in Earth Versus the icons of Washington are destroyed. One reading would be that the monster/aliens represent a threat to the American way of life for which these icons are metonyms, but this is not the place for such discussions.

In 1956 Harryhausen and O'Brien contributed a dinosaur sequence, that took eight weeks to produce, to The Animal World. Here Harryhausen used dinosaur models cast from moulds instead of a technique where each muscle was built up over a metal armature and then covered with a properly textured skin. The mould process was cheaper, but did not produce the same realism as the build-up technique. The next monster animated by Harryhausen was Ymir, a creature from Venus. Harryhausen's generated the idea for the story in the early 50s when he wanted to holiday in Europe. He set the story in Europe, and it began with a secret US mission to Venus, which returned with a specimen of a life form from that planet, named Ymir. Twenty Million Miles to Earth was finally produced-by Charles Schneer-in 1957 and the icons of possible destruction are those associated with Rome: the Colosseum, the Roman Forum, the Temple of Saturn and the Tiber River, and these once again enhance the impact of the film narrative. Harryhausen then moved on to fantasy films to continue his career in 
stop-motion photography with films such as The Golden Voyage of Sinbad (1974).

Both Pal and Harryhausen were artists in a genre that allowed them to develop their abilities, and conversely, were artists who developed the contemporary parameters of a genre they helped create through those abilities. By their ability to transmogrify the unreal into the real they created the essential element of science fiction: to establish the realism of a discourse that verged on the ludicrous and constantly flirted with the danger of failure through an inability to convince an audience of the realism of the narrative. Unlike the writer of a novel who created the conditions for the willing suspension of disbelief through the juxtaposition of words, Pal and Harryhausen created a set of images that, when played in a projector, created those same conditions. The corporations were interested in Pal and Harryhausen's abilities for their proven success at the box office and were thus happy to fund films where these abilities were further developed and exploited.

Science fiction films, then, are just as much a product of an industrial context as they are of other contexts. While the dominant metaphor of the social context of the fifties is one of stability and conformity-although the subtext of the fifties is a subversion of this image-the metaphor of the industrial context is one of significant fissuring in the fabric of production, distribution and exhibition. Science fiction film was in part an attempt to play in a football field where the goalposts had not only been changed, but the code was different. By the end of the decade, the studio system had been demolished, the television set had firmly ensconced itself in the corner of the family room where it both challenged the dominance of film as screen entertainment and provided a new market for old films and made-for-television films, new film makers developed new films for a new audience of teenagers, drive-ins provided a sometimes ignored market for film, and films continued to develop new technologies that would allow for the representation of the unreal as real on screen. Coupled with the social and historical contexts, these threads explain in part the emergence, concerns and narrative structure of science fiction films of the fifties. The thesis turns now to examine in more detail the part paid by science and scientists in these films. 


\section{PART II}

\section{SCIENCE AND}

\section{SCIENTISTS}




\section{Four}

\section{The (liberating) nature}

\section{and (rhetorical) function}

\section{of science}

Every social order in some sense seeks the assent of those it rules, and this assent to the governing power is what legitimates its rule. Two factors are involved here, then: the claim to legitimacy by the ruling authority, and the belief in the order's legitimacy granted by its subjects. ${ }^{1}$

There is absolutely no social criticism, of even the most implicit kind, in science fiction films. No criticism, for example, of the conditions of our society which create the impersonality and dehumanization which science fiction fantasies displace onto the influence of an alien It. Also, the notion of science as a social activity, interlocking with social and political interests, is unacknowledged. Science is simply either adventure (for good or evil) or a technical response to danger. And, typically, when the fear of science is paramount-when science is conceived of as black magic rather than white-the evil has no attribution beyond that of the perverse will of an individual scientist. In science fiction films the antithesis of black magic and white is drawn as a split between technology, which is beneficent, and the errant will of a lone intellectual. 2

Sontag's two claims - that social criticism is absent from science fiction films and that the acknowledgment that science is a social and political activity is also absent-are difficult to support in any careful reading of the science fiction films of the decade. This chapter focuses on the social and political practices that science and the scientist were involved in, and argues that the social nature of science was indeed a powerful rhetorical presence in the films of the decade.

Some films have reasonably obvious and unambiguous codes that articulate the discourse of science within society. Briefly, the criticism in The

1 Paul Ricoeur 1986 Lectures on ideology and utopia New York: Columbia University Press

2 Sontag 1976, 129 
Thing is initially of science uncontrolled by social constraints; social constraints as construed by the military. The mad scientist whom Sontag mentions is represented as requiring social monitoring for the good of humanity and, while useful, science must be under the control of the people as symbolised by the military. Similarly, the 'good' scientist in Creature From The Black Lagoon (1954) constructs an ecological model of science, which was radical for contemporary scientific paradigms and is acceptable to the ecological paradigm of some contemporary science. 3 In The Fly science is warned not to research those areas that are considered socially to be inviolable. There is a criticism of the 'bad' aspects of science in some of these films, nowhere more so than in the films about nuclear war, beginning with Five in 1951 and ending with On The Beach in 1959. Whether debated explicitly as in On The Beach or not, films with this theme are inherently social commentaries on the social practice of science.

Yet most science fiction films of the fifties are composites of rhetorical codes that educate, argue and persuade; in short, that foreground science as a social practice. Some films educate an audience about some scientific principle and that principle is then used as the launch pad to extrapolation. Educative elements of the films are persuasive as well, arguing for or against a particular paradigm of science that is the foundation for the science of the film. This chapter examines those pedagogical and persuasive functions of science fiction films arguing that these functions are a significant feature of the genre, 4 as is the nature of science as a social institution. While the science represented in these films is not assumed to be a direct reflection of the reality of the day it is possible to see that the representations of science are woven from social and scientific threads that comprise the fifties world in the USA. In this world, science can be either liberating or uncontrolled, progressive or dangerous, filled with potential for good as for evil. Science will lead to a new utopia or to a dystopia of catastrophic consequences. The debate is whether the social institution of science-in the plurality of representations exhibited in fifties science fiction

3 The term paradigm is used in two ways. It's used in the Kuhnian sense mentioned in chapter one, indicating one of a number of ways of seeing the world, and suggesting the kind of scientific questions that should be asked and the work that should be done within appropriate scientific theories. Second, in a very general sense, science is itself a paradigm, contrasted with other non-scientific paradigms.

4 Indeed, not only of fifties science fiction. A scene in Jurassic Park, where the visiting scientists as well as the audience were shown an instructional film on the way that DNA could be carried through millennia, was important to setting up the credibility of the science of the film. 
films - should gain the approval of those it rules (in Ricoeur's terms) through claiming legitimacy as a useful and powerful knowledge and practice.

While a function of science fiction films is to educate, the function of the science within some films is to liberate. Just as the discipline of science aimed to liberate from the web of superstition and irrational beliefs, so too the function of science within science fiction was to liberate people from those same clinging threads of tradition and irrationality. The topical issue where this liberating effect is most in view is in the position and status of women, and the potential for science to liberate them from the traditions and beliefs about the suburban mother figure that were cast as the norm in the fifties in various media modes such as magazines and television sitcoms. At the same time the seeming paradox of such a position is clear: while science is represented as cold, hard, rational and logical, it also acts to liberate women from a stereotype where they are represented as something other than human, into a state where, through training in a rational discipline, they become more human. I will return to this issue, but first I would like to discuss general issues of science practice.

Sontag's dismissal of the possibility that science is anything other than adventure or a technical response to danger is only one of a number of readings. The science that is constructed is not ideologically coherent across the genre; the films exhibit a range of positions from Sontag's technicist, adventure-oriented, Faustian individualist scientist to that of science as politically and socially concerned, liberal and democratic, with science as one institution in a unified culture. While these two extremes are here posited as either end of a linear spectrum, a more suitable metaphor is that of a web, or a rhizome, with representations of science occupying one or more nodes (as the representation of science is not necessarily consistent in any one film) on the web or the rhizome, and linking into other institutions that form other nodes, such as the military, government, tertiary institutions, business, the individual citizen. These nodes connect with other nodes joining in ways that are not easily catalogued as simply a linear spectrum. The films of the decade represent and construct science as being both 'good' and 'evil', occasionally within the same film but more often focusing on one or another of these judgments about science, and further, the relationship between science and nature. Either science is a 'natural' exploration 
of the universe and is therefore essentially benign in its control of that universe through such knowledge, or science crosses the boundary of natural taboos to discover information that is essentially 'unnatural', harmful and therefore dangerous. One question then, is whether science does have boundaries, and if so, where are those boundaries and by whom are they established.

A further question relates to the social implications of scientific activity; that is, whether science has any social effects and, if so, what those social effects are. This question is intimately associated with the question of the nature of science itself, for if science is a discipline of change, for example, then its social effects are likely to involve change as well. This question is significant for this chapter because of Sontag's claim that science in science fiction is not contextualised as a social practice.

Before examining in detail the close dependency of the notions of science and change, I would like to address a question of methodology in choosing films, that derives from the idea that change and science are closely related. In discussing films and historical periods, examining generalities in certain thematic or narratival features common across films is not unusual. But in the consideration of change in a social context it is reasonable to examine single films where instances exemplifying change or arguing for a different social or other context are represented. In the corpus of films of the genre there may be only a few that exhibit such representations because the nature of change is that it is different from the status quo. To define such appearances as aberrations in favour of generalising about features common to all films is undoubtedly a reasonable methodology in the discussion of films whose genre is not embedded in social or other change; however, in this instance, where the representation of change only occurs in a minority of films-it has to, or it would not be describing change-the flagging of particular, and perhaps unique films, is the only possible methodology.

I have mentioned in chapter one that the examination of change is one concern of the genre of science fiction in the period under examination. Extrapolation on contemporary trends and discoveries in social, scientific and other areas of human activity has been a feature of science fiction since the golden age of pulp science fiction in the 30 s and 40 s. Thus the appearance of certain themes and arguments in only a few science fiction films is legitimate 
reason to discuss those themes and arguments further. For example the thesis that the role of women was anchored to suburban homes, with the attendant threads associated with suburbia, becomes increasingly problematic, and this change figures in the themes and narratives of science fiction films. It is the role of women and the changing nature of that role that is not only argued in science fiction films, but is attributed to the nature of science; the rationality of science, which challenges taken-for-granted traditions, questions such things as traditional roles of women (although traditional here means in the last century, since the roles of women have been as fluid as any other social domain).

At this point it is useful to restate the notion that science in science fiction films has-as well as a nature-a function, closely associated with its nature. 'At this point' because I have suggested above that a particular role is 'argued' in science fiction film on the basis of the science, and it is this argument that is a function of science. Briefly, the function of science in some films is to suggest a particular case, to legitimate itself perhaps; for instance, films function to persuade to particular positions through scientific argument, or at least, pseudoscientific argument. This argument is scientific in its logic: an observation is made that challenges prior knowledge, further observations are made, followed by challenges to the previously held paradigm and new formations are then constructed along the lines of the new paradigm. This is the general sense of the claim that science fiction films argue and persuade, and it is developed further in this chapter. It is closely entwined with a discussion of the nature of science.5

\section{The liberating nature of science}

It is germane to the argument to summarise some of the threads describing the fifties that are made in chapter two, before examining the social implications of the nature of science as it applies to certain social practices and to women. On one level the fifties was a time of staid conformity and suburban consensus, but on another level the cultural dissonance was cracking that façade of social harmony and peace. The practices of marriage and divorce were in a state of flux; whilst other orders of change resulted from the achievement of the goal of

5 The beauty of hypertext is that a link could be provided here to a discussion of the function of science for those people who wished to read that section before returning here. The linearity of argument in both oral and written modes-and the particular rationality that is labelled as scientific-tends to suggest that one thing always follows another. However, hypertext allows for non-linear modes of argument. 
full employment, a new mobility discovered through increased access to the automobile, flourishing suburbs and associated consumer icons such as the fast food outlet, the drive-in and the integrated shopping centre. The conformity that marks the fifties in social behaviour masks the quite profound transformation occurring in the structure of people's lives, and this shift is indicated by a discourse about change emerging in cultural products. Science fiction is one stage - or to be more in keeping with the filmic thrust of this thesis, one 'set'-where this change is discussed.

The role and position of women and their representation in film is a useful thread to continue the investigation into the relation of science to social change. In relation to the changing representation of women, amongst others, chapter one examines the alternate social structures in the work of Robert Heinlein, Isaac Asimov and in the corpus of science fiction where extrapolation on current social trends occurs. While those references are to novels, the film Project Moonbase, based on Heinlein's work, features a woman president of the USA in the year 1970, as well as a woman leader of a space expedition, which

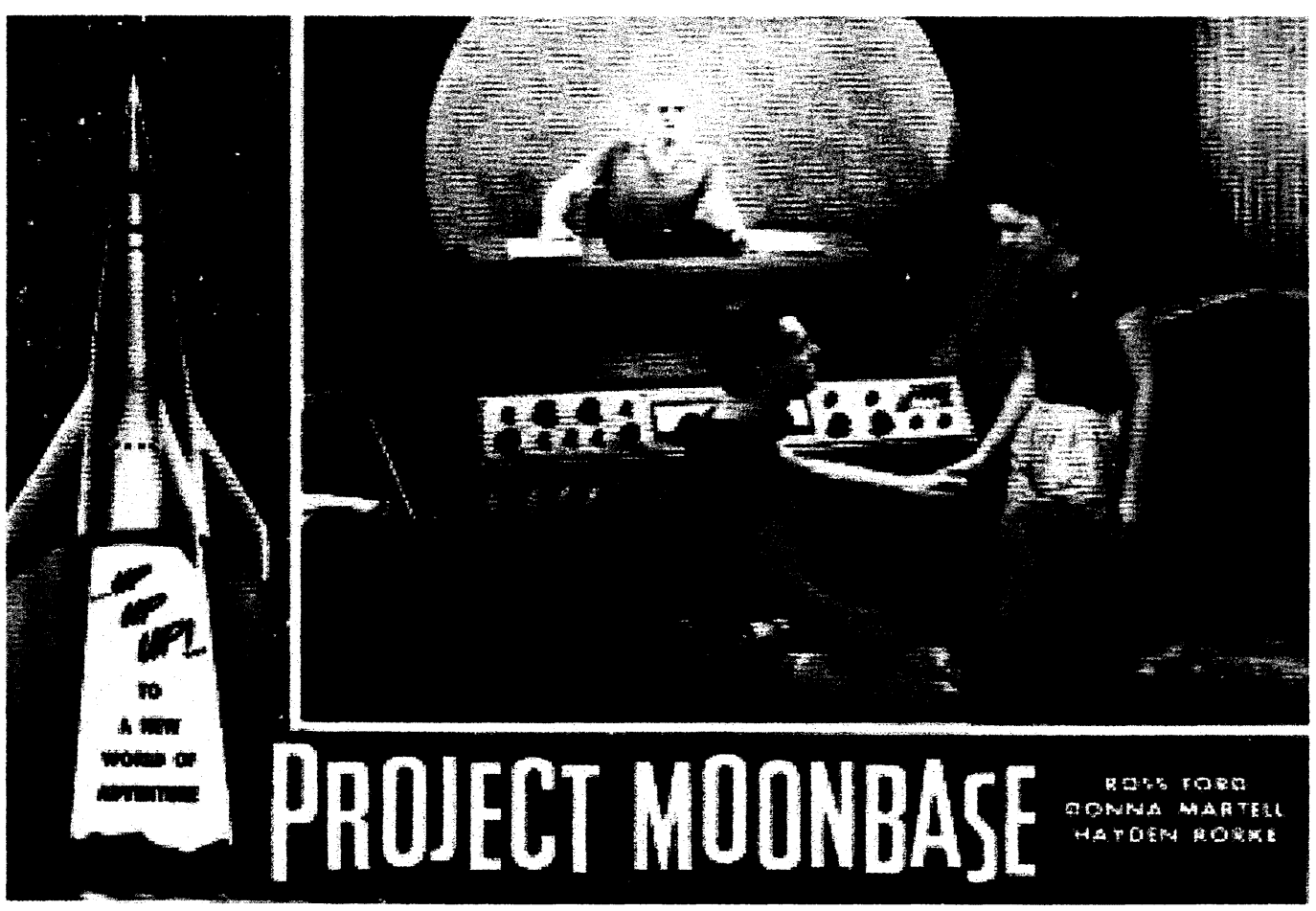

Figure 5: Project Moonbase postulated one woman as mission commander and another as President of the US. 
stands in sharp contrast to the images of women with strollers lining up outside the latest drive-in suburban shopping complex. This is not to suggest that fifties science fiction films always argue for change.

Some films express an anxiety about change, or about the rate at which it is taking place. Some films are decidedly conservative, proposing a traditional view of marriage and family for example, as well as establishing a context for the control of science by the military. The Thing weaves a status quo of home and hearth, of traditional values and practices, against which are contrasted both the excesses of science, and the scientist who vocalises sentiments that challenge that status quo. In this instance the status quo finally vanquishes radical science. The scientist's practices, and challenges to the status quo, derive from a paradigm of 'pure' science, resulting in the belief in the value of alien life forms, and the overriding imperative of the quest for knowledge. Yet the social practices that are defended by the airmen are those of marriage, family, individual action, distrust of the state, and similar social positions. What is unstated in the film, yet acknowledged implicitly through that unstated position, is the link between science and change. The protagonists in The Thing are airmen whose motivating principle is that science is out of control and, while useful in some respects, needs to be tightly controlled. Science is the agent of change in social dimensions, and it is change that needs to be tightly reined. Thus the position of the film vis-a-vis science is analogous to its position vis-a-vis change.

By contrast, in Earth Versus the Flying Saucers, elements of the canon with regard to the character of scientists are constructed in the opening scenes of the film through argument and the dialectic of difference. The character Carol expresses certain opinions, which, she clearly indicates, are the values of the status quo regarding marriage and the position of women. We then see the antithesis of that belief. Carol is driving the car with her husband of a few hours. He suddenly puts away the tape recorder he was using to make notes-it's the size of a suitcase - and proceeds to neck with her while she is driving. She articulates the belief that scientists are unpractised in the art of romance.

Carol (jokingly) Now that we're married Doctor Marvin you don't have to sneak up on me.

Russell You always did have eyes at the back of your head.

C Besides it's not safe when you're driving. I thought intellectual giants were supposed to be backwards and shy. 
$\mathrm{R} \quad$ My very great teacher Miss Hickey said I was a quick study.

C You're starting something you're not going to be able to finish.

Less ostensibly, Carol suggests a different approach to and practice of marriage through what is seen but not voiced. The new-found mobility and freedom that is signified by the car she is driving in the opening scenes has already impacted on the tradition of marriage. 'Dr and Mrs Marvin'-Carol's radicalism is limited-are returning from their secret marriage in the city. No one was invited to the marriage and her family-her mother is absent from the film-was not informed. Indeed, in a later scene when she tells her father they are married he is not shocked or nonplussed; he celebrates the marriage with a hamburger at the Marvin's house. This construction of the institution of marriage is offered as legitimate, and normal in this context. The fact that her husband is a scientist at a secret high-level defence facility partly evinces the argument that science is the handmaiden of social change.

What is not normal is the disjuncture with the notion of marriage as it is evoked in the 50s Dreamtime. Contrary to that dreaming there are here no glory boxes, no beautiful gowns or crying mothers, and so on. The construction of marriage in the middle class sense that the doxa requires is not legitimated here. This marriage is not the orthodox rite of passage into complete womanhood nor is there any suggestion that the purpose of marriage is procreation. And this position, while not radical, was the focus of stormy debate ushered in by a science that is harnessed to social change. While the stance of the Catholic Church was (and still is) that marriage is for procreation, women such as Kate McCormick and Margaret Sanger in the fifties promoted the view, amongst other related views, that the human sex drive should be separated from reproductive functions. Throughout the fifties, McCormick funded the scientific work of Goody Pincus and M C Chang, in their efforts to produce a contraceptive pill that finally became readily available in 1960.6 Other forms of contraception were available, although not as convenient. The importance of the disarticulation of procreation from the sex drive cannot be underestimated; it underpins the change in the lifestyles, expectations and roles of, initially, women, but also in the nineties, men.

I will continue to focus on women in these films to illustrate elements of

6 Halberstam 1993, 282-294, 599-606 
cultural change and the role of science in this change. The first point to note is that the role and position of women is a significant and explicit theme and argument of some science fiction films. In Earth versus the Flying Saucers Carol is the wife of the scientist but she is not a scientist herself. The change that is argued for in the film does not go so far as to include the construction of women in positions that are powerful in the constructed world and power relationships of the film. This is not to say that Carol is powerless-far from it-but in the world of that film Doctor Marvin is powerful in that he is influential within the institutions of science and the military, as well as within the film's narrative.

\section{Change through tertiary education}

The power and influence that women wield in some films is directly proportional to their educational achievements; that is, this selected group attained their power from education, an education that was powerful partly because it was associated with science. The distinction between the medieval world and the Renaissance is in part the focus on science as embodied, perhaps, in the person of Michelangelo. Because of the shift away from the superstitions of the medieval world, education was seen to be the key to liberation from those very superstitions into a world of understanding and appreciation of observable fact. It was fact that the earth revolved around the sun and this fact could only be shown by scientific observation and reasoning. This 'method' overturned the superstition of earlier paradigms that were built on the older legend that the sun revolved around the earth, and largely this new understanding was achieved through an education where older stories of legend could be challenged. In this enlightenment, the challenging of traditional views and practices was a farreaching effect of the scientific paradigm. The ability to understand science and the knowledge such science revealed was esteemed in some circles. In some films of the fifties science and education in general were a key to a different-more powerful, more influential, more fulfilling-life.

The representation of woman as housewife is generally absent from science fiction films. There are exceptions of course but they only highlight the general. Yet even the exceptions do not follow the expected fifties stereotype: the lead woman in I Married a Monster From Outer Space is anything but powerless, even though she is, or she wants to be, a traditional wife and, she hopes, a sexual partner to her husband and thence mother to their children. Her role as both the 
narrator for the film and the character around whom the narrative is woven is unusual for many genres. 7 She is at the same time the agent who forwards the narrative through her decisions and actions. Other films challenge the orthodoxy of women residing in the home, by depicting women in a wider range of roles. Women are tertiary-educated in areas ranging from the less-awesome library science (War of the Worlds) to the relatively influential palaeontology (Beast From 20,000 Fathoms, Them). Women are sometimes constructed as operating outside the boundaries of the known and explicable and are applauded for this inexplicable ability: in The Crawling Eye women are constructed as psychic, baffling a group of men scientists who are convinced by the demonstration of the paranormal even though they are unable to explain the phenomenon.

Education is a bulwark against the transformation of the human into the simulacrum, as a bulwark against a mindless, soulless and passionless existence where minds would be easily controlled and feeling and human emotion would be both unknown and irrelevant. Early in Invasion of the Body Snatchers Dr Miles Bennell and Becky reminisce about their college days and remember that they could have become 'involved' at that time, but Becky did not want to do that as they would not have completed their education. Immediately they greet the policeman who did drop out of college to get married. He is one of the first to be absorbed into a pod being, and distributes the pods and leads the pursuit of Miles and Becky. The inference is that education will ensure a degree of resistance to the absorption of the human; education is inherent in the definition of the human.

A science education and a scientific practice are not the preserve of men. While women do not take the lead but rather are the 'love interest' of men, they are at the same time often scientists in their own right. (The common element of these films is the love relationship. Indeed the establishment of the tension that involves the imperative to establish some kind of relationship between male and female is a feature of many films, closing with the resolution of this love relationship. A notable exception to this generality is It Came From Beneath the Sea.) Kay is a marine scientist in Creature From the Black Lagoon, although she does not practice science in the film. Anne Lansing is a research assistant in Hideous Sun Demon. These women require some science education to legitimate their

7 One exception is the romance. 
appearance in the geographical or narratival locations of the films. Thus their science education may be simply to allow for the imperative of the narrative that requires the 'love interest'. Nevertheless their science education and training challenges the status quo of women who learn homecraft and needlework and leave 'real' education to men.

Such films construct science as a liberating and broadening discipline in the enlightenment tradition and in that tradition scientific knowledge is valued by society. To learn about science is to acquire a socially valued knowledge that increases mobility and opens doors that would not otherwise have been opened. The liberation that science effects is a liberation from all kinds of social conditioning that do not allow one to realise one's potential. From her perspective as a scientist Doctor Patricia Medford, in the classic Them, argues for change. How she is different from other representations of women is significant as the representation of this difference occupies significant narrative space in the film. It is useful to outline the episodes in the film to establish the extent to which the issue permeates the film and to follow the construction of the argument that defines the status quo and then argues against it.

FBI agent Robert Graham is perplexed about how to address Dr Patricia Medford, alternating between "Miss" and "Doctor" and exhibiting elements of self-consciousness about this. Seeing his lack of ease she tells him to call her Pat. Her education is superior to his and she speaks a language he does not understand; for example, when she is telling him about the ants' life cycle he cannot understand her and says, "Why don't we all talk English. Then we'd have some basis for understanding". Her grasp and use of practical technology is superior to her scientist father's and is constructed in a series of shots of him and her in different aeroplanes talking on the radio. He is supremely incompetent in both physically handling the radio and the radio protocols that are used, while her ease and competence are all the more significant for their juxtaposition with his. In what might be considered to be a condescending manner were the roles reversed, she makes allowance for his lack of expertise. A further consideration that I will not pursue at this time is that this scene highlights the competence and understanding of youth over age.

However Pat is not only competent in the relatively simple technology of the radio, she is also a competent leader in dangerous situations. She leads the 
two men into the female ant's lair to determine if all the giant ant eggs have been destroyed. While men still carry the weapons and do the fighting, she commands authoritatively, in a scene that is quite startlingly similar to that of Aliens (1986) of decades later when Ripley leads some men into the nest chamber of the mother alien. The significance of this scene is not only in Pat's leadership of the men but in the way that the lead was narratively and filmically won by her. The struggle between the new and the old paradigms, with science education as the agent for transition from the new to the old, is clear in the following dialogue:

Graham What are you made up for?

Dr Pat I'm going with you and Ben.

G Oh no you're not.

P Listen Bob. Someone with scientific knowledge has to go. My father's physically unable to do it. That leaves me.

G That leaves you here. Now look. We don't know what we're going to find down there or what'll happen. But one thing's for sure. It's no place for you or any other woman.

But being a woman no longer makes any difference. Graham takes the position that embodies historical and masonic ideals of chivalry, an ideal that was generally uncontested by men and women in WW2. However, Pat is different in that she operates from an authority derived from knowledge. Her power does not lie in the domain of a stereotypical conception of the female, but in the domain of knowledge, and a certain form of knowledge, that is, scientific knowledge. The scene continues with her father siding with her against Graham and using as justification her status as scientist:

Dr Harold I didn't ask her to go, Robert. She wanted to. And being a scientist myself, I couldn't very well forbid her.

P A trained observer has to go into the nest.

G What for?

P There are more important things to find out than whether all the ants are dead. You wouldn't know what to look for.

Bob Well, you tell us what to look for....

Pat (volume has been rising. She cuts him off, is almost yelling.) Look Bob. There's no time to give you a fast course in insect pathology. So let's stop the talk and get on with it.

Bob OK, OK.

The scene opens in what might be regarded as a traditional way for such scenes with the man telling the woman she cannot accompany them on a dangerous mission. Unlike what might be regarded as the stereotype, she does not want to be by their side to give them strength nor look after them if they are 


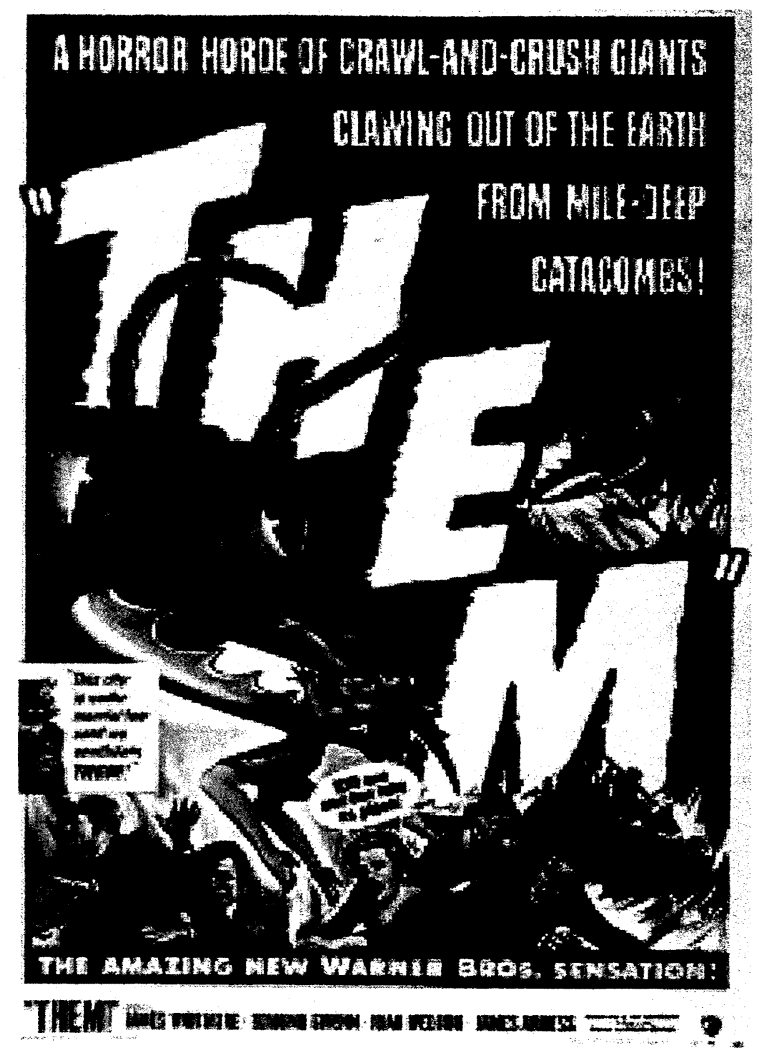

Figure 6: While the film argued an equality of women, the poster was no different from others.

injured but rather it is her scientific knowledge that underpins her claim to go, to lead. Graham bases his rejection of her claim on her gender but she finally takes command in a voice that is authoritative, powerful and not brooking of any further opposition. She undermines and reverses the representation of women as talkers, as opposed to men who act, in her command, "So let's stop the talk and get on with it". (In a later very close copy of this film, The Black Scorpion, the significant departure is that the woman does not want to go down into the nest at all. In all other ways the film is similar, even down to the film-within-a-film about the scorpion being released from, in this case, not amber but lava.)

Science is the fulcrum for change and it significant that the knowledge passes from the father to the daughter. ${ }^{8}$ While as her father Dr Harold might find it necessary to urge her not to accompany the men, as a scientist that would be impossible because science operates on a different set of axioms, namely rational and logical processes that leave little room for emotion or feeling. The liberation implicit in science practice constructs Pat Medford as a character who argues and asserts a position rather than meekly surrendering to a greater power. Similarly, the palaeontologist Lee Hunter in Beast From 20,000 Fathoms wins her position as graduate assistant to Professor Elson on the basis of her practice of scientific argument:

Tom You're fond of Dr Elson aren't you. How did you become his assistant?

8 In the otherwise forgettable Beast With a Million Eyes (1956) the father is again the agent for education. The mother and father argue about allowing the daughter to go to college for her education. The father wants the daughter to go to college believing that an education is important, but the mother does not want her to attend college. 
Lee

I suppose by continually antagonising him. I was one of his students and to hear him tell it all I ever did was to challenge him and argue with him. I was afraid he was going to expel me, but instead, he asked me to be his assistant after I graduated. So I graduated and here I am.

While Them! goes some way to linking education to liberation the narrative largely centres around the activities of men. Not so in the far more complex It Came From Beneath the Sea, where the logic or rationality of science is not divorced from the sexuality of the human. Because of her training in science Professor Lesley Joyce is asked by the navy to research a problem that is 'beyond the scope of navy men', again highlighting the lack of power of the physical to solve the problem and the strength of rational logic and scientific knowledge, where physical power characterises the male and the other is not gender oriented. She is chosen, along with her apparent romantic interest Dr Carter, as the 'best minds of the nation'. Further, Dr Carter states that Professor Joyce is the most authoritative voice there is on the subject under consideration, thereby rejecting any central role for men in the narrative. The claim is repeated and gains in hortatory significance from that repetition, when the submarine commander Matthews enquires of Carter:

Matthews Forgive my ignorance Doctor, but what makes her so unique?

Dr Carter Professor Joyce is head of marine biology at the South-Eastern Institute of Oceanography. I would say that she is the outstanding authority on marine biology.

It is she rather than Dr Carter who solves the scientific puzzle of the nature of the material adhering to the diving plane of the submarine. Here the science has no room for alien notions of love, conquest and machismo that is the operational paradigm for Commander Matthews. Kenneth Tobey is interesting in this role and the intertextual references that are mobilised here. In The Thing Tobey played Captain Hendry, an airman whose purpose was to control the dangerous extravagances of science and to subjugate it to the control of the military, there seen as a metonym for that conservative normalcy comprising family structures with women as powerful, yet certainly not liberated by science. Ironically Tobey now plays a similar part except that feminine science is not only superior to but is also subtly dismissive of his machismo.

Narratively Joyce is a powerful voice. Her science bestows this authority on her and it is not compromised in the structure of the narrative. She takes centre stage in the explanation of the material to the defence commanders who want to know what is happening, and in other forums; she is able on her own 
authority to order a plane to continue research. But her status still needs to be argued both for Matthews and possibly for the film's audience. As in other films like Earth Versus the Flying Saucers the boundaries of the argument are explicitly stated and held up to examination and opposing argument. Dr Carter, Joyce and Matthews argue the situation with Matthews positing the traditional view and Carter arguing the enlightened view. Matthews loses convincingly.

Matthews: Maybe you could help me convince her that she ought to beat it and let the navy deal with the job.

Carter: Beat it! What does she say?

Matthews: What difference is it what she says?

Carter: Look Pete, you don't see too many women in the sea-going navy.

Matthews: Are you kiddin'?

Carter: $\quad$ On shore, sure. But there's a whole new breed who feel they're just as smart, just as creative as men. And they are. They don't like to be overprotected; they don't like to have their initiative taken away from them.

Joyce: $\quad$ A, you want me to miss the opportunity to see this specimen, one that may never come again. B, you'd be making up my mind for me, and C, I not only don't like being pushed around but you underestimate my ability to help in a crisis.

Carter: $\quad$ My sympathies are entirely on her side.

Matthews: It didn't take me very long to lose that argument, did it.

In The Thing, Tobey won the argument against the man scientist who wanted to do exactly as Joyce now does; that is, to examine the specimen. Like the woman in The Thing, Joyce is going to offer a solution, but this time it is a scientific solution rather than one based on cooking expertise. Joyce clearly articulates her position that draws on scientific practice, a position whose purpose is to ensure that she has a chance to scientifically investigate, to ensure that she is not patronised, and to ensure that she is not underestimated.

This science of which Carter and Joyce are functionaries does not imply that scientists are physically inept specimens. The scientists are not the nerds, not the longhairs that marked certain representations of the scientist in the early fifties, a representation that was tracked in chapter two. In It Came From Beneath the Sea, science is robust and physical in two quite interesting ways. Dr Carter is a physically powerful person and is able to rescue Matthews when he gets into difficulty while fighting the monster on the Golden Gate Bridge. The human icons of science and the military are both equal in physical power and when working cooperatively are able to overcome the threat that the monster embodies. Second, Professor Joyce is not a nerd either. Her existence and 
expertise within the paradigms of science do not imply a non-engagement with elements of sexual attraction and eroticism that were generally absent in science fiction films of the decade. A singular scene has her on the beach with Matthews supposedly searching for evidence of the monster. Stepping off a rock into his arms her body slides down over his in slow motion and with a suggestiveness that could be possible only in a film industry that had to consider the Code. Her sexuality is full-blooded, powerful yet never overwhelming. If anything her science enables her to participate in these activities from a position of equality rather than from one of subservience generated from an awe of the knowledge that the man allegedly has. Again the hortatory functioning of these scenes is significant: she is equal to and in some ways superior to the men she mixes with, yet presents no threat to them, but both male and female benefit from a new kind of relationship based on respect rather than on traditional values or, for that matter, based on an ideology of mutual opposition.

The closure of this film is unusual in that the relationship issue is not settled. While the usual Hollywood resolution involves the coming together of man and woman in some kind of climactic harmony, this film does not close with a passionate embrace signifying the final acceptance of togetherness between man and woman. Rather Joyce sides with neither man. She rejects Matthew's suggestion of marriage and family:

Matthews: I mean women can change, move away, get married, have a family.

Joyce: Well there is that possibility but (a), there isn't time for that to happen to me, (b) I can be reached at the school and (c), how would you like to collaborate with me on a book How to catch a Seabee.

Matthews: Say Doctor you know you were right about this new breed of woman.

Joyce seems to speak in this discourse of classification, which might be a function of her science training.

The important element here is that closure does not hinge on the resolution of the sexual tension: she does not get married to either person but continues her scientific work yet is still a sexual being as her final passionate kiss with Matthews attests. In this she subverts the happy ending through marriage that narratively follows from the tension and conflict involved in the process of finding a mate. 
In summary, one representation of science is linked to its potential to cause change, in that the fundamental tenets of the scientific method-observation, reasoning, validation-are liberating agents from superstition and tradition (which are, in part, constructs). Those elements of science will lead to a new relationship between male and female based on an equality of ability and knowledge while retaining sexual attraction. Following the model of Asimov's Dr Susan Calvin-beginning in 1940-as a powerful woman and scientist, it is generally incumbent on such women to give up other feminine pursuits like sexual attraction and procreation, although, in fairness to Asimov, both pursuits are inextricably linked until the fifties. ${ }^{9}$ Science is a powerful tool for innovative change in fifties science fiction films just as it was in the science fiction of the golden age of pulp magazines.

While for various reasons such as production values the films above have status as classics of the genre, other films that are less well known and less well made are significant for their representations of the relationship between science and women. While the quest for knowledge and eternal youth have been related themes of narratives throughout the history of the west they have most often been associated with men. In the history of film men figure in horror films as the pursuers of knowledge and power above all else. A variation on this theme is the subject of The Wasp Woman. Here the woman uses the scientific secrets generated by the foreign (that is, heavily Europeanaccented) old man scientist in her quest for eternal youth. Surprisingly for the time, she is the owner of a very successful cosmetics company and

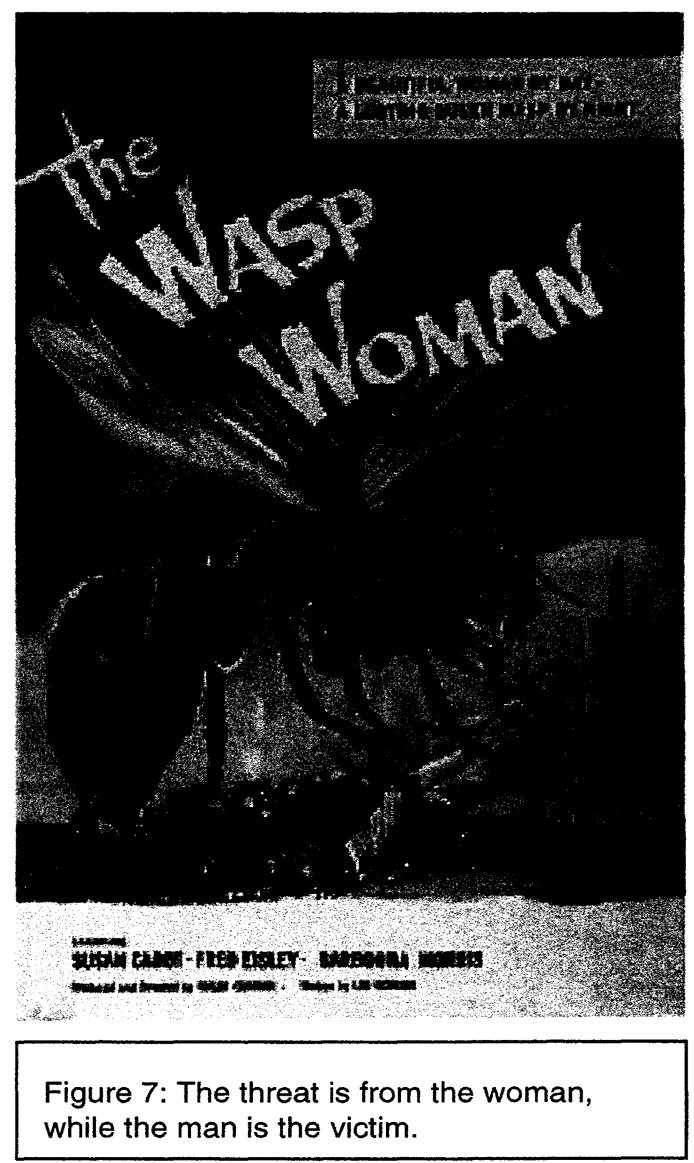

9 Isaac Asimov 1940 'Strange playfellow' Super science stories reprinted as 'Robbie' in I, Robot 1968, St Albans: Panther 
chairs a board of directors comprising equal numbers of men and women. While in many films the man scientist is in search of omniscience or eternal youth and must be destroyed, here the woman searches for eternal youth and the wealth that such a discovery will bring. Like the men scientists before her she tries to subvert the rules of nature by remaining young and so she suffers for her rebellion like many male literary and mythological creations since Prometheus. The film is directed by Roger Corman, who was the leading filmmaker for AIP, suggesting that films that represented changing roles for women are not the preserve of long-established members of the Big Eight.

The British-made Cosmic Monster (1958) introduced the woman into the film as computer scientist Michelle Dupont, who was unwanted by the leader of the research, Dr Laird. Using the standard procedure of introducing the stereotypical belief which is subsequently debunked, 10 the horror of working with a woman scientist is first canvassed:

\begin{tabular}{|c|c|}
\hline \multicolumn{2}{|c|}{ Brigadier Cartwright } \\
\hline Dr Laird & A woman! You must be joking. \\
\hline Graham & He has to be joking. \\
\hline Cart. & $\begin{array}{l}\text { I'm afraid not. There's no-one else available to operate this } \\
\text { computer of yours. }\end{array}$ \\
\hline Laird & A woman. This is preposterous! This is highly skilled work. \\
\hline Cart. & She's very highly qualified, Doctor. \\
\hline Graham & $\begin{array}{l}\text { Yeh, I know the type. Frustrated, angular, spinster, very dedicated } \\
\text { to her calling, without sense of humour, bossy, and infuriatingly } \\
\text { right every time. }\end{array}$ \\
\hline
\end{tabular}

Later, these beliefs as to both her ability and her attitude are shown to be incorrect, and she is able to take her place as a member of the team to which she adds a competence that no-one else has:

Laird You were hopelessly wrong. Miss Dupont is brilliant and not at all bossy. She's not a bit frustrated and I think she's quite goodlooking.

Other films from this selection present scenarios based on the relationship between women and science. Science is the basis for the power that allows the conquest of the universe, and the scientific literacies of other galactic civilisations are a cause for concern in this 'alien invasion' sub-genre of science fiction films. Women are generally absent from this matrix of power but not always: in the two films Astounding She Monster and Devil Girl From Mars single women

10 As described above in Earth Versus the Flying Saucers 
represent the alien power. 11 While the alien in Astounding is basically a messenger from the Master of the Galaxy of Stars about a New Galactic World Order, and as such is noteworthy only through the representation of the alien as female, that in Devil Girl is one representation of an individual in a culture where women have won the gender wars. Her servant, Johnny, is a mechanical man 'improved' through the replacement of his human brain with an electronic brain. Because men lost the gender wars on Mars, explains Nayra, they are falling into physical and mental decline; hence her trip to Earth to collect a few robust specimens. She declines the offer of an old geriatric man scientist in favour of younger, physically attractive men. She is a scientist in a scientific paradigm that the old Prof Hennessey claims is very much in advance of Earth's. The two scientists discuss science, nuclear fission and perpetual motion, highlighting the primitive state of Earth's science when compared with their science. While Cat Women of the Moon and its remake, Missile to the Moon, are not essentially of the invasion sub-genre, the constructed systems are cultures dominated by women who are powerful but are not necessarily scientists.

Other films outside the sub-genre of 'alien invasion' represent women in positions of some power. In Angry Red Planet Dr Iris Ryan is the only undamaged survivor of a pioneering flight to Mars and is also the narrator of the story, a role generally held by men. Like Dr Joyce, she is a biologist and is in love with a nonscientist who is the commander of the flight, and she discovers the scientific problem of the growth attached to the commander's arm. In This Island Earth nuclear scientist Dr Ruth Adams is the equal in both scientific and narrative power of the leading man, Dr Cal Meacham.

In these films as well as those discussed earlier, science is allied with power. Science underpins that power and allows for the development of that power in both a personal sense but also at the level of nation, state and planet. Science is equated with power; scientific knowledge is the knowledge of power; those with that scientific knowledge are powerful. Equally interesting here though are those films where women are not empowered by science.

\section{Science as dangerous change: The conservative paradigm}

In this group of films not only are women not empowered by science but

11 Conspiracy theorists would find the reference interesting for another reason, in that it links a 'New World Order' to an alien invasion. 
the significant women are antagonistic to the power that science represents and manifests. These films and the paradigms they hold to can be classified as conservative in that the narrative revolves around the subjugation of science to other institutional and social groups. While the films above argue the value of science as an agent of change other films question the value of this change. They do not question the proposition that science generates change but only challenge the usefulness and the validity of such change. They argue that the social changes that science causes have implicitly negative effects and they provide a strong contrast to those films where science is in some way liberating. The 'liberating' films suggest an existence for women that is more fulfilling than whatever had gone before. This conservative group of films argue that such fulfilment is a chimera.

Conservative films argue that science does not necessarily fulfil more than any other activity and, for women, the job of marrying and having a family is more interesting and more fulfilling than pursuing a practice in science. Science and its promised 'liberation' may be only a phantom constructed by a radical fringe, the liberation may be only a straw person. The woman scientist 'Hutch' in The Night the World Exploded wants to leave her job as scientific assistant to get married. Her justification is that "A girl can't work all her life", and she perceives that a career is an empty goal: "I'm a scientist but I'm a woman too...I don't want to end up with just a dream and a hope chest." 12 Love more than science is what moves the universe quite literally, as at the end of the film when the danger of devastation by earthquake has passed, kissing the lead man causes her to swoon: "Maybe I spoke to soon. The Earth started trembling again."

In such films the opposition of women vis-a-vis science takes a number of forms: either they reject the idea that science is anything other than just work, or the women who take up science are unattractive, such that a family is not seen as an option for them, or they are players in the dance of romanticism. The first option is discussed above. The second, in which the woman scientist is unattractive, is narratively insignificant to the extent of invisibility; though she is noticed in The Thing where a heavily accented, woman scientist is introduced as part of the team at the Arctic base, but plays no further role in the weaving of the

12 Interestingly, she is given first billing over the man lead in the credits, which is unusual. While her voice might be seen to be that of a conservative man writer, one of the writers of the screenplay is a woman. 
narrative. The third possibility is significant in that same film, where Nikki is the romantic interest for Captain Pat Hendry. No character states Nikki's surname, and this is perhaps significant to understanding her position of inferiority in terms of her control of institutional power and her (in)ability to exercise authority because of her institutional affiliation. She is quite happy supporting the man and can be characterised as 'the coffee girl': like other women in other films she wanders calmly through scenes of chaos and pandemonium offering coffee. But she is not stupid or powerless. She uses her female understanding of cooking to suggest the method whereby the monster-a giant super-intelligent carrot-can be exterminated; that is, after listing frying, boiling and other methods of dealing with vegetables, they decide on roasting. Interestingly, it is her knowledge of the mundane and her ability to transfer this knowledge to different applications that provides the solution to the problem that the military men have been unable to solve. That she is 'better' than her romantic interest Hendry is suggested by her ability to drink him under the table as well as her sense of calm when all around is chaos. That she does in fact have power over Hendry is illustrated in a scene where he suggests a simmering violence towards her that she both controls and defuses without fluster. This woman-like the men she supports-rejects the notion that science will deliver a better world and takes her place with those who see science as being ultimately a golem that requires careful control. Science is not liberating; on the contrary it is the life of the family, where roles are clearly defined and males are sexual predators while females have the power of accepting or denying that predation, that comprises true fulfilment.

As I suggested early in this chapter, science, with its achievements, is not always aligned with nature in a benign and mutually beneficial partnership of exploration and harnessing of nature's secrets. The notion that science is the destroyer of culture, of nature and life and is therefore to be resisted is present in the films discussed above, but plays an even more foregrounded role. In three significant films women are agents of opposition to the advances of a science that threatens global annihilation. In Red Planet Mars, The Fly and Day the Earth Stood Still women are the nurturers of civilisation and nature through their concern for the human race and its future. Scientist André's wife in The Fly expresses fear and anxiety about the taboo areas science seems to be entering, accusing André 
of 'playing at God'. Her fear is also for the 'speed' of the times that was part of the cultural context discussed in chapter two:

the suddenness of our age- electronics, rockets, earth satellites, supersonic flight, and now this.... Everything's going so fast.

The fear for and of the future associated with the fear that science has crossed the dividing line separating healthy progress from the apocalypse is the concern of Linda Cronyn, the wife of the radio astronomer Chris in Red Planet Mars. Their argument is the argument between science as progress and the destruction that science has brought about; that is, between science as enhancing nature and science as destroying nature. While Chris enthuses, "It's like having a grandstand seat at the creation of the world", Linda retorts, "Or its death". Their argument about the nature of science is worth repeating as it encapsulates and summarises the range of positions taken about science in science fiction films of the decade, and the effect and implications of that science. In particular, it reflects the discourse that surrounded nuclear testing:

Linda $\quad$ Fear Chris. Always eating fear. The whole world's scared. Why shouldn't I be. Every woman in the world; we all live in fear. It's become our natural state. Fear our sons will have to fight another war or fear they'll face worse. We've lived on the edge of a volcano all our lives. One day it has to boil over.

Chris Me talking to Mars won't affect Vesuvius, Lyn.

Linda Chris, how can you be so sure? Can't you understand. Science has made the volcano we're sitting on. Nobel invented dynamite to ease man's life. It's eased a good many into annihilation. Einstein split the atom to create energy. Is terror energy?!

Chris Well that's rubbish Lyn. Scientifically we've advanced further in the past 60 years than we have in the previous 2,000. Radio, television, automobile, aeroplane, atomic fission, jet propulsion. And now... well, you saw those pictures tonight and heard what Mitchell said. If we can once talk to Mars we may be talking to brains as far ahead of ours as ours are from monkeys. In one moment we may be able to leap ahead another 2,000 years.

[Linda is not impressed.]

Linda And you have done it. You'll be the next to advance science, and maybe us. Right into oblivion!

Chris Linda!

While in these films women assert that science has taken humanity to the brink of destruction, other films portray a logical, scientific system that has taken us over the brink and into the abyss of human annihilation through nuclear warfare. But before discussing that group of films, it is worthwhile, in closing the discussion of women in science fiction films, to briefly discuss another example 
where women and their role is in some way an issue outside the realms of science. Indeed, in Journey to the Center of the Earth, scientific rationality is outside the ability of women to comprehend, although statements of this nature within the film have to be taken with the grain of salt that permeates the film as a whole. Scientist Sir Oliver dismisses one query as a 'typical female question'. Women are not accepted in the scientific activity of exploration, although one ends up making the trip. In one interesting scene-interesting because of the possibilities suggested by its inclusion in the film-the woman is advised to discard her corsetry because of the heat of the interior of the planet and because it will impair her breathing. She does so, perhaps suggesting that the world they are entering has a logical system that demands a different set of responses, prefiguring the 'bra-burning' of the late sixties. Later in the film, when they have returned to civilisation, the woman announces, "I'm wearing stays again".

\section{Nuclear holocaust: the responsibility of science}

A group of films took up the idea of nuclear holocaust, the idea that the events the women foresaw in the films discussed above, did come to pass. As is detailed in chapter 2, the issues surrounding the splitting of the atom in 1939 are the context for the production of films about nuclear war. Briefly, nuclear weapons - the atomic bomb initially and then the hydrogen bomb-were used as foreign policy instruments of 'compellence' leading to a strategy of brinkmanship where the ambiguous threat of the deployment of nuclear weapons supported at least six occasions of confrontation.13 On the one hand were the policy elite like Eisenhower advocating the use of nuclear warheads like any other weapon in the arsenal, like a bullet, and on the other hand were some scientists and humanist groups whose arguments were reflected in films like $O n$ the Beach. The latter did not view these latest achievements of science in a positive light.

The film industry was not slow to pick up on the dramatic potential of the nuclear issue and the threads of narrative that could be woven around a backdrop of total destruction. While nuclear explosions figured in the science fiction films of the decade, only some continued the thread into the realm of nuclear war and holocaust: Five, Day the World Ended, On the Beach and The Time

13 Michael Strada 1986 'Kaleidoscopic nuclear images of the Fifties' J of popular culture Winter, 20, 179-198 
Machine. At first glance, these films argue the ultimate negative judgment on science, but such a judgment is simplistic as the arguments that are part of the narrative in On the Beach reveal. While Day does not contain any judgments about what occurred before the events the film depicts, except that nuclear destruction was in some way a fulfilment of prophecy, On the Beach contains argument about the nature of science, but more so the nature of a humanity that would use the discoveries of science to threaten the existence of life on the planet. The social responsibility of science is the subject of the argument in the film and the question as to the nature of a science that would develop the capabilities for self-destruction is canvassed. But even this simplistic view that science or humanity was in some way responsible, as if the use of a single bomb was the issue, is discounted in favour of the argument about the absolute lack of choice that exists in a nuclear exchange. In response to the question of who started the war, CSIR scientist Dr Julian Osborne replies that Albert Einstein was generally responsible, but he qualifies this by arguing that the nature of nuclear warfare is such that no-one is capable of controlling it. In answer to the suggestion that 'eggheads' were responsible he replies::

The trouble with you is you want a simple answer. There isn't any. The war started when people accepted the idiotic principle that peace could be maintained by arranging to defend themselves with weapons they couldn't possibly use without committing suicide. Everybody had an atomic bomb, and counter bombs, and counter-counter bombs. The devices outgrew us, we couldn't control them. I know. I helped build them, God help me.

Osborne points out the idiocy of the policy and practice of Mutual Assured Destruction, where any country (that is, the Soviet Union) that launched a first strike would be destroyed by a counter-strike that would have to be launched before any missiles struck:

Somewhere some poor bloke probably looked at a radar screen and thought he saw something; knew that if he hesitated one thousandth of a second his own country would be wiped off the map, so ... so he pushed a button, and, and...the world went crazy. And...

While the decade opens with science being held responsible for the fear of total destruction in an aside in The Thing, On the Beach attributes the blame to other causes than science alone. The simplistic argument of The Thing that science is to blame for all the evil in the world does not carry the day in this film.

As foreshadowed above in terms like 'argue' and 'persuade', any discussion of the nature of science in science fiction film is not complete without 
consideration of the function of science, taken as a separate discussion point, a discrete node on the web of meaning of science in science fiction films, yet not separable from its nature. The two organising principles of nature and function are interrelated to the extent that the function of science in the film is a significant element in the description of its nature.

\section{The rhetorical function of science}

This chapter, with others, has suggested that fifties science fiction films are persuasive, rhetorical discourses that posit fluid tenets about science and its effects, in order to legitimate, or argue against, the claim of science to be a worthwhile social institution and a fundamental paradigm that explains reality. This is of course not all they are, but their structure and tradition is that of the classical Hollywood story melded to the documentary and news films that were an integral part of the war effort in the previous decade. The results of this melding are films that contain arguments about science, about the nature of science, about science and progress, about the relationship of science to the military and/or to the government, about the relative power of these institutions, about science, the world and people, in short, the contested and changing interface between science and civilisation. This section continues by examining the pedagogy that functions implicitly and explicitly in science fiction films, and suggests as well a persuasive function, mobilised through the establishment of an environment of truthfulness and rationality about the events in the film. A second thread of persuasion weaves the pre-eminence of science as an repository of truth.

Science has functioned pedagogically, narratively and satirically in other texts. Fifties science fiction films manifest similar functions of science to those French narratives of the $17^{\text {th }}$ to the $20^{\text {th }}$ centuries that allude to science or in some other way construct science within the story, where the function of science is pedagogical, narratival and satirical.14 The function in focus here is that of pedagogy used to drive the narrative. Certain scenes in science fiction films function as explicit pedagogical devices to both establish a common level of understanding for the audience that is crucial to the development of the plot, and

14 Arthur Evans 1989 'Functions of science in French fiction' Studies in the literary imagination 22:1, Spring, 79-100 
establish a factual and credible scientific accuracy that then legitimates events that might otherwise be regarded as a barrier to the 'willing suspension of disbelief'. The two pedagogical devices science fiction uses are the simple filmwithin-a-film and second, the scientist acting as teacher for an audience, sometimes comprising both diegetic characters and also the film's audience, a device that effectively brings the audience into the diegetic domain of the film.

The interpolated material in the film-within-a-film occasionally takes the form of an animation. Destination Moon contains the earliest example from the decade of the fifties (and Jurassic Park is a good example from the nineties, again signifying the longevity of the device). The scene is worth detailed discussion as in it can be seen a range of significant pedagogical elements that recur in other films. The character in the cartoon is Woody Woodpecker who converses with an off-screen narrator. The use of a comic cartoon character serves to demystify the discourse of science without diminishing its power; in fact, the power of science is constructed through this dialogue between an off-screen narrator who is therefore omniscient and omnipotent and an on-screen character. That character is removed from the audience in that he is a cartoon creature, yet he is wellenough known to be recognised. That he will learn in the context of the in-film cartoon is pedagogically sound as is the learning the audience will do.

The cartoon functions to teach and to legitimate the discourse and knowledges of science, specifically the application of science to space exploration. Initially the omniscient narrator invokes the authority of contemporary canonical yet popular journals to answer Woody's doubt.

Woody It's ridiculous. Comic book stuff.

Narrator Comic book stuff eh. Life magazine doesn't think so. Nor Look, nor Pic, nor Collier's, nor your biggest daily newspapers.

Woody It'll never get off the ground; no propellers.

Narrator Rockets do not employ propellers, they use jets.

Woody So do gas stoves but they don't fly to the moon.

Woody is positioned to voice the scepticism of many in the audience. He articulates common misconceptions so that the omniscient narrator, the persuader, can answer those misconceptions; he voices what were the common myths surrounding rockets, which he uses as the basis for a joke. The cartoon, the text within the text, continues with an explanation of Newton's law that action and reaction are equal and opposite, and its application in rocket 
propulsion:

Narrator

Obviously you know nothing about rockets. Now let's pretend that umbrella of yours is a shotgun. Shoot it. [Woody does, and suffers exaggerated recoil.]

Woody Who pushed me?

$\mathrm{N}$

The gun, Woody. The charge not only fired out of the muzzle. It kicked back with equal force against the barrel.

Woody It wouldn't happen again in a hundred times.

$\mathrm{N}$

Shoot it at the ground a few times in rapid succession and see what happens. [Woody does, and he takes off, and stays 'up' by shooting the gun.]

$\mathrm{N}$

The same principle applies to rockets. It's the same shotgun kick of the explosives that throws the rocket forward. That kick, incidentally, is quite independent of the air around the rocket. It works just as well in a vacuum, or in outer space, which is a vacuum. The moon is a great deal easier to reach than you realise.

Having learned the physics of rocket propulsion Woody is then taught the

physics of gravity as it acts at a planetary level to affect and assist space flight:

Woody

Oh sure. It's a cinch. Only 240,000 miles, paved highway and a gas station at every intersection.

$\mathrm{N}$

Fuel is no problem Woody. The engines do not have to blast all the time, just long enough to get you away from the gravitational pull of the earth, following which, you fall wherever you're headed for. Get in and I'll demonstrate.

Woody Hey, let me out of here. Help, help.

$\mathrm{N}$

The jets blast powerfully enough to counteract the gravitational pull of the earth. [This gravitational pull is represented graphically by a large magnet implanted within the earth.] Once out of the earth's atmosphere the rocket just keeps on going, encountering no resistance to slow it up. The rocket does not appear to be travelling, but the high speed, or escape velocity as we call it, is about seven miles a second. It keeps falling in outer space in the direction in which it was started. Now, as it nears the moon, that planet's gravitational field begins to pull it towards it.

The narrator and Woody continue by discussing the effects of an atmosphere without air.

$\mathrm{N}$

Woody

$\mathrm{N}$

Woody

$\mathrm{N}$

Woody

$\mathrm{N}$

Woody

$\mathrm{N}$
Can't hear you Woody, no air, remember. Turn on your aerial. Hey, no brakes on this thing. I'm going to crash. How do I land? Very simple. Just reverse the take-off.

Yeh, but what about the wings?

Can't use them. The moon has no air.

Now he tells me.

Turn the ship around. Use the shotgun kick of the exhaust to brake the speed and set her gently on her tail.

So we made it. How do we get home from this piece of cheese.

Shooting a rocket from the moon to the earth is a great deal easier than shooting from the earth to the moon because it is downhill almost all the way. The V2 rocket could do it today. On the return 
trip we use the wings to glide in, and for economy's sake, finish the landing like this.

Woody Sensational. I'm sold. I'll back it to the hilt. Here's my two bucks. Well, when do we start building?

The scientific facts that are necessary to an understanding of space travel, the difference between jet and rocket engines, the effect of gravity and other elements of space travel are canvassed and explained for a non-scientific, yet nevertheless interested, audience. Having had the physics explained to him, Woody is convinced and awed by the potential of the operation, and is prepared to support it with funds, which is the action the film-within-a-film is motivating. The cartoon educates both the diegetic audience-a group of wealthy industrialists and businessmen-and the wider audience viewing the film; the diegetic audience respond to the cartoon by agreeing to financially back the proposal to build a spacecraft to travel to the moon (having seen that it is feasible and necessary), while the non-diegetic audience, who have similar understandings to the industrialists, might be convinced of the feasibility and necessity of such a project and thus support other, real-world proposals for space exploration.

While the Woody cartoon is factual in its science, in other films similar devices such as the film-within-a-film function to both teach and persuade. The life cycle of the ant and the wonder of this is the subject of the film-within-a-film in Them! and, prefiguring Jurassic Park, displays an ant that has been mummified in amber for 50 million years being released and returning to life.

Wonder lay in the macro theatre as well as the micro world of ants. The scientists and Manning's wife-along with the film's audience of course-in Amazing Colossal Man view a film of the destructive effects of a nuclear explosion. The scientist intones, "Something out there is beyond the limits of our knowledge", and the narrative function of this positioning of the interpolated film vis-a-vis the on-screen and off-screen audience is to demolish any difference between the diegetic characters listening to the presentation and us, the film's audience. By making us part of the diegesis of the film and participants in it, our continued commitment to the constructed reality is enhanced. Like the Woody cartoon, this film acts to educate us about the power of nuclear weapons as well as persuade us that science and scientists command the elemental forces of nature. The stock footage, released by the Defence Department, graphically evincing the power of nuclear explosions appears in many fifties science fiction 
films. As film-within-a-film, its function is to educate and persuade, and this discussion continues below. In The Brain From Planet Arous the stock footage is a film-within-the-film and is used to illustrate the power of the alien to destroy. Of course intertextual associations for a contemporary audience are obvious: the power the alien wields is far more extensive than a few buildings being disintegrated by a nuclear explosion recognisable by an audience as such; the image of destruction is only the synecdoche for a vast global destruction that was associated with the screening of documentaries and news stories about nuclear explosions. Indeed, the awe surrounding such manifest power was not only experienced by Oppenheimer, resulting in his quoting the Bhagavadgita at the first explosion, but seized on by the film corporations as a formidable device to reproduce awe in film audiences.

While the film-within-a-film is one device functioning to both educate and invite the participation of the audience in the world and power of science it is not the only such device. The scientist-as-lecturer, as pedagogue, functions to both blur the distinction between the non-diegetic and diegetic audience, and to educate those two groups. This function is similar to the film-within-a-film as the device sets in place the (il)logical systems on which story may continue to build. In Amazing Colossal Man the medical doctor Lindstrom explains to Carol the aberrant physiology that explains Glen's rapid heart and bodily growth, amongst other things. In this instance the explanation is specious but the scene functions to establish a plausible cause for Glen's growth. The white-coated scientist in his laboratory is a metonym for truthfulness and authenticity and narratively such a posture of truthful explanation is a mechanism that can actuate our willing suspension of disbelief in the film's story.

Similar pseudo-scientific reasoning occurs in many films of the fifties with scant respect paid to the 'class' or status of the film. While Amazing Colossal Man was reasonably successful (resulting in two sequels) Astounding She Monster is not regarded as anything but a cult film, yet the geologist Cutler has deduced, as he explains to his romantic interest Margaret, that the alien is protected from Earth's atmosphere by a thin sheet of metal. This reasoning is crucial to the earthlings endeavours to destroy the alien. In Giant Claw the scientist attempts an explanation of anti-matter that would allow the giant bird to appear in our universe. In The Fly Engineer André explains to his wife Helene the science of 
dematerialisation that is necessary to legitimate the events in the film.

While the science in such examples might be credible only to those who currently believe that aliens are already among us and preparing some for ascension, other scientific explanations in other films blur the distinction between truth and fiction either because the science is accurate or in other cases, while the science is initially accurate, the extrapolation is specious. 15 In Creature From the Black Lagoon the scientist discusses the position of lungfish in the evolutionary scale and then speculates that the archetypes for many creatures might still exist in the depths of the ocean, likening the unknowns of the ocean to those of space. Dr Marvin articulates the state of rocket science in the opening scenes of Earth Versus the Flying Saucers accompanied by animations of satellites revolving around the Earth and footage of satellite engines igniting. Naturally for films that derive their narrative from nuclear issues, explanations revolving around some implication of nuclear warfare or testing are common. Given the unconfirmed but vaguely theorised effects on organisms of exposure to radiation, the explanations in films pass in most cases for truth. The doctor in Attack of the Giant Leeches theorises that the beast is a mutation caused by radioactivity from a missile-landing site. Many films used nuclear effects as the fundamental cause of the film's thesis without explanation because it had become such a recognised filmic convention that it no longer needed to be elaborated.

Less well understood science was more likely to require explanation. While the dinosaurs of Jurassic Park came from DNA in amber, the scientist in The Black Scorpion has to explain that the scorpion was released from lava where it had been existing in a state of suspended animation. While relying on nuclear radiation as the fundamental cause of the problem in Hideous Sun Demon, the story requires the explanation of events subsequent to exposure, realised in the medical scientist Dr Stern, who is the explainer of science to the audience and to Lansing and Burnell. He explains the biology and scientific accuracy of human growth from one cell, through many species like fish to a multi-celled creature like a human being. Then the speculation begins, the introduction of some form of extrapolation on a scientific fact. In this case the exposure to the isotope has

15 There is an analogy with the crazed scientist in vampire films, who authenticates vampirism by his ravings about bats and insect-eating plants. 
reversed the growth process so that the affected McKenna is reverting to some form of life lower than man. The paradigm is evolutionary, and in McKenna's case the radiation from the unknown isotope has caused the problem.

The film in which both the scientist-as-pedagogue and the legitimating function of science are clearly elaborated is Invaders From Mars. Science is the key to an understanding of the most basic questions of the universe, and the scientist is the master of this knowledge. In the social hierarchy then, the female Pat Blake is below 'Stu' (Dr Stuart Kelston); the doctor of the person, the medical doctor, is below the doctor of the physical sciences; the expert on the physical universe is superior to the expert on the universe of the body and soul. Blake learns from Kelston and is in awe of his knowledge. Like us she wants to know the information he has; like us she is awed by this knowledge; she is constructed as being awed, as wanting to know. The film assumes our interest in the physical universe and both reinforces this interest and establishes science as ultimate knowledge by teaching about that science in a very long scene where Stu explains the universe for us, mediated through the diegetic audience of the child David and Blake. The camera shot reinforces our inclusion into the film's diegesis: Pat and David constitute the frame for the shot from between the backs of Pat and the boy David framing Stu, as though they were the first row of a seating arrangement in which we occupied the second and subsequent rows. Kelston becomes the teacher and the lesson is about the possibility of life in the universe and contains these paraphrased nuggets of information, that follow an extensive factual 'lesson' on astronomy, incorporating graphics and animations.

The other side of the moon is dark and unknown and anything could be happening there and obviously is. He states emphatically, as if it were a proven fact that, 'There is other life in the universe'. We believe him-he is, after all, the teacher at a time when teachers were respected as authorities. There is life on Mars according to the astronomer, and the inhabitants have been 'watching us and' he adds, appealing to paranoia, 'spying on us'. He is quite adamant that UFOs are real and we accept this uncritically. The young boy David can estimate the size of the UFO-exactly 150 feet in diameter. Kelston describes the various types of UFOs and recounts past sightings which are not able to be explained in other terms. $16 \mathrm{He}$ has access to scientific reports which state this, again basing his

16 see chapter two for the discussion on UFOs. 
authority on science. Science says that there are UFOs, hence there are.

The two, representing us, ask him questions and after he tells them a little more Pat Blake expresses our view: 'It's fantastic.' In the question-answer method Kelston is constructed as the archetypal teacher.

$\begin{array}{ll}\text { Pat } & \text { What do you think it's all about Stu? What David thought it was? } \\ \text { Stu } & \text { Possibly. } \\ \text { David } & \text { A spaceship! } \\ \mathrm{P} & \text { But from where? } \\ \mathrm{S} & \text { From outer space. Come here. Let me show you. } \\ & \text { This part of the universe contains } 22 \text { planetary systems, } \\ \mathrm{P} & \text { conceivably within reach of us. } \\ \mathrm{S} & \text { Where's the sun? } \\ \mathrm{P} & \text { Our sun? It isn't shown here. If it were it would be about this size. }\end{array}$

The scene continues in this way for an extended time so that we are in no doubt about the possibility, indeed the probability, of invasion, proven to us through the veracity of science and scientists.

(One part of this scene bears little narrative or structural relation to any other part of the film, yet seems to model the notion of space defence that was pivotal to Reagan's defence policy known as Star Wars. Kelston somehow focuses the telescope on a rocket in launching position:

David It looks like some sort of atomic device out there!

Stu It is an atomic device. The highest-powered rocket ever conceived. If we can shoot a rocket far enough into space it will anchor there. Then it's merely a matter of time before we set up interplanetary stations equipped with atomic power and operated by remote control. Then if any nation dared attack us, just by pushing a few buttons we could wipe them out in a matter of minutes.)

These elements are devices that teach the audience about science but the process is more complex than that. In addition to the pedagogical function, the discourse of science and the discourse about science function to persuade the audience to any one of a number of positions with regard to science, its creations and initiates. This argument is complex and requires a discussion of the discourse of science as the discourse of truth, a position that is constructed in some science fiction films.

Evans argues that, while science and literature are increasingly being considered 'as part of a common and culturally embedded network of human 
perception and rhetoric', they were not always seen as similar discourses. 17 Indeed the father of the scientific method, René Descartes, deplored the art of rhetoric as contrary to science. Francis Bacon expressed similar arguments about the gulf between scientific and other writing, viewing scientific writing as far superior. The aim of science was different from the aim of the rhetoric that had been taught in academies since the Roman Empire:

The true end, scope or office of knowledge consists not in any plausible, delectable, reverend or admired discourse, or any satisfactory arguments, but in effecting and working, and in discovery of particulars not revealed before. 18

Bacon's argument was that science existed for the benefit and betterment of humanity through a depiction and elucidation of the natural state of affairs, that is, the way things occurred in nature and the way those findings were applied. Scientific discourse is different from and opposed to the hierarchy of relationships and the persuasion based on speech strategies that is intrinsic to rhetoric. Galileo's scientific section of Discoveries and opinions is an example of this new discourse of science: the writer effaces himself from the text and embraces language that is neither manipulative nor persuasive. In this discourse is an equality between reader and writer in that the reader could perform the observations and become the same observer of this natural occurrence.

The most easterly star was seven minutes from Jupiter and thirty seconds from its neighbour; the western one was two minutes away from Jupiter. The end stars were very bright and were larger than that in the middle, which appeared very small. The most easterly star appeared a little elevated toward the north from the straight line through the other planets and Jupiter. The fixed star previously mentioned was eight minutes from the western planet along the line drawn from it perpendicularly to the straight line through all the planets....

I have reported these relations of Jupiter and its companions with the fixed star so that anyone may comprehend that the progress of those planets, both in longitude and latitude, agrees exactly with the movements derived from planetary tables. 19

The distance and hierarchy between writer and reader is obliterated in such scientific texts as both are readers of the natural world. The exploration of the real and the natural-the pursuit of 'truth'-constructs a discourse endeavouring to be only true or perhaps to be proven as false. The point is that truth and falseness are ascertained through the scientific method of observation,

17 Evans 1989, 79

18 Bacon in David Wellbery \& John Bender (eds) 1990 The ends of rhetoric Stanford: Stanford University, 8

19 Galileo in Wellbery \& Bender 1990, 10 
experimentation and replication. The writer-scientist as actor, as repository of truth, as teacher effaces himself in this discourse: truth lies in the observation, in the phenomena, in the discourse, in the method. Truth is external to and independent of any person. In Evans' terms:

...by eliminating the narrator as a mediating presence between the reader and the text, it [scientific discourse] strives to maintain a single, autonomous, authoritative, and machine-like narrative voice whose sole function is to communicate factual information. In so doing, it seeks systematically to reduce the paradigmatic to its simplest form in an attempt to communicate more effectively the "pure" referent. 20

The type of discourse is a feature of many science fiction films of the fifties and occurs in the film-within-a-film discussed above. The off-screen narrator in Destination Moon, for example, appears to be communicating only factual information as the chief concern, yet, as we have seen, the scene positions the audience-both the diegetic and non-diegetic audience-both to accept the teachings of science and to support further spending in that field. Galileo's text, while it apparently effaces the scientist, establishes science and the scientific method as powerful, and those who practise it are, by virtue of proximity to the ark of the covenant, also powerful. Voiceover narration in films is, as we will see, a device to establish, educate, persuade and to establish authority.

The documentary style that foregrounds an off-screen exposition is an overt example of the effacing of the narrator, who, as in Galileo's text above, creates a discourse of objectivity and truth. The documentary style equates in function to the film-within a film referred to above in that it functions pedagogically. The classical documentary style is significant because of its realism and a primary element of that realism is the off-screen spoken text, where the speaker is not present but authoritatively overwhelms the on-screen activity. The effect is to prevent the characters who may be on-screen from interpreting events or feelings. Only one interpretation and history is possible; the power and authority of the expert or of science itself is uncontested. Other ways of seeing are proscribed. ${ }^{21}$ (I would prefer not to call this spoken text a 'narrative' as this confuses the distinction between 'exposition' and 'narration' which is important for this discussion. By exposition I mean the statement constructed as truthful and told for pedagogical ends. These pedagogical ends may have the additional function within the film of advancing the narrative; that

20 Evans 1989, 80

21 Albert Moran 1987 Projecting Australia PhD thesis, Griffith University, 226 
is, while the on-screen or off-screen audience may learn something from the exposition the function is also to enable the narrative to continue.)

The effect of this style is to construct a discourse where the omniscient, offscreen presence (which is often the state or affiliated agencies) explains to the audience (whether off-screen or on-screen) the 'truthful' explanation and cause of any given occurrence and persuades that science is powerful. This exposition then sets the scene for the continuation of the narrative.

In science fiction film this type of exposition is a feature of the genre. Although it is not present in all science fiction films it occurs with such regularity that some attempt must be made to explain it. In films where it occurs the offscreen narrator (who is always male) begins with a description of events that have been occurring or with some kind of exposition about natural or man-made phenomena or with some kind of speculation about unexplained events. The events always have global significance. The narrator in this classical documentary style is anonymous and voice cues as to the speaker's identity are elided so the audience does not reflect on questions like "Who is speaking?" and "Why is he saying those things?" 22 The shots are often of a military exercise, the solar system, or the destruction associated with a nuclear explosion. Creature From the Black Lagoon exemplifies the functioning of the documentary opening to construct a web of truthfulness. In this case the function of the documentary is to educate in scientific literacy juxtaposing at once a methodology of 'truth' with a tale of fiction. Here the narration explicates the scientism of evolution, defining this evolution within a religious interpretation that did not maintain the literal truth of biblical timelines.

In the beginning God created the heaven and the Earth, and the Earth was without form and void. This is the planet Earth, newly born, and cooling rapidly from a temperature of 6000 degrees to a few hundred in less than five billion years. The heat rises, meets the atmosphere, clouds form, and rain pours down upon the hardening surface for countless decades.

The similarities between this text and that of Galileo confirm it to be authoritative, truthful and apparently without the persuasive devices of classical rhetoric. Paradoxically this discourse of objectivity in the documentary style goes beyond the simple exposition of a scientific fact. Embedded in the discourse is a function that is rhetorical in that it is persuasive. Lawrence Prelli applies Foucault's notion of discursive formations to scientific discourse, arguing that 
science is a discursive formation and as such is rhetorical:

Any discourse is rhetorical insofar as it involves the selective use of symbols to induce cooperative actions and attitudes regarding particular orientations for attaching meanings to situations.23

Even such apparently objectively coded exposition is involved in both the reflection and construction of a discursive formation of science. That discursive formation is rhetorical in Prelli's sense as it does use symbols to induce cooperative actions and attitudes and for attaching meanings to situations. The off-screen narrator constructs a hierarchy of power, with him in an authoritative position as the disembodied voice of truth explaining the nature of the universe and the laws pertaining to it or simply describing the manifestations of power within the web of the film's narrative.

In The Giant Claw the Early Warning System in the Arctic is the topic of this description. Here the exposition functions to establish the power and preeminence of science as both the explainer of events and the underpinning methodology for technology. It is rhetorically coded to establish the threat to the world of what is to come (and I say this with tongue firmly planted in cheek as the panic and fear the filmmakers attempt to create never even vaguely germinates.) To establish the possibility that giant creatures could exist without our knowledge is the function of the off-screen exposition in Giant Gila Monster. While these examples are from films described as ' $B$ ' (at most), other more enduring films provide better examples of factual knowledge that leads to speculation. Invaders from Mars opens with the familiar off-screen narrator intoning known facts about the universe and then questions applicable to those facts. The shot is of the stars with the camera moving slowly towards and into them. The music is haunting. The man's voice states:

The Heavens. Once an object of superstition, awe and fear, now a vast region for growing knowledge. The distance of Venus, the atmosphere of Mars, the size of Jupiter and the speed of Mercury - all this, and more, we know, but their greatest mystery the heavens have kept a secret: What sort of life, if any, inhabits these other planets? Human life like ours, or life extremely lower in the scale, or dangerously higher? Seeking the answer to this timeless question, forever seeking, is the constant preoccupation of scientists everywhere. Scientists famous and unknown. Scientists in great universities and in modest homes. Scientists of all ages.

The function of science here is to answer the questions that are globally significant. Even though science has not answered those questions in the past

23 Lawrence Prelli 1989 A rhetoric of science: inventing scientific discourse Columbia SC: U of Sth Carolina Press, 87 
that is not a reason to stop the process. At the same time the universal nature of the scientific endeavour is highlighted. Science crosses all national, class and age barriers although gender barriers are not considered here. Science is the universal method for working out some of the universal questions. Science is the only paradigm that will or can answer these questions; other possibilities are excluded.

In War of the Worlds the documentary opening portrays the various military weapons of mass destruction. The narrator explains the capacity of science to develop weapons of total destruction but then turns to the necessity for these to be available for an even bigger battle that would involve the world acting in concert. The voice is tense and urgent, commanding respect for the position that is being established in the documentary. The tense voice is present in the documentary opening of Killers From Space that focuses on the preparation for a nuclear test. On the one hand these documentary openings function as exposition establishing the truth of a situation and a particular paradigm through their recourse to science. On the other hand they function to persuade an audience to a position that may be different from-if ever so slightly-that which they currently hold.

To summarise then we may say that in science fiction films the nature of science is an issue that is reformulated through the pedagogical and narrative systems functioning in the films. Thus it is not only a 'taken-for-granted' notion of science that functions as pedagogy; it is science itself in at least one of its various guises that is constructed and then argued for or against. Less explicitly the filmic events circulating about science are hortatory in that they function to persuade without explicitly stating an argument; that is, they operate on a subtextual level. It is to that particular persuasive function I will now turn.

Martin's model of hortatory argument theorises the mechanisms of persuasion.24 According to Martin a hortatory thesis is one where some attempt is made to change the world, where a text challenges a foundational, or naturalised, taken-for-granted reality. In this case the texts are certain science fiction films. However it is not essential to define the naturalised reality; the text will do that. In hortatory exposition the naturalised reality is the web constructed through and by the text, which the text then explicitly challenges. The

24 J R Martin 1985 Exploring and challenging social reality Deakin University, 16-50 
construction of this naturalised reality may be implicit in or explicit to the hortatory text. In contrast analytical exposition does not challenge the naturalised reality while still constructing it. The opening scenes of Earth Versus the Flying Saucers, discussed above, where Carol Marvin articulates a common stereotype of science which is then dismembered by the film's action, is an example.

This model is not dissimilar to the notion of the discursive formation of science, and is useful in that it explains the dynamic of the argument: the establishment of a particular formation, a naturalised reality, followed by the persuasion to a different reality through certain rhetorical, filmic conventions. In creating a particular naturalised reality film can persuade against that reality or for it. That naturalised reality is not an absolute; it is relative and assumes a reality when it is described either explicitly or implicitly. The film story participates in the formation of the discourse of science and in the 'persuading to' of an audience. The films are rhetorical in Prelli's sense of inducing others to share an orientation and to make sense through mediating the information through that orientation.

Consider once again the exposition that opens Invaders From Mars (above). We are here invited to share an orientation presented as scientific about the possibility of life outside this planet. We are informed that scientists are seekers after truth and that the search is defined as the quest for alien life forms. But not only are the scientists looking for these forms, they are also attempting to discover whether such life is 'good'; that is, friendly to us in evolutionary terms or 'bad' - 'dangerously higher' - than humans in evolution. The audience is persuaded to this classification of alien life forms as somewhere on a good-bad continuum. Science then is not only concerned with a discovery of a neutral phenomenon; inextricably bound within such an exploration is a system of values to be applied to any discovery that comes out of the exploration. Science is not the 'making transparent' in Bacon's terms. 25

To further tease out this argument I would like to draw on those texts that hinge on UFOs as the starting point for the narrative. As pointed out in chapter two UFOs were an emergent social phenomenon of the late forties and fifties. 
The demarcation between reality and fiction was blurred, with the reported sightings of UFOs and subsequent investigations by government authorities and debate as to the reality of these UFOs. The debate was significant in the late $40 \mathrm{~s}$ and 50s: UFOs were an issue. An official investigation followed the first sighting of a formation of gleaming discs by Kenneth Arnold near the Rocky Mountains on 24 June 1947, an event that became the first 'official' UFO sighting. ${ }^{26}$ Nineteen fifty-two was a fecund year for UFOs, when there were 1500 reports of UFOs worldwide. (Three hundred remain unexplained.) The most significant sighting was the so-called 'Washington Invasion' where, on the summer evening of 19 July 1952, five strange lights hovered and manoeuvred for hours over the White House, the city and the surrounding countryside. The lights reappeared a week later, now increased to between six and twelve.

Two F94 jet interceptors were scrambled to investigate them, but the pilots could find nothing and returned to base. However, when a third jet was sent up the pilot radioed that he was approaching a cluster of huge blue and white lights. As he closed in on them the lights moved to form a ring around him and travelled along with him for about 15 seconds before moving slowly away. 27

This 'invasion' is recalled in the film Earth Versus the Flying Saucers where icons of US democracy such as the Washington Monument are the targets of attack by flying saucers.

In those films drawing on the UFO phenomenon Martin's mechanism of hortatory argument is an applicable model to apply to the structure of the argument. The establishment of the paradigm of science as truthful is followed by the exposition of scientific observation; namely UFOs. Through its claim to truth, the scientific paradigm constructs an argument that may be outside the parameters of truthfulness the audience holds to.

The Day the Earth Stood Still uses a slightly different strategy in persuading to a particular position. An element in the methodology of science-observation -functions as an appeal to objective 'truth' and this methodology combines with the authoritative institutional voices of the BBC and US radio reporters. The film opens with a shot of a rotating radar antenna, followed by a shot of a radar tracking room where an object is being tracked along a coastline. The statement of an off-screen narrator indicates the object is moving at an incredible speed. Zooming out, the camera frames people discussing the object with someone

26 Ted Wilding-White 1989 All about UFOs London: Usborne, 4

27 Wilding-White 1989 ibid, 8 
speaking on a phone. The subsequent scenes are of different countries with people listening to radios or speaking into radio microphones. The $\mathrm{BBC}$ announcer is followed by the US announcer who, after giving speed details of the objects, reads:

This is not another flying saucer scare. Scientists and military men are already agreed on that. Whatever it is it's something real.

The reality of scientifically developed technology (the radar, radio), the war room, the speech registers of military men, and the radio announcers work together to construct a discourse of fact, of authenticity, of 'actuality' that functions to persuade to a position which posits the appearance of the UFO as real, as authentic, as true. The object is real as distinct from fictional. The science paradigm functions to differentiate fact from fiction and in this case the science legitimates the claim of the object to be real. Narratively, to establish the reality of something like a UFO increases its potential to create panic. In the case of this film though the narrative is different, in that the potential is to create the opposite to panic; namely, reflective thought. Another announcer in Washington then mentions how normal everything is: 'The beautiful spring weather, the tourist crowds around the public monuments and other buildings.' The shot changes to scenes of these public monuments, and the people to-ing and fro-ing. The object then appears in the sky above Washington and the drama begins with shots of the police and the military moving out in force. This section of the film can be seen as a metonym for the fifties: beneath the facade of normalcy exists the first cracks in a rupturing that was to threaten that normalcy in the sixties. Another interpretation is that the threats to fifties society were real, were powerful and potentially destructive of that society. In this case the threat was of humanity-in the sense of the machines of humanity-against humanity.

Whether or not UFOs existed or exist is not the topic of this thesis but the fact is that UFOs, that objects from outer space, were believed in by significant numbers. 28 While appearing to be ambivalent, Jung agrees with one Edward Ruppelt: something is seen but one doesn't know what.29 Jung recommends to the reader books by a Major Donald Kehoe as these books are 'based on official material and studiously avoid the wild speculation, naivete or prejudice of other

28 see chapter 2: 'The appearance of UFOs'

29 Edward I Ruppelt 1956 'The report on unidentified flying objects' in C G Jung 1959 Flying saucers London: Routledge \& Kegan Paul, xiii 
publications' 30 Ironically perhaps, the book Jung refers to is Flying saucers from outer space and is credited in the film Earth Versus the Flying Saucers as being the basis for that film. The relationship, then, is one where the phenomenon of UFOs are real or they could be real. The filmmaker, basing his work on the possibility of UFOs as documented by rational beings like Kehoe, mobilises the belief that they could be real as the fulcrum for the narrative.

Many films of the 50s incorporated this suggestion of the reality of UFOs and argued for their reality, basing the credibility of the film on an acceptance of the reality of UFOs. The documentary is here used as an hortatory genre; through the 'depiction' of 'reality' the audience's reticence to believe is overcome, or may be overcome. The documentary opening suits the construction of a possible truth: the reality of UFOs. In Invaders from Mars an unseen male narrator extols first, the virtues of science and knowledge over ignorance and second, the dedication and vocation of scientists (see the extract above). Notable too is the stated belief that more advanced forms of life might be 'dangerous' to our own. The argument moves from the explication of a reality to speculation about that reality, and the speculation is constructed as truthful through its juxtaposition with fact.

Phantom From Space is based on a UFO landing. Once again the 'factual' construction is achieved through the documentary genre, the imprimatur of the government suggested by the military footage of, in this case, radar and air force shots, acting on an audience who believes, or is open to believing, in the reality of UFOs. The narrative language is 'officialese':

This is Washington DC. And in the files of the Central Bureau there is a story so strange in its implications that it defies ordinary classification. It is the story of a handful of people, who in the course of one desperate night, held back a wave of panic and pandemonium.

It began after sundown. Time seven fifteen. As flight A Coast Patrol from Trappis field returning to base [sic]. When the nightly Air Force transport pointed north toward Japan via the Great Circle route. While at sea the Navy and Coastguard maintained their usual round-the-clock vigil. And from the equator to the arctic the radar network swept the skies with eyes that never sleep.

Time seven nineteen....

The narration to open Earth $v$ the flying saucers is quite accurate, showing the degree to which the narration could be 'factual'; that is, the narrative was not only designed to persuade to a position that was difficult to defend, but also to

30 Jung 1959 xiii 
simply persuade through explanation and revelation of the factual, as that

'factual' is documented in Kehoe's book mentioned above.

Since Biblical times, man has witnessed and recorded strange manifestations in the sky and speculated on the possibility of visitors from another world. Today from the skies of California, the fields of Kansas, the rice paddies of the Orient, the air lanes of the world, come persistent reports of UFOs Unidentified Flying Objects - which we have come to know as flying saucers.

In Dayton, Ohio, the Air Intelligence Command gathers and sifts data from all quarters of the globe. Ninety-seven percent of the objects prove on investigation to be of natural origin, but $3 \%$ still are listed as unknown. The Air Force is aware of the widely held belief that some of these could be flying saucers from another planet. While there is nothing conclusive in the evidence, the probing and digesting of information about UFOs continues unceasingly.

As a result, headquarters of the Hemispheric Defence Command in Colorado Springs issued an order. All military installations are to fire on sight at any flying objects not identifiable. But even if they did so [sic], the military wondered if their scientific know-how and their best weapons would be effective in any battle of the Earth versus the Flying Saucers.

The documentary also introduced to the audience films where UFOs and alien invasion were coupled with nuclear testing. Indeed, without the defence department supplied stock footage of nuclear explosions, many of the films would not have been made, as this footage was used time and time again.

A further variation on the documentary style of opening combines elements of apocalyptic warnings with the contemporary applications of science. The existential fear that was an element of post-Hiroshima culture is both reflected in and is a part of documentary beginnings. The golem of nuclear devastation that appeared in various fifties texts (discussed in chapter 2) found expression in films like Day the World Ended where on-screen text stating

What you are about to see may never happen, but to this anxious age in which we live, it presents a fearsome warning...Our story begins with ...THE END!

is followed by shots of the mushroom cloud of a nuclear explosion with an offscreen narrator suggesting he is reading or repeating some work of prophecy:

And the elements shall melt with fervent heat. The Earth also. And the works that were therein shall be burned up. This is T D Day. Total Destruction by nuclear weapons.

Doubtless Roger Corman's aptitude for taking successful plots and recycling them in cheaper versions was at work here. A similar structure to that above is followed in Pal's When Worlds Collide. Here the on-screen text reference is specific with a shot of a Bible opening to quotes from Jehovah's warning to Noah about his displeasure at events on Earth. The off-screen narrator then 
explains the possibility of collision with another planet and describes the constant search that men of science engage in the quest to discover some of the secrets of the universe. The similarity in the structure of this text with that of War of the Worlds is not necessarily coincidental as both were produced by George Pal at

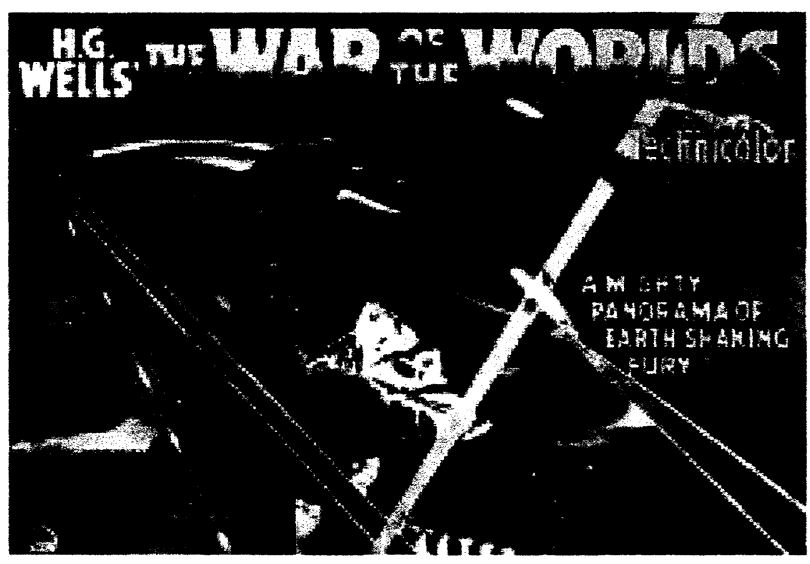

Figure 8: War of the Worlds exploited fear of the meaning of UFOs.

Paramount. Scientists were more than others aware of the potential for holocaust the nuclear sciences had revealed. In Them! the scientist Dr Medford states: "We may be witnesses to a Biblical prophecy come true: 'And there shall be destruction and darkness come upon creation and the beasts shall reign over the Earth'."

Ricouer's analysis and explanation of the process whereby authority is legitimated applies to science in fifties science fiction. Through its positioning as both the destroyer of and the saviour of civilisation, science is confirmed as a major institutional power, while its legitimacy to authority-and the limits and balances qualifying that authority-is both canvassed and contested in an arena with shifting goalposts. Science as a powerful authority claims legitimacy by virtue of its power, and while that claim is contested to varying degrees, its power is never denied. The power of science lies in its ability to both provide answers and to control the fundamental (that is, atomic) forces of nature. Its practitioners are privy to that understanding and have power over those forces. The metaphor I have been suggesting is similar to certain religious constructions, with science as revealed truth and scientists as priests. This discussion and metaphor is revisited in the next chapter.

While Ricouer's argument is evinced, Sontag's claims that the nature of science is a decontextualised ephemera without social and cultural underpinnings cannot be supported. The nature of science is indeed social, and its underpinning of political and cultural change is foregrounded in science 
fiction films of the decade. Even in the worst possible scenario, when science contributes to the end of civilisation in its present form, the simplistic argument that science itself is to blame is overturned in favour of the position that humans, as a political and social culture, make decisions that place themselves in potentially destructive situations. In these films the nature of science is never as crystallised as Sontag claims; the differences across films attest to the vigour of the argument and the breadth of positions. The nature of science in these films cannot be explained in a sentence; yet it does support the seed of liberation for women that suggests an equality with men, a liberation and an equality that may yet also be a chimera. The point is that the nature of science in these films is indeed woven in the social order of the films and the times, and its representation in films is a representation of a social practice that impacts on other social practices.

As in most critiques of science fiction film, the sciences discussed here have been those of the 'hard', inorganic or biological sciences (where the alien biology is the subject of examination). But another area of science is rarely, if ever, separated from the general discussion of sciences, and that science refers to human beings; that is, the sciences that deal with the human organism. An examination of those sciences, and the scientists represented as wielding that scientific knowledge, is both useful and uncovers new threads in the web of science fiction. 


\title{
Five
}

\section{Medical and psychological science}

\author{
"You're a doctor, please tell me."-Carol Manning, Amazing Colossal Man
}

The preceding chapter, and the other chapters in this thesis, have referred to the sciences of the inorganic or alien organic subjects. Indeed, the focus of the genre has been sciences like astronomy, physics, the nuclear sciences, aeronautics, anthropology, and biology (of the alien life form). As a general rule, scientists in science fiction films are experts in these 'hard' disciplines of science; the disciplines that can be grouped by their subject of study; that is, non-human material, and sometimes that material is organic. Yet the rule is generated by selective vision; another group of sciences is also represented in science fiction films; namely, the sciences concerned with the human organism in both its physical and sentient elements. Medical doctors, medical scientists and psychiatrists represent the human sciences. These scientists appear generally with other scientists of the non-human in films like Invaders From Mars and The Thing, but occasionally, as in Invasion of the Body Snatchers, they take the primary role in the film and other scientists are excluded. In this chapter the term 'human science' means science concerned with humans and their health, while 'human scientist' does not refer to the species of scientist, but rather to a scientist concerned with the human organism.

The concern of the human scientists is to preserve and study both the human organism and also the essential humanity of that organism against threats to that humanity, which might come from aliens in the case of Invasion of the Body Snatchers and Invaders From Mars, from other scientists in the case of The Thing, or from a scientific experiment that backfires in some way, in the case of Amazing Colossal Man. The questions this chapter addresses in a general sense are those that arise from these concerns:

- In any one film, are human scientists-doctors, for example-any different from the scientists of the material world and alien beings? 
- Does science in a general sense-that is, not human science-always benefit humanity?

- Do the human sciences always benefit humanity?

A common answer to these questions is impossible to sustain. The range of positions is traced later in this chapter, suffice to say that the range of threads is as diverse as those found in the previous chapters, evincing once again a shifting of the ground and an accommodation with change that are both reflected and argued in these films.

The construction and representation of human science is no different from the construction and representation of other sciences: human science is constructed not only through the representation of itself, but through its splicing into other cultural institutions, and it is through a constant weaving and reweaving that human science can define itself with respect to these other cultural institutions. Such negotiation does not operate at the level of abstract concepts, rather it is through the interaction of scientists with representatives of other institutions that the position of human science is negotiated, contested and defined. For the relationship is one of power, a dynamic relationship that involves the agents of cultural institutions-such as human scientists-persuading us, the audience, of the authenticity of their claims.

This group of human scientists operates in ways that are significant to a consideration of the function and nature of the 'human' sciences and the representation of these sciences within a broader cultural context. The relationship of this group to other institutions like the state, the military, the police and the community in which the group exists manifests the webs that underpin both the sciences of the body and mind and the institutional contexts. As in other chapters of this thesis, differing and opposing ideologies and positions are woven into the various webs of interactions, structures and representations. In brief, these films exhibit the general characteristic of focusing on the human, but in diverse ways and according to different paradigms that are sometimes in conflict:

- The subject of concern is the human rather than the alien. For example, rather than overcoming an invasion, scientists are concerned with the human within the context of an alien invasion. Where there is no alien invasion, the subject is still the human rather than the cataclysmic.

- The medical doctor does not exhibit the heroism of other scientists and the 
military in the face of alien incursions. He or she does not play a leading part in the destruction of the alien in those films where such destruction is part of the narrative.

- Some human scientists are integrated into the community, such as in Invaders From Mars and Invasion of the Body Snatchers, while others work for a military that keeps secrets from the community, as in Amazing Colossal Man. The notion of community is not fixed, but constantly reformulated.

- Human scientists act as metonyms for the state against the community when the community's protective mechanisms are perceived to have failed; at other times the state acts against the human, but so too does the community.

- Human scientists exhibit a concern for the individual, for the human, over the non-human.

- Rhetorically, human scientists perform a similar function to other scientists, establishing the scientific possibility of the logic and the events constructed in the film and arguing for the primacy of science as the legitimate explanatory paradigm. I tease out the rhetorical functioning of science and scientists in the discussion of Amazing Colossal Man, below.

This chapter draws on four films: Invasion of the Body Snatchers, Invaders from Mars, The Thing and, as stated above, Amazing Colossal Man. The films illustrate the range of positions in response to the questions posed at the beginning of the chapter:

- The Thing and Invaders From Mars construct the human scientists as dissimilar to other scientists, but in quite different ways. Amazing Colossal Man constructs human scientists as little different to others in that they work for the military, and withhold information from the community. Apart from the human scientist, no other type of scientist appears in Invasion of the Body Snatchers, but within that film the human scientists exhibit differences from each other.

- Invaders From Mars is the only film that argues that non-human science benefits humanity; the other three posit science as being potentially, if not actually, harmful to humanity.

- Invasion of the Body Snatchers is the only one of the four that suggests an ambivalent answer to the question of the extent to which the human sciences benefit humanity. The other films suggest that the human sciences will benefit humanity, within the paradigm, the logic, of the films. 
Given that diversity of positions, a systematic examination of the texts using those as organising principles would not result in a reasonably coherent argument. But another possible lever into the representation of the human scientists that takes into account the three questions posed at the beginning of the chapter is through the notion of community, which is a dominant thread running through the films. In all the films to some degree, the doctor, the human scientist, is the metonym for a human community (with human characteristics that are relative to the particular film and not absolute) that works against a science that seeks to impose the coldness of its rationality on the rest of the community. The cold, rational science does not necessarily include all the scientists, for in Invaders From Mars some scientists of the non-human are not 'cold', but in a general sense the statement is accurate.

It is almost as if an interest of fifties science fiction film is to define the human - both as an individual and within a community-through constructing the non-human, using the rhetorical device detailed in chapters two and four of constructing a particular case and then juxtaposing an alternative to it in order to highlight change and difference. Given the rapidity of change within the social context of the USA, the technology that promised robots, the ability to selfdestruct, the possibility of aliens, the fear generated by uncertainty that pervades fifties texts, the fear of mind control, then the appearance of speculations about the nature of the human do not appear out of place. Robots, like Robby in Forbidden Planet, can be seen as both a reflection of an interest in and the possibility of creating a mechanical man as well as a redefining of the human, posing, by virtue of their manifestation on screen, a question mark about the status and characteristics of the human. Indeed, Robby is an interesting figure because he begins a thread in science fiction film of the 'feeling' automaton, the robot that has feelings, further developed in the character of HAL in later films like 2001 where the humans are devoid of feelings. But in a general sense, the human sciences-with their focus on the essence of being that comprises the human, such as 'feeling' - contrasts with the coldness and belligerent rationality of a non-human science that has apparently abandoned a concern for the wellbeing of humans.

Similarly, the fifties context helps to explain the focus on community as a survival organism of the human species, responding to the threat of annihilation in a nuclear holocaust, or to the other fears that almost define the cold war. 
If the Martians didn't raze our civilization, then our scientists would. At a time when numerous Americans were afraid of one another-when the Right feared the Left, when the Left feared the Right, when many moderates feared contamination from either side-our films mirrored the preoccupations of the cold war.1

The human sciences are the 'caring' sciences, the sciences that nurture the human organism. Hence it follows that in the face of perceived annihilation, or alien invasion, or some other speculated possibility that would re-weave the social and cultural web, the refocussing on the human community as a functioning response is both legitimate and understandable. The healthy human community provides a possible response to and is a guardian against the scenarios that were in circulation. Again that suggestion is not one that relies on some version of a grand narrative, simply that some filmmakers perceived particular story lines that posed these sorts of arguments.

The films fill out the territory surrounding these questions, but without posing any definite answers common to all.

\section{Invasion of the Body Snatchers}

Invasion of the Body Snatchers has been interpreted in many ways, and one of the most popular is that the film warns of the consequences of communist infiltration. In the contemporary context of the cold war, the fear of mind control and the power of propaganda, such an interpretation is reasonable. However, the film transcends those immediate contexts to construct a world of simulacra, where the copy subsumes the original and finally destroys it in a way that seems to prophesy what Jean Baudrillard traces as the replacement of the real by the 'hyperreal', that is, 'by models of a real without origin or reality'. 2 Baudrillard is concerned that we might come to assume that there is nothing beyond the copy itself, nothing that indicates that there is an original with a history. These copies are the fourth stage of Baudrillard's phases of the image, where the copy bears no relation to any reality whatever and is its own pure simulacrum. ${ }^{3}$ The copy is without humanity, and it is in that interrogation of humanity through juxtaposition with the copy that the film is most powerful. It posits a humanity, and highlights it further through the construction of an alternative world where

\footnotetext{
Nora Sayre 1982 'Watch the skies' Grand Street 1:2 Winter, 51

Jean Baudrillard 1988 'Simulacra and simulations' Selected writings (ed Mark Poster) Oxford: Basil Blackwell, 166

Jean Baudrillard 1988, 170
} 
the systems are different, are inhuman. ${ }^{4}$ Just as the humans construct and exist within a community, so too do the simulacra, and it is the representation of community, and the place of the human sciences within it, that is a major concern of the film.

One element of the human is a sense of caring within a developed community. That community with which the caring doctor is interwoven exists in opposition to the isolation and alienation of the loner who is, in some way, estranged from the community. Such an opposition acts as a catalyst to crystallise the nature of the community, its homogeneity in the sense of its shared values, its heterogeneity in the sense of its gender and flexible class groupings, its sense of a number of intertextually related lives where continuity is the key to acceptance and to an understanding of the value of community. Body Snatchers argues that the strangers are in fact becoming the real, that the simulacra is truly that, because the original is no longer a factor in the equation. In Invaders From Mars, discussed below, the stranger takes on a different guise. In Body Snatchers the inhabited become the community in simulacrum, and the humans become the outsiders, the disappearing original. The community becomes something other than that constructed in the early scenes of the film, with the simulacra subsuming the human, destroying it in the process so that only vague traces remain within simulations.

In the system of argument suggested in this thesis, the status quo has to be defined and woven so that the changed, the new, can be contrasted strongly with the old. Hence the threads of the community of pre-invasion Santa Mira are described in the detail required for an understanding of the change. The human is made evident, and then made even clearer when the non-human is juxtaposed with it. The human scientist, in this case the medical doctor, is crucial to this web of meaning that is the composition of the human.

The empiricism of science has usurped the authority of religion to explain certain material elements of the universe, a usurpation that has continued since Copernicus claimed that the Earth circled the sun and not vice versa. A logical outgrowth of such a trend in the realm of the human is the transfer of religious functions from clerics to scientists. Thus a characteristic of medical doctors is

4 I Married a Monster From Outer Space also concerns itself with the turning of humans into simulacra. 
their priest-like function, through both their participation in the community over a long period of time and the authority that this work - caring for the health of people (a concept that mirrors the shift in the idea of health from the spiritual to the physical) - gives them, because they are in a position to know the private lives of the people in the community. Partly, the act of participating in the process of life and contributing positively to the protection and nurturing of life adds to their stature; partly, the linking of close secrets with the medical profession allows the comparison with priests. Dr Miles Bennell in Invasion of the Body Snatchers functions in a similar fashion to the minister Dr Blake likens herself to in Invaders From Mars, but there are marked differences that will be seen later.

Unlike Blake in Invaders, Bennell does not have to argue that the community should confide in him, as such a role is unproblematic. People come to consult him on all kinds of issues; medical as well as the more general healthrelated concerns they might have about themselves or others in the community. This model of the human community is constructed time and again: Becky comes to speak with Miles about her uncle; she is concerned for him. Miles is the community repository of health and sickness, to be consulted when people are concerned about the health and well being of others, both physically and otherwise. Young Jimmy Grimaldi is brought to Bennell complaining that his mother is not really his mother, for which Bennell prescribes pills for Jimmy to take, but in contrast to a similar scene in Invaders From Mars, he does not attempt to remove the child from his parents. Instead he asks the grandmother to look after the child for the night. He gives drugs-tablets every four hours, possibly to calm the boy down-but does not trespass on the ultimate right of parents, or an extended family member, to be responsible for their children. Bennell never extends his authority, nor is it extended to him, to the extent of breaking up the family unit. People know each other and the notion of 'stranger' is antithetical to the community, thus providing the dramatic contrast when the pods begin to colonise bodies, when simulacra become strangers to humans, and consolidate as a simulacrum of a community.

The family

As previous chapters have argued, the fifties were a time of quickening, of 
change. 5 The family, the nuclear family comprising two parents with 2.4 children living in suburbia, was the stereotype for white, middle and working class people but it was a contested stereotype, and it was, even as it was being established, slowly being rewoven under the influence of the changes in other threads. Nevertheless the notion of the family, in whatever guise, was still pivotal to a sense of community; the family remained the fundamental unit within this community, but it was a family in a state of redefinition, where the ideal was a marriage of the cosmopolitanism through education and travel of Becky and Miles with the caring elements of a small-town community.

Becky, after her stint of marriage in London and divorce in Reno, returns to live in Santa Mira with her father, who is, initially, supportive of her and her activities. A similar network exists for the child who is brought to Bennell by the grandmother: an extended family network exists in the small community, although not in the same house. People are related to others living in the community, and take some interest in the affairs of others in their family. The narrative imperative of bringing Becky and Miles together occurs through such an extended family: Becky is worried about her cousin, Wilma, who is obviously known to Bennell through his immediate response, as is the fact that Becky and Wilma are cousins:

$\begin{array}{ll}\text { Bennell: } & \text { Now seriously, what's the trouble? } \\ \text { Becky: } & \text { It's my cousin. } \\ \text { Bennell: } & \text { Wilma? What's the matter with her? } \\ \text { Becky: } & \text { She has a... well I guess you'd call it a delusion. You know her } \\ & \text { uncle, Uncle Ira? } \\ \text { Bennell: } & \text { Sure, I'm his doctor. } \\ \text { Becky: } & \text { Well Miles, she's got herself thinking he isn't her uncle. }\end{array}$

Here is the web of family relationships that make up a small-town community. Becky is, firstly, concerned about her cousin, a relative she has not seen for some five years. Her concern is such that she visits one of the community doctors of her own volition. Her cousin is convinced that her uncle is not her uncle, not a significant fact to this point but what is significant is the fact that the family is so extended. The second aspect to this extended family network is that Miles knows them all, as he is the doctor for 'Uncle Ira' and knows Wilma is Becky's cousin. This information is, as indicated by his speech responses and manner, well

5 see also David Halberstam 1993 The fifties New York: Fawcett Columbine, 799 
known to him.

\section{Doctoring the mind}

A relatively new thread in the web of community is the community psychiatrist, the doctor of the mind who works in concert with the doctor of the body. The psychiatrist is no longer just a doctor for the wealthy groups in the social web, but the burgeoning middle class as well. The belief that the mind was a very unstable entity, subject to control without the conscious knowledge of the person, is a significant thread in the construction of the mind and manifests in other texts such as The hidden persuaders, ${ }^{6}$ and in films-like It Conquered the World and Killers From Space-where mind control, truth drugs and the practice of brainwashing are unexamined threads in human society.

The psychiatrist is introduced in Body Snatchers, not as one who deals with madness in whatever guise, but simply as one who, as a functionary of modern society, 'helps' people. The work of the psychiatrist, Dan Kauffman, is introduced to us when Miles visits Wilma, Becky's cousin, to talk with her about Uncle Ira. She is concerned that she is going 'crazy':

Wilma: $\quad$ Miles, am I going crazy? Don't spare me, I've got to know.

Miles: $\quad$ No you're not. Even these days it isn't as easy to go crazy as you might think. But you don't need to be losing your mind to need psychiatric help. I'd like you to see a doctor friend of mine.

Miles is genuine in his respect for psychiatrists and psychiatry and in his belief in their role. He constructs psychiatry as a 'help', a way of talking about and resolving a problem. But although Miles is sincere in his recommendation to Wilma, he shares with the rest of society the seemingly playful disdain for the psychiatrist. He meets Kauffman in the company of another doctor-who, by the way, is also a part of the community because he 'brought Becky into the world'-and this conversation ensues:

Miles: $\quad$ This is Miss Driscoll. Dr Kauffman. Our one and only psychiatrist.

Becky: $\quad$ How do you do.

Miles: $\quad$ Watch out what you say. Ed, you remember Becky.

Dr Percy: I I should. I brought her into the world.

Dr Kauffman: You did us all a favour.

Becky: Hullo Dr Percy.

Miles: $\quad$ This saves me a phone call. I've got a mixed-up kid and a woman who need a witch doctor.

6 Vance Packard 1957 The hidden persuaders New York: McKay 
Dr Kauffman: The boy says his father isn't his father and the woman says her sister isn't her sister.

Miles: $\quad$ That's pretty close. I knew you'd been studying hypnosis but when did you start reading minds.

Becky is introduced to Dr Kauffman because, obviously, he had not met her. But in addition, he stands for psychiatry in general, and in the small community that is a relatively new discipline, a new agency. Miles knows the value of psychiatry; as a GP he referred a patient to the psychiatrist, but he mirrors the ambivalence of community attitudes to psychiatry in the metaphor of witch doctor, and his reference to hypnosis and mind reading. The psychiatrist, then, is not the personification of the community health custodian as is the physician. Along with the rest of the community, both Dr Percy and Dr Kauffman succumb to the pods and the changes they bring. Psychiatry is no defence; knowledge of the workings of the mind is no defence.

The human scientist not only cares for the people in the community, but he (Miles) also establishes conventions and argues for change to those conventions within that community. As an educated person who has had the benefit of exposure to the cosmopolitanism of contemporary university environments, and the cities in which they exist, his positioning as an agent of social change is respected within that community. In one sense the film is progressive, even radical, in its construction of divorce and divorced men and women as being acceptable to a closely-knit, small and therefore conservative community. Within that community traditional values exist: extended families-with the care and concern for others in the family-childhood, the suburban houses with lawns, demarcated from those of others by a picket fence, education as a force for social mobility and prestige, and the feelings and emotions generated by closeness and these community values.

Becky articulates her desire to enjoy and live for these values when she is threatened by the pod civilisation, "I want to love and be loved. I want your children. I don't want a world without love or grief or beauty. I'd rather die." According to the film, these are the essential human qualities, the defining characteristics that separate humans and their simulacra. Miles indicates that the process of dehumanisation is not sudden.

Miles: In my practice I've seen how people have allowed their humanity to drain away. Only it happens slowly instead of all at once. They didn't séem to mind.

Becky: Just some people? 
Miles: $\quad$ All of us a little bit. We harden our hearts, grow callous. Only when we have to fight to stay human do we realise how precious it is to us, how dear.

Miles likens tendencies in contemporary pod-less communities to the podaffected communities. Miles means that the problem is not just one caused by pods, but a general malaise, a general loss of the difficult-to-define 'humanity' that binds people in functional and happy communities. That humanity includes those elements associated with the heart in heart/head dichotomies: emotion, love, grief, procreation, warmth, and beauty. Those are the human, heart values with which the physician, concerned with the health of the whole being within the small-town community can appreciate and align himself with. And those values are not always those of the non-human sciences. The scientist of the body is concerned with the health of the individual bodies and the community body. His (in this case) fight against the inhumanity that is both a product of the times and the pod invasion is the type of fight a physician has to engage in. The scene with Wilma and Miles talking together on the lawn at her home is a cosy representation of the idealised fifties community except for the fact that it is under threat from internal and external influences. That community is nonthreatening in an overt sense, and comprises a blending of traditional and modern elements, combining in a way that is both idealised, and mysteriously, providing a context for the establishment of the pod civilisation.

The pod civilisation is not the only alien group casting lecherous eyes over the resources and beings of planet Earth, or more specifically, the US section of it. The Martians are coveting those resources, and in their attempted colonisation they highlight elements of US society that in some cases parallel, and in others contrast with those of Body Snatchers.

\section{Invaders from Mars}

As with many science fiction films, at first glance Invaders From Mars is narratively similar to Invasion of the Body Snatchers. An alien force lands on Earth and colonises through the establishment of a fifth column within the established social order, whose purpose is to assist the aliens in their goal. Yet distinctive differences in social and political threads in the films are clear. The function and responsibility of the doctor are examples.

Dr Pat Blake attends the young David after a series of traumatic events. She 
says, 'Doctors are sort of like ministers; you can tell them anything.' The similar function of medicine and religion is foregrounded while the displacement of a function of religion by medical science is clear. She is his confessor and his friend but in a different way from Bennell in Body Snatchers. In the same way that the power of religion manifests in part through its participation in the formation of community and its consequent intimacy with the life of the community, the medical scientist acts as a metonym for the state-indeed, she is a state employee-and the state is now the repository of information about the comings and goings, and both public and private activities, of the citizens of the community. The state enters the private lives of its citizens and uses that knowledge in ways that are appropriate to its self-described aims. Blake signifies this intrusion of the state into both the private domain (signifying as well the dissolution of that notion of privacy), and into a domain of trust that was traditionally generated between community institutions and individuals by virtue of their participation in the community over time. In this state the trust is not generated in this way but is replaced by a simple telling of whom is to be trusted. She greets the young David in the police station:

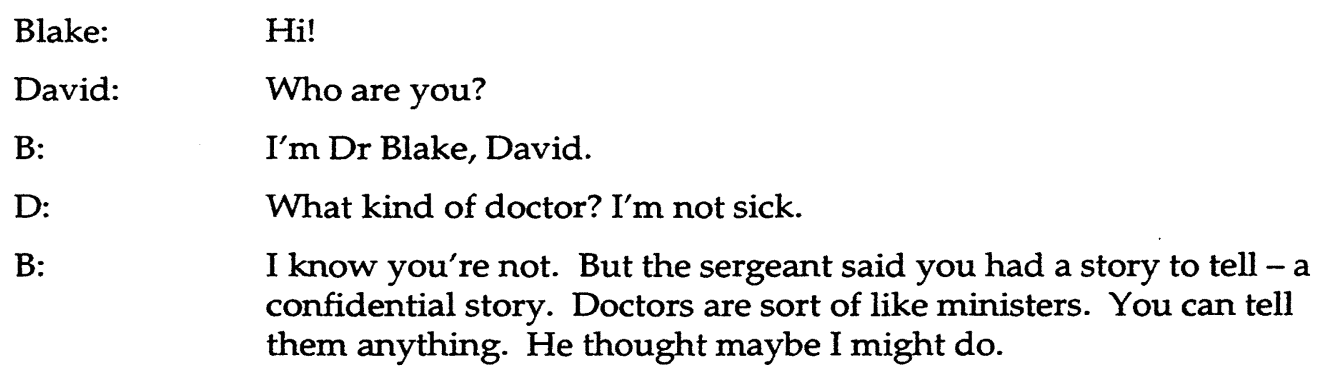
confidential story. Doctors are sort of like ministers. You can tell them anything. He thought maybe I might do.

The alienating, anonymous corporate state is implicit in the trademark 'Hi!', the jovial bonhomie of one who does not know the addressed but has some interest in speaking with him. The reply is that of one who is not interested and who is suspicious. David's subsequent trust in Pat Blake can occur only because she tells him that she is trustworthy by virtue of her profession. While David is convinced by this argument, the fact that it has to be so stated and argued suggests that he does not automatically see her as similar to a minister, as one who can be confided in by virtue of her community stature. The familiarity that is a product of time spent in a community is absent.

Significantly perhaps, women are sometimes personified as being able to overcome a certain reticence on the part of some characters. Dr Joyce in It Came From Beneath the Sea mobilises both her feminine charms and an assumed role as 
psychiatrist to elicit information from a sailor who has been traumatised-as one would be-by his experiences in escaping from a giant octopus. Suggestive acts lull the sailor into a sense of warmth and break down any resistance he might have to opening up and telling her the truth about events concerning the giant octopus, stories that he had not told other male psychiatrist interviewers for fear of being labelled as insane. Similarly in The Brain Machine, a film that is marginally science fiction, the British psychiatrist acts in a similar fashion towards an unstable patient from whom she is trying to elicit information.

As in Body Snatchers, the strangers highlights the threads of community by virtue of their 'strangeness'. The strangers in Invaders are the parents after they have been implanted and the state, through its agents like Pat Blake, then steps in to ensure the community is protected, and to assume the protective role of the community against the stranger. The naturalised position being argued is that the state is incorruptible, while the parents are. The parents are constructed as in some way incapable of fulfilling their protective roles, signifying a serious incursion into the formation of the family as the fundamental unit of community. Into the vacuum created by this corruption is drawn the state in the person of $\mathrm{Dr}$ Blake, acting to protect where the family has failed. 7 The state is the macrocosmic community and is not prone to corruption where the microcosmic, or local, community may be. The construction of the state in a caring role is significant, as the state usurps the power of the community when the community as exemplified by the parents can no longer provide proper care and guidance. When faced with a child who is convinced his parents are not really his parents, Dr Blake assumes legal responsibility for the child through the authority vested in her by a government agency, the city health department.

Even though certain individuals within the state are corrupted, this makes no difference to the state's overall integrity, as such blemishes have little impact in the long term on an institution that is essentially acting for the good of others. In this state, children can be and are locked in jails for their 'own good', as Blake explains to the child. Isolation and imprisonment are justified when it is in the best interests of the child, interests that are judged and determined by the state. Thus the relationship of the doctor with the state is a constantly rewoven thread.

7 This thread emphasising the protective role of the state is a minor, but significant element in later science fiction like the Terminator films, where the camera angle is such that the police motto 'To protect and to serve' is enlarged momentarily on screen. 
In Invaders From Mars the doctor Blake foregrounds the contrasting paradigms of state and those of the community we have seen in operation above. She is a metonym for the 'caring' function of the state against parents who are uncaring, and the city health department for whom she works emulates those government departments that oversee and regulate interactions in a state that is caring to a fault. The conversation between Blake and David, above, could not have occurred in the small community of the traditional, conservative US mould but only in the anonymous, alienated neo-community created as an adjunct to the technical, scientific state that stepped in when necessary to defend the communal life.

The function of the human scientist is to protect people, possibly requiring intervention that is both authoritarian and that flows from a conception of the state as an all-powerful bureaucracy, wielding power even over the unit of society that is traditionally and mythically the foundation of free society; namely, the family. When parents act in ways not condoned by the state, the state may intervene as it sees fit. Blake prevents David's parents from taking him away from her control and she then places her arm around his shoulders while he puts his arm around her waist. Acting metonymically as the state, Blake is able to command the enforcement arm of the state to assist her in preventing the natural parents removing their son from the police station. Mrs Maclean, David's mother, arrives to collect him from the station whereupon David is very happy but we, the audience, know his happiness is illusory through close-ups of her face: the mother has been implanted. As mother and son walk to the door of the station it opens and the father, George, appears. David pulls away from the mother yelling "No! No!". Dr Blake—who has been speaking on the phone-emerges from the office:

Pat Blake: Just a minute. Sergeant, that boy is not to leave this building. George (father): Who are you?

Pat: I'm Doctor Blake from the city health department. Your son is in my care.

G: $\quad$ He is not. Chief Barros told my wife...

P: $\quad$ I don't care what anybody told her, the boy stays here.

Mother: What's be been telling you? He's been reading those trashy science fiction magazines. He's completely out of control.

P: $\quad$ It may interest you to know, Mrs McLean, that your son is running a high temperature. His heart action is unnaturally fast. It's too soon to tell but he has every symptom of polio and I'm having him 
removed to the isolation ward of the general hospital. [She stands with her arm around her right shoulder; his around her waist. She is his protector.]

M: $\quad$ No. He has to go with us.

P: $\quad$ If he's well in the morning we'll discuss it then.

She does not have to request the parents; she is quite within her rights to command. The hierarchy is such that she has the authority to command the police sergeant in her position as an officer of the state health department. She can even override the command of the police chief and the police sergeant is bound to obey her rather than his own chief. She is able to act unilaterally and without being accountable in removing the child from the family. She functions from then on as his protector and for most of the film she is in his company often with her arms around his shoulders with him standing in front of her.

At another level the metaphor of the family is reinforced. While this might appear contrary to the argument that the state-as-community functioned to disempower the family, it suggests a new and different conception of the family for a new and different social and political formation. The film foregrounds the wedding of knowledge and caring, nature and nurture, in the relationship of Blake with Stu Kelston. Blake, the maternal and female, the caring and protecting agent joins with two related element of the masculine: the powerful and the knowledgeable (in the Cartesian sense), embodied in the military as protector against external threats, and second, the signifier of powerful knowledge, the astronomer Stu Kelston. The masculine and feminine act cooperatively to protect and nurture the son of the union, David. This relationship, comprising male and female, links the notion of parenting to the function of the state. In the absence of suitable parents, the state assumes parenthood and can do that, the film argues, without any other interest besides that of the child. The state is the overarching parent, the parent that steps in because the older family paradigm is no longer appropriate to the new world where threats may arise within that structure.

In order to have the protection of the state some personal rights have to be foregone especially when the protection so provided is for one's own good. The democratic state sometimes needs to be authoritarian in order to protect that democracy. After a discussion with David, Blake walks out of the cell where they have been talking and locks it. He complains and her reply indicates that it is just for the rules; she was doing it only because of the rules. Some people have to be locked up for their own good and that incarceration is, paradoxically, their 
protection in a cell which is, paradoxically, a location of safety. The institution is the safe place; not the traditional family.

Invaders is not a radical film in the way that It Came From Outer Space is a left-wing film. ${ }^{8}$ It is not a right-wing film, because it argues that the centre coalition of science and the military are the guardians of the community. It is then, partly by default, centrist, liberal-democratic and syndicalist but in its centrism it argues for, in effect, a view of the state that is closer to Stalinist practice than the normal conception of free-world and western. Besides assuming the functions of parents, the state can imprison for one's own good. The individual, having committed no wrong, can be deprived of his freedom for no reason except to comply with the rules that can't be questioned. The state can remove children from their parents if an accusation is made against the parents or the state believes the parents to be not acting in the child's best interests. In so doing the state always acts with the best interests of the populace at heart and never out of self-interest or against the interest of its citizens, although outward appearances might contradict this tenet. Traditional parents are not trustworthy in that sometimes, through no fault of their own, they act without the best interests of the populace or their children at heart. Children are able to complain about this to the security forces, in this case the police, who will investigate the story or have it investigated. Children have to be removed from their influence in order to be protected and the state has this right. In a similar thread the scientists in Amazing Colossal Man are associated with the powerful state whose motives are hidden and not able to be questioned in the normal course of events.

While Dr Bennell, in Body Snatchers, is an authority in the community because he has been there for enough time to establish his membership, Blake seems to be something of an outsider in the community. While Blake has to tell the boy that she is trustworthy, Bennell would never have to do that in any conscious sense; his authority is unproblematic. He is conservative in his attitudes about and to the community, in contrast to the radical syndicalism argued positively in Invaders From Mars. He is a traditional physician in his medicine, and because he is in private practice, the secrets he learns by virtue of his profession do not belong to the state. In contrast, Blake is an employee of a

8 Peter Biskind 1983 Seeing is believing New York: Pantheon, 102-159, classifies films in these terms. 
government agency, which compromises the secrets that she learns by virtue of her pastoral role. While Blake is able, through her status as a government officer to command policemen, Bennell does not have any power over the instruments of the state and does not command the forces of the law. In fact, the opposite is the case: the forces of law attempt to control and command him; much of the narrative focuses on this attempted controlling.

Nevertheless, it cannot be forgotten that David's natural father is a scientist, and so, while science is important, it is, or it should be, subject to the control of the state acting as both an agent of the family, but also as the family in macrocosm. A similar argument is sustained in The Thing, discussed below. The film also utilises the fear that reading comics would turn one's brain into jelly, and one's life into juvenile delinquency. It is the implanted father who, in his attempt to regain control of his son, suggests that his son is imagining the story about seeing aliens and that such imagining is the consequence of reading too many comic books. In the context of the fifties, such an argument was not unusual. 9

\section{Amazing Colossal Man}

Another version of the human scientist acting as an agent of the state is the case of the human scientists in Amazing Colossal Man. Here the threat to 'community' in its various guises is not only from external sources as represented by some kind of alien life form, but also from an alliance of medicine and the military whose concern is to hide information from the community. The doctors in Amazing Colossal Man have no contact with any public community; even the military community in which they function is limited, initially to a military hospital and then to a secret research hospital. Within that military community the doctor's work is secret. (Recall that the doctors in Killers From Space work with the military and the government, administering truth drugs to another scientist on the command of the FBI, to discover secrets the scientist might have about aliens.)

For the community of the general public, signified to some extent by Colonel Manning's fiance Carol, the case of Manning remains secret through the

9 Shearon Lowery \& Melvin Fleur 1988 'Seduction of the innocent: the great comic book scare' Milestones in mass communication research London: Longman 
strategies of a medical-military alliance that not only attempts to hide the information from the public but attempts to alter records so that no trace of Manning publicly exists. On trying to find Manning at the military hospital Carol finds that he is not listed as a patient and that no record of him exists nor is there any public record of the two doctors who have worked on Manning-one of whom she met at the hospital at the time of his initial surgery-Doctors Linstrom and Coulter. Carol reads the receptionist's address list and discovers that both doctors are listed now at a military research hospital in Nevada. On arrival at the Nevada hospital the gatekeeper informs her that the hospital has had no patients since the war; others in the research centre also claim to know nothing of Manning. The only contact the hospital has with the local community is a truck delivering supplies of meat at which time the guards at the gate make it clear that any speculation on the part of the driver about the research hospital's work was not welcome and would not be responded to. The work of these doctors is not in the interests of the public community, nor especially of the individual in that they work to prevent Manning from growing on the one hand, but on the other to research and document the processes that are occurring to him. Their interest is scientific in that it focuses on the effects of exposure to nuclear weapons on the human body, but the community's interests are not those of Doctors Coulter and Linstrom. The community is signified only by occasional shots of a television news anchor asking the government-but speaking to the invisible audience of the news broadcast and also to us, the audience of the film-what is going on in the research hospital.

Colossal Man with Invasion of the Saucer Men and The Blob mobilises the suspicions we might have about the secretive predilections of the state and develops that thread into an organising principle of the narrative. That we are not always told the truth by the state or, at another level, that we are told deliberate lies in order to distract attention from the real situation is an element in the context of the fifties discussed in chapter 2.

\section{The rhetoric of medical science}

As I indicated above, human science has a rhetorical function in a similar vein to non-human sciences. While the function of the medical scientists in the film is to work for the interests of science rather than the community, their 
rhetorical function is to explain science and to give credence to the fiction of the narrative. The explanatory mise-en-scene of Amazing Colossal Man resembles that in other films where other types of scientist, non-human as well as human, explain the unknown to the audience. In the first instance the medical doctors are bandaging Glen Manning immediately after his exposure to the blast.

One doctor exclaims that he, Manning, has burns to $100 \%$ of his body and expresses amazement that he should be alive with such massive burns. He continues: 'He'll die of shock before morning and if that doesn't do it infection will....He's already lost enough body fluid to be fatal.' We are exposed to the information that shock or infection will kill where there are such extensive burns, and that body fluids such as lymph are essential to fighting infection. It is through such information that the filmmaker achieves two effects: we learn about the physiological effects of burns and they learn that, because Manning still lives, something out of the ordinary has occurred. Without this explanation of the normal, we cannot appreciate the abnormal as abnormal. As we have seen in the case of other sciences, the rhetoric of the human sciences establishes the possibility that the events constructed in the film could occur, that the science underpinning those events is more than plausible, and thus the audiences can enter into the 'willing suspension of disbelief'. For example, in a later scene the two medical researchers explain the problem to a physicist and the reasons for the sense of strangeness, the reasons the audience should register the events as out-of-the-normal. Dr Linstrom explains:

When sixty or seventy percent of a person's body is burned, he doesn't have much chance for survival. Now if he should live, the skin that was destroyed does not grow back; it remains dead scar tissue. When a man suffers over $95 \%$ body-burn and less than a day later looks normal I'd say there was a mystery.

Linstrom speculates that there might have been some effect of the plutonium explosion of which medical scientists were unaware, but which could cause skin and tissue to regenerate. He states the obvious: that such knowledge would be of massive benefit. Following that, the physicist-who, we learn, had been in charge of the plutonium explosion-shows a film of the explosion to describe the effects. Through stock footage of two houses being obliterated, this film-within-a-film shows the first wave of intense heat following the explosion, then the blast. The effects are as realistic as the documentary genre allows. The film-within-a-film functions to show what many films had shown since the early 
1950s, that a nuclear explosion is an extremely powerful event. But narratively, the film-within-a-film here functions as part of the structuring of the admission by the scientist that their knowledge is limited, and that, as he puts it, "Something out there is beyond the limits of our knowledge." We are told that we are crossing the boundaries of knowledge: it is not that physicists and medical researchers know everything; it is that their knowledge reveals itself to be limited. That is, because of their learning and knowledge the possibilities that the film canvasses might be quite plausible, and from this point in the rhetorical process the rest of the film's narrative becomes something other than idle speculation of a religious prophet. The film speculates on possible unknowns, speculates that all is not certain. In the realm of the scientific certainty, more possibilities become apparent, and these are exploited a few scenes later when Linstrom and Coulter explain to Carol Forrest (and us) the process whereby Manning is growing. Once more, they explain the scientific process whereby the body heals itself, followed by the point where their knowledge is no longer sufficient, the point in the narrative where the 'strangeness' is made clear and explained without being solved.

Forrest: What happened? What made him grow?

Coulter: Glen Manning is growing from eight to ten feet a day. At the moment he's 18 feet tall. Tomorrow he'll be 26. The next day 35, maybe 40 and the next day...

F: $\quad$ But you've got to stop it.

Linstrom: $\quad$ Miss Forrest, we're trying, believe me we're trying. Let me explain it to you. Now as you probably already know the body is like a factory, continually producing new cells to replace older cells, damaged cells or destroyed cells. Now this happens in all the different parts of the body. Bone cells grow new bone cells, skin cells grow new skin cells and so on, throughout the body. Now let me show you. (He walks over to an illustration, a graphic, and places an X-ray on the viewer) Now the broken bone shown in this $X$-ray became the healed bone in this $X$-ray, by means of bone cell growth. Now notice that the new cells join the broken bone together so that you no longer see any break.

Now a cut, say in your hand, heals in the same way, with new cells replacing the damaged ones.

C: $\quad$ It is this delicately balanced process of new cells replacing dying cells or damaged cells that's causing the growth problems of Glen.

F: But how can this make his whole body grow?

C: $\quad$ The whole process is out of balance. For some unknown reason new cells are growing at an accelerated or speeded-up rate, while at the same time the old cells are refusing to die. This is what makes Glen grow. That's what made the new skin. 
As I've noted in earlier chapters, the power of science is that it is able to explain phenomena and here its power is to explain phenomena associated with the human body, and in this case the explanation of the mutation process is similar to the process of growth of cancerous cells. While in the last years of the $20^{\text {th }}$ century such an explanation of tissue growth and mutation might be redundant, in the fifties such health information was not as readily available in a broad sense, in the television documentaries, illustrated magazine articles and other media events that saturate today's context. Through science, both in its principles and also its applied form as technology, the human organism is being explored and understood, while posing new questions in the process. The human scientists are concerned with the human being involved in the accident, and with the possibility of advances in healing that seem to be occurring with Manning. The fact that the military wants the episode kept a secret does not violate the general claim that the doctors are concerned for people, for humanity, with whatever qualities or otherwise that humanity is constructed.

Rhetoric, then, was not only used to explain to us and convince us of the power of non-human science, but also the power of human sciences.

\section{The Thing}

In The Thing the human scientist, the medical doctor Chapman, is similarly associated with the military, but here the debate is between on the one hand the military as metonym for community of which Chapman is spokesperson and scientific equal to the Nobel Prize-winning Dr Carrington, who, on the other hand, heads the community of science and the 'inhumanness' it represents. The military 'family' is the microcosm of the US community, and is constructed through appropriate codes: the warmth of a fire while a blizzard is raging, the bonhomie and camaraderie of the team, the naturalised authority of the leader as well as his egalitarianism, the sense of family coded by Hendry with his wife-tobe, Miss Nicholson, with 'the children' airmen grouped around as a family unit. That community stands for the wider community of the United States, with a naturalised family as its template for the social web. The logical systems of community are constructed with humanity as the focus, and this focus is implacably opposed to the community of science, which is the binary in its foundations; that is, the community of science is a logical system based on the 
quest for knowledge without regard to consequences. The human community in this film is supremely ecological, as it stands against the science that does not take into account global consequences of actions that further the realms of knowledge.

Dr Chapman is a retiring figure through much of this film, but at crucial times his role is foregrounded together with his support for the discourse of the family sustained by Captain Hendry and the other airmen, against the cold, rational science argued most forcefully by Professor Carrington; as a scientific equal he sides with and speaks for humanity against science. The difference is one of logic, based on reason and the Hippocratic oath, a rational system where the criteria for rationality is the health of humans, as opposed to a rational system where the criteria for rationality is a concern for knowledge that subsumes the interests of the

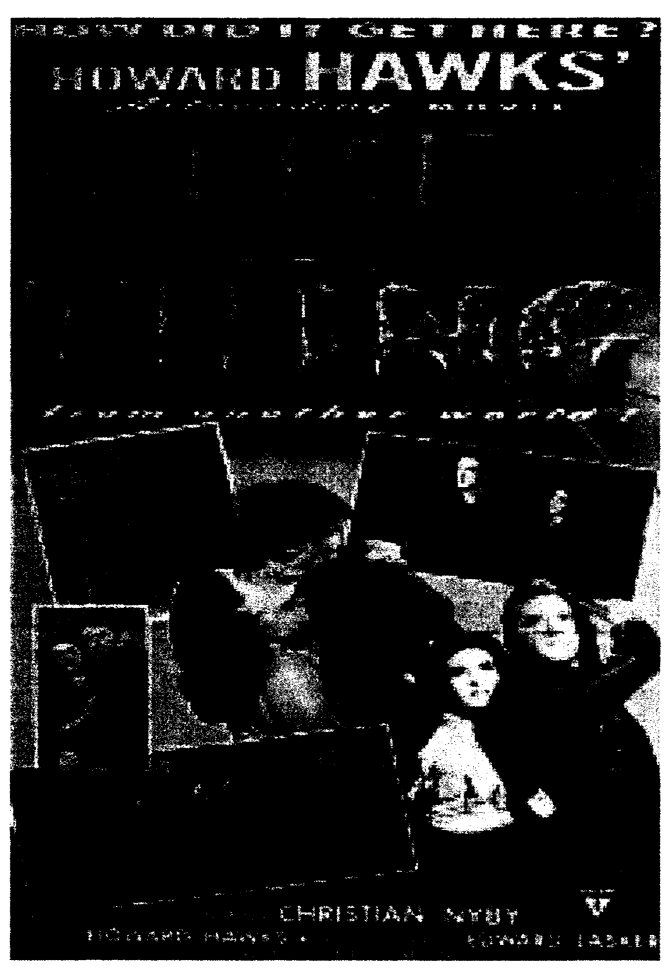

Figure 9: The community must prevail over untrammelled science.

human to scientific knowledge.

Chapman's concern for humanity drives his opposition to Carrington's reification of the quest for scientific knowledge:

Carrington: [to Chapman] Excuse me Doctor, may I?

[To Hendry] Captain. In relation to removing the body from the ice, I'd like to point out that there are organisms that survive after death and that cold can destroy them. In view of...

Chapman: On the other hand these same organisms may be dangerous. They may be carrying disease germs from another planet, germs we couldn't cope with medically....

The threads that Chapman articulates are those represented by Captain Hendry, where a sense of caring is foregrounded, even though Hendry himself is outwardly brusque, uncaring. It is a world that clearly chooses the human over 'knowledge'. This world of the medical doctor, airmen and woman contrasts with and opposes the world of science, which is driven by a different set of rules 
and priorities. Here we see most clearly the fissuring at the interface of the rational processes of human science and those of the non-human sciences:

Chapman: We've read your notes, Doctor. I think you should have consulted with the rest of us.

Carrington: I have all the help I need. Your opinion has not been asked.

Chapman: It has, by Captain Hendry. I've given it to him. I'll repeat it for you. We're facing something unpredictably dangerous. The creature in the greenhouse is obviously multiplying itself in an identical fashion.

$\cdots$

It'll need more blood. It'll make every effort to obtain what it needs.

Carrington: It's imprisoned. It's therefore harmless.

Chapman: How can you be sure of our safety, or more importantly, the safety of the world?

Through the juxtaposition of the human and non-human scientists and their respective arguments, the case for, and the parameters of, a human community is established and thrown into relief. The ecological argument-that is, that the consequences of actions now possible through science, will have effects that go far beyond the present and the immediate geographic context-is espoused to further a 'traditional' representation of the human community, yet the argument itself is one that is only possible when science has created tools that threaten the very existence of that humanity. The ecological paradigm, the notion that global consequences might result from actions, is an emerging construct of the fifties, in the sense that global destruction was not threatened by a vengeful Creator as a result of transgression of laws, but by human beings who have now that power that was previously reserved to such a Creator/Destroyer.

The function of the human scientist is to safeguard the existence of the 'normal' humans against the excesses of the scientists who, as Hendry pointedly states at the beginning of the film, created the atom bomb. The human scientist appreciates the human community as the most significant priority in decisionmaking that impacts on that humanity and is able, through his or her scientific education, to argue the human case on equal terms with non-human scientists. The caring tradition of medicine is extrapolated into the caring for the health of the community, and the human scientist is the custodian of the health of the community.

In the literature of fifties science fiction film, the human sciences have been 
either neglected or subsumed into the discussion of the general sciences as a matter of course. Yet these sciences focus attention on such questions as the definition of the human in the face of experiments and practices in science that challenge and question established understandings and definitions of the human and the community that humans establish. Nuclear power harnessed in weapons that could destroy much human life, scientific achievements that appear to reify the quest for knowledge over the life and growth of humans and their communal web, a military and industrial complex that is not accountable to a human community; all are issues that are both reflected in and proposed by science fiction films where the human sciences are represented.

In general, the human scientists assist in establishing benchmarks for the human. They act in ways that counter the practices of the inorganic sciences, when those sciences suggest that the human is not an element in the consideration of priorities. The human scientists, in these films at least, argue for considerations of the human, as that humanity is defined within the film. The films, in turn, argue for a human science that is focussed on the human and where the doctor of the human organism establishes control over the arguable excesses of a non-human science. The human scientists argue from a foundation similar to the non-human scientists in terms of levels of learning and intellectual capacity, hence they are able to articulate a coherent argument that the unlearned yet eminently practical, such as Captain Hendry, are not able to voice. In these films, the human scientists are generally a subversive group in the web of science, but a force for humanity in the web of community.

The films establish notions of community, changing notions to be sure, but like many other science fiction films of the decade, these too participate in a discourse of change, of debate, of re-formation and re-definition. The films argue for the practices of community that are conducive to the strengthening of that community. New notions of community spring up in the face of change, in the face of fear, to re-establish the familiar and to embrace and draw into themselves the changed rules and practices that have to be absorbed into community, such as new constructions of marriage, and divorce. The re-establishment of the rule of the community is coexistent with fears of losing some central criteria of the human that the context of history and culture threatens.

The human scientist deserves closer attention and consideration in science fiction films, as his or her practices are not the same as those of other scientists, 
and the function of the human scientists is often to counter the practices of the non-human scientists. 


\section{Conclusion}

By 1961 science fiction films were losing their appeal to filmmakers. In that year only ten were made, even using the very broad, inclusive criteria for science fiction film that Willis uses (that has been commented on earlier). ${ }^{1}$ The decline continued throughout the sixties, until 2001: A Space Odyssey was released in 1968 and re-invigorated and rewrote the genre partly through a narrative that reflected contemporary concerns and through special effects that utilised contemporary technology. In a sense though, 2001 only repeated what other successful science fiction films had done; that is, it took a particular speculation - in this case the suggestion that human life was initiated and was in some way influenced by extra-terrestrial consciousness-and wove it into a credible narrative. The film also drew on the contemporary culture of hallucinogenic drugs in both its special effects and the narrative of some kind of 'cosmic rebirth' into a different state of consciousness. In addition, 2001 turned science fiction films into a legitimate and successful art film form. It too, then owes its success to representing and recycling contemporary cultural threads.

From 2001, emerging possibilities in the area of special effects, as well as different social and cultural threads, saw the genre metamorphose into the bigbudget, technically spectacular films like the Terminator duo, the Alien quartet and the Robocop series. It would be wrong to view these later films as only special effects extravaganzas. The films mirror, argue for, and trace changes in cultural threads and concerns about the nature of science and technology, for example. The same concerns that are apparent in fifties science fiction films, with some changes because of changing specifics; that is, the relationship between science and society; the relationship between technology and society; the nature, roles and construction of men and women that is canvassed in Terminator 2; the nature of the human, in the same film; the nature versus nurture argument in Aliens, and so on. Science fiction films continue to explore the possibilities, and reflect and distort current threads in the web of culture and history, a web that is

1 Donald Willis (ed) 1985 Variety's complete science fiction reviews New York: Garland 
marked by continual change and re-weaving without which science fiction film would be difficult to envisage. That generic characteristic germinated and first flowered in fifties science fiction film.

This thesis has a number of threads woven through it. One is the linking of science with change in a very generalised sense, but also the particular changes brought about by science that were both the subject and the motive force of the narrative, the science that argued for change, the science that speculated about change, the science that generated change. Applied science and technology continued to impact on filmmaking, and new techniques were mobilised in the transmogrification through special effects into the real. This science existed in, and in part moulded, the context: a context of change within culture, history and within the film industry. A significant group of threads tracked the response to change in such developments as the reformulation of community, the notion of community, and the various roles of governments, science and individuals within that. At the same time science fiction film was the product of corporations whose sole purpose was to make a profit for shareholders and owners, and thus the emergence of science fiction can be partly explained from this perspective.

Chapter one examined the genre of science fiction, beginning with a discussion of the history and the science influences in the development of the notion of genre. The definitions of critics in the jigsawing of the 'truth' of science with the fabulation of fiction exemplified the range of positions critics have taken in their understanding and mapping of the boundaries of the genre. I argued that science fiction is different from other genres because of the intrinsic element of change, both in science and in the culture that changed in part as a response to discoveries in and applications of science. The writings of science fiction authors added to the argument that science fiction was both about science and the effects of science, and that the genre was concerned, in part, with social change. The discussion of the two genres that are at either ends of the spectrum of science fiction, horror and fantasy, suggested a further thread in the science fiction genre: a consciousness of the global. Marketing, and audiences and their intertextual references, were discussed as a crucial element in the notion and determination of genre, and following on from this, the absence of stars from science fiction films was seen to be in part due to the eclipsing of human actors by special effects. 
In chapter two I described the historical and cultural contexts which were relevant to science fiction in terms of Parrinder's 'message' and texts. 2 The chapter began by suggesting the emergence of science fiction in terms of 'grand narratives' and the existential condition of humanity, and the focus then moved to the immediate history of the fifties that was relevant to science fiction films, including nuclear science and the social implications of that science. Woven through that history was a discussion of change, and the fear of uncertainty that change engenders. The chapter argued that the appearance of UFOs was an element in that history and that fear, as both a product of fear and also contributing to it. Another interrelated thread was the relationship of the military with Hollywood, a marriage that had been always close, but that reached new levels of harmony in World War 2 when documentary films were both information and propaganda. 3 The cold war and a history of cooperation accounted for certain elements of the texts of science fiction films. Chapter two examined as well the threads of the social context, including that dynamic of nuclear families, suburbs, mobility, freeways, consumer credit, full employment, and children that impacted on and was refracted through the prism of science fiction film. I examined as well the audiences of science fiction, and traced the emergence of teenagers as a new market for such films.

The context of the film production industry was the focus for chapter three, as this context was also undergoing change during the fifties. The legal changes broke up the studio system so that independent productions assumed a greater importance; the saturation of the suburbs with television forced other changes on the industry; and the growth of drive-ins established a new market for film, that was recognised only slowly by the traditional distribution chains, and capitalised on by emerging producers. I outlined the history of two corporations as case studies to illustrate the changes that were occurring, and used two special effects artists/technicians as case studies illustrating the significance of the notion of the transmogrification of the unreal into the real in science fiction films, and the technical and artistic innovations and developments that actualised this transmogrification.

In the next chapter I argued that science has both a nature and a function,

2 Parrinder 1980, 29-36

Erik Barnouw 1993 Documentary: a history of the non-fiction film $2^{\text {nd }}$ ed Oxford: Oxford University
Press 
and the representation of women in certain films was used to establish the social implications of a science that could be liberating. Science fiction films were the sites for contestation about cultural, political and science practices in a context of change and fluidity, and the films can be seen as rhetorical contributions to the debate about those changing practices. The films served to educate about science and the possibilities that new discoveries in science allowed for, as well as acting as a foundation on which the speculative narrative could be built. Within this process was a further rhetoric: of science itself and its validity as an explanatory system that represented 'truth', and was therefore a valuable discipline that demanded respect. On the other hand, other films challenged that rhetoric, indicating debate and fluidity rather than hegemony,.

The place of the medical and psychological sciences was unravelled in chapter five. As scientists of the human organism, this group might have been expected to act differently from those of the non-human sciences because of some intrinsic dedication to the pre-eminence of human life. And in some films such a difference was apparent, and the relationships between the sciences was traced and explained. At the same time these scientists were significant in the construction and representation of community, and the films argued for certain notions of community that were different from film to film, as well as related notions of the state and the relationship between people and the state. The idea and practices of family as an element of community as well as a microcosm of community were found to be spheres of contestation and difference.

The task for this thesis was to establish the credentials of science fiction films to be taken seriously as legitimate cultural artefacts, an examination of which would contribute to an understanding of science in the fifties in the broadest terms, as well as contributing to a greater appreciation and understanding of the culture and history of the fifties, as well as the film industry itself. The thesis has answered questions about the nature of science, about its relationship with other cultural institutions like the military, about the fascination with speculation that resulted from, in part, the discoveries and theories of science, about an industry in change, but also a society in change. It has shown that, far from being just scary monster movies, science fiction films were involved with the issues of the day, and indeed, helped construct the agendas that made certain threads into significant areas of debate. While science 
fiction films purport to be about both science and fiction, they are about society and the real present. The metaphors from fifties science fiction pervade our culture; for example, writing of the impact of the IOC delegation to various countries bidding to stage the Olympic Games, journalist Sally Gare draws on fifties metaphors:

He [Andrew Jennings] talks of the Olympic effect on otherwise sane and reasonably moral people as if it were the invasion of the pod people. "When the IOC visits a bidding city, they bring a plague and they poison the local people...."4

I'll close by returning to Independence Day. Part of the film's narrative comprises the plucking of emotional chords in the characters and us, the audience, that act to unify people and nations in a glorified contest against the all-conquering aliens. On the one hand this might be seen as weepy emotionalism; on the other it can be seen in grand narrative terms as an overwhelming desire to transcend difference and to be unified to do battle with a common foe. While not an unusual technique-being mobilised in documentaries during wars or by politicians during elections-the difference here is that the film is not a documentary and that the territory is not one country but, like some science fiction films of the fifties, is the planet and its peoples. It is the consciousness of the necessity for global thinking as distinct from national thinking that first appeared in fifties science fiction films, and that still remains in the realm of fiction.

4 Shelley Gare 1999 'Self-interest can make you deaf' The Weekend Australian February 6-7, 18 


\section{Bibliography}

\section{Print}

Aldridge, Alexandra 1983 'Science fiction and emerging values' in Robert Myers (ed) The intersection of science fiction and philosophy London: Greenwood

Amis, Kingsley 1976 'Starting points' in M Rose (ed) Science fiction: a collection of critical essays Englewood Cliffs, NJ: Prentice-Hall

Angenot, Marc \& Darko Suvin 1979 'Not only but also: reflections on cognition and ideology in science fiction and SF criticism' Science-fiction studies v6

Anger, Kenneth 1986 Hollywood Babylon London: Arrow

Arbur, Rosemarie 1983 'Teleology of human nature for mentality' in Robert Myers (ed) 1983 The intersection of science fiction and philosophy London: Greenwood Press

Ash, Brian 1977 The visual encyclopedia of science fiction London: Pan

Asimov, Isaac 1940 'Strange playfellow' Super science stories reprinted as 'Robbie' in I, Robot 1968, St Albans: Panther

1941 'Liar' Astouding science fiction reprinted in Asimov 1983 The complete robot Sydney: Grafton Books

1945 'Escape' in Asimov 1968 I, Robot St Albans: Panther

1960 Foundation St Albans: Panther

1968 I, Robot St Albans: Panther

1980 In joy still felt: the autobiography of Isaac Asimov, 1954-1978 New York: Avon

1983 The complete robot Sydney: Grafton Books

1984 Asimov on science fiction London: Granada

— 1984 'Movie science' in Danny Peary (ed) Omni's screen flights/screen fantasies New York: Doubleday

—_ \& Robert Silverberg 1990 Nightfall Sydney: Doubleday

Bacon, F in David Wellbery \& John Bender (eds) 1990 The ends of rhetoric Stanford: Stanford University

Bader, Chris 1995 'The UFO contact movement from the 1950s to the present' Studies in popular culture 17:2 
Balio, Tino (ed) 1990 Hollywood in the age of television Boston: Unwin Hyman 1990 'Introduction to Part I' in Tino Balio (ed) Hollywood in the age of television Boston: Unwin Hyman

1990 'New producers for old: United Artists and the shift to independent production' in Balio (ed) Hollywood in the age of television Boston: Unwin Hyman

Barbour, Michael G 1996 'American ecology and American culture in the 1950s: who led whom? Bulletin of the ecological society of America 77:1

Barnes, Ian 1989 'Interpreting media images of science and technology' Media Information [International] Australia n54, November

Barnouw, Erik 1993 Documentary: a history of the non-fiction film Oxford: Oxford University Press

Barr, Charles 1974 'Projecting Britain and the British character: Ealing studios' Screen education, Spring

Barraclough, David 1992 Movie record breakers: the biggest, the baddest and the best movies of all time London: New Burlington

Barthes, Roland (Stephen Heath trans, ed) 1977 Image, music, text Glasgow: Fontana

Bateson, Gregory 1972 Steps to an ecology of the mind New York: Ballantine

Baughman, James L 1990 'The weakest chain and the strongest link: the American Broadcasting Company and the motion picture industry, 1952-60' in Tino Balio (ed) Hollywood in the age of television Sydney: Unwin Hyman

Bayer, William 1973 The great movies New York: Grosset \& Dunlap

Beja, Morris 1979 Film and literature New York: Longman

Belton, John 1990 'Glorious technicolor, breathtaking cinemascope, and stereophonic sound' in Tino Balio (ed) Hollywood in the age of television Sydney: Unwin Hyman

Bennett, Tony \& Janet Woollacott 1987 Bond and beyond: the political career of a popular hero London: Macmillan

Biskind, Peter 1983 Seeing is believing: how Hollywood taught us to stop worrying and love the fifties New York: Pantheon

Bloch, Robert 1984 'The special effectiveness of George Pal' in Danny Peary (ed) Omni's screen flights/screen fantasies New York: Doubleday

Bogert, Frans van der 1983 'Nature through science fiction' in Robert Myers (ed) The intersection of science fiction and philosophy London: Greenwood

Bordwell, David \& Kristin Thompson 1993 Film art: an introduction 5th (international) ed, Sydney: McGraw-Hill 
Bosworth, Patricia 1997 'Hollywood on trial' Vanity fair April (excerpted from Patricia Bosworth Anything your little heart desires: an American family story Simon \& Schuster

Braucourt, Guy 1972 'Interview with Don Siegel' in William Johnson (ed) Focus on the science fiction film Englewood Cliffs, NJ: Prentice-Hall

Broadcasting April 2 1951, in Tino Balio (ed) 1990 Hollywood in the age of television Boston: Unwin Hyman

Broderick, Mick 1988 Nuclear movies: a filmography Northcote, Vic: Post-Modern Publishing

Bromfield, Louis 1952, 'The triumph of the egghead' The freeman v3, December 1, in Richard Hofstadter 1964 Anti-intellectualism in American life London: Jonathan Cape

Brooks, Tim \& Earle Marsh 1992 The complete directory to prime time network TV shows, 1946-present (5th ed) New York: Ballantine

Brosnan, John 1974 Movie magic: the story of special effects in the cinema London: Macdonald

1991 The primal screen: a history of science fiction film Sydney: Macdonald

Butor, Michel 1972 'The 'crisis in the growth of science fiction' in James Hall \& Barry Ulanov Modern culture and the arts $2^{\text {nd }}$ ed Sydney: McGraw-Hill

Cameron, Ian 1973 Adventure in the movies New York: Crescent

Camus, Albert 1978 The collected fiction of Albert Camus (trans Stuart Gilbert) London: Book Club

Clareson, Thomas (ed) 1977 Many futures, many worlds Ohio: Kent State University Press

Cohan, Steven \& Linda Shires 1988 Telling stories: a theoretical analysis of narrative fiction London: Routlege

Collins, Richard 1976 'Genre: a reply to Ed Buscombe' in B Nichols (ed) Movies and methods: an anthology Berkeley: University of California

Conquest, Robert 1976 'Science fiction and literature' in M Rose (ed) Science fiction: a collection of critical essays Englewood Cliffs, NJ: Prentice-Hall

Cook, David 1996 A history of narrative film New York: Norton

Cooke, Alistair 1940 'Douglas Fairbanks: The making of a screen character' in Richard Dyer 1979 Stars London: British Film Institute

Corliss, Richard 1996 "The invasion has begun: Independence Day arrives to lead the assault of science-fiction movies, TV shows and books on the cultural mainstream' (cover story) Time July 8, 148:3

Coughlan, Robert 1951 'Now it is trouble that is supercolossal in Hollywood' Life v31, August 13 in Garth Jowett 1976 Film: the democratic art Boston: Little, Brown and Company 
Crowther, Bruce 1988 Film noir: reflections in a dark mirror London: Columbus

Culbert, David 1988 'Our awkward ally: Mission to Moscow (1943)' in John O'Connor \& Martin Jackson (eds) American history/American film New York: Ungar

Daniels, Les 1977 Fear: a history of horror in the mass media Sydney: Paladin

Darwin, Charles 1859 On the origin of species by means of natural selection or the preservation of favoured races in the struggle for life 1st ed [1st ed, London : J Murray, reprinted] Cambridge Mass: Harvard University Press, 1966

Delany, Samuel R 1977 'Critical methods: speculative fiction' in Thomas Clareson (ed) Many futures, many worlds Ohio: Kent State University Press

1994 Silent interviews Hanover, NH: University Press of New England

del Rey, Lester 1980 The world of science fiction 1926-1976: the history of a sub-culture New York: Garland

Denisoff, R Serge \& William Romanowski 1989 'The Pentagon's top guns: movies and music' Journal of American Culture 12:3

Denzin, Norman K 1991 Hollywood shot by shot: alcoholism in American cinema New York: Aldine de Gruyter

Dille, Robert (ed) 1969 The collected works of Buck Rogers in the $25^{\text {th }}$ century New York: A\& W Publishers

Docherty, Thomas 1988 Teenagers and teenpics: the juvenalization of American movies in the 1950s Boston: Unwin Hyman

Docker, John 1989 'Williams' challenge to screen studies' Southern review 22:2 July

Dornan, Christopher 1988 "The "problem" of science and the media: a few seminal texts in their context, 1956-1965' J of communication enquiry 12:2, Summer

Double, Richard 1983 'There are no persons' Robert Myers (ed) The intersection of science fiction and philosophy London: Greenwood

Dyer, Richard 1979 Stars London: British Film Institute

Eames, John Douglas 1975 The MGM story: The complete history of fifty-seven roaring years London: Octopus

Edwards, Phil 1984 Beyond imagination: fantasy, science fiction and horror movie guide Sydney: Magazine Productions

Ellison, Harlan 1974 'Adrift just off the Islets of Langerhans' The magazine of fantasy and science fiction October

Ellul, Jacques 1964 (trans. John Wilkinson) The technological society New York: Random House

- 1984 'Lurching down memory lane with It, Them, The Thing, Godzilla, HAL 9000 ...that whole crowd' in Danny Peary (ed) Omni's screen flights/ screen fantasies New York: Doubleday 
Evans, Arthur 1988 'Science fiction vs scientific fiction in France: from Jules Verne to J-H Rosny Aine' Science-fiction studies v15

1989 'Functions of science in French fiction' Studies in the literary imagination 22:1 Spring

Everman, Welch 1993 Cult horror films New York: Citadel

Farber, Manny 1952 'Blame the audience' in Todd McCarthy \& Charles Flynn 1975 Kings of the Bs New York: Dutton

'The fifties: why they weren't so bad' 1993 The Australian Magazine: special issue September 18-19

Finch-Reyner, Sheila 1985 'The unseen shore: thoughts on the popularity of fantasy' J of popular culture 18:4 Spring

Finler, Joel 1985 All-time box office hits London: Columbus

Flynn, Charles 1974 'The schlock/kitsch/hack movies' in Todd McCarthy \& Charles Flynn 1975 Kings of the Bs New York: Dutton

— \& Todd McCarthy 1975 'The economic imperative: why was the B movie necessary?' in Todd McCarthy \& Charles Flynn Kings of the Bs New York: Dutton

Foucault, Michel 1988 Madness and civilization: a history of insanity in the Age of Reason New York: Vintage

Frewin, Anthony 1988 One hundred years of science fiction illustration 1840-1940 London: Bloomsbury

Friend, Beverly 1977 'Virgin territory' in Thomas Clareson (ed) Many futures, many worlds Ohio: Kent State University

Fruth, Bryan et al 1996 'The atomic age: facts and films from 1945-1965' J Popular Film E Television 23:4, Winter

Galileo in David Wellbery \& John Bender (eds) 1990 The ends of rhetoric Stanford: Stanford University

Gare, Shelley 1999 'Self-interest can make you deaf' The Weekend Australian February 6-7, 18

Geduld, Harry 1978 'Genesis II: the evolution of synthetic man' Geduld \& Ronald Gottesman (eds) Robots robots, robots Boston: New York Graphic Society

Geduld, Harry \& Ronald Gottesman (eds) 1978 Robots, robots, robots Boston: New York Graphic Society

Gernsback, Hugo (ed) 1928 'The Rise of Scientifiction' Amazing Stories Quarterly 1:2, Spring, reproduced in Anthony Frewin (1974, published 1988 One hundred years of science fiction illustration London: Bloomsbury

Gifford, Denis 1971 Science fiction film London: Studio Vista

Golding, William 1954 Lord of the flies: a novel London: Faber \& Faber 
Gomery, Douglas 1986 The Hollywood studio system London: Macmillan

1991 Movie history: a survey Belmont, Calif: Wadsworth

Griffith, Richard 1976 'Cycles and genres' in B Nicholls (ed) Movies and methods Berkeley: University of California

Guerrero, Edward 1990 'Aids as monster in science fiction and horror cinema' J of popular film and television 18:3, Fall

Hacking, Ian (ed) 1981 Scientific revolutions Oxford University Press

Halberstam, David 1993 The fifties New York: Fawcett Columbine

Hall, James \& Barry Ulanov Modern culture and the arts $2^{\text {nd }}$ ed Sydney: McGrawHill

Hardy, Phil (ed) 1984 Science Fiction: The Aurum film encyclopedia London: Aurum

Harryhausen, Ray 1974 Film fantasy scrapbook London: Tantivy

Hartley, John 1996 Popular reality: journalism, modernity, popular culture Sydney: Arnold

Hawkes, Terence 1977 Structuralism \& semiotics London: Methuen

Haynes, Rosslyn 1989 'Scientists in literature and the media: how do they rate?' Media information [international] Australia n54 November

1994 From Faust to Stranglove: representations of the scientist in western literature Baltimore: John Hopkins University

Heinlein, Robert 1953 The man who sold the moon London: New English Library

1956 (first published 1954) 'The green hills of Earth' The green hills of Earth London: Pan

1961 Stranger in a strange land New York: Putnam

1972 'Shooting Destination Moon' in William Johnson (ed) Focus on the science fiction film Englewood Cliffs NJ: Prentice-Hall

_ (Virginia Heinlein ed) 1989 Grumbles from the grave New York: Ballantine

Herken, Gregg 1982 The winning weapon New York: Vintage

Hersey, John 1972 Hiroshima Ringwood: Penguin

Hodgens, Richard 1972 'A brief, tragical history of the science fiction film' in William Johnson (ed) Focus on the science fiction film Englewood Cliffs NJ: Prentice-Hall

Hofstadter, Richard 1964 Anti-intellectualism in American life London: Jonathan Cape

Holister, Geoffrey 1981 'In praise of modelling' Impact of science on society 31:4 
Holte, Jim 1986 'Pilgrims in space: puritan ideology and the American science fiction film' in Donald Palumbo (ed) 1986 Eros in the mind's eye New York: Greenwood

Huntington, John 1976 'Science fiction and the future' in M Rose (ed) Science fiction: a collection of critical essays Englewood Cliffs NJ: Prentice-Hall

Jacobs, Lea 1992 'The B film and the problem of cultural distinction' Screen 33:1 Spring

Jancovich, Mark 1996 Rational fears: American horror in the 1950s Manchester: Manchester University Press

Johnson, William (ed) 1974 Focus on the science fiction film Englewood Cliffs, NJ: Prentice-Hall

1974 'Journey into science fiction' in William Johnson (ed) Focus on the science fiction film Englewood Cliffs NJ: Prentice-Hall

Jowett, Garth 1976 Film: the democratic art Boston: Little, Brown

Jung, C G 1959 Flying saucers: a modern myth of things seen in the skies (trans. RFC Hull) London: Routledge \& Kegan Paul

Kaminsky, Stuart M 1974 American film genres: approaches to a critical theory of popular film Dayton, Ohio: Pflaum

Kast, Pierre 1972 'Don't play with fire' in William Johnson (ed) Focus on the science fiction film Englewood Cliffs NJ: Prentice-Hall

Kenna, Rudolph \& William Grandison 1989 Somethin' Else: 50s life and style Glasgow: Richard Drew

Kerr, Paul 1979/80 'Out of what past?: Notes on the B film noir' Screen Education Autumn/Winter

- (ed) 1986 The Hollywood film industry London: Routledge \& Kegan Paul

King, J Norman 1977 'Theology, science fiction and man's future orientation' in Thomas Clareson (ed) Many futures, many worlds Ohio: Kent State University

Kirkham, Pat \& Janet Thumim (eds) You Tarzan: masculinity, movies and men London: Lawrence \& Wishart

Kitses, Jim 1969 Horizons West Bloomington, Indiana: Indiana University Press

Kafka, Franz 1974 The castle (trans Willa \& Edwin Muir) Harmondsworth: Penguin

Koppes, Clayton R \& Gregory D Black 1987 Hollywood goes to war: how politics, profits and propaganda shaped World War II movies London: Collier Macmillan

Kramer, Stanley 1984 'On the Beach: A renewed interest' Danny Peary (ed) Omni's screen flights/screen fantasies New York: Doubleday

Kuhn, Annette (ed) 1990 Alien zone: cultural theory and contemporary science fiction cinema New York: Verso 
Kyle, David 1976 A pictorial history of science fiction Sydney: Hamlyn 1977 The illustrated book of science fiction ideas and dreams Sydney: Hamlyn

Kyrou, Ado 1972 'Science and fiction' in William Johnson (ed) Focus on the science fiction film Englewood Cliffs NJ: Prentice-Hall

Lambourne, Robert, Michael Shallis \& Michael Shortland 1990 Close encounters: science and science fiction New York: Adam Hilger

Landon, Brooks 1992 The aesthetics of ambivalence: rethinking science fiction film in the age of electronic (re)production London: Greenwood Press

Lasch, C 1978 The culture of narcissism New York: W W Norton

Laura, Ernesto G 1957 'Invasion of the body snatchers' Bianco e Nero 18:12

Lhamon, WT Jr 1990 Deliberate speed: the origins of a cultural style in the American 1950s Washington: Smithsonian Institution

Lievrouw, Leah A 1990 'Communication and the social representation of scientific knowledge' Critical studies in mass communication research 7:1

Lloyd, Ann (ed) 1986 The illustrated history of the cinema London: Orbis

Logan, Jeffrey 1953 The complete book of outer space New York: Maco

Lowery, Shearon A \& Melvin L de Fleur 1988 Milestones in mass communication research $2^{\text {nd }}$ edn London: Longman

Lucanio, P 1987 Them or us: archetypal interpreations of fifties alien invasion films Bloomington: Indiana University Press

MacLachlan, Gale \& Ian Reid 1994 Framing and interpretation Carlton: Melbourne University Press

Malmgren, Carl 1991 'Against genre/theory: the state of science fiction criticism' Poetics today 12:1 (Spring)

Maltin, Leonard 1997 Leonard Maltin's movie and video guide 1997 edition New York: Signet

Martin, J R 1985 Exploring and challenging social reality Deakin University

McCarthy, Todd \& Charles Flynn 1975 Kings of the Bs New York: Dutton

McDonald, Neil N 1987 'Images of the scientist in the popular film' The Mendelian 3

McGauran, Peter 1989 'Science and technology as the new commonsense' Media information [international] Australia n54 November

Medawar, Peter 1986 The limits of science Oxford University Press

Medved, Harry \& Michael Medved 1980 The golden turkey awards Sydney: Angus \& Robertson 
Miller, Douglas \& Marion Nowak 1977 The fifties: the way we really were New York: Doubleday

Moran, Albert 1987 Projecting Australia PhD thesis, Griffith University

Morris, Chris 1974 'Roger Corman: the schlemiel as outlaw' in Todd McCarthy \& Charles Flynn 1975 Kings of the Bs New York: Dutton

Moskowitz, Sam 1976 'That early coinage of "science fiction"' Science-fictions studies iii:part 3, November

Murphy, Brian 1972 'Monster movies: they came from beneath the fifties' J of popular film 1 Winter

Myers, Robert (ed) 1983 The intersection of science fiction and philosophy London: Greenwood Press

Nagl, Manfred (trans David Clayton) 1983 'The science-fiction film in historical perspective' Science-fiction studies v10

Naha, Ed 1984 'Cautionary fables: an interview with Roger Corman' in Danny Peary (ed) Omni's screen flights, screen fantasies New York: Doubleday

Neale, Stephen 1980 Genre British Film Institute

Nicholls, B (ed) 1976 Movies and methods: an anthology Berkeley: U of California Press

Norman, Barry 1987 Talking pictures London: Hodder and Stoughton

O'Connor, John \& Martin Jackson (eds) American history/American film New York: Ungar

Palumbo, Donald (ed) 1986 Eros in the mind's eye New York: Greenwood

Park, Jihang 1997 'Wasted opportunities: The 1950s rearmament programme and the failure of British economic policy' J of contemporary history 32:3

Parrinder, Patrick 1980 Science fiction: its criticism and teaching London: Methuen

Peake, Mervyn 1969 Gormenghast Harmondsworth: Penguin

Peary, Danny 1984 (ed) Omni's screen flights/screen fantasies New York: Doubleday

Pippin, Robert 1991 Modernism as a philosophical problem Cambridge, Mass: Blackwell

Prelli, Lawrence 1989 A rhetoric of science: inventing scientific discourse Columbia SC: U of Sth Carolina Press

Pressman, Jack 1988 Uncertain promise: Psychosurgery and the development of scientific psychiatry in America, 1935 to 1955 AnnArbor: University Microfilms International

Pringle, David (ed) 1996 The ultimate encyclopedia of science fiction: the definitive illustrated guide Sydney: The Book Company

Propp, Vladimir 1970 Morphology of the folk tale Austin: University of Texas 
Rabkin, Eric 1976 The fantastic in literature Princeton University Press

Rieder, John 1982 'Embracing the alien: science fiction in mass culture' Sciencefiction studies $\mathrm{v} 9$

Ricoeur, Paul 1986 Lectures on ideology and utopia New York: Columbia University Press

Rimmon-Kenan, Shlomith 1983 Narrative fiction: contemporary poetics London: Methuen

Rose, Hilary \& Steven Rose 1970 Science and society Ringwood: Penguin

Rose, Mark (ed) 1976 Science fiction: a collection of critical essays Englewood Cliffs, NJ: Prentice-Hall

1981 Alien encounters: anatomy of science fiction Cambridge: Harvard University

Rosenberg, Norman \& Emily Rosenberg 1991 In our times: America since World War II (4th edn) Englewood Cliffs: Prentice Hall

Rosenheim, Shawn 1995 'Extraterrestrial: science fictions in A brief history of time and The Incredible Shrinking Man' Film Quarterly 48:4 Summer

Rothman, Stanley, David J Rothman \& Stephen P Powers 1990 'Hollywood views the military' Society 28:1

Rovin, Jeff 1975 A pictorial history of science fiction films New Jersey: Citadel

Rovin, Jeff 1993 Classic science fiction films New York: Citadel

Ruppelt, Edward I 1956 'The report on unidentified flying objects' in C G Jung 1959 Flying saucers London: Routledge \& Kegan Paul

Ruppersburg, Hugh 1987 'The alien messiah in recent science fiction films' J of popular film and television 14:4 Winter

Samuels, Stuart 1988 'The age of conspiracy and conformity: Invasion of the body snatchers' in O'Connor, John \& Martin Jackson (eds) American history/American film New York: Ungar

Sarris, Andrew 1974 'Beatitudes of B pictures' Todd McCarthy \& Charles Flynn 1975 Kings of the Bs New York: Dutton

Sartre, Jean-Paul 1965 Nausea (trans Robert Baldick) Harmondsworth: Penguin

Sayre, Nora 1982 Running time: films of the cold war New York: Dial Press

1982 'Watch the skies' Grand Street 1:2 Winter

Schatz, Thomas 1981 Hollywood genres Sydney: McGraw-Hill

Schelde, Per 1993 Androids, humanoids, and other science fiction monsters: science and soul in science fiction films New York: New York University Press

Scheuer, Steven (ed) 1990 Movies on TV and videocassette 1991-1992 Sydney:

Bantam 
Schmidt, Stanley 1977 'The science in science fiction' in Thomas Clareson (ed) Many futures, many worlds Englewood Cliffs NJ: Prentice-Hall

Scholes, Robert 1974 Structuralism in literature London: Yale University Press 1976 'The roots of science fiction' in Mark Rose (ed) Science fiction: a collection of critical essays Englewood Cliffs, NJ: Prentice-Hall

— \& Eric Rabkin 1977 Science fiction: history, science, vision New York: Oxford University Press

Sconce, Jeffrey 1995 'Brains from space: mapping the mind in 1950s science and cinema' Science as culture 23, 277-302

Segrave, Kerry 1992 Drive-in theaters: a history from their inception in 1933 London: McFarland

Shapiro, Benjamin 1990 'Universal truths: cultural myths and generic adaptation in 1950s science fiction films' J of popular film and television 18:3, Fall

Sklar, Robert 1976 Movie-made America: a cultural history of American movies New York: Vintage Books

Sless, David 1991 'Communication and certainty' Australian journal of communication $18: 3$

Snow, C P 1981 The physicists London: Macmillan

Sobchack, Vivian 1987 Screening space: the American science fiction film 2nd ed, New York: Ungar

1988 'Cities on the edge of time: the urban science fiction film' East-west film journal 3:1

Solman, Gregory 1992 'The illusion of a future' Film comment 28, March/April

Sontag, Susan 1966 'The imagination of disaster' Against interpretation New York: Farrar, Straus \& Giroux

- 1976 'The imagination of disaster' in M Rose (ed) Science fiction: a collection of critical essays Englewood Cliffs, NJ: Prentice Hall from Sontag 1966 Against interpretation New York: Farrar, Straus \& Giroux

Spigel, Lynn 1988 'Installing the television set: popular discourses on television and domestic space, 1948-1955' Camera obscura n16

1992 Make room for TV: Television and the family ideal in postwar America Chicago: University of Chicago Press

Staudenmaier, John 1989 Technology's storytellers: reweaving the human fabric London: MIT Press

Stableford, Brian 1989 'The plausibility of the impossible' Foundation v46 Autumn

Stacks, Don, Mark Hickson \& Sidney Hill 1991 An introduction to communication theory Sydney: Holt, Rinehart \& Winston 
Steffen-Fluhr, Nancy 1984 'Women and the inner game of Don Siegel's Invasion of the Body Snatchers' Science-fiction studies v11

Strada, Michael 1986 'Kaleidoscopic nuclear images of the fifties' J of Popular Culture Winter

1987 'The cinematic bogy man comes home: American popular perceptions of external threat' Midwest Quarterly 28:2

Straw, Will 1987 'The discipline of forms: mannerism in recent cinema' Cultural studies 1:3

Strawn, Linda May 1974 'Samuel Z Arkoff' in Todd McCarthy \& Charles Flynn 1975 Kings of the Bs New York: Dutton

Strick, Philip 1976 Science fiction movies London: Octopus

Suid, Lawrence 1981 'Hollywood and Vietnam' J of American culture 4:2 1988 'The Pentagon and Hollywood: Dr Strangelove...' in John O'Connor \& Martin Jackson (eds) American history/American film New York: Ungar

Suvin, Darko 1979 ' The state of the art in science fiction theory' Science fiction studies 13:3 Spring

Telotte; J P 1988 'The ghost in the machine: consciousness and the science fiction film' Western Humanities Review 42:3 Autumn

1989 'Science Fiction in double focus: Forbidden Planet' Film Criticism 13:3, Spring

1991 'The tremulous public body: Robots, change, and the science fiction film' J of Popular Film and Television 19:1, Spring

1995 Replications: a robotic history of the science fiction film Chicago: $U$ of Chicago Press

Thompson, John B 1981 Critical hermeneutics: a study in the thought of Paul Ricoeur and Jürgen Habermas Sydney: Cambridge University Press

Thomson, David 1984 'The fear of intelligence in futuristic films' in Danny Peary (ed) 1984 Omni's screen flights/screen fantasies New York: Doubleday

Timpone, Anthony (ed) 1996 Men, makeup and monsters New York: St Martin's Griffin

Todorov, Tzvetan 1973 The fantastic (trans Richard Howard) Cleveland: Case Western Reserve University

Tudor, Andrew 1976 'Genre and critical methodology' in B Nicolls (ed) Movies and methods: an anthology Berkeley: U of California Press

Torry, Robert 1991 'Apocalypse then: benefits of the bomb in fifties science fiction films' Cinema journal 31:1

Tulloch, John \& Manuel Alvarado 1983 Doctor Who: the unfolding text London: Macmillan 
Turner, Graeme 1988 Film as social practice London: Routledge

Umland, Sam 1986 'Sexual freaks and stereotypes in recent science fiction and fantasy film: loathing begets androgyny' in Donald Palumbo (ed) Eros in the mind's eye New York: Greenwood

Variety Film Review 1950, 3 May

VFR 1950, 28 June

VFR 1951 'Lost Continent' 25 July

VFR 1951 'When worlds collide' 29 August

VFR 1953, 4 Mar

VFR 1953, 8 April

VFR 1953 'Spaceways' 8 July

VFR 1953, 2 September

VFR 1953, 16 December

VFR 1956, 12 September

VFR 1957, 12 June

VFR 1957, 10 July

VFR 1958, 8 January

VFR 1958, 10 September

VFR 1958, 10 December

Velikovsky, Immanuel 1950 Worlds in collision New York: Doubleday

Verne, Jules undated From the Earth to the Moon Sydney: Scholastic

Warrick, Patricia 1977 'Images of the man-machine intelligence relationship in science fiction' in Thomas Clareson (ed) (ed) Many futures, many worlds Englewood Cliffs NJ: Prentice-Hall

Wasser, Frederick 1995 'Is Hollywood America? The trans-nationalization of the American film industry' Critical studies in mass communication v12

Weart, Spencer 1988 Nuclear fear: a history of images Cambridge, Mass: Harvard University Press

Wellbery, David \& John Bender (eds) 1990 The ends of rhetoric Stanford: Stanford University

Wells, Paul 'The invisible man: shrinking masculinity in the 1950s science fiction B-movie' in Pat Kirkham \& Janet Thumim (eds) You Tarzan: masculinity, movies and men London: Lawrence \& Wishart 
Whyte, William (first published 1956) 1963 The organisation man Mitcham, Victoria: Pelican

White, Timothy 1990 'Hollywood's attempt at appropriating television: the case of Paramount Pictures' in Tino Balio (ed) Hollywood in the age of television Boston: Unwin Hyman

Wilding-White, Ted 1989 All about UFOs London: Usborne

Willis, Donald (ed) 1985 Variety's complete science fiction reviews New York: Garland

Wilson, Gahan 1971 'Science fiction horror movie pocket computer chart' The National Lampoon November, 22

Wright, Will 1975 Six guns and society Berkeley: University of California Press

Zipperstein, Steven J 1997 'Commentary and American Jewish culture in the 1940s and 1950s' Jewish social studies 3:2 Winter

\section{Digital}

Grant, Judith 1998 'Trust no one: paranoia, conspiracy theories and alien invasions' Undercurrent n6, Spring http://darkwing.uoregon.edu/ ucurrent/uc6/6-grant.html (last accessed $24 / 12 / 98)$

Heaven's Gate site (archived) http://www.wave.net/upg/gate/index.htm (last accessed 20/12/1998)

Internet Movie Database http://us.imdb.com/ (last accessed 24/12/98)

Microsoft CD-ROM 1995 Cinemania '95 Biographical details for Leslie Nielsen, Microsoft Corp

Rodkey, Jim 1997 Ray Harryhausen http://www3.leba.net/jrodkey/harryhausen/harryhis.html (accessed $4 / 2 / 98)$

Screening the past: an international electronic journal of visual media and history http://www.latrobe.edu.au/www/screeningthepast/ (last accessed 24/12/98)

Undercurrent http://darkwing.uoregon.edu/ ucurrent/home.html (last accessed 24/12/98

Vieth, Errol 1998 'Introduction: the pioneer filmmakers' CQU Screen Studies unit http://infocom.cqu.edu.au/Study/Winter Units/51215 Screen Studies/I ntro/intro prims.html (accessed 28/12/98) 


\section{Filmography}

The films here are generally from the period 1950-1960, except where other films have been noted in the text of the dissertation, or where the film is significant to the culture and history of the fifties, or the genre of science fiction film. Thus some films are not of the genre of science fiction, but have been used in the discussion. These entries are not detailed. The cast and crew lists for the science fiction entries are not always complete. While the credits usually have been taken from the film itself, they sometimes differ from those on the Internet Movie Database (http://us.imdb.com/).

Abyss, The 1989 James Cameron (d), Gale Anne Hurd (p), 20th Century Fox, Lightstorm Entertainment, Pacific Western

Aliens 1986 James Cameron (d), Gale Anne Hurd (p), Brandywine Productions; Concorde Pictures; $20^{\text {th }}$ Century Fox

Alligator People, The 1959 Roy del Ruth (d), Jack Leewood (p), Associated Producers, $20^{\text {th }}$ Century Fox

Amazing Colossal Man, The 1957 B I Gordon \& A J Nicholson (d), Samuel Z Arkoff (p), American International Pictures

Lt-Col Glenn Manning-Glenn Langan; Carol Forrest-Cathy Downs; Dr Paul Lindstrom-William Hudson; Col Hallock-James Seay; Dr Eric Coulter-Larry Thor; Richard Kingman-Russ Bender; Sgt Taylor-Lynn Osborn; Typist-Diana Darren; Control Officer-William Hughes; Lt in room-Jack Kosslyn; Girl in bath-Jean Moorhead

produced, directed and story by Bert I Gordon, A James Nicholson, Samuel Z Arkoff; screenplay-Mark Hanna, Gordon; camera-Joe Biroc; editor-Ronald Sinclair; music-Albert Glasser; SFX-Gordon

Amazing Transparent Man, The 1960 Edgar G Ulmer (d), Lester D. Guthrie (p), AIP/Miller Consolidated Pictures

Laura Matson-Marguerite Chapman; Joey Faust-Douglas Kennedy; Major Paul Krenner-James Griffith; Dr. Peter Ulof-Ivan Triesault; Julian-Boyd 'Red' Morgan; Maria Ulof-Carmel Daniel; Drake-Edward Erwin; Smith-Jonathan Ledford; Security Guard-Norman Smith; Security Guard-Patrick Cranshaw

exec prods- Robert L. Madden, John Miller; original music-Darrell Calker; cinematography-Meredith M. Nicholson; costume design-Jack Masters; production design-Ernst Fegté; film editing-Jack Ruggiero; set dresser-Louise 
Caldwell; special effects-Roger George; music editor-Gilbert D. Marchant; camera operator-Jack McCoskey; sound editor-Don Olson

America 1924 D W Griffith (d\&p), United Artists

American Graffiti 1973 George Lucas (d), Coppola, Universal, Lucasfilm

Angry Red Planet 1960 Ib Melchior (d), Sid Pink, Norman Maurer (p), Orion Picture, AIP

Colonel Tom O'Banyon-Gerald Mohr; Dr Iris Ryan-Nora Hayden; Prof Theodore-Les Tremayne; Chief Warrant Officer Sam-Jack Kruschen; MajorGeneral Treegar-Paul Hahn; Prof Paul Weiner-J Edward McKinley; Dr Frank Gordon-Tom Daly; TV newsreader and special narration-Don Lamond screenplay-Ib Melchior, Sid Pink; original story-Sid Pink; dir photo-Stanley Cortez; assoc producer-Lou Perloff; editor-Ivan Hoffman; music-Paul Dunlap

Animal World, The 1956 Irwin Allen (d\&p), Windsor

Apache Woman 1955 Roger Corman (d), Samuel Z Arkoff, Alex Gordon, James H Nicholson; Golden State Productions

Astounding She Monster 1957 Ronnie Ashcroft (d\&p), Hollywood International Picture

Dick Cutler $\backslash 2$ nd narrator-Robert Clarke; Nat Burdell-Kenne Duncan; Margaret Chaffee-Marilyn Harvey; Esther Malone-Jeanne Tatum; The SheMonster-Shirley Kilpatrick; Brad Conley-Ewing Brown; Radio Newscaster-Al Avalon; Narrator-Scott Douglas

story \& screenplay-Frank Hall; dir photo-William C Thompson; musicGuenther Kauer; production manager-John Nelson; sound-Dale Knight; costume-Maureen; wardrobe-Norma McClaskey; chief electrician-Lee Cannon; property master-Tony Portoghese; makeup-Nichola Veher; grip master-Charles Morris

Atomic Man, The (aka The Time Slip) 1956 Ken Hughes (d), Alec C Snowden (p), Allied Artists Pictures/Toden Production

Mike Delaney-Gene Nelson; Jill Rabowski-Faith Domergue; Det Insp ClearyJoseph Tomelty; Robert Maitland-Donald Gray; Emmanuel Vasquo-Vic Perry; Dr Bressler-Paul Hardtmuth; Dr Preston-Dr Stephen Rayner/Jarvis-Martin Wyldeck; Peter Arne

dir photography-AT Dinsdale; film editor-Geoffrey Muller; sound editor-Jim Groom; art director-George Haslam; music supervisor-Richard Taylor; sound supervisor-Richard A Smith; sound recordists-Dick Smith, Ron Abbott; first assistant director-Denis Johnson; second asst director-Ted Sturgis; screenplayCharles Eric Maine; production-Tony Owen 
Attack of the 50 Foot Woman 1958 Nathan Juran (d), Jacques R. Marquette (p), Woolner, Allied Artists

Nancy Fowler Archer-Allison Hayes; Harry Archer-William Hudson; Honey Parker-Yvette Vickers; Dr. Cushing-Roy Gordon; Sheriff Dubbitt-George Douglas; Jess Stout-Ken Terrell; Dr. Von Loeb-Otto Waldis; Nurse-Eileen Stevens; Tony (\& Space Giant)-Mike Ross; Charlie-Frank Chase

writer-Mark Hanna; exec prod-Bernard Woolner; music-Ronald Stein; cinematography-Jacques R. Marquette; film editing-Edward Mann

Attack of the Giant Leeches (aka The Giant Leeches) 1959 Bernard I Kowalski (d), Gene Corman (p), American International Pictures

Steve Benton-Ken Clark; Liz Walker-Yvette Vickers; Nan Greyson-Jan Shepard; Cal Coulston-Michael Emmet; Doc Greyson-Tyler McVey; Dave Walker-Bruno Ve Soto; Sheriff Kovis-Gene Roth; Slim Reed-Daniel White; Lem Sawyer-George Cisar

original story and screenplay-Leo Gordon; music-Alexander Laszlo; exec prodRoger Corman; dir photog-John M Mickelman; editor-Carlo Lodato; property master-Dick Rubin; sound-Al Everton; art director-Dan Haller

Beast From 20,000 Fathoms, The 1953 Eugene Lourie (d), Hal Chester, Jack Dietz (p), Warner Bros

Tom Nesbitt-Paul Christian; Lee Hunter-Paula Raymond; Prof Elson- Cecil Kellaway; Capt Jackson-Donald Woods; Col Evans-Kenneth Tobey; Corporal Stone-Lee Van Cleef

SFX-Ray Harryhousen; screenplay-Lou Morheim, Fred Freiberger; from a Saturday Evening Post story by Ray Bradbury ('The Fog Horn', but not a close resemblance); camera-Jack Russell; editor-Bernard W Burton; music-David Buttolph

Beast With a Million Eyes, The 1955 David Kramarsky (d), Samuel Z. Arkoff (p), American Releasing Corp (later AIP)

Allan Kelly-Paul Birch; Carol Kelly-Lorna Thayer; Sandy Kelly-Dona Cole; Larry-Dick Sargant; Him-Leonard Tarver; Old Man Webber-Chester Conklin

exec prod-Roger Corman; assoc prod-Chuck Hanawalt; screenplay-Tom Filer; camera-Everett Baker; editor-Jack Killeser; music-John Bickford; cinematography-Everett Baker; film editing-Jack Killifer; spaceship stringpuller-Forrest J Ackerman; music supervisor-John Bickford; monster effects, monster creator-Paul Blaisdell; production manager-Jonathan Haze; technical director-Shelton Mitchell; assistant director-Donald Myers; art director-Albert S. Ruddy 
Dr. Ed Wainwright-Peter Graves; Audrey Aimes-Peggie Castle; Gen. John Hanson-Morris Ankrum; Col. Tom Sturgeon-Thomas Browne Henry; Capt. James Barton-James Seay; Frank Johnson-Than Wyenn; Maj. Everett-Richard Benedict; Cpl. Matthias-Larry J. Blake; Frank, a soldier-Hylton Socher;

Newscaster-John Close; Gen. John T. Short-Frank Wilcox; Norman Taggart-Paul Grant

writing-Fred Freiberger, Lester Gorn; music-Albert Glasser; cinematographyJack A. Marta; editing-Aaron Stell

Beginning or the End 1947 Norman Taurog (d), Samuel Marx (p), MGM

Major General Leslie Groves-Brian Donlevy; Colonel Jeff Nixon-Robert Walker; Matt Cochran-Tom Drake; Anne Cochran-Beverly Tyler; Jean O'Leary-Audrey Totter; Dr J Robert Oppenheimer-Hume Cronyn; Dr John Wyatt-Hurd Hatfield; Dr Enrico Fermi-Joseph Calleia; President Roosevelt-Godfrey Tearle; Dr Marre-Victor Francen; Dr Chisholm-Richard Haydn; Dr Vannevar Bush-Jonathan Hale; K T Keller-John Litel; General Thomas Farrell-Henry O'Neill; Captain William Parsons-USN Warner Anderson

writing-Robert Considine, Frank Wead; original music-Daniele Amfitheatrof; cinematography-Ray June; costume design-Irene; film editing-George Boemler; special effects-A Arnold Gillespie

Birth of a Nation 1915 D W Griffith (d\&p), David W Griffith Corp, Epoch Producing Corporation

Black Scorpion, The 1957 Edward Ludwig (d), Frank Melford, Jack Dietz (p), Warner Bros

Henry Scott-Richard Denning; Teresa-Mara Corday; Arturo Ramos-Carlos Rivas; Juanito-Mario Navarro; Dr Belazco-Carlos Muzquiz; Jose do la CruzPascual Pena; Florentina-Fanny Schiller; Father Delgado-Pedro Galvan; Major Cosio-Arturo Martinez

screenplay-David Duncan, Robert Blees; story-Paul Yarwitz; camera-Lionel Lindon; editor-Richard van Enger; music-Paul Sawtell

Blob, The 1958 Irvin S Yeaworth (d), Jack H Harris (p), Paramount

Steve-Steve McQueen; Judy-Aneta Corsaut; Police Lieutenant-Earl Rowe; Old Man-Olin Howlin; Dr T Hallen-Steve Chase; Sgt Jim Bert-John Benson; Danny Martin-Kieth Almoney; George, café owner-Vince Barbi; Teenager-James Bonnett; Teenager-Molly Ann Bourne; Sally, waitress-Julie Cousins; Kate, nurse -Pamela Curran; Marty, mechanic-Jasper Deeter; Teenager-Robert Fields; Teenager-Anthony Franke; George Gerbereck; Hugh Graham; Mrs Porter-Elinor Hammer; Officer Ritchie-George Karas; Elizabeth Martin-Audrey Metcalf; David Metcalf; Tom Ogden; Charlie Overdorff; Lee Payton; Josh Randolph; Ralph Roseman; Eugene Sabel; Henry Martin-Elbert Smith; Teenager-Diane Tabben 
written by Kate Phillips, Theodore Simonson; cinematography-Thomas Spalding; editing-Alfred Hillman; music-Burt Bacharach, Ralph Carmichael, Hal David; assoc prod-Russell S Doughten Jr; prod design-William Jersey, Karl Karlson; special effects-Bart Sloane

Brain From Planet Arous 1958 Nathan Hertz (aka Juran) (d), Jacques Marquette (p), Howco International

Steve-John Agar; Sally Fallon-Joyce Meadows; Dan-Robert Fuller; John FallonThomas Henry; Colonel in conference room-Kenneth Terrell; Col Frogley-Henry Travis; Gen Brown-E Leslie Thomas; Sheriff Paine-Tim Graham; Russian-Bill Giorgio

screenplay-Ray Buffum; music-Walter Greene; dir photo-Jacques Marquette; editor-Irving Schoenberg; asst director-Bert Chervin; sound-Philip Michell; makeup -Jack Pierce; tech advisor-J L Castingham; properties-Richard M Rubin; assoc prod-Dale Tate

Brain Machine, The (1956) Ken Hughes (d); Alec Snowden (p); RKO Radio Pictures

Dr Geoffrey Allen-Patrick Barr; Dr Phillipa Roberts-Elizabeth Allen; Frank Smith-Maxwell Reed; Insp Durham-Russell Napier; Spencer Simon-Gibb McLaughlin; Det Supt John Harris-Neil Hallett; Louie, a gangster-Mark Bellamy; Gym owner, Charlie-Bill Nagy; Henry Ryan-Edwin Richfield; Edward Jarritt-Clifford Buckton; Dr Richards-John Horsley

writing-Ken Hughes; cinematography-Josef Ambor

Brain That Wouldn't Die, The 1959 (released 1962) Joseph Green (d), Rex Carlton (p), Rex Carlton/American International

Dr Bill Cortner-Herb Evers; Jan Compton-Virginia Leith; Kurt-Leslie Daniel; Doris Powell-Adele Lamont; Blonde Stripper-Bonnie Sharie; Brunette StripperPaula Maurice; Peggy Howard-Marilyn Hanold; Dr Cortner-Bruce Brighton; Amy Freeman; Fred Martin; Donna Wilson-Lola Mason; Nurse-Doris Brent; Beauty contest MS-Bruce Kerr; Jeannie-Audrey Devereau; Monster-Eddie Carmel

gaffer-Vincent Delaney; grip-John Haupt Jr; special FX-Byron Bauer; soundRobert Lessner, Emil Kolisch; screenplay-Joseph Green; story by Rex Carlton, Joseph Green; dir photo-Stephen Hajnal; associate prod-Mort Landberg; film editor-Leonard Anderson; theme music by Abe Baker, Tony Restaino; production manager-Alfred Lessner; asst dir-Tony La Marca; art dir-Paul Fanning; camera operator-John S Priestley. The film was shot in 1959, copyright 1960 by Rex Carlton, released by AIP in 62 or 63. (Personal interview with director Joseph Green.)

Cat Women of the Moon 1954 Arthur Hilton (d); Jack Rabin, Al Zimbalist (p); Astor, Z-M Productions 
Laird Grainger, commander-Sonny Tufts; Kip Reissner, co-pilot-Victor Jory; Helen Salinger, navigator-Marie Windsor; Douglas Smith -William Phipps; Walt Walters-Douglas Fowley; Alpha-Carol Brewster; Lambda-Susan Morrow; Zeta-Suzanne Alexander; Cat-Woman-Betty Arlen; Cat-Woman-Roxann Delman; Cat-Woman-Ellye Marshall; Cat-Woman-Judy Walsh

writing-Roy Hamilton, Jack Rabin (story), Al Zimbalist (story); music-Elmer Bernstein; cinematography-William P. Whitley; editing-John A. Bushelman; assistant director-Robert E. Barnes; production supervisor-Ralph E. Black; spider puppet-Wah Chang; title \& optical effects-David Commons; mechanical effects-Willis Cook; special effects-Al Zimbalist

Charly 1968 Ralph Nelson (d\&p), Selmur Pictures

Cocoon 1985 Ron Howard (d), George Zanuck, Lili Fini Zanuck, David Brown (p), Zanuck/Brown, $20^{\text {th }}$ Century Fox

Conspirator 1949 Victor Saville (d), Arthur Hornblow (p), MGM

Cosmic Monster, The (aka The Strange World of Planet X) 1958 Gilbert Gunn (d), George Maynard (p), Distributors Corp of America; John Bash Productions

Gilbert Graham-Forrest Tucker; Michelle Dupont-Gaby Andre; 'Smith'-Martin Benson; Dr Laird-Alec Mango; Brig Gen Cartwright-Wyndam Goldie; Jimmy Murray-Hugh Latimer; Mrs Tucker-Sandy Nicholls; Insp Burns-Richard Warner; Helen Forsyth-Patricia Sinclair; Gerard Wilson-Geoffrey Chater; Mrs Hale-Hilda Fennemore; Jane Hale-Susan Redway.

screenplay-Paul Ryder; novel-Rene Ray; dir photog-Joe Ambor; artistic dir-Bernard Sarron; SFX-Anglo-Scottish Pictures; prod manager-John Dark; editor-Francis Bieber; music-Robert Sharples

Crawling Eye, The (UK release) Trollenberg Terror (US release) 1958 Quentin Lawrence (d), Robert S Baker, Monty Berman (p), Eros

Alan Brooks-Forrest Tucker; Philip Truscott-Laurence Payne; Sarah PilgrimJennifer Jayne; Anne Pilgrim-Janet Munro; Prof Crevett-Warren Mitchell; KleinFrederick Schiller; Brett-Andrew Faulds; Dewhurst-Stuart Saunders; HansColin Douglas; Wilde-Derek Sydney; First Villager-Richard Golding; Second Villager-George Herbert; German Woman-Anne Sharpe; Child-Caroline Glaser; Pilot-Gerard Green; First student climber-Jeremy Longhurst; Second student climber-Anthony Parker; Carl-Leslie Heritage; Fritz-Theodore Wilhelm; Jack Taylor

screenplay-Jimmy Sangster; story of the television series by Peter Key; dir photMonty Berman; music composed by Stanley Black; prod super-Ronald C Lisles; art dir-Duncan Sutherland; editor-Henry Richardson; camera operator-Desmond Davis; prod man-Charles Permane; asst director-Norman Harrison; continuity-Yvonne Richards; make up-Eleanor Jones; hairdresser-Joy Vigo; sound recordist-Dick Smith 
Creature From the Black Lagoon 1954 Jack Arnold (d), William Alland (p), Universal

David Reed-Richard Carlson; Kay-Julia Adams; Mark Williams-Richard Denning; Carl Maia-Antonio Moreno; Lucas-Nestor Paiva; Dr Thompson-Whit Bissell; Zee-Bernie Gozier; Chico-Henry Escalante

screenplay-Harry Essex (see It Came From Outer Space), Arthur Ross; story-Maurice Zimm; dir phot-William Snyder; special photography-Charles S Welbourne; editor-Ted Kent; music-Joseph Gershenson

Creature With the Atom Brain 1955 Edward L Cahn (d), Sam Katzman (p), Clover, Columbia

Dr. Chet Walker-Richard Denning; Captain Dave Harris-S. John Launer; Frank Buchanan-Michael Granger; Dr. Wilhelm Steigg (as Gregory Gay)-Gregory Gaye; Joyce Walker-Angela Stevens; Penny Walker-Linda Bennett; Dr. Kenneth Norton-Nelson Leigh; Chief Camden-Charles Evans; D.A. MacGraw-Tristram Coffin; Mayor Bremer-Pierre Watkin

writing-Curt Siodmak; cinematography-Fred Jackman Jr; editing-Aaron Stell; music conductor-Mischa Bakaleinikoff

Day the Earth Stood Still, The 1951 Robert Wise (d), Julian Blaustein (p), 20 Century Fox

Klaatu-Michael Rennie; Helen Benson-Patricia Neal; Tom Stevens-Hugh Marlowe; Dr Barnhardt-Sam Jaffe; Bobby Benson-Billy Gray; Mrs BarleyFrances Bavier

screenplay-Edmund $H$ North; based on story by Harry Bates; camera-Leo Tover, music-Bernard Herrmann; SFX-Fred Sersen

Day The World Ended 1956 Roger Corman (d\&p) Golden State/American International Pictures

Rick-Richard Denning; Louise-Lori Nelson; Ruby-Adele Jurgens; Tony-Touch Connors; Maddison-Paul Birch; contaminated man-Jonathan Haze;

Pete-Raymond Hatton; Radek-Paul Dubov

story, screenplay-Lou Rusoff; presented by James Nicholson \& Samuel Z Arkoff; music-Ronald Stein; exec prod-Alex Gordon; special effects-Paul Blaise, camera-Jock Feindel; editor-Ronald Sinclair; music-Ronald Stein

Destination Moon 1950 Irving Pichel (d), George Pal (p), Eagle Lion

Dr Charles Cargraves-Warner Anderson; Jim Barnes-John Archer; General Thayer-Tom Powers; Joe Sweeney-Dick Wesson, Emily Cargraves-Erin O'BrienMoore; Brown-Ted Warde 
screenplay-Rip van Ronkel, Robert A Heinlein, James O'Hanlon; based on Rocketship Galileo by Robert A Heinlein. Heinlein also the technical advisor. camera (Technicolor)-Lionel Linden; editor-Duke Goldstone; cartoon sequence-Walter Lantz; Music-Keith Stevens; SFX-Lee Zavitz

Devil Girl From Mars 1954 David Macdonald (d), Edward J \& Harry Danziger Danziger productions/Spartan

Michael-Hugh McDermott; Ellen-Hazel Court; Albert-Peter Reynolds; DorisAdrienne Corris; Professor-Joseph Tomelty; Mr Jamieson-John Laurie; Mrs Jamieson-Sophie Stewart; Tommy-Anthony Richmond; David-James Edmond; Newsreader-Stuart Hibberd; Nyah-Patricia Laffan

play by John Mather and James Eastwood; screenplay-James Eastwood; dir photography-Jack Cox; dir SFX-Jack Whitehead; art director-Norman Arnold; prod manager-Jack Martin; music-Edwin Astley; editor-Brough Taylor; sound editor-Gerald Anderson; sound-Bert Ross, Red Law; assistant director-Max Varnel; orchestrations-Albert Elms; continuity-Betty Forster; chief electrician-Lou Lavelly; make-up-George Partelton; costume-Ronald Cobb

Dr Cyclops 1940 Ernest Shoedsack (d), Merian Cooper (p), Paramount

Dr Strangelove: or How I Learned to Stop Worrying and Love the Bomb 1964 Stanley Kubrick (d\&p), Hawk Films, Columbia

Earth Versus the Flying Saucers 1956 Fred F Sears (d), Charles H Schneer (p), Sam Katzman (exec. prod.), Columbia

Dr Russell A Marvin-Hugh Marlowe; Carol Marvin-Joan Taylor; Maj. Huglin-Donald Curtis; General Hanley-Morris Ankrum; Professor Kanter-John Zaremba; Admiral Enright-Tom Browne Henry; General Edmunds-Grandon Rhodes; Motorcycle Officer-Larry Blake; Cutting-Harry Lauter; Dr Alberts-Charles Evans; Sgt Nash - Clark Howat

screenplay-George Yates, Raymond Marcus; short story-Curt Siodmak from Flying saucers from outer space by Major Donald E Keyhoe; technical effects-Ray Harryhausen; camera-Fred Jackman Jr

ET: The Extra-Terrestrial (1982) Steven Spielberg (d), Kathleen Kennedy, Steven Spielberg (p), Amblin, Universal

Fiend Without a Face 1957 Arthur Crabtree (d), John Croydon (p), MLC Producers Associates

Major Cummings-Marshall Thompson; Capt. Chester-Terence Kilburn; Sgt Kasper-Michael Balfour; Dr Warren-Gil Winfield; Nurse-Shane Cordell; Col Butler-Stanley Maxted; Mayor-James Dyrenforth; Barbara Griselle-Kim Parker; Atomic Engineer-Kerrigan Prescott; Prof Walgate-Kynaston Reeves; Dr Bradley-Peter Madden 
screenplay-Herbert Leeder; original story-Amelia Reynolds Long; editor- $R$ McNaughton; lighting cameraman-Lionel Banes; set designer-John Elphick; special effects-Ruppel \& Nordhoff, Peter Neilson; asst director-Douglas Hickox; camera operator-Leo Rogers; music-Buxton Orr

Fire Maidens From Outer Space 1955 Cy Roth (d), George Fowler, Cy Roth (p), Criterion Films; Topaz Films

Heista-Susan Shaw; Luther Blair-Anthony Dexter; Larson-Paul Carpenter; Sydney Stanhope-Harry Fowler; Dr Higgins-Sydney Tafler; Duessa-Jacqueline Curtis; Anderson-Rodney Diak; Maya Koumani; Prasus-Owen Berry; Richard Walter; Fire Maidens-Norma Arnould, Jan Holden, Sylvia Burrows, Eunice Jebbett, Ann Elsden, Sonia Martin, Marcella Georgius, Kim Parker, Corinne Gray, Barbara Pinney, Gloria Haig, Dinah Ann Rogers

music-Trevor Duncan; cinematography-Ian Struthers; costume design-Cynthia Tingey; prod design-Scott MacGregor; editing-Lito Carruthers

First Man Into Space 1959 Robert Day (d), John Croydon, Charles Vetter Jr (p), Metro Goldwyn Mayer

Commander C E Prescott-Marshall Thompson; Tia Francesca-Marla Landi; Lt Dan Prescott-Bill Edwards; Capt Ben Richards-Robert Ayres; Wilson-Bill Nagy; Dr Paul von Essen-Carl Jaffe; Mexican consul-Robert Delgardo; State Dept Official-John McLaren; Witney-Richard Shaw; Clancy-Bill Nick

screenplay-John C Cooper \& Lance Hargreaves; based on a story by Wyott Ordung; camera-Geoffrey Faithfull; music-Buxton Orr; editor-Peter Mayhew

Five 1951 Arch Oboler (d\&p), Arch Oboler Productions, Columbia

Michael-William Phipps; Roseanne-Susan Douglas; Eric-James Anderson; Charles-Charles Lampkin; Mr Barnstaple-Earl Lee

writing-Arch Oboler; original music-Henry Russell; cinematography-Sid Lubow, Ed Spiegel, Louis Clyde Stoumen, Arthur Swerdloff; production designArch Oboler; editing-John Hoffman, Sid Lubow, Ed Spiegel, Louis Clyde Stoumen, Arthur Swerdloff; special sound effects-Gus Bayz

Flash Gordon Conquers the Universe 1940s Flash Gordon-Buster Crabbe. This is vol 2, of this serial, covering episodes 4,5 and 6 .

Fly, The 1958 Kurt Neumann (d\&p), $20^{\text {th }}$ Century Fox; CBS Fox

Andre-David Hedison; Helene-Patricia Owens; Francois Delambre-Vincent Price; Inspector Charas-Herbert Marshall; Emma-Kathleen Freeman; Nurse Andersone-Betty Lou Gerson; Philippe-Charles Herbert; Dr. Ejoute-Eugene Borden; Orderly-Harry Carter; French Waiter-Arthur Dulac; Gaston-Torben Meyer; Police Doctor-Franz Roehn; Doctor-Charles Tannen 
writing credits (story)-George Langelaan, James Clavell; original music-Paul Sawtell; cinematography-Karl Struss; costume design-Adele Balkan, Charles Le Maire; film editing-Merrill G. White; special photographic effects-L.B. Abbott; set decorator-Eli Benneche; colour consultant-Leonard Doss; assistant director-Jack Gertsman; special effects-James B Gordon; sound-Eugene Grossman; art director-Theobold Holsopple

Forbidden Planet 1956 Fred McLeod (d), Wilcox Nicholas Nayfack (p), MGM

Dr Morbius-Walter Pidgeon; Altaira Morbius-Anne Francis; Commander Adams-Leslie Nielsen; Lt 'Doc' Ostrow-Warren Stevens; Lt. Farman-Jack Kelly; Chief Quinn-Richard Anderson; Cook-Earl Holliman; Bosun-George Wallace; Grey-Bob Dix; Youngerford-Jimmy Thompson; Strong-James Drury

screenplay-Cyril Hume; based on story by Irving Block, Allen Adler; camera (Eastman color) George J Folsey; editor-Ferris Webster; SFX-A Arnold Gillespie, Warren Newcombe, Irving G Ries, Joshua Meador

From Hell It Came 1957 Dan Milner (d), Richard Bernstein (p), Allied Artists, Milner Bros

Dr. William Arnold-Tod Andrews; Dr. Terry Mason-Tina Carver; Prof. ClarkJohn McNamara; Mrs. Mae Kilgore-Linda Watkins; Tano-Robert Swan; Chief Maranka-Baynes Barron; Eddie-Mark Sheeler; Korey-Suzanne Ridgeway; Naomi-Tani Marsh; Orchid-Grace Mathews; Norgu-Lee Rhodes; Kimo-Gregg Palmer; Maku/The Tabanga-Chester Hayes; Dori-Lenmana Guerin

writer-Richard Bernstein, Jack Milner; assoc prod-Jack Milner, Byron Roberts; music-Darrell Calker; cinematography-Brydon Baker; costume design-Frank Delmar; editing-Jack Milner

Getting Straight 1970 Richard Rush (d\&p), Columbia

Giant Gila Monster, The 1959 Ray Kellogg (d), Ken Curtis (p), McLendon Radio Pictures/Hollywood Picture Corp

Chace Winstead-Don Sullivan; Lisa-Lisa Simone; Mr Harris-Shug Fisher; BobJerry Cortwright; Gay-Beverly Thurman; Gordy-Don Flourney; Chucky-Clarke Browne; Sherry-Pat Simmons; Rick-Pat Reeves; Whila-Ann Sonka; Sheriff-Fred Graham; Wheeler-Bob Thompson; Compton-Cecil Hunt; Steamroller Smith-Ken Knox; Liz Humphries-Yolanda Salas; Eb Humphries-Howard Ware; Agatha Humphries-Stormey Meadows; Janice Stone; Gay McLendon; Jan McLendon; Grady Vaughn; Desmond Doogh

original story-Ray Kellog; screenplay-Jay Simms; cinematography-Wilfred Cline; music-Jack Marshall; special songs-Don Sullivan; music associate-Audray Granville; special photographic FX-Ralph Hammeras, Wec Risser; art designerLouis Caldwell; set decorator-Louise Caldwell; sound-Earl Snyder; film editor-Aaron Stell; Sound FX-Milton Citron, James Richard; prod manager-Ben Chapman 
Giant Claw, The 1957 Fred F Sears (d), Sam Katzman (p), Columbia

Mitch MacAffee-Jeff Morrow; Sally Cordwell-Mara Corday; Lt Gen Edward Considine-Morris Ankrum; Pierre Broussard-Louis D Merrill; Dr Karol Noymann-Edgar Barrier; Gen Van Buskirk-Robert Shayne; Pete-Ruell Shayne; Maj Bergen-Clark Howat; Lieutenant-Morgan Jones

written by Samuel Newman, Paul Gangelin; music-Mischa Bakaleinikoff; cinematography-Benjamin Kline; editing-Anthony DiMarco, Saul Goodkind; technical effects-Ralph Hammeras, George Teague

Give 'em Hell, Harry! 1975 Steve Binder (d), Joseph E. Bluth, Al Ham, David Permut, Bill Sargent, John J. Tennant (p), Theatre Television

Godzilla 1954 Inoshiro Honda, Terry Morse (d), Tomoyuki Tanaka (p), Embassy Pictures (in US)

Hideto Ogata-Akira Takarada, Dr. Kyohei Yamane-Takashi Shimura, Dr. Daisuke Serizawa-Akihiko Hirata, Emiko Yamane-Momoko Kochi; Steve Martin-Raymond Burr; Dr. Tabata-Fuyuki Murakami; Reporter Hagiwara-Sachio Sakai; President of Nankai Shipping Company-Toranosuke Ogawa; Masaji-Ren Yamamoto; Chief of Emergency Headquarters-Takeo Oikawa; Chairman of Diet Committee-Miki Hayashi; Mr. Oyama-Seijiro Onda; Shinkichi-Toyoaki Suzuki; Security Officer Tomo Iwanaga (U.S. version only)-Frank Iwanaga; Gisaku, Oto Island Patriarch-Kokuten Kodo

US version producers-Richard Kay; Joseph E. Levine; Tomoyuki Tanaka; music -Akira Ifukube; cinematography-Guy Roe, Masao Tamai; production designSatoshi Chuko, Takeo Kita; film editing-Terry O. Morse, Yasunobu Taira; screenplay-Takeo Murata, Inoshiro Honda; special effects- Teisho Arikawa, Kuichiro Kishida, Hiroshi Mukoyama, Fuminori Ohashi, Eiji Tsuburaya, Akira Watanabe

Golden Voyage of Sinbad 1974 Gordon Hessler (d), Ray Harryhausen, Charles H Schneer (p), Columbia

Great Rupert 1950 Irving Pichel (d), George Pal (p), Eagle-Lion

Hideous Sun Demon 1959 Tom Boutross, Robert Clarke (d\&p), Clarke-King Enterprises/Pacific International Releasing

Dr Gilbert McKenna-Robert Clarke; Ann Russell-Patricia Manning; Trudy Osborne-Nan Peterson; Dr Frederick Buckell-Patrick Whyte; Dr Jacob HoffmanFred La Porta; Lt Peterson-Will Hampton; Suzy-Donna King; George Messorio-Peter Similuk; Dr Stern-Robert Garry; Suzy's mother-Xandra Conkling; Del Courtney; Cass Richards; Helen Joseph; Bill Currie; Fran Leighton; John Murphy; Chuck Newell; Darryl Westbrook; Pearl Driggs; Bob Hafner; Tony Hilder; David Sloan 
screenplay-E S Seeley Jr; additional dialogue-Doane Hoag; original idea-Robert Clarke; editor \& co-director-Tom Boutross; art dir \& ass prod-Bianbattista Cassarino; assoc prod-Robin Kirkman; assistand dir-Tom Miller; script continuity-Deanie Follis; sound-Doug Menville; asst editor-Ron Honthaner; makeup - Ben Sarino; prod manager-Robin Kirkman; photography-John Morrill, Vilis Lapenieks, Stan Follis; singer-Marylyn King; music-John Seeley

Hot Angel, The 1958 Joe Parker (d), Stanley Kallis (p)

I Married a Communist 1949 Robert Stevenson (d), Jack Gross, Sid Rogell (p), RKO Radio Pictures

I Married a Monster From Outer Space 1958 Gene Fowler Jr (d\&p), Paramount

Bill Farrell-Tom Tryon; Marge Farrell-Gloria Talbott; Swanson-Peter Baldwin; Harry-Robert Ivers; Ted-Chuck Wassil; B girl-Valerie Allen; Mac-Ty Hungerford; Dr Wayne-Ken Lynch; Collins-John Eldredge; Sam Benson-Alan Dexter; Weldon-James Anderson; Helen Rhodes-Jean Carson; Schultz-Jack Orrison; Charles Mason-Steve London; Bartender- Maxie Rosenbloom

story, screenplay-Louis Vittes; camera-Haskell Boggs; editor-George Tomasini; billed as dualler with The Blob.

Incredible Shrinking Man, The 1957 Jack Arnold (d), Albert Zugsmith (p), Universal International

Scott Carey-Grant Williams; Louise Carey-Randy Stuart; Clarice-April Kent; Charlie Carey-Paul Langton; Dr Thomas Silver-Raymond Bailey; Dr Arthur Bramson-William Schallert; Barker-Frank Scannell; Nurse-Helene Marshall; Nurse-Diana Darrin; Midget-Billy Curtis

screenplay-Richard Matheson, written by Matheson; special photographicsClifford Stine; optical FX-Roswell A Hoffman, Everett H Broussard; music-Joseph Gershenson; camera- Ellis W Carter; editor-Al Joseph

Independence Day 1996 Roland Emmerich (d), Centropolis Film Productions, 20 ${ }^{\text {th }}$ Century Fox

Invaders From Mars 1953 William Cameron Menzies (d), Edward L Alperson (p), 20th-Fox

Dr Pat Blake-Helena Carter; Dr Stuart Kelston-Arthur Franz; David MacLean; Jimmy Hunt; George MacLean-Leif Erickson, Mary MacLean-Hillary Brooke; Colonel Fielding-Morris Ankrum; Sgt Rinaldi-Max Wagner; Kathy Wilson-Janine Perreau

screenplay-Richard Blake; camera (Cinecolor) John Seitz; editor-Arthur Roberts; music-Raoul Kraushaar

Invasion of the Body Snatchers 1955 Don Siegel (d), Walter Wanger (p), Allied Artists 
Miles-Kevin McCarthy, Becky-Dana Wynter, Danny-Larry Gates, Jack-King Donovan, Theodora-Carolyn Jones, Sally-Jean Willes, Nick-Ralph Dumke, Wilma-Virginia Christine; Ira-Tom Fadden; Driscoll-Kenneth Patterson; Sam-Guy Way; Doctor-Whit Bissell; Sam Peckinpah had a part in the movie.

screenplay-Daniel Mainwaring; based on Collier's magazine serial by Jack Finney; music-Carmen Dragon; dir phot-Ellsworth Fredericks; special effects-Milt Rice; editor-Robert $S$ Eisen

Invasion of the Saucer-Men 1957 Edward L Cahn (d), J H Nicholson, R J Gurney (p), American International Pictures

Johnny-Steve Terrell; Joan-Gloria Castillo; Joe-Frank Gorshin; Larkin-Raymond Hatton; Art-Lyn Osborn; Doctor-Russ Bender; Lt Wilkins-Douglas Henderson; Colonel-Sam Buffington; Detective-Jason Johnson; Mr Hayden-Don Shelton; 1st soldier-Scott Peters; Waitress-Jan Englund; Sgt Bruce-Kelly Thordsen

original story-Paul Fairman; screenplay-Robert J Gurney and Al Martin; film presented by Samuel Z Arkoff, Nicolson; music-Ronald Stein; exec Prod-Samuel $Z$ Arkoff; editors-Ronald Sinclair, Charles Gross Jr; music-Ronald Stein

Iron Curtain, The 1948 William Wellman (d), Sol Siegel (p), $20^{\text {th }}$ Century Fox

It Came From Beneath the Sea 1955 Robert Gordon (d), Charles H Schneer (p), Columbia Pictures

Commander Pete Mathews-Kenneth Tobey; Dr Lesley Joyce-Faith Domergue; John Carter-Donald Curtis; Admiral Burns-Ian Keith; Admiral Norman-Dean Maddox Jr; Griff-Lt Chuck Griffiths; Bill Nash-Harry Lauter; Captain Stacy-Capt Richard W Peterson; Robert Chase-Del Courtney; Navy Interne-Tory Avery; reporter-Ray Storey; Hall-Rudy Puteska; Aston-Jack Littlefield; McLoed-Ed Fisher; King-Jules Irving

screenplay-George Worthing Yates, Hal Smith; story-George Worthing Yates; dir photo-Henry Freulich; technical effects-Ray Harryhausen; exec prod-Sam Katzman; art director-Paul Palmentola; film editor-Jerome Toms; set decorator-Sidney Clifford; asst director-Leonard Katzman; special effects-Jack Erickson; sound-Josh Westmoreland; music conducted by Mischa Bakaleinikoff; unit manager-Leon Chooluck

It Came From Outer Space 1953 Jack Arnold (d), William Alland (p), Universal

John Putnam-Richard Carlson; Ellen Fields-Barbara Rush; Sheriff Matt Warren-Charles Drake; Frank-Joe Sawyer; George-Russell Johnson; Jane-Kathleen Hughes; Pete Davis-Dave Willock; Dave Loring-Alan Dexter

screenplay-Harry Essex; written by-Ray Bradbury; special photography (SFX)-David Horsley; camera-Clifford Stine; editor-Paul Weatherwax; music-Joseph Gershenson 
It Conquered the World 1956 Roger Corman (d), James H Nicholson, Roger Corman ( $\mathrm{p})$, American International Pictures

Paul Nelson-Peter Graves; Claire Anderson-Beverly Garland; Tom Anderson-Lee van Cleef; Joan Nelson-Sally Fraser; Pete Shelton-Charles B Griffith; Gen Pattick-Russ Bender; Pvt Manuel Ortiz-Jonathan Haze; Sgt Neil-Dick Miller; Taggart Casey

story \& screenplay-Lou Russoff; exec prod-James Nicholoson; camera-Frederick West; editor-Charles Gross; music-Ronald Stein

I Walked With a Zombie 1943 Jacques Tourneur (d), Val Lewton (p), RKO Radio Pictures

I Was a Communist for the FBI 1952 Gordon Douglas (d), Bryan Foy (p), Warner Bros

Journey To the Centre of the Earth 1959 Henry Levin (d), Charles Brackett (p), 20th Century-Fox

Alec McEwen-Pat Boone; Prof Oliver Lindenbrook-James Mason; Carla-Arlene Dahl; Jenny-Diane Baker; Count Saknassemm-Thayer David; Hans-Peter Ronson; Groom-Robert Adler; Dean-Alan Napier; Prof Bayle-Alex Finlayson; Paisley-Ben Wright; Kirsty-Mary Brady; Chancellor-Frederick Halliday; Rector-Alan Caillou

screenplay-Charles Brackett \& Walter Reisch, based on novel by Jules Verne; camera-Leo Tover; editors-Stuart Gilmore, Jack Holmes; music-Bernard Herrman

Killers From Space 1954 W Lee Wilder (d\&p), Fred M Muller (p), RKO

Doug Martin-Peter Graves; Colonel Banks-James Seay; Briggs- Steve Pendleton; Ellen Martin-Barbara Bestar; Dr Kruger-Frank Gerstel; Deneb-Tala-John Merrick; Major Clift-Shep Menken

screenplay-Bill Raynor; from a story by Myles Wilder; music-Manuel Compinsky; cinematography-William Clothier; editor-William Faris; lightingJim James; production supervisor-Mack V. Wright

Killer Shrews, The 1959 Ray Kellogg (d), Ken Curtis (p), McLendon Radio Pictures/Hollywood Pictures Corp

Thorne Sherman-James Best; Ann Craigis-Ingrid Goude; Jerry Farrell-Ken Curtis; Dr Radford Baines-Gordon McLendon; Dr Milo Craigis-Baruch Lumet; 'Rook' Griswold-Judge Henry Dupree; Mario-Alfredo de Soto

story \& screenplay-Jay Simms; director photo-Wilfred M Cline; camera operator-Henry Kokojan, George Nogle; camera assistants-William Ranaldi, Harry Gianneschi; music composed by Harry Bluestone, Emil Cadkin; music supervisor-Harry Bluestone; music editor-Gil Marshand; film editor-Aaron 
Stell; sound effects-Milton Citron; sound-Earl Snyder; art-Louis Caldwell; set decorator-Louise Caldwell; script supervisor-Audrey Blasdel; makeup-Cornie Daniel; production manager-Ben Chapman

King Kong 1933 Merian C Cooper, Ernest B Schoedsack (d\&p), RKO Radio Pictures

Lost Continent 1951 Sam Newfield (d), Sigmund Neufeld (p), Lippert Pictures, Sigmund Neufeld Productions

Major Joe Nolan-César Romero; Michael Rostov-John Hoyt; Robert Phillips-Hugh Beaumont; Lt Danny Wilson-Chick Chandler; Sgt Willie Tatlow-Sid Melton; Stanley Briggs-Whit Bissell; Native Girl-Acquanetta; Maria Stevens-Hillary Brooke; M P -Murray Alper; Simmons-William E. Green

writing-Richard Landau, Carroll Young; exec prod-Robert Lippert; original music-Paul Dunlap; cinematography-Jack Greenhalgh; production designFrank Paul Sylos; editing-Philip Cahn; special effects-Augie Lohman

Manchurian Candidate, The 1962 John Frankheimer (d), George Axelrod, John Frankenheimer (p), United Artists

Manster, The 1960 George Breakston, Kenneth Crane (d), George Breakston (p), Lopert Pictures

Larry Stanford-Peter Dyneley, Linda Stanford-Jane Hylton, Dr Robert Suzuki-Satoshi Nakamura, Tara-Terri Zimmern; Ian Matthews-Nora van Hawley; Police Superintendent Aida-Jerry Ito; Emiko Suzuki-Toyoko Takechi; Dr H B Jennsen-Alan Tarlton; Kenzo Kuroki; Shinpei Takagi; George Wyman

screenplay-Walt Sheldon; orig story-George Breakston; dir photog-David Mason; prod man-Yuj Honda; music-Hirooki Ogawa; editor-Kenneth Crane; assoc prod-Robert Perkins. [This film was banned in Finland; I suggest because it was so racist in terms of negative stereotypes of Japanese.]

Mesa of the Lost Women 1953 Herbert Tevos, Ron Ormond (d), G William Perkins, Melvin Gordon (p), Howco Productions/Roy Ormond Productions, Jay Frances White Jr \& Joy N Houck Presentation

Dr Aranya-Jackie Coogan; Dan Mulcahey-Richard Travis; 'Doc' Tucker-Allan Nixon; Doreen-Mary Hill; Grant Phillips-Robert Knapp; Pepe-Chris Pin Martin; Masterson-Harmon Stevens; Van Croft-Niko Lek; Wu-Samuel Wu; Frank-John Martin; Tarantella-Tandra Quinn; Narrator-Lyle Talbot; Kelly Drake; George Burrows; Candy Collins; Delores Fuller; Dean Reisner; Doris Lee Price; Mona McKinnon; Sherry Moreland; Ginger Sherry; Chris Randall; Dianne Fortier; Kerna Greene; June Benbow; Katina Vea; Fred Kelsey;

special FX-Centaur Productions, Ray Mercer; dialogue director-Herb A Lightman; makeup-Paul Stanhope, Harry Ross; narrated by Lyle Talbot; dir photog-Karl Struss, Gil Warrenton; film editors-Hugh Winn, Ray Lockert; 
supervising editor-W Donn Hayes; screenplay-Herbert Tevos; musical scoreHoyt S Curtin; dialogue supervision-Orville H Hampton; asst director-Theodore Joos; set decorator-Theodore Offenbecker; wardrobe-Oscar Rodriquez; script supervisor-Sam Freedle; property masters-Ernest Johnson, Oscar Lau; transportation-George N Brown

Metropolis 1926 Fritz Lang (d), Giorgio Moroder (p), UFA

Mighty Joe Young 1949 Earnest Schoedsack (d), Merian C Cooper (p), Argosy, RKO Radio Pictures

Missile to the Moon 1959 Richard Cunha (d), Marc Frederic (p), Astor Pictures; Marc Frederic \& George Foley Production, Layton Film Productions

Steve Dayton-Richard Travis; June Saxton-Cathy Downs; The Lido-K J Stevens; Gene Fennell-Tommy Cook; Alpha-Nina Bara; Lon-Gary Clarke; Dirk GreenMichael Whelen; Lambda-Laurie Mitchell; Marjorie Hellen; Col Wickers-Henry Hunter; Lee Roberts; Zema-Leslie Parrish; Sheriff Cramer-Lee Roberts; (international beauty contest winners) Miss Florida, Miss New Hampshire, Miss Virginia, Miss New York State, Miss France, Miss Germany (and others).

screenplay-H E Barrie, Vincent Fotre; dir photo-Meredith Nicholson; editor-Everett Dodd; music-Nicholas Carras; prod manager-Ralph Brooke

Mission to Moscow 1943 Michael Curtiz (d), Robert Buckner (p), Warner Bros

My Son John 1952 Leo McCarey (d), Paramount

Mysterians, The 1959 Inoshiro Honda (d), Tamoyuki Tanaka (p), Toho (Metro release)

Joji Aisumi-Kenji Sahara; Etsuko Shiraishi-Yumi Shirakawa; Hiroko-Momoko Kochi; Ryoichi Shiraishi-Akihiko Hirata; Dr Adachi-Takashi Shirmura; Commander Morita-Susumu Fujita; Captain Seki-Hisaya Ito; Commander Sugimoto-Yoshio Kosugi; Dr Kawanami-Fuyuki Murakami; General Hamamota-Minosake Yamada

screenplay-Takeshi Kimura, from an original story by Jojiro Okami; camera-Hajime Koizumi; editor-Hiroichi Iwashita; music-Akaira Ifukube; sfx-Eiji Tsuhuraya

Night the World Exploded 1957 Fred F Sears (d), Sam Katzman (p), Columbia

Laura Hutchinson-Kathryn Grant; Dr David Conway-William Leslie; Dr Ellis Morton-Tris Coffin; Governor Cheney-Raymond Greenleaf; General BartesCharles Evans; Sheriff Quinn-Frank Scannell; General's aide-Marshall Reed screenplay-Jack Natteford, Luci Ward; camera-Benjamin Kline; editor-Paul Borofsky

On the Beach 1959 Stanley Kramer (d\&p), United Artists 
Dwight Towers-Gregory Peck; Peter Holmes-Anthony Perkins; Julian OsbornFred Astaire; Moira Davidson-Ava Gardner; Mary Holmes-Donna Anderson; Admiral Bridie-John Tate; Lt Hosgood-Lola Brooks; Farrel-Guy Doleman; Swain-John Meillon; Sandstrom-Harp McGuire; Bensen-Ken Wayne; DavisRichard Meickle; Ackerman-Joe McCormick; Davidson-Lou Vernon; ProudeBasil Buller-Murphy; Port Man-Paddy Morgan; Dr Forster-Kevin Brennan; Salvation Army Captain-John Casson; Morgan-Grant Taylor

from the novel by Nevil Schute, screenplay-John Paxton, production design-Rudolph Sternad; camera-Giuseppe Rotunno; music-Ernest Gold; editor-Frederick Knudston

Phantom From Space 1953 W Lee Wilder (d\&p) Fred Muller, Max Wulson (p), United Artists

Lt Hazen-Ted Cooper; Dr Wyatt-Rudolph Anders; Barbara Randall-Noreen Nash; Major Andrews-James Seay; Lt Bowers-Harry Landers; Wakeman-Jack Daly; Phantom-Doc Sands; Mobile Centre Dispatcher-Steve Acton; Agent JoeBurt Wenland; Betty Evans-Lela Nelson; Agent Charlie-Tom Bailey

screenplay-Bill Raynor, Alex Weldon, Myles Wilder; camera-William Clothier; SFX-Alex Welden; editor-George Gale; music-William Lava; photographic effects-Howard A. Anderson; production manager-Bartlett A. Carre; special effects-Alex Weldon

Phantom From 10,000 Leagues 1956 Dan Milner (d), Jack Milner (d\&p) American Releasing Corp (AIP)

Ted-Kent Taylor; Lois-Cathy Downs; King-Michael Whalen; Wanda-Helene Stanton; George-Philip Pine; Bill-Rodney Bell; Andy-Pierce Lyden; Ethel-Vivi Janiss; Sheriff-Michael Garth

screenplay-Lou Rusoff; original story-Dorys Lukather; camera-Bryden Baker; editors-Milner brothers; music-Ronald Stein

Plan Nine From Outer Space 1958 Edward D Wood (d\&p), Reynolds Pictures

Jeff Trent-Gregory Walcott; Paula Trent-Mona McKinnon; Lieutenant John Harper-Duke Moore; Colonel Tom Edwards-Tom Keene; Patrolman Larry-Carl Anthony; Patrolman Kelton-Paul Marco; Inspector Daniel Clay-Tor Johnson; Eros-Dudley Manlove; Tanna-Joanna Lee; The Ruler-John Breckinridge; General Roberts-Lyle Talbot; Danny-David De Mering; Air Force Captain-Bill Ash; Reverend-Reverend Lynn Lemon; Man in Cemetery-Ben Frommer; Woman in Cemetery-Gloria Dea; Policeman-Conrad Brooks; Vampire Girl-Vampira; Ghoul Man-Béla Lugosi; Himself-Criswell

writing-Edward D. Wood Jr; assoc prod-Charles Burg, Hugh Thomas; exec prod-J Edward Reynolds; music-Bruce Campbell, Wolf Droysen, Trevor Duncan, Franz Mahl, John O'Notes, Van Phillips, Steve Race, Wladimir Selinsky, 
James Stevens, Gilbert Vinter; cinematography-William C. Thompson; costume design-Dick Chaney; editing-Edward D. Wood Jr.

Project Moonbase 1953 Richard Talmadge (d), Jack Seaman (p), Galaxy Pictures

Maj Bill Moore-Ross Ford; Colonel Breiteis-Donna Martell; Gen "Pappy" Greene-Hayden Rorke; Dr Wernher-Larry Johns; Dr Roundtree-Herb Jacobs; Sam, an enemy agent-Robert Karnes; Polly Prattles-Barbara Morrison; Capt Carmody, pilot-Peter Adams; Commodore Carlson-James Craven; Madame President-Ernestine Barrier; Bellboy-Robert Paltz; Chaplain-John Straub; Blockhouse Air Controller-John Tomecko

writing-Robert A. Heinlein, Jack Seaman; assoc prod-Karl Johnson; music by-Herschel Burke Gilbert; cinematography-William C. Thompson; costume design-Jack E. Miller; production design-Jerome Pycha Jr; editing-Roland Gross.

Psycho 1960 Alfred Hitchcock (d\&p), Shamley, Paramount

Quatermass and the Pit 1959 Rudolph Cartier (d), BBC (serialised television production)

Prof Quatermass-Andre Morell; Dr Matthew Roney-Cec Lindner; Colonel Breen-Anthony Bushell; Captain Potter-John Stratton; Barbara Judd-Christine Finn; James Fullalove-Brian Worth; Truck Driver-Van Boolen; Grab OperatorMichael Ragham; Workman-Lionel Ngakane; Old Workman-George Dudley; Foreman-John Rae; Museum Official-Malcolm Watson; Journalists-Stanley Vine, Mark Eden, Patrick Maynard, Allan McClelland, Bill Shine, Ian Wilson; BainesArthur Hewlett; Armitage-Michael Bird; Private Secretary-Richard Dare; The Minister-Robert Perceval; Miss Dobson-Nan Braunton; Police Inspector-Ian Ainsley; Sergeant-Michael Ripper; Corporal Gibson-Harold Goodwin; Private West-John Walker; First Private-Clifford Cox; Second Private-Brian Gilmar; PC Ellis-Victor Platt; Young Constable-Kenneth Warren; Policeman-Patrick Connor; Mrs Chilcot-Hilda Barry; Mr Chilcot-Howell Davies; Miss Groome-Madge Brindley; Sladden-Richard Shaw; News Editor-Tony Quinn; Nuttall-Keith Banks; George-Frank Crane; Abbey Librarian-Fletcher Lightfoot; News Vendors-Bernard Spear, John Hamblin; Dr Klein-Kenneth Seeger; Vicar-Noel Howlett; Electrician-Harold Siddons; Official-Edward Burnham; TV Technician-John Scott Martin; Woman Journalist-Anne Blake; TV InterviewerAnthony Pendrell; Blonde-Louise Gainsborough; Man in the Blazer-Arthur Brander; Tattered Man-Sydney Bromley; Newscaster-Stewart Nichol; Pilot-Bud Knapp; Narrator-Alexander Moyes; Other parts played by John Barrett, Chales Maunsell, Lee Richardson, Edward Malin.

mil advisor-Lt Col PJ Hands MBE, ERD, RE (AER); make-up supervisorChristine Hillcoat; wardrobe supervisor-Pamela Glanville; SFX-Jack Kline, Bernard Wilkie; film cameraman-AA Englander; film editor-Ian Callaway; music composed by Trevor Duncan; designer-Clifford Hatts; writer-Nigel Kneale

Red Danube, The 1949 George Sidney (d), Carey Wilson (p), MGM 
Red Planet Mars 1952 Harry Horner (d), Anthony Veiller, Donald Hyde (p), United Artists

Chris Cronyn-Peter Graves; Linda Cronyn-Andrea King; Calder-Herbert Berghof; Arjenian-Marvin Miller; Carey-Walter Sande; President-Willis Bouchey; Sparks-Morris Ankrum; Stewart-Orley Lindgren; Roger-Bayard Veiller; Burdette-Richard Powers; Dr Mitchell-Lewis Martin; Dr Boulting-House Peters Jr; Peter Lewis-Claude Dunkin; UMW President-Gene Roth; BorodinJohn Topa; Commentator-Bill Kennedy; Woman-Grace Leonard; Man-Vince Barnett

screenplay-John L Balderston, Anthony Veiller; from a play by John L Balderston \& John Hoare; dir photog-Joseph Biroc; prod supervisor-Joseph Paul; film editor-Francis Lyon

Return of the Fly 1959 Edward L Bernds (d), Bernard Glasser (p), 20th Century Fox

François Delambre-Vincent Price; Philippe Delambre-Brett Halsey; Ronald Holmes, alias Alan Hinds-David Frankham; Insp. Beecham-John Sutton; Max Berthold-Dan Seymour; Cecile Bonnard-Danielle de Metz; Mme. BonnardJanine Grandel; Sgt. Dubois-Richard Flato; Lt. MacLish-Barry Bernhard; The Priest-Francisco Villalobos; Granville, a reporter-Jack Daly; Gaston-Michael Mark; Insp. Evans-Pat O'Hara; Home Nurse- Joan Cotton

writer-Edward L Bernds; music-Paul Sawtell, Bert Shefter; cinematographyBrydon Baker; film editing-Richard C. Meyer

Return of the Jedi 1983 Richard Marquand (d), Howard G Kazanjian (p), $20^{\text {th }}$ Century Fox, Lucasfilm

Rocketship X-M 1950 Kurt Neumann (d\&p), Lippert Pictures

Col Floyd Graham-Lloyd Bridges; Dr Lisa Van Horn-Osa Massen; Dr Carl Eckstrom-John Emery; Maj William Corrigan-Noah Beery Jr; Harry Chamberlain-Hugh O'Brian; Dr Ralph Fleming-Morris Ankrum; Physician-John Dutra; First Reporter-Patrick Aherne; Third Reporter-Judd Holdren; Martian girl-Sherry Moreland; Martian Woman-Kathy Marlowe

writing-Kurt Neumann, Dalton Trumbo; exec prod-Murray Lerner; original music-Ferde Grofé Sr; cinematography-Karl Struss; production design-Theodore Holsopple; editing-Harry W. Gerstad; special effects-Don Stewart

Robot Monster 1953 Phil Tucker (d), Phil Tucker (p), Three Dimensional Pictures

The Professor's Assistant/Roy-George Nader; Alice-Claudia Barrett; Mother /Martha-Selena Royle; The Professor/George-John Mylong; Johnny- Gregory Moffett; Ro-Man/Great Guidance-George Barrows; Robot (voice)-John Brown 
writing-Wyott Ordung; assoc prod-Alan Winston; exec prod-Al Zimbalist; music-Elmer Bernstein; cinematography-Jack Greenhalgh; editing-Bruce Schoengarth, Merrill G White

Seconds 1966 John Frankenheimer (d), Edward Lewis (p), Paramount

Shampoo 1975 Hal Ashby (d), Warren Beatty (p), Columbia

Snow Creature, The $1954 \mathrm{~W}$ Lee Wilder (d\&p), United Artists release

Dr Frank Parrish-Paul Langton; Peter Wells-Leslie Denison; Subra-Teru Shimada; Leva-Rollin Moriyama; Inspector Karma-Robert Kino; Airline Manager-Robert Hinton; Joyce Parrish-Darlene Fields; Corey Jr-George Douglas; Fleet-Robert Bice; Harry Bennett-Keith Richards; Dr Dupont-Rudolph Anders; Lieutenant Dunbar-Bill Phipps; Edwards-Jack Daly; Guard in warehouse-Rusty Westcott

screenplay and story-Myles Wilder; music composed and conducted-Manuel Compinsky; dir photography-Floyd Crosby; prod supervisor-Mack V Wright; sssociate-Fred Müeller; film editor-Jodie Copelan; sound recorder-Robert Roderick; special effects-Lee Zavitz; art director-Frank Sylos; lighting-Bill G Neff

Solyaris 1972 Andrei Tarkovsky (d), Viacheslav Tarasov (p), Creative Unit of Writers \& Cinema workers, Unit Four, Mosfilm

Spaceways 1953 Terence Fisher (d), Michael Carreras (p), Hammer Film

Dr Stephen Mitchell-Howard Duff; Dr Lisa Frank-Eva Bartok; Dr Smith-Alan Wheatley; Prof Koepler-Philip Leaver; Dr Toby Andrews-Michael Medwin; Dr Philip Crenshaw-Andrew Osborn; Vanessa Mitchell-Cecile Chevreau; Gen Hayes-Anthony Ireland; Col Daniels-Hugh Moxey; Minister-David Horne; Sgt Peterson-Leo Phillips; Mrs Rogers-Marianne Stone; Mrs Daniels-Jean Brough writing-Richard Landau, Charles Eric Maine, Paul Tabori; cinematographyReginald H. Wyer; editing-Maurice Rootes

Star Wars 1977 George Lucas (d), Gary Kurtz (p), Lucasfilm, 20 Century Fox

Teenage Devil Dolls 1955 B. Lawrence Price Jr (d\&p), Eden

Cassandra Light-Barbara Marks; Mr Leigh-Bramlet L Price; Lt David JasonRobert A Sherry; Johnny Adams-Robert Norman; Margo Rossi-Elaine Lindenbaum; Sven Bergman-Joel Climenhaga; Mrs Leigh-Lucille Price; Sgt Schwartz-Victor Schwartz; Jimmy Sanchez-Anthony Gorsline; William Kendell; Stutzman-Joe Popavich; Cholo Martinez-B Lawrence Price Jr; Narrator-Kurt Martell; Russel Packard-William Kendall

written by B Lawrence Price Jr; music by Robert Drasnin; cinematographyWilliam Lieb, David Saxon; editing- B. Lawrence Price Jr 
Teenage Monster (aka Meteor Man) 1958 Jacques Marquette (d\&p), Howco Production

Anne Gwynne; Stuart Wade; Gloria Castillo; Charles Courtney; Charles the Monster-Gilbert Perkins; Norman Leavitt; Gabe Mooradian; Stephen Parker; Jim McCullough; Frank Davis; Arthur Berkeley;

screenplay-Ray Buffum; music-Walter Greene; dir photography-Taylor Byars; assis dir-Ken Walters; film editor-Irving Schoenberg; sound-Phillip Mitchell; makeup-Jack Pierce; wardrobe-Jerry Bos; assis film editor-Morris Fever; property-Richard M Rubin; assoc prod-Dale Tate; film processing and optical effects-Consolidated Film Industries

Teenagers From Outer Space 1959 Tom Graeff (d\&p), Topor Corp

Derek (as David Love)-Tom Graeff; Betty Morgan-Dawn Anderson; Thor-Bryant Grant; Grandpa Morgan-Harvey B. Dunn; Joe Rogers-Thomas Lockyer; Spacecraft Captain-King Moody; Nurse Morse-Helen Sage; Dr. C.R. Brandt-Frederick Welch; Carl Dickensen; Alice Woodward-Sonia Torgeson; Billy Bridges; James Conklin; The Leader- Gene Sterling; Ralph Lowe; Bill DeLand; Hilda, Simpson's Secretary-Ursula Hansen; Bob Williams; Don DeClue writing-Tom Graeff Tom Graeff; cinematography-Tom Graeff; editing-Tom Graeff; special effects-Tom Graeff

Terminator 2: Judgment Day 1991 James Cameron (d\&p), Le Studio Canal, Carolco Pictures, Lightstorm Entertainment, Pacific Western

Them! 1954 Gordon Douglas (d), David Weisbart (p), Warner Bros

Sgt Ben Peterson-James Whitmore; Dr Harold Medford-Edmund Gwenn; Dr Patricia Medford-Joan Weldon; Robert Graham-James Arness; Brig Gen O'Brien -Onslow Stevens; Major Kibbee-Sean McClory; Ed Blackburn-Chris Drake; A little girl-Sandy Descher; Mrs Lodge-Mary Ann Hokanson; Capt of Troopers -Don Shelton; Crotty-Fess Parker; Jensen-Olin Howlin

story-George Worthing Yates; screenplay-Ted Sherdeman, adapted by Russell Hughes; music-Bronislau Kaper; dir phot-Sid Hickox; art dir-Stanley Fleischer; film editor-Thomas Reilly; sound-Francis Scheid; set decorator-G W Berntsen; wardrobe-Moss Mabry; make up-Gordon Bau

Thing From Another World, The 1951 Christian Nyby (d), Howard Hawks (p), Winchester Pictures (RKO release)

Nikki-Margaret Sheridan; Captain Patrick Hendry-Kenneth Tobey; Dr Carrington-Robert Cornthwaite; Skeely-Douglas Spencer; Lt Eddie Dykes-James Young; Crew Chief-Dewey Martin; Lt Ken Erickson-Robert Nichols; James Arness 
screenplay-Charles Lederer; from a story 'Who goes there' by John Campbell Jnr; music-Dimitri Tiomkin; ass prod-Edwin Lasker; SFX - Donald Stewart; camera-Russell Harlan; editor-Roland Gross

Things to Come 1936 William Cameron Menzies (d), Alexander Korda (p), London Films (belonged to Korda)

John Cabal/Oswald Cabal-Raymond Massey; The Boss-Ralph Richardson; Mary Gordon-Ann Todd; Theotocopulos-Cedric Hardwicke; Edward Chapman-Pippa Passworthy; Roxana/Rowena-Margaretta Scott; Dr Harding-Maurice Braddell; Mrs Cabal-Sophie Stewart; Richard Gordon-Derrick de Marney; Katherine Cabal-Pearl Argyle; Maurice Passworthy-Kenneth Villiers; Morden Mitani-Ivan Brandt; The Child-Anne McLaren; Janet Gordon-Patricia Hilliard; Great Grandfather-Charles Carson; John Clements

screenplay by H G Wells from the novel The shape of things to come; cameraGeorges Perinel; music by Arthur Bliss; costume design-John Armstrong, Rene Hubert, Marchioness of Queensbury; editing-Charles Crichton; Francis Lyon; special effects-Edward Cohen, Ned Mann

This Island Earth 1954 (5) Joseph Newman (d), William Alland (p), UniversalInternational

Exeter-Jeff Morrow; Dr Ruth Adams-Faith Domergue; Cal Meacham-Rex Reason; Brack-Lance Fuller; Steve Carlson-Russell Johnson; The Monitor-Douglas Spencer; Joe Wilson-Robert Nichols; Dr Adolph Engelborg-Karl L Lindt

screenplay-Franklin Coen, Edward O'Callaghan; based on novel by Raymond F Jones The alien machine; art direction-Alexander Golitzen, Richard H Riedel; sound-Leslie I Carey, Robert Pritchard; film editor-Virgil Vogel; special photography-Clifford Stine \& Stine; cinematography-Clifford Stine; music-Joseph Gershenson

Time Machine, The 1960 George Pal (d\&p), MGM

Time Traveller-Rod Taylor; Filby-Alan Young; Weena-Yvette Mimieux; Dr Hillyer-Sebastian Cabot; Anthony Bridewell-Tom Helmore; Walter Kemp-Whit Bissell; Mrs Watchett-Doris Lloyd

screenplay-David Duncan; based on novel by H G Wells; music-Russell Garcia; special photographic effects-Gene Warren, Wan Chang; camera - Paul C Vogel; editor-George Tomasini; music-Russell Garcia

Trip to the Moon, 1902 George Melies Also called 'A voyage to the moon'

12 to the Moon 1960 David Bradley (d); Fred Gebhardt (p); Columbia

Capt John Anderson-Ken Clark; Dr Hideko Murata-Michi Kobi; Dr Feodor Orloff-Tom Conway; Dr Luis Vargas-Tony Dexter; Roddy Murdock-Bob 
Montgomery Jr; Dr William Rochester-Phillip Baird; Dr Erich Heinrich-John Wengraf; Dr David Ruskin-Richard Weber; Dr Etienne Martel-Roger Til; Dr Selim Hamid-Tema Bey; Dr Asmara Markonen-Cory Devlin; Dr Sigrid Bomark-Anna-Lisa; Secretary General of the Internatioal Space Order-Francis X Bushman

screenplay-De Witt Bodeen; story-Fred Gebhardt; art director-Rudi Feld; music composition-Michael Andersen; dir photog-John Alton; special photographic effects-Howard Anderson; additional special effects-E Nicholoson; assoc prod-Thom E Fox

20 Million Miles to Earth (The Giant Ymir) 1957 Nathan Juran (d), Charles H Schneer (p), Morningside Movies

Col Robert Calder-William Hopper; Marisa Leonardo-Joan Taylor; Gen McIntosh-Thomas Browne Henry; Dr Leonardo-Frank Puglia; Dr Judson Uhl-John Zaremba; Contino-Jan Arvan; Pepe-Bart Bradley; Police Commissioner-Tito Vuolo; Verrico, a fisherman-George Khoury; Mondello, a fisherman-Don Orlando; Maples, a reporter-George Pelling; Farmer-Sid Cassel; Dr Sharman-Arthur Space

writing-Christopher Knopf, Robert Creighton Williams; music-Mischa Bakaleinikoff; cinematography-Irving Lippman; visual effects-Ray Harryhausen

2001: A Space Odyssey 1968 Stanley Kubrick (d\&p), MGM

Unnatural: The Fruit of Evil 1952 Arthur Maria Rabenalt (d), Styria Carlton (p), CCA (German release)

Alraune-Hildegarde Neff; Erich von Shroheim; Frank Braun-Carlheinz Boehm; Doctor Mohn- Harry Halm; Julia Koschka; Count Geroldingen-Harry Meyen; Governess- Denise Vernac

based on novel 'Alraune' by Hans Heinz Ewers; screenplay-Kurt Heuser; music-Werner Richard Henmann; song lyrics-Robert Gilbert; camera-Friedl Benh-Grund; sets-Robert Herlth; costumes-Herbert Ploberger; sound-KlangFilm Eurocord; cinematography-Friedl Behn-Grund

War of the Colossal Beast 1958 Bert I Gordon (d\&p), Carmel Productions, AIP

Joyce Manning-Sally Fraser; Maj Mark Baird-Roger Pace; Col Glenn Manning-Duncan 'Dean' Parkin; Dr Carmichael-Russ Bender; Sergeant Luis Murillo-Rico Alaniz; John Swanson-George Becwar; Miguel-Robert Hernandez; Captain Harris-Charles Stewart; Mrs Edwards-June Jocelyn; Neurologist-John McNamara; Joan-Loretta Nicholson; Raymond Winston; Newscaster-Jack Kosslyn; Mexican Doctor-George Navarro; Correspondent Pent-Bob Garnet

writing-Bert I Gordon, George Worthing Yates; exec prod-James H Nicholson, Sam Z Arkoff; music-Albert Glasser; cinematography-Jack A. Marta; editing-Ronald Sinclair 
War of the Worlds 1953 Byron Haskin (d), George Pal (p), Paramount Pictures

Clayton-Gene Barry; Sylvia-Ann Robinson; Gen Mann-Les Tremayne; Dr Pryor-Bob Cornthwaite; Dr Bilderbeck-Sandro Giglio; Pastor Collins-Lewis Martin; Gen Mann's aide-Housely Stevenson Jr; Radio Announcer-Paul Frees; Wash Perry-Bill Phipps; Col Heffner-Vernon Rich; Cop-Henry Brandon; Salvatore-Jack Kruschen;

narration-Sir Cedric Hardwicke; screenplay-Barré Lyndon; dir phot-George Barnes; edited-Everett Douglas; music-Leith Stevens; associate prod-Frank Freeman; photographic FX-Gordon Jennings, Wallace Kelley, Paul Lerpae, Ivyl Burks; astronomical art-Chesley Bonestell

Wasp Woman, The 1960 Roger Corman (d\&p), Allied Artists Television Corp

Janice Starlin-Susan Cabot; Bill Lane-Fred Eisley; Mary Dennison-Barboura Morris; Arthur Cooper-William Roerick; Eric Zinthrop-Michael Mark; Les Hellman-Frank Gerstle; Bruno ve Sota; Paul Thompson-Roy Gordon; Jean Carson-Carolyn Hughes; Maureen Reardon-Lynn Cartwright; Frank Wolff; Lani Mars; Phillip Barry

screenplay-Leo Gordon; story-Kinta Zertuche; dir photography-Harry C Newman; prod manager-Jack Bohrer; film editor-Carlo Lodata; art director-Dan Haller; sound-Philip Mitchell; makeup-Grant Keats; property master-Karl Brainard; music-Fred Katz

West Side Story 1961 Jerome Robbins, Robert Wise (d), Robert Wise (p), United Artists, Beta Productions

When Worlds Collide 1951 Rudy Maté (d), George Pal (p), Paramount

Dave Randall-Richard Derr; Joyce-Barbara Rush; Tony-Peter Hanson; StantonJohn Hoyt; Dr Hendron-Larry Keating; Julie Cummings-Judith Ames; Dean Frey-Stephen Chase; Harold Ferris-Frank Cady; Dr Bronson-Hayden Rorke; Ottinger-Sandro Giglio; Student-Mary Murphy; Stewardess-Laura Elliot

screenplay-Sydney Boehm; based on novel by Edwin Balmer \& Philip Wylie; camera-John Seitz, W Howard Greene; SFX-Gordon Jennings, Harry Barndollar; music-Leith Stevens

Wild in the Streets 1968 Barry Shear (d), Samuel Z Arkoff, James Nicholson (p), AIP

Yellow Cab Man 1950 Jack Donohue (d), Richard Goldstone (p), MGM

Yellow Submarine 1968 George Dunning (d), Al Brodax (p), King Features, Apple Corp, Suba Films 